\title{
Novel nanostructured materials from cellulose esters
}

\author{
Dissertation \\ to attain the degree \\ “Doctor rerum naturalium” (Dr. rer. nat.) \\ of the Faculty of Forest Sciences and Forest Ecology \\ Georg-August-Universität Göttingen
}

within the doctoral program "Wood Biology and Wood Technology" of the Graduate School of Forest and Agricultural Sciences (GFA)

Submitted by

Jiaxiu Wang

Born on the $11^{\text {th }}$ January 1990 in P.R. China

Göttingen, 2020 


\section{1st Referee:}

Prof. Dr. Kai Zhang, Dept. Wood Technology and Wood-based Composites, Georg-AugustUniversität Göttingen

\section{2nd Referee:}

Prof. Dr. Carsten Mai, Dept. Wood Biology and Wood Products, Georg-August-Universität Göttingen

Date of oral examination: Oct 6, 2020 


\section{Acknowledgement}

I thank Professor. Dr. Kai Zhang sincerely for his four-year supervision. First and foremost, he invested time and energy to culture me a positive and healthy approach for research. $\mathrm{He}$ enlightened me to read, think, and discuss widely to generate novel ideas, new perspectives as well as to doubt and revise existing knowledge. He reminded me to carry the questions and the goals with me before reading, find the answers after reading to derive the required information in an efficient way. He encouraged me to think from a whole new perspective when the experiment results were not as previously anticipated. He recommended me to practice as much as possible to acquire necessary skills for conducting research, such as writing papers, giving presentations and so on. He taught me to undertake life-long learning and utilize a better mode of thinking to improve my overall capability in research. I gratefully appreciate all the efforts he made to culture me into a competent researcher. His attitudes and methods for research will benefit me all the rest of my life.

I would like to thank Prof. Dr. Philipp Vana and Prof. Dr. Carsten Mai. As my second and third advisors, they allocated time to listen to my progress reports, to give me valuable instructions and suggestions. They enthusiastically provide me support such as experimental instruments and so on. I want to express my gratitude to Prof. Dr. Carsten Mai for reviewing my dissertation. I also would like to thank the other members of the examination board for your valuable time as well as insightful questions and discussion. I would thank Dr. Inga Mölder, Mr. Robert Grenzdörffer, Dr. Gehard Büttner and Prof. Dr. Carsten Mai for their instructions about the regulations of my doctoral study. I would like to thank Mr. Mirko Küppers for his endeavor to guarantee the smooth going of my experiments. I am also thankful for the help provided by Ms. Brigitte Junge and Ms. Doris Waldmann on other issues during my doctoral study.

I greatly thank all group members in Wood Technology and Wood Chemistry. I appreciate the communication, discussion and cooperation we conducted in research. I am grateful for the nice and friendly environment we created together for both research and life. I am proud of all the achievements we made and thankful for all the troubles we met and solved. I also want to extend my thanks to all members in Wood Biology and Wood Products for mutual sharing of facilities as well as all the fun and good memories we have. Special thanks to Mr. Lukas Emmerich, for 
the nice collaboration and kind help.

I sincerely thank Prof. Dongge Ma, who is my supervisor during my master study. I thank his supervision as well as encouragement and support during my master study. I thank him especially for his open-minded support and help for my study abroad. I unfeignedly thank China Scholarship Council (CSC) for providing the scholarship to support my doctorial study.

Last but not the least, I am very thankful to my family: my parents, my brother and sister. Thank you for striving with all your might to give me love, trust, understanding and encouragement unconditionally. I am grateful to all my friends. Thank you for sharing your life and experience with me. Thank you for all your care and accompany. 


\section{Abstract}

Cellulose, the most abundant natural polymer on earth, constitutes virtually an inexhaustible source for the fabrication of nanostructured materials. Combining its biocompatibility and biodegradability, cellulose-based nanostructured materials possess significant benefits when compared to conventional nanostructured materials. Nanostructured materials, such as cellulose nanocrystals and cellulose nanofibers, have been isolated from cellulose, via top-down approaches. The present thesis focuses on the bottom-up approach for constructing nanostructured materials with cellulose derivatives, which are chemically functionalized with improved solubility and processability in comparison with cellulose. Specifically, cellulose esters were utilized in this study, to construct nanostructured materials including nanoparticles (NPs) and nanostructured membranes.

The solvent-responsive swelling behaviors of surface-modified NPs made from cellulose 10undecenoyl ester (CUE) were investigated. Swelling solvents, which have diverse interactions with the NPs, including the surface-functionalized part (SFP) and the interior nonfunctionalized part (INP), were added to the colloidal systems. Distinct swelling modes of NPs were obtained by tracking the sizes of NPs via dynamic light scattering (DLS). (1) The sizes of the NPs increased exponentially when using the swelling solvent, which has good interactions with both the SFP and the INP. (2) A logarithmic increase of the sizes of NPs was observed when using the swelling solvent, which has good interaction with the SFP, but inferior interactions with the INP. Excess use of this type of swelling solvent can cause slight shrinking of the INP and thus the decrease of the sizes of NPs after substantial swelling. (3) A dispersant with a smaller viscosity resulted in NPs with tight structure, which impeded the swelling at the starting stage. Thus, the size of NPs increased in a sigmoidal mode, even when the swelling solvent, which has good interactions with both the SFP and INP, was utilized. The investigation of the solvent-responsive swelling behaviors of NPs provided a route for adjusting the sizes of NPs according to practical requirements.

Self-compounded multifunctional nanocomposite membranes were obtained from cellulose cinnamate (CCi). Two distinct morphologies: CCi-NPs and CCi matrix were obtained in selfcompounded CCi nanocomposite membranes, with CCi-NPs either firmly embedded in CCi 
matrix or fused with adjacent NPs. This unique self-compounded compact structure imparted good mechanical and barrier properties to the membranes with tensile strength and Young's modulus of $93.9 \pm 4.6 \mathrm{MPa}$ and $3.1 \pm 0.2 \mathrm{GPa}$, respectively, while the oxygen permeability, water vapor permeability and oil permeability were as low as $(8.48 \pm 2.39) \times 10^{-13}$ $\mathrm{cm}^{3} \cdot \mathrm{cm} / \mathrm{cm}^{2} \cdot \mathrm{s} \cdot \mathrm{cmHg},(0.94 \pm 0.03) \times 10^{-11} \mathrm{~g} \cdot \mathrm{m}^{-1} \cdot \mathrm{s}^{-1} \cdot \mathrm{Pa}^{-1}$ and $0.008 \pm 0.003 \mathrm{~g} \cdot \mathrm{mm} \cdot \mathrm{m}^{-2} \cdot$ day $^{-1}$, respectively. Moreover, $\mathrm{CCi}$ membranes also demonstrated excellent heat and humidity resistance, with decrease of storage modulus $<10 \%$ when humidity increased from $21 \% \mathrm{RH}$ to $94 \% \mathrm{RH}$ and storage modulus value $>2.0 \mathrm{GPa}$ even at temperature of $98^{\circ} \mathrm{C}$. CCi membranes also demonstrated good UV-shielding properties by total shielding of UVB and UVC as well as partial shielding of UVA. Furthermore, the CCi membranes also demonstrated exceptional photothermal conversion functions. The temperature of $\mathrm{CCi}$ membranes can increase from room temperature to $96^{\circ} \mathrm{C}$ in $10 \mathrm{~s}$ with UV irradiation.

Especially, the humidity sensitivity of CCi with low degree of substitution (DS) inspired the development of a new type of eco-friendly plastics: hydroplastics. Self-compounded nanocomposite membranes from CCi with DS of 0.27 were fabricated. The membranes were mechanically strong and stiff with a tensile strength of $92.37 \pm 2.18 \mathrm{MPa}$ and Young's modulus of $2.56 \pm 0.03 \mathrm{GPa}$, which were superior than most of the widely-used plastics, including thermoplastics (e.g. PE, PP, PET and PVC) and thermosetting plastics (e.g. epoxies and phenolics). Moreover, the membranes were programmed into versatile two dimensional and three dimensional shapes via a facile, eco-friendly hydrosetting process, i.e. using water to manipulate the plasticity of membranes for shaping. This hydrosetting process endowed the reversible and random transformation between various shapes of $\mathrm{CCi}$ membranes. The programmed shapes maintained stable for at least 6 months. Moreover, one same membrane can be programmed for multiple times (at least 15 times) without fatigue, thus the plastics can be reused with extended life-cycles.

This thesis is a cumulative work with 3 publications. One of them is published, one under review and another one submitted. The background and objectives of this study, results and discussions, general conclusions and perspectives are shown in sections 1-4. 


\section{Zusammenfassung}

Cellulose, das weltweit am häufigsten, natürlich vorkommende Polymer, offeriert eine nahezu unerschöpfliche und nachhaltige Quelle zur Herstellung nanostrukturierter Materialien. Im Besonderen die hohe Biokompatibilität gepaart mit der biologischen Abbaubarkeit von nanostrukturierten Materialien auf Cellulosebasis, stellen maßgebliche Vorteile gegenüber herkömmlichen, am Markt verfügbaren Produkten dar. Bis dato wurden Nanokristalle sowie Nanofasern aus Cellulose isoliert; entsprechende, nanostrukturierte Materialien wurden dabei primär in sog. , Top-down` Ansätzen gewonnen, über die ausführlich in der Literatur berichtet ist. Im Rahmen der vorliegenden Arbeit wurden nanostrukturierte Materialien auf Cellulosebasis ausschließlich im sog. ,Bottom-up“ Ansatz konstruiert. Dabei wurden Cellulosederivate eingesetzt, die chemisch funktionalisiert wurden und im Vergleich zu Cellulose eine verbesserte Löslichkeit und Verarbeitbarkeit aufwiesen. Konkret wurden Celluloseester verwendet, um nanostrukturierte Materialien, im konkreten Fall Nanopartikel (NPs) und nanostrukturierte Membrane, zu konstruieren.

Verschiedene Lösungsmittel wurden mit oberflächenmodifizierten NPs aus Cellulose-10undecenoylester (CUE) in Kontakt gebracht und das Quellverhalten dieser untersucht. Die eingesetzten Lösungsmittel unterschieden sich vor allem hinsichtlich ihrer Wechselwirkung mit den NPs, im Besonderen bei Differenzierung in oberflächenfunktionalisierte Bereiche (SFP) sowie innere, nicht funktionalisierte Bereiche (INP). Eine Betrachtung der Dimensionsänderungen von NPs mittels der Methode der dynamischen Lichtstreuung (engl.: Dynamic light scattering, DLS) deutete auf unterschiedliche Quellmodi der NPs hin. (1) Die Größe der NPs nahm exponentiell zu, wenn Lösungs- bzw. Quellmittel eingesetzt wurden, die sowohl mit dem SFP als auch mit dem INP gute Wechselwirkungen aufwiesen. (2) Eine logarithmische Zunahme der Dimensionen von NPs wurde beobachtet, wenn Lösungs- bzw. Quellmittel verwendet wurden, die eine gute Wechselwirkung mit dem SFP, jedoch eine schlechte Wechselwirkungen mit dem INP aufwiesen. Der übermäßige Einsatz dieser Art von Lösungsmittel verursacht unter Umständen eine Dimensionsabnahme (Schwinden) des INP und bedingt so in Summe eine Verringerung der Gesamtdimensionen der NPs bei überproportional hoher Quellung. (3) Der Einsatz eines Dispergiermittels mit geringerer Viskosität führte zu NPs 
mit dichter Struktur, die eine Dimensionszunahme (Quellen) im Anfangsstadium zunächst einschränkten. Die Dimensionen der NPs zeigten im konkreten Fall Zunahmen mit sigmoidalem Verlauf, auch, wenn Lösungs- bzw. Quellmittel eingesetzt wurde, welche sowohl mit dem SFP als auch mit dem INP gute Wechselwirkungen zeigten. Die Untersuchung des Lösungsmittel abhängigen Quellverhaltens der NPs brachte letztlich Erkenntnisse, die für die Anpassung von NP-Größen an unterschiedliche, praktische Anforderungen genutzt werden können.

Aus Cellulosecinnamat (CCi) wurden selbstcompoundierend multifunktional Nanokompositmembranen erhalten. Zwei unterschiedliche Morphologie-Typen - CCi-NPs und CCi-Matrix - wurden in selbstcompoundiert CCi-Nanokompositmembranen detektiert, wobei CCi-NPs entweder fest in die CCi-Matrix eingebettet oder mit benachbarten NPs fusioniert waren. Diese einzigartige, selbstcompoundiert und kompakte Struktur verlieh den Membranen gute mechanische Eigenschaften, mit einer Zugfestigkeit und einem Elastizitätsmodul von 93,9 \pm 4,6 $\mathrm{MPa}$ bzw. 3,1 $\pm 0,2 \mathrm{GPa}$, während die Sauerstoffpermeabilität, die Wasserdampfpermeabilität und die Ölpermeabilität in zuvor genannter Reihenfolge im Bereich von $(8,48 \pm 2,39) \times 10^{-13} \mathrm{~cm}^{3} \cdot \mathrm{cm} / \mathrm{cm}^{2} \cdot \mathrm{s} \cdot \mathrm{cmHg},(0,94 \pm 0,03) \times 10^{-11} \mathrm{~g} \cdot \mathrm{m}^{-1} \cdot \mathrm{s}^{-1} \cdot \mathrm{Pa}^{-1}$ und 0,008 $\pm 0,003 \mathrm{~g} \cdot \mathrm{mm} \cdot \mathrm{m}^{-2} \cdot \mathrm{Tag}^{-1}$ lagen. Darüber hinaus zeigten CCi-Membranen auch eine ausgezeichnete Wärme- und Feuchtigkeitsbeständigkeit mit einer Abnahme des Speichermoduls $<10 \%$, wenn die Feuchtigkeit von $21 \%$ relativer Luftfeuchtigkeit (RH) auf $94 \%$ RH erhöht wurde, und einem Speichermodulwert > 2,0 GPa, der selbst bei einer Temperatur von $98{ }^{\circ} \mathrm{C}$ erreicht wird. CCi-Membranen zeigten eine hohe Abschirmung von UV Strahlen; sie zeigten sich undurchlässig für UVB- sowie UVC-Strahlung, während UVA-Strahlung in Teilen absorbiert wurde. Außerdem, Die CCi-Membranen zeigten auch außergewöhnliche photothermische Umwandlungsfunktionen. Die Temperatur von CCi-Membranen kann durch UV-Bestrahlung in $10 \mathrm{~s}$ von Raumtemperatur auf $96^{\circ} \mathrm{C}$ ansteigen.

Im Besonderen die Sensitivität von CCi gegenüber Feuchte, in Kombination mit einem niedrigen Substituierungsgrad (engl.: Degree of substitution, DS), ebneten den Weg zur Entwicklung eines neuen Typs umweltfreundlicher Kunststoffe, des sog. „Hydroplastik“. Selbstverbundene Nanokomposit Membranen aus CCi mit einem DS von 0,27 wurden 
hergestellt. Die Membranen zeigten gute mechanische Eigenschaften, mit einer Zugfestigkeit von $92,37 \pm 2,18 \mathrm{MPa}$ und einem Elastizitätsmodul von 2,56 $\pm 0,03 \mathrm{GPa}$; entsprechende Wertbereiche lagen oberhalb derer, wie sie von den meist und weit verbreiteten Kunststofftypen, u.a. thermoplastische (z. B. PE, PP, PET und PVC) und duroplastische Kunststoffe (z. B. Epoxide und Phenole), erreicht werden. Darüber hinaus wurde gezeigt, dass die Morphologie von CCi Membranen mittels einfacher, umweltfreundlicher „Hydrosetting-Verfahren“, d.h. unter Verwendung von Wasser zur Beeinflussung der Plastizität, in verschiedene zweidimensionale und dreidimensionale Formen veränderbar sind. Dabei ermöglichen entsprechende „Hydrosetting-Prozesse“ eine reversible und zufällige Transformation der CCiMembranen zwischen verschiedenen Morphologien. Die Formen zeigten sich dabei bis zu 6 Monate stabil, wobei ein- und dieselbe Membran mehrfach (mindestens 15 Mal) umgeformt werden kann, sodass die Gebrauchsdauern und Lebenszyklen entsprechender Kunststoffe maßgeblich erhöht sind.

Die vorliegende Doktorarbeit ist eine kumulative Arbeit, deren Basis 3 Publikationen in wissenschaftlichen Fachzeitschriften bilden. Eine Publikation wurde bereits veröffentlicht, eine weitere befindet sich im Begutachtungsprozess während die dritte Publikation kürzlich zur Begutachtung eingereicht wurde. Die drei Publikationen bilden den Kern der Arbeit während Zielsetzungen und Forschungsfrage, Ergebnisse und Diskussion, allgemeine Schlussfolgerungen und Pektiven in den Abschnitten 1 bis 4 zu finden sind. 


\section{Table of contents}

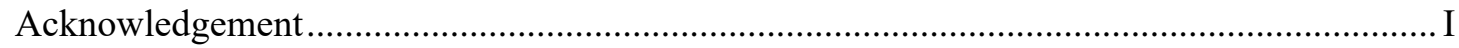

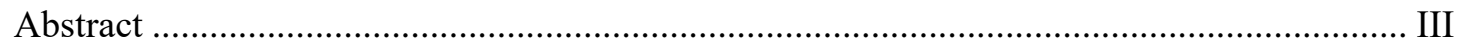

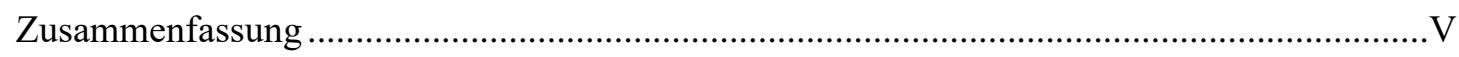

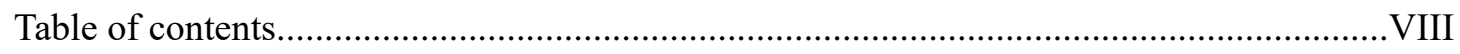

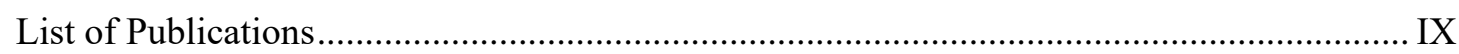

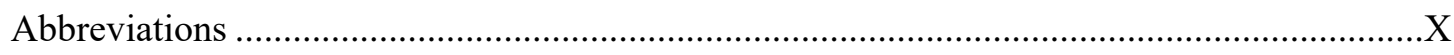

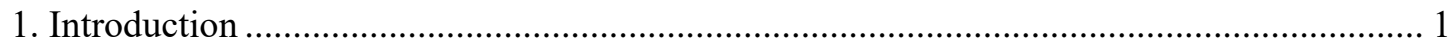

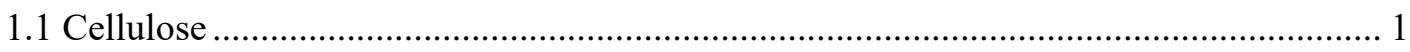

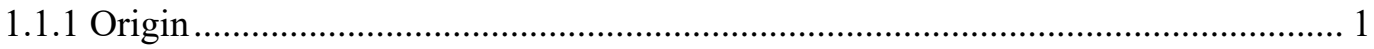

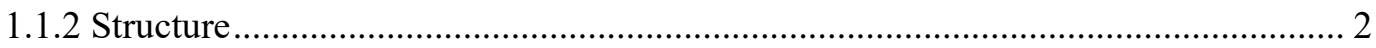

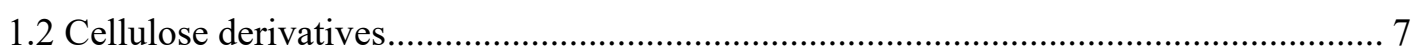

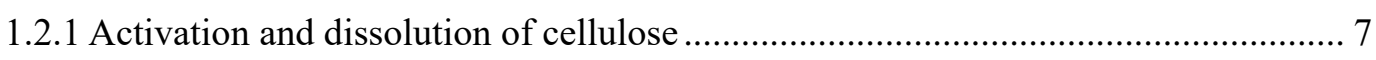

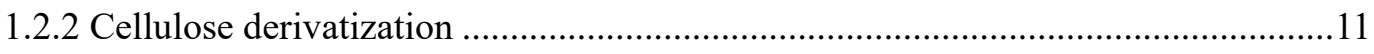

1.3 Nanostructured materials based on cellulose derivatives ............................................. 13

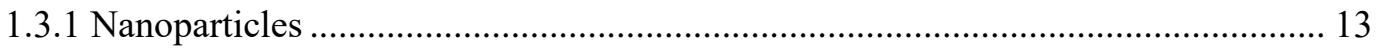

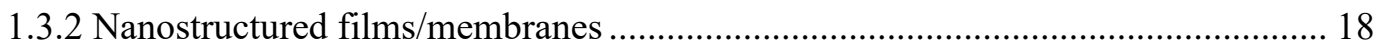

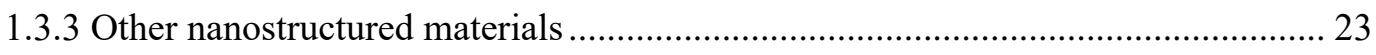

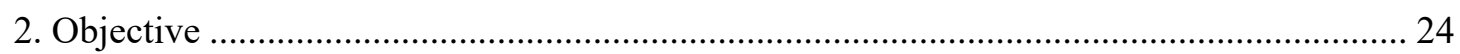

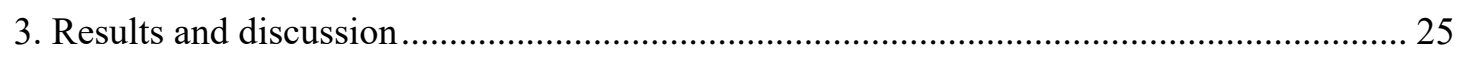

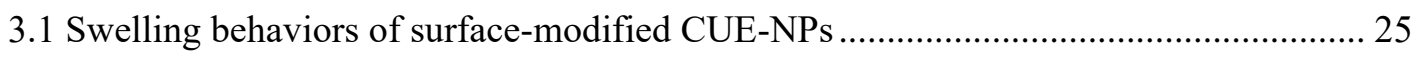

3.2 Self-compounded multifunctional nanocomposite membranes .................................. 30

3.3 CCi hydroplastic polymer as eco-friendly hydrosetting plastics .................................. 38

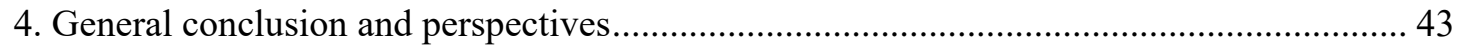

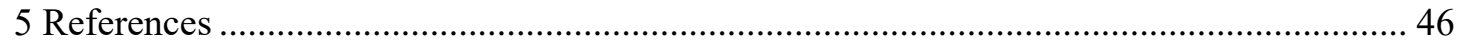

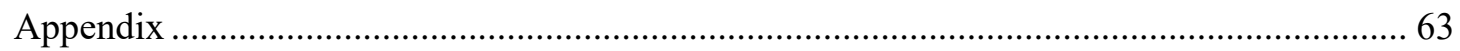

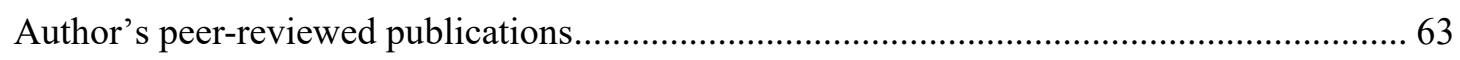

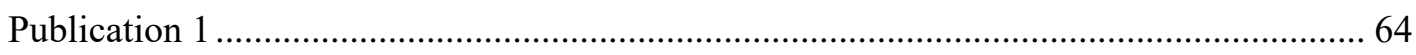

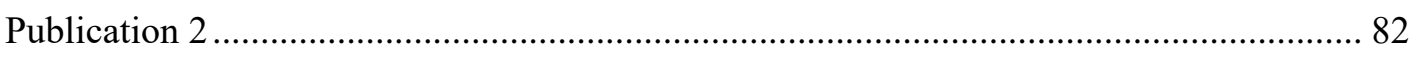

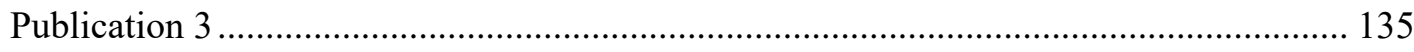

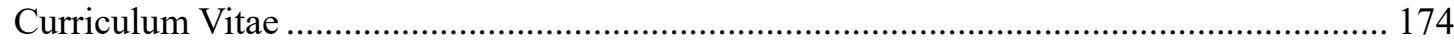




\section{List of Publications}

Publication 1

Modular adjustment of swelling behaviors of surface-modified solvent-responsive polymeric nanoparticles based on cellulose 10-undecenoyl ester

Jiaxiu Wang and Kai Zhang*, J. Phys. Chem. C, 2018, 122, 13, 7474-7483.

Publication 2

Self-compounded nanocomposites: Toward multifunctional membranes with superior mechanical, gas/oil barrier, UV-shielding and photothermal conversion properties

Jiaxiu Wang, Yu Cao, Bea Jaquet, Christoph Gerhard, Wei Li, Xiaodong Xia*, Judith Elisabeth Rauschendorfer, Philipp Vana, Kai Zhang*, ACS Appl. Mater. Interfaces, under review, 2021.

Publication 3

Hydroplastic polymer as eco-friendly hydrosetting plastics

Jiaxiu Wang, Lukas Emmerich, Jianfeng Wu, Philipp Vana, Kai Zhang*, Nature Sustainability, under review, 2021. 


\section{Abbreviations}

AGU

Anhydroglucose unit

CA

Cellulose acetate

$\mathrm{CA}^{\prime}$

Cysteamine

$\mathrm{CCi}$

Cellulose cinnamate

CLE

Cellulose lauroyl ester

$\mathrm{CMC}$

Carboxymethylcellulose

CSE

Cellulose stearoyl ester

CUE

Cellulose 10-undecenoyl ester

DLS

Dynamic light scattering

DMAc

Dimethylacetamide

DMF

Dimethylformamide

DMSO

Dimethyl sulfoxide

DP

Degree of polymerization

DS

Degree of substitution

EC

Ethyl cellulose

HPC

Hydroxypropyl cellulose

$\mathrm{I}_{\mathrm{C}}$

Index of crystallinity

IR

Infrared

MPA

3-mercaptopropionic acid

NMMO

N-Methylmorpholine N-oxide

NMR

Nuclear magnetic resonance

ODT

1-octadecanethiol

PDI

Polydispersity index

$\mathrm{RH}$

Relative humidity

SEM

Scanning electron microscopy

TBAF

Tetra-n-butylammonium fluoride

TEM

Transmission electron microscopy

THF

Tetrahydrofuran 


\section{Introduction}

\subsection{Cellulose}

\subsubsection{Origin}

Cellulose constituents the most abundant biopolymer on earth. Cellulose can be found in plants, animals, bacterials, algea etc. Mostly, cellulose exists as the structural material with hemicellulose and lignin in the wood cell walls. Cellulose accounts $40-50 \%$ of wood mass. ${ }^{1}$ Cellulose can also be found in other plants such as cotton, flax, hemp, grasses as well as in agricultural residues and so on (Figure 1, Table 1). ${ }^{2}$ Cellulose in the seed hairs of cotton is rather pure, with a content as high as $95 \%$. Bacterial cellulose can be generated by various bacteria, principally of the genera acetobacter, agrobacterium, sarcina, rhizobium. ${ }^{3,4}$ Bacterial cellulose is of high purity and high crystallinity with a high DP. ${ }^{5}$ Cladophora cellulose, extracted from green algea, is highly crystalline ( $>95 \%)$, with low moisture adsorption capacity, outstanding solution processability, high specific surface area and tunable mesoporosity. ${ }^{6}$ In addition, there are cellulose of animal origin. Tunicate cellulose can be isolated from the outer tissue of tunicates. $^{7}$
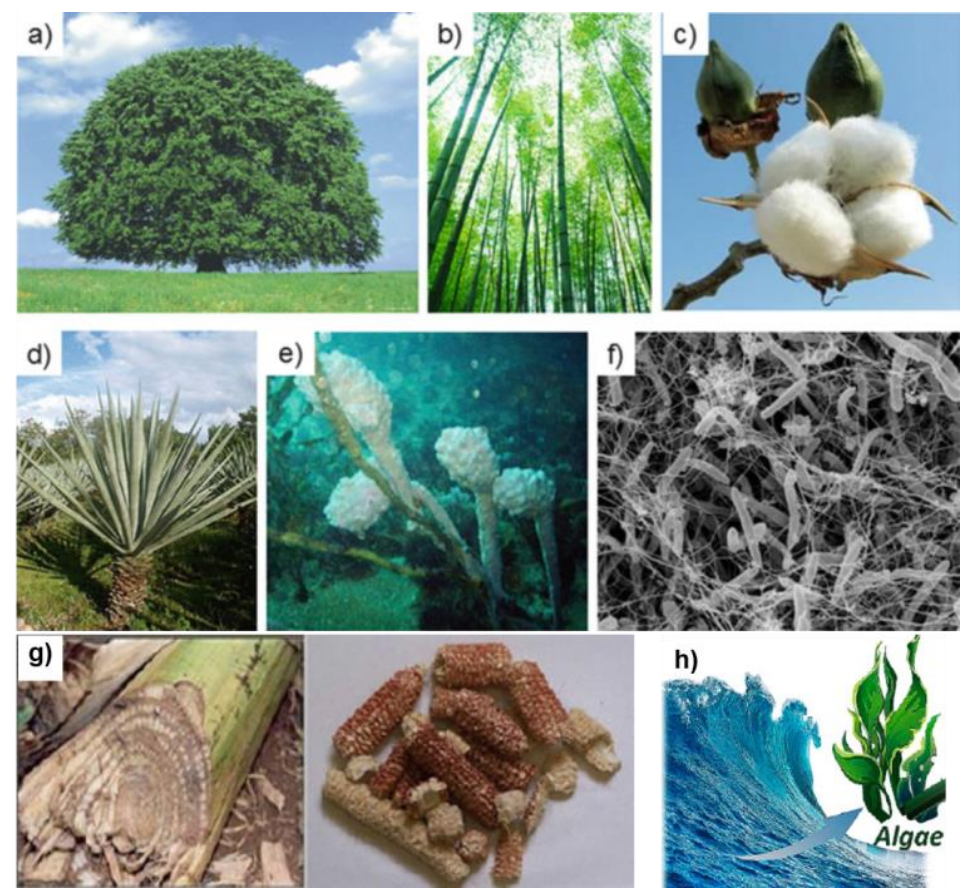

Figure 1 Selected sources for natural cellulose: (a) hard wood (beech tree), (b) bamboo, (c) cotton, (d) 
sisal, (e) tunicine, (f) Gluconacetobacter xylinum, (g) agricultural residues, and (h) algea (Reproduced from Popa, ${ }^{1}$ Heinze et $\mathrm{al}^{2}$ and Zhou et al. $^{6}$ Copyright from Smithers Rapra 2011, Springer 2018 and American Chemical Society 2019)

Table 1 Chemical composition of representative cellulosic materials (Adapted from Hon, ${ }^{8}$ Copyright from Marcel Dekker, Inc 1995)

\begin{tabular}{c|c|c|c|c}
\hline \multirow{2}{*}{ Source } & \multicolumn{4}{|c}{ Composition (\%) } \\
\cline { 2 - 5 } & Cellulose & Hemicellulose & Lignin & Extract \\
\hline Hardwood & $43-47$ & $23-25$ & $16-24$ & $2-8$ \\
\hline Softwood & $40-44$ & $25-29$ & $25-31$ & $1-5$ \\
\hline Baggase & 40 & 30 & 20 & 10 \\
\hline Corn cobs & 45 & 35 & 15 & 5 \\
\hline Wheat straw & 30 & 50 & 15 & 5 \\
\hline Flax (retted) & 71 & 21 & 2 & 6 \\
\hline Hemp & 70 & 22 & 6 & 2 \\
\hline Cotton & 95 & 2 & 0.9 & 0.4 \\
\hline
\end{tabular}

\subsubsection{Structure}

Cellulose was first isolated from plants by Anselme Payen in $1838 .{ }^{9}$ Cellulose is a linear long polymer chain with D-glucopyranose as the repeating units (Figure 2). These units in cellulose chain are connected by $\beta-(1 \rightarrow 4)$ glucosidic bonds, linking the $C-1$ of one pyranose ring to the C-4 of the next one. During the linkage bonds formation, one molecule of water is lost, and thus the repeating unit is also referred as anhydroglucose unit (AGU). Due to the constraints of $\beta$-linkage, the $\mathrm{AGU}$ rotate with an angle of around $180^{\circ}$ to each other. The $\mathrm{OH}$ at $\mathrm{C}-1$-position at one end of the cellulose chain is an aldehyde group with reducing activity, called reducing end. The $\mathrm{OH}$ at $\mathrm{C}-4$-position at the other end is an alcohol-borne $\mathrm{OH}$, thus is named nonreducing end. The number $\mathrm{n}$ denotes the DP of cellulose, which depends on the origin of cellulose. For instance, the DP of cellulose from wood is around 10000 while that from cotton is around 15000 . DP can be determined by viscosity measurement, light scattering and sizeexclusion chromatography. 


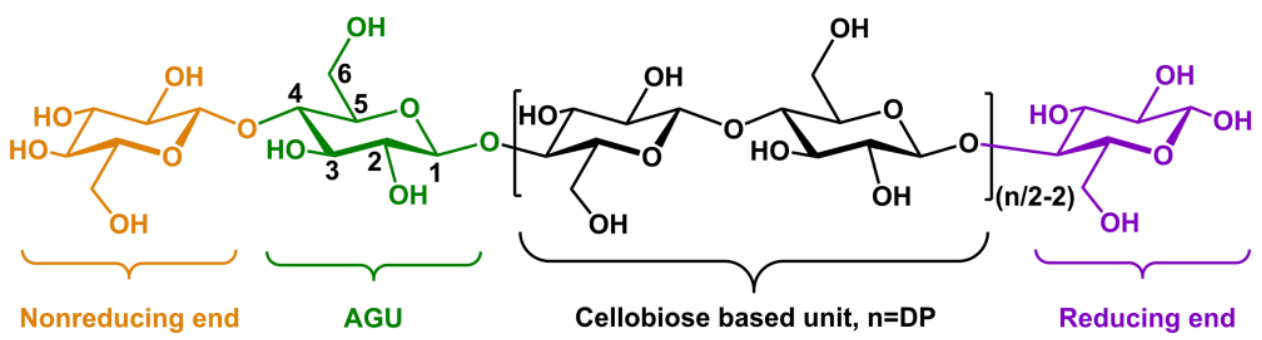

Figure 2 Molecular structure of cellulose (Reproduced from Qi et al. ${ }^{10}$ Copyright from Springer 2017)

The oxygen in the D-glucopyranose ring and the glucosidic linkage bond as well as the three hydroxyl groups of the AGU can interact with each other to form intermolecular and intramolecular hydrogen bonds in cellulose. The hydrogen bonds significantly influence the properties of cellulose. ${ }^{11}$ Cellulose chains also possess hydrophobic area (around the $\mathrm{C}$ atoms ) that can influence the properties, such as solubility. Cellulose I and cellulose II have different hydrogen bonding systems (Figure 3). The IR ${ }^{12,13}$ and ${ }^{13} \mathrm{C}$ NMR spectroscopy ${ }^{14}$ revealed that, in cellulose I, the hydroxyl group in $\mathrm{C} 3$ and the ether oxygen in the next glucopyranose ring, together with the oxygen in $\mathrm{C} 6$ and the hydroxyl group in $\mathrm{C} 2$, form intramolecular hydrogen bonds. These intramolecular bonds and the glucoside bonds jointly result in the rigidity or stiffness of cellulose chain. ${ }^{15}$ The oxygen in $\mathrm{C} 3$ and the hydroxyl groups in $\mathrm{C} 6$ of another cellulose chain form the intermolecular hydrogen bond. The hydrogen bonds, the weak C-H...O bonds and the hydrophobic interactions lead to the cellulose chain assembling in layers, which has been determined by synchrotron X-ray and neutron diffraction. ${ }^{16,17}$ In cellulose II, the hydroxyl group in $\mathrm{C} 2$ formed intermolecular hydrogen bonds with the hydroxyl groups in $\mathrm{C} 2$ as well as $\mathrm{C} 6$ of the neighboring cellulose chain while the intramolecular hydrogen bonds of hydroxyl groups in $\mathrm{C} 2$ are absent. ${ }^{18}$ Cellulose II is more strongly bonded with intermolecular hydrogen bonds and more densely packed than cellulose I, thus, cellulose II is more thermodynamically stable, less reactive than cellulose I. ${ }^{15}$ 
(a)

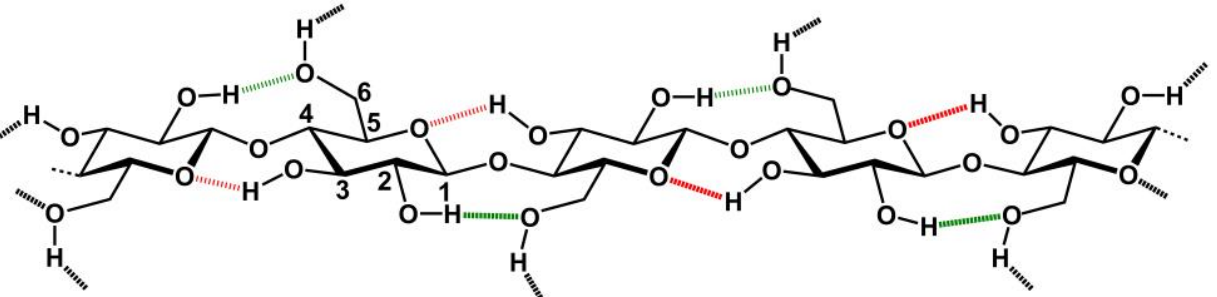

(b)

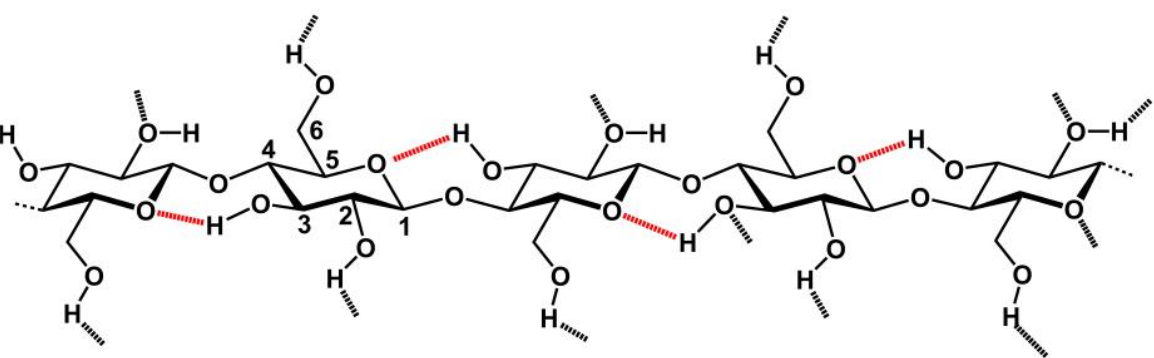

Figure 3 Hydrogen bonding systems of (a) cellulose I and (b) cellulose II (Reproduced from Tashiro and Kobayashi, ${ }^{19}$ Copyright from Elsevier 1991)

Cellulose from almost all the natural sources consists of two crystal forms, $\mathrm{I}_{\alpha}$ and $\mathrm{I}_{\beta}$, with various proportions. ${ }^{20}$ According to the atomic-resolution synchrotron and neutron diffraction data, Cellulose $I_{\alpha}$ and $I_{\beta}$ differ in the symmetry and direction of hydrogen bonding (Figure 4) ${ }^{16,17}$ In cellulose $I_{\alpha}$, all chains are crystallographically identical with slight difference in conformation. In cellulose $\mathrm{I}_{\beta}$, two distinct chains, shaded yellow and grey, array in alternating sheets, which pass through the origin and the center of the unit cell, respectively.
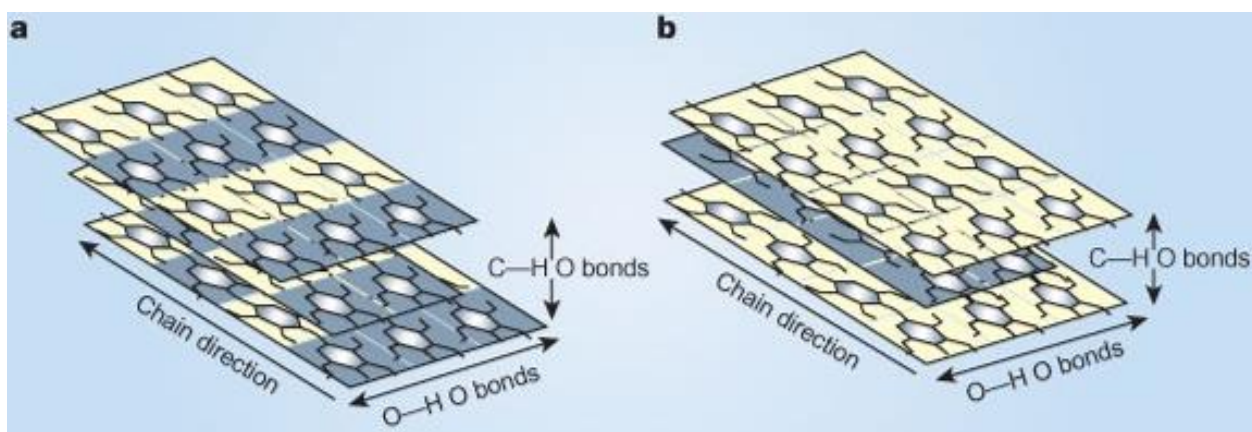

Figure 4 Symmetry and direction of hydrogen bonding in cellulose I: a cellulose $\mathrm{I}_{\alpha}$ and $\mathbf{b}$ cellulose $\mathrm{I}_{\beta}$ (Adapted from Jarvis, ${ }^{21}$ Copyright from Springer Nature 2003).

The intramolecular and intermolecular hydrogen bonds arrange cellulose chains in threedimensional ordered crystalline structures. Four allomorphs of crystalline cellulose, namely, 
cellulose I, cellulose II, cellulose III, and cellulose IV, were found by using X-ray diffraction and ${ }^{13} \mathrm{C}$ solid state NMR. ${ }^{22}$ Cellulose I is isolated from natural source with a parallel crystalline structure. Cellulose $\mathrm{I}$ is composed of two allomorphs, $\mathrm{I}_{\alpha}$ and $\mathrm{I}_{\beta}$, with diverse component ratios depending on the sources. $\mathrm{I}_{\alpha}$ is more found in primitive organisms, such as bacterial and algea, while $\mathrm{I}_{\beta}$ is more present in higher plants and animals, like trees, cotton and tunicates. Cellulose $\mathrm{I}_{\alpha}$ is metastable and can be transformed into cellulose $\mathrm{I}_{\beta}$ by annealing. ${ }^{23}$ Cellulose $\mathrm{I}_{\alpha}$ has a triclinic symmetry with one chain while cellulose $\mathrm{I}_{\beta}$ has a monoclinic symmetry with two chains (Figure 5a). Cellulose II can be obtained by regeneration from the solution of cellulose I or mercerization. The transformation from cellulose I to cellulose II is irreversible. Neutron fiber diffraction analysis elucidated that cellulose II has an antiparallel crystalline structure arranged in monoclinic symmetry with two chains (Figure 5b). Cellulose I and cellulose II can be transformed into cellulose $\mathrm{III}_{\mathrm{I}}$ and cellulose $\mathrm{III}_{\mathrm{II}}$, respectively, after treatment with liquid ammonia or organic amine. ${ }^{1824-26}$ The cellulose III $_{\mathrm{I}}$ and cellulose $\mathrm{III}_{\mathrm{II}}$ have the same unit cell in crystalline structure (Figure 5c). However, cellulose chains arrange in parallel mode in cellulose III while antiparallel in cellulose III II. $^{26}$ The transformation from cellulose I and cellulose II to cellulose III is reversible. Cellulose III $_{\mathrm{I}}$ and cellulose $\mathrm{III}_{\mathrm{II}}$ can be converted into cellulose I and cellulose II, respectively by mild heating in water. Cellulose $\mathrm{III}_{\mathrm{I}}$ and cellulose $\mathrm{III}_{\mathrm{II}}$ can be transformed into cellulose $\mathrm{IV}_{\mathrm{I}}$ (Figure $5 \mathrm{~d}$ ) and cellulose $\mathrm{IV}_{\mathrm{II}}$, respectively by heating in glycerol at $260{ }^{\circ} \mathrm{C}$ for 20 mins. $^{27}$ Cellulose $\mathrm{IV}_{\mathrm{I}}$ and cellulose $\mathrm{IV}_{\mathrm{II}}$ can be converted back to cellulose I and cellulose II via drastic acid or alkali treatments. Figure 6 summarizes the transformation of cellulose among its various polymorphs. 

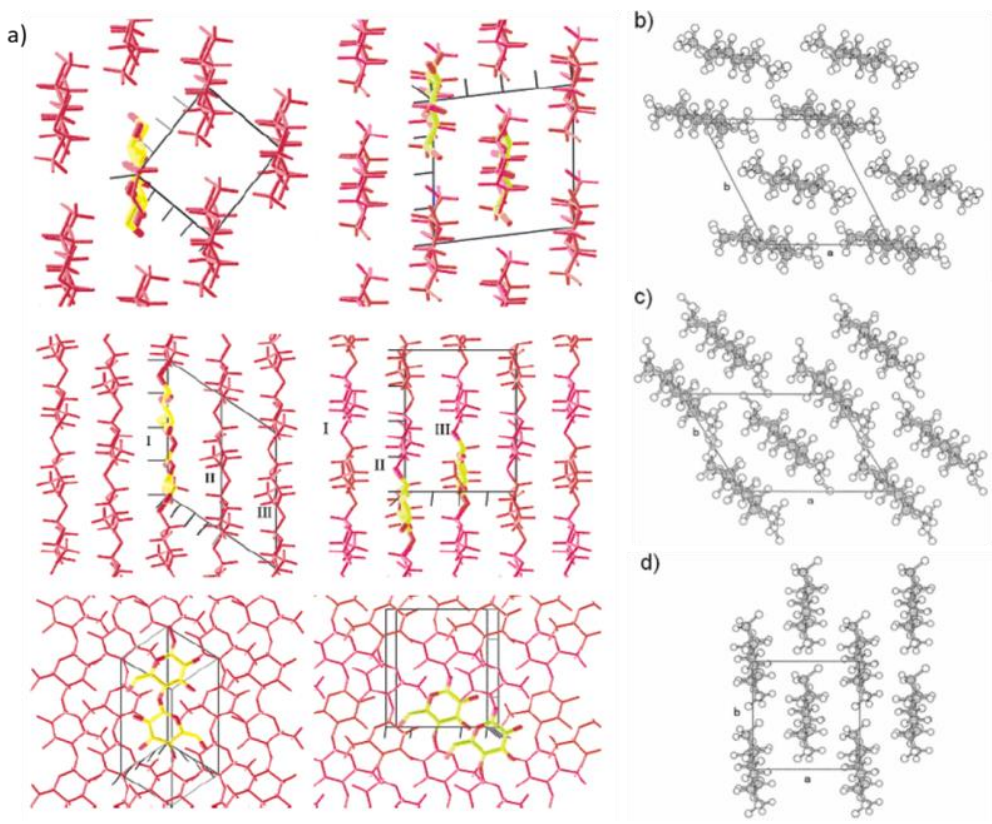

Figure 5 (a) Projections of the crystal structures of cellulose $\mathrm{I}_{\alpha}$ (left) and $\mathrm{I}_{\beta}$ (right) down the chain axes (top), in the plane of the hydrogen bonded sheets and perpendicular to the chain axis (middle), and perpendicular to the hydrogen bonded sheets (bottom) (Adapted from Nishiyama et al ${ }^{17}$, Copyright from American Chemical Society 2003). Models of (b) cellulose II, (c) cellulose IIII, (d) cellulose IV in a-b plane (Adapted from Zugenmaier ${ }^{28}$, Copyright from Elsevier Science Ltd. 2011)

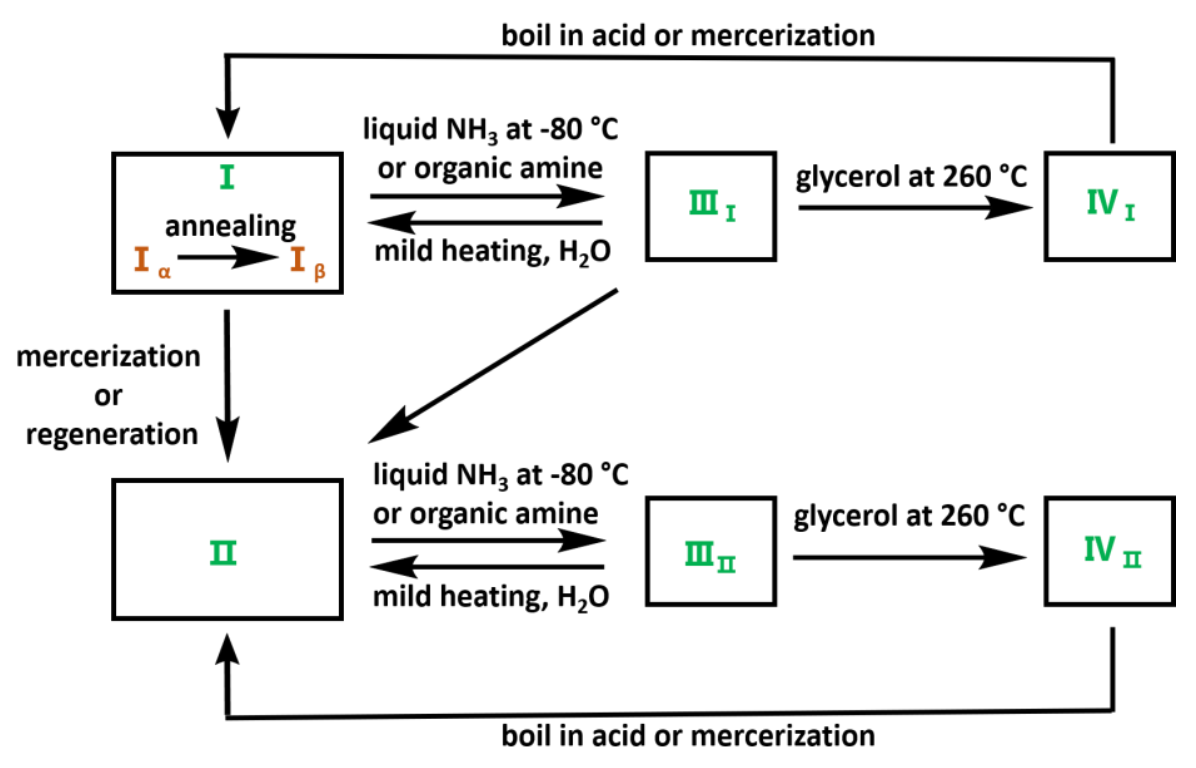

Figure 6 Various polymorphs of cellulose and the transformation among them. (Reproduced from Kono et al ${ }^{24}$ Copyright from American Chemical Society 2004) 


\subsection{Cellulose derivatives}

\subsubsection{Activation and dissolution of cellulose}

For the derivation of cellulose, the precise prediction and control of DS is usually difficult, and it is often infeasible to apply the experience of one cellulose derivative to another. One of the primary challenge lies in the accessibility of hydroxyl groups, which affects the rate and yield of reactions. The elementary crystallites, which assemble into the fibrillar structure, involve intermolecular hydrogen bonds, dipolar interaction and van der Waals interaction. These interactions make the hydroxyl groups in crystalline region very difficult to access. Thus, activation is usually needed to make the hydroxyl groups more accessible and increase the solubility and chemical reactivity.

The activation of cellulose can be mainly realized via intercrystalline swelling and intracrystalline swelling.

\section{Intercrystalline swelling}

Intercrystalline swelling of cellulose can be realized by using water, alcohol and other organic solvents as well as solvent mixers. The mechanisms of intercrystalline swelling via various solvents are akin to that of water vapor sorption, i.e. solvent molecules penetrate into the interstices between crystalline fibrillar structural units and swell the less-ordered areas as well as also possibly less-ordered cross-linking areas.

The degree of swelling depends on some key factors such as DP, $\mathrm{I}_{\mathrm{C}}$, content of $\alpha$-cellulose and pore volume distribution. ${ }^{29,30}$ The extent of intercrystalline swelling can be improved by solvent-exchange. Solvent-exchange is usually conducted by using small, dipolar solvents, followed by the solvents desired. For instance, swelling of cellulose in DMF increased $61 \%$, $45 \%, 65 \%$ and $62 \%$ after pretreatment with water, ethanol, DMSO, formamide. ${ }^{31}$ Organic solvents can be "trapped" in the interstices between crystalline fibrillar structures. These organic solvents can not be removed even after heating at elevated temperature for extended time under reduced pressure. These "trapped" organic molecules impeded the formation of hydrogen bonds and increased the reactivity.

The efficient swelling by water is due to the unique $3 \mathrm{D}$ structure of water molecules, the capability to remain their bulky characteristics in cellulose and the involved additional water 
molecules which not bonded to cellulose directly ${ }^{32-34}$. The high dipole moment and relatively small molecule volume of DMSO make it an efficient swelling solvent for cellulose. Strong hydrogen bonds between DMSO and mono-/disaccharides, oligomers and cellulose have been reported. ${ }^{35-37}$

\section{Intracrystalline swelling}

Compared with intercrystalline swelling, which increases the accessibility of hydroxyl groups via opening and widening the micropores in cellulose by using various swelling solvents, further treatments by increasing the concentrations of swelling solutions will further increase the accessibility of hydroxyl groups by splitting the crystalline structures.

Intracrystalline swelling can be realized by using various mineral acids. For instance, optimum swelling can be reached with a concentration of $62.5 \%$ sulfuric acid at $0-20{ }^{\circ} \mathrm{C}$. Similarly, intracrystalline swelling occurs at concentration ranging from 70-81\% for phosphoric acid, 59$69 \%$ for nitric acid and $37-38 \%$ for chloric acid. ${ }^{38-40}$ In addition, the transformation from cellulose I to cellulose II has been observed by these mineral acids with high concentration. ${ }^{40-}$ ${ }^{42}$ Intracrystalline swelling can also be achieved by alkali hydroxides. Complete transformation of cellulose I to cellulose II occurs by treatment of $14 \%$ aqueous $\mathrm{NaOH}$ for $2 \mathrm{hrs}$ at room temperature. ${ }^{43}$ In addition to the concentrations, the swelling extent also depends on the alkali metal hydroxide applied, with the order of $\mathrm{LiOH}>\mathrm{NaOH}>\mathrm{KOH}>\mathrm{RbOH}>\mathrm{CsOH}$. This order results from the hydration of these alkali metal ions. Hydrated ions are tetrahedral in structure with four water molecules in the first shell and additional water molecules in the outer layer. Larger ions have less binding water molecules in the outer layer compared with smaller ions. ${ }^{44}$ Intracrystalline swelling can also be achieved by using organic bases such as ammonia, amine, amine complexes and amine oxides. The lone electron pair of ammonia leads to the formation of ammonia-cellulose complexes, which are not stable and decompose by heating or washing with solvents including water, alcohol, acetone and THF. ${ }^{45}$ Natural cellulose can be transformed into cellulose III by treatment of liquid ammonia, which can be reversed by removing ammonia via washing with water. ${ }^{46}$ Aliphatic amines swell cellulose by formation of amine-AGU complexes. Compared with aliphatic monoamines, aliphatic diamines swell cellulose faster and form more thermally stable complexes. Aqueous solutions of amines also swell cellulose. 
Metal-amine complexes can easily swell and possibly dissolve cellulose including those with a high DP.

\section{Dissolution}

Dissolution of cellulose is required for characterization, shaping and homogeneous chemistry of cellulose. Solvents of cellulose were divided into non-derivatizing solvents and derivatizing solvents. Non-derivatizing solvents dissolve cellulose via non-covalent bonds while derivatizing solvents dissolve cellulose with covalent bonds.

\section{Non-derivatizing solvents}

Electrolytes in dipolar aprotic solvents are useful solvent systems for cellulose. Typical solvent systems encompass strong electrolytes, such as $\mathrm{LiCl}, \mathrm{LiBr}, \mathrm{TBAF} \times 3 \mathrm{H}_{2} \mathrm{O}$, and dipolar aprotic solvents such as DMAc, DMF, DMSO and so on. ${ }^{47}$ These solvent systems can dissolve cellulose even with a high DP and Ic. For DMAc/LiCl systems, the pretreatment is important for the dissolution. Different pretreatments of cellulose and the same subsequent reaction can lead to distinct DS. Pretreatments can be realized by mercerization followed by washing, solvent displacement and heating solid cellulose or heating using solvent for heat transfer. ${ }^{48}$
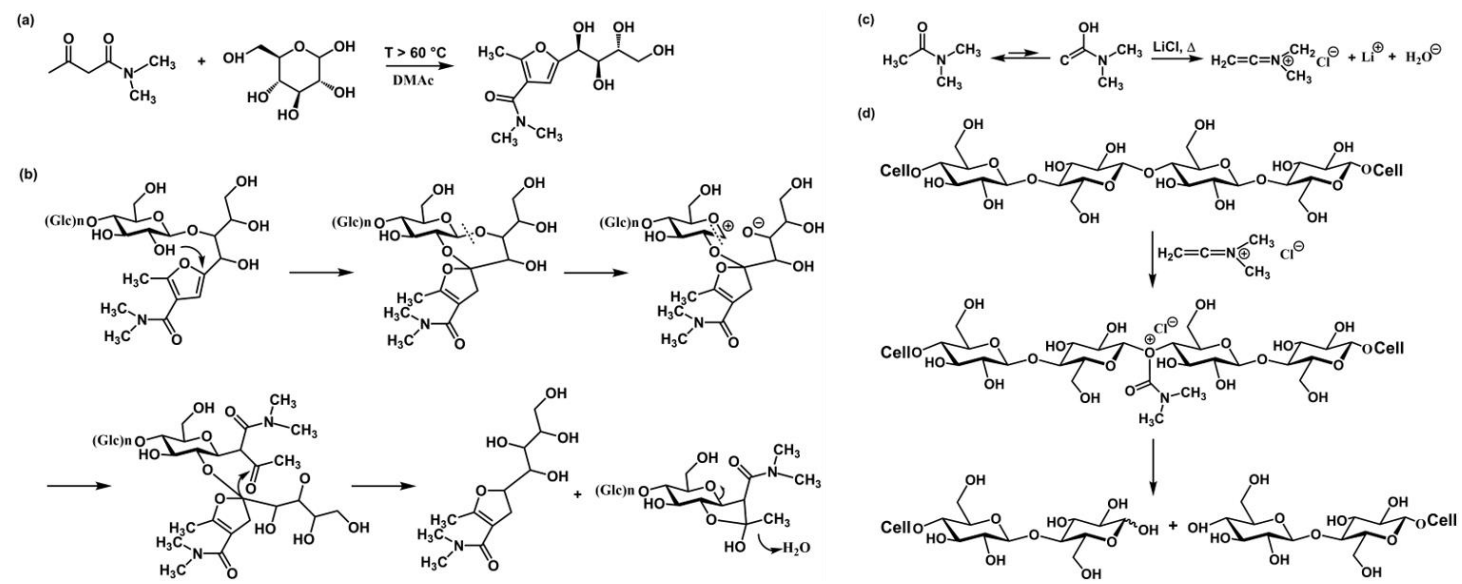

Figure 7 Mechanisms of (a-b) endwise slow degradation and (c-d) fast degradation via cleavage of glycosidic bonds of cellulose in DMAc/LiCl solvent system. (Reproduced from Rosenau et al, ${ }^{49}$ Copyright from Springer-Verlag Berlin Heidelberg 2006)

Heating cellulose in dipolar aprotic solvents can cause degradation of cellulose. For instance, at temperature $>80{ }^{\circ} \mathrm{C}$, DMAc auto-condensed to $\mathrm{N}$, N-dimethylacetoacetamide: 


\section{$2 \mathrm{CH}_{3} \mathrm{CON}\left(\mathrm{CH}_{3}\right)_{2} \rightarrow \mathrm{CH}_{3} \mathrm{COCH}_{2} \mathrm{CON}\left(\mathrm{CH}_{3}\right)_{2}+\mathrm{HN}\left(\mathrm{CH}_{3}\right)_{2}$.}

$\mathrm{N}, \mathrm{N}$-dimethylacetoacetamide can react with the reducing end of cellulose and cause the endwise slow degradation of cellulose (Figure 7a-7b). Another faster side reaction that cause the degradation of cellulose initiated from N, N-dimethylketeniminium ion, which formed from the enol tautomer of DMAc. This formation process can be accelerated by $\mathrm{Li}^{+}$coordination to $\mathrm{C}=\mathrm{O}$ of DMAc. The highly reactive cation from solvent result in cleavage of glycosidic bonds of cellulose (Figure 7c-7d). To avoid the degradation, cellulose can be heated with dry $\mathrm{LiCl}$ at $110{ }^{\circ} \mathrm{C}$ under reduced pressure, and then DMAc can be added before restoring normal pressure. ${ }^{50}$ This method leads to activated cellulose with small DP change $(\leq 6 \%)$ compared with that before treatment. ${ }^{51}$

Regarding to the mechanism of $\mathrm{DMAc} / \mathrm{LiCl}$ dissolving cellulose, several mechanisms have been suggested (Figure 8). ${ }^{52}$ Mechanism $\mathrm{A}$ and $\mathrm{C}$ are similar since the Li-N interaction should be weak. Mechanism D and E could have problem that $\mathrm{Cl}^{-}$only played a minor role or no role for the cellulose dissolution, which contradict with the fact that $\mathrm{LiCl}$ is more efficient than $\mathrm{LiBr}$ for the dissolution of cellulose. ${ }^{53}$ Thus, the most dominant mechanism is $\mathrm{Cl}^{-}$- $\mathrm{H}-\mathrm{O}-\mathrm{Cell}$.

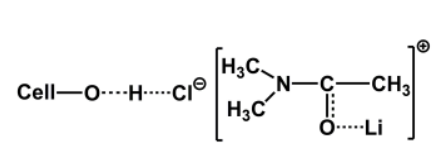

(A)

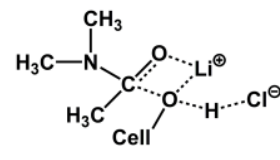

(B)

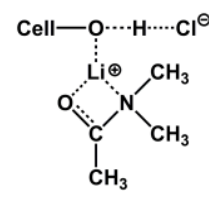

(C)

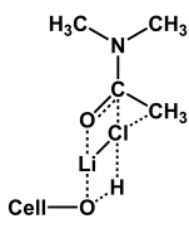

(D)

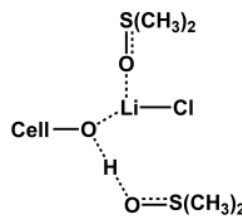

(E)

Figure 8 Suggested mechanisms of dissolution of cellulose using dipolar aprotic solvent/LiCl. (Reproduced from EI Seound et a ${ }^{52}$ Copyright from Springer-Verlag Berlin Heidelberg 2005)

It should be noted that other solvents can be more efficient than $\mathrm{DMAc} / \mathrm{LiCl}$, for instance, $\mathrm{R}_{4} \mathrm{NF}$ $\times \mathrm{nH}_{2} \mathrm{O}$ / dipolar aprotic solvent, DMAc/quaternary ammonium chloride can dissolve cellulose without pretreatment. ${ }^{47,54,55}$ Acetone/quaternary ammonium chloride and 1,3-dimethyl-2imidazolidinone/ $\mathrm{LiCl}$ also dissolve cellulose efficiently. ${ }^{56,57} \mathrm{TBAF} \times 3 \mathrm{H}_{2} \mathrm{O} / \mathrm{DMSO}$ can dissolve cellulose at room temperature. ${ }^{58,59}$ Ionic liquids are another type of solvent to dissolve cellulose. Cations such as imidazolium, quaternary ammonium and anions like halogenides, carboxylates, and phosphates are frequently used for the dissolution of cellulose. ${ }^{60}$ Aqueous metal-complex 
solvents including transition metal complexes with amines, $\mathrm{NH}_{3}$ or tartaric acid, can dissolve cellulose with acid-base principle. ${ }^{61-63}$ Aqueous alkali hydroxides can swell cellulose and further dissolve it at higher concentration. Melts of iorganic salt hydrates and their mixtures can also dissolve cellulose. N-Oxides of tertiary amines, NMMO, as the typical example, are also an important category of cellulose solvent.

\section{Derivatizing solvents}

Derivative solvents dissolve cellulose via forming covalent bonds. Examples of derivative solvents range from $\mathrm{N}_{2} \mathrm{O}_{4} / \mathrm{DMF}, \mathrm{HCOOH} / \mathrm{H}_{2} \mathrm{SO}_{4}, \mathrm{~F}_{3} \mathrm{CCOOH}, \mathrm{Cl}_{2} \mathrm{CHCOOH}$, to paraformaldehyde/DMSO and $\mathrm{ClSi}\left(\mathrm{CH}_{3}\right)_{3}$, with cellulose nitrate, formate, trifluoacetate, dichloroacetate, hydroxymethyl and trimethylsilyl as the derivatives, respectively. These firstgeneration derivatives can be further reacted to obtain second derivatives, where the firstgeneration derivatives serve as protecting group (e.g. cellulose nitrate) or a more reactive group (e.g. silyloxy moiety) for the subsequent reactions. ${ }^{64,65}$

\subsubsection{Cellulose derivatization}

Several points should be noted when considering the derivatization of cellulose, e.g. the completeness of reaction, the purity of the products, the inter-/intramolecular interactions and the number of phases during the reactions. Homogeneous reactions refer to the reactions where cellulose is dissolved before the reaction and the system remain homogeneous until the end of the reaction. The derivatization of cellulose evolves many categories of reactions, namely esterification, etherification, oxidation, grafting and so on. As this thesis used esterification for the derivatization, only esterification is introduced here.

Industrial production of cellulose esters applies mainly heterogeneous reactions. Products with a low DS are usually not produced in this way because the products will be unevenly substituted both within AGUs and along the cellulose backbone under heterogeneous conditions. This uneven substitution can cause problems in practical usage, such as irreproducible products, formation of gel particles in solvents. ${ }^{66}$ And it is difficult to control the simultaneous reaction of two competitive reagents for the acylation of cellulose under heterogeneous conditions.

In comparison, esterification of cellulose under homogeneous conditions has the following 
advantages: evenly substitution both within AGUs and along cellulose backbone, little degradation, high reproducibility, good control of two competing derivatizing reagents and regioselectivity. ${ }^{52}$ It should be noted that visual homogeneity not necessarily present welldispersed cellulose. Aggregates can exist in electrolyte/dipolar aprotic solvents. However, many reported examples showed reproducible products, which indicated that the aggregates in solvents under homogeneous conditions should be highly swollen and hydroxyl groups should be much more accessible than those under heterogeneous conditions. Homogeneous esterification has its limitations, for instance, low cellulose charges. Cellulose solutions can change from isotropic and viscous, through anisotropic and very viscous, to gel with the increase of cellulose concentration. Raising temperature and application of strong shearing can decrease the viscosity ${ }^{67}$ Adding DMSO or DMAc as diluent solvent is also effective to avoid phase separation. ${ }^{68}$ The decrease of DP is normally small, $<8 \%$, in DMAc/ $\mathrm{LiCl}$, or ionic liquids. ${ }^{69,70}$ Homogeneous reaction conforms to green chemistry in that the reaction occurs with equimolar or quasi equimolar reagents/ $\mathrm{OH}$ groups with or without catalysts.

In particular, the esterification used in this thesis evolves reaction of cellulose and acyl chlorides under heterogeneous (pyridine) and homogeneous conditions (DMAc/LiCl, pyridine). The reaction between acyl chloride and cellulose is nucleophilic substitution in principle. The ester formation mechanism with the presence of pyridine as base can be depicted as shown in Figure 9a. ${ }^{71}$ In this mechanism, pyridine is consumed and ends up as protonated. Thus, at least one equivalent of pyridine is needed for the reaction. In fact, pyridine is more nucleophilic than $\mathrm{OH}$ groups of cellulose. It attacks acyl chloride rapidly and form highly electrophilic intermediate. This intermediate then reacts with cellulose and yields cellulose esters. Pyridine speeds up the reaction and has no change after the reaction, therefore pyridine is acting as a nucleophilic catalyst (Figure 9b). ${ }^{71}$ 
(a)

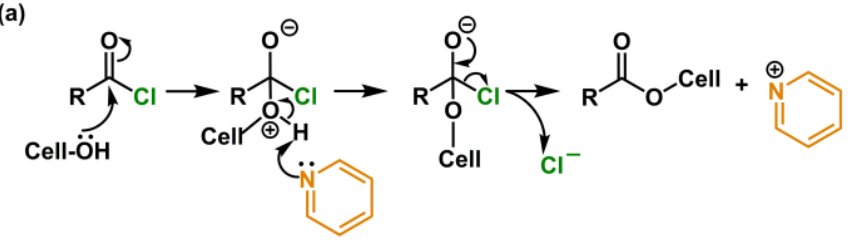

(b)

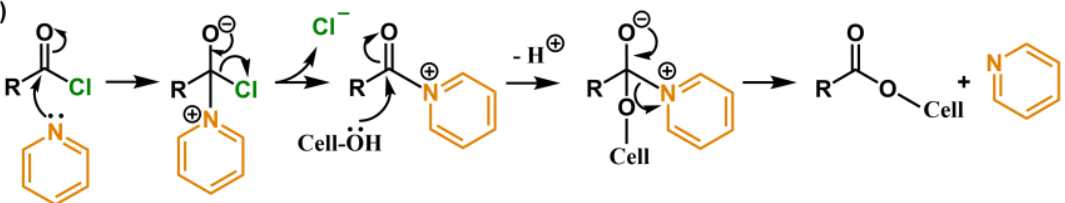

Figure 9 Mechanisms of cellulose esters formation via reaction of cellulose and acyl chloride with pyridine as (a) base and (b) catalyst. (Reproduced from Clayden et $\mathrm{al}^{71}$ Copyright from Oxford University Press 2001)

\subsection{Nanostructured materials based on cellulose derivatives}

\subsubsection{Nanoparticles}

Nanoparticles can be made from cellulose derivatives via methods, such as nanoprecipitation via dialysis and dropping techniques, nanoemulsion-evaporation and other modified methods including flash nanoprecipitation etc.

\subsubsection{Nanoprecipitation}

A "nanoprecipitation" process is also known as "solvent-displacement" or "solvent-shifting" process, or "ouzo process". When the nonsolvent is added to the polymer solution, the solubility of polymer is decreased and the polymer precipitates into nanoparticles. ${ }^{72}$ Nanoprecipitation is usually performed via dialysis or dropping techniques. The dialysis techniques separate polymer solutions and nonsolvent by using a dialysis membrane. The solvent is removed slowly by several changes of the nonsolvent and the nanoparticle suspensions are obtained. ${ }^{73}$ The dropping technique is performed by adding polymer solution to nonsolvent or vice versa by adding nonsolvent to polymer solution. ${ }^{74}$ The solvent is usually removed by heating or dialysis. The principle of nanoparticle formation during this "solvent-shifting" process is usually based on the spontaneous interfacial precipitation initiated by the concentration fluctuation of polymer in the boundary layer. ${ }^{75}$ The ternary phase diagram of polymer, solvent and non-solvent (Figure 10) includes homogeneous region and heterogeneous region, separated by the binodal. 
The homogeneous region has a high content of solvent while the heterogeneous region locates in area with low content of solvent. The spinodal within the binodal represent the region where only macroscopic aggregates exist. The area between binodal and spinodal is the metastable region where both macroscopic particle and nanoparticles are formed since the concentration of polymer is high enough to generate large particles and their coagulation. The "ouzo region" is within the metastable region where polymers aggregate only as nanoparticles and no macroparticles exist. The nanoprecipitation usually starts from a polymer solution with low concentration (red point, Figure 10), then by adding nonsolvent, the system transfer in the homogeneous region (red line), cross the binodal, and finally reach and stay in the "ouzo region". The size of nanoparticles usually can be influenced by two mechanisms: (1) nucleation-growth and (2) nucleation-aggregation. ${ }^{76}$ The properties of nanoparticles made from nanoprecipitation depends on the intrinsic properties of polymers and external factors such as initial polymer concentration, solvent/non-solvent ratio, dropping rate and so on. ${ }^{77,78}$

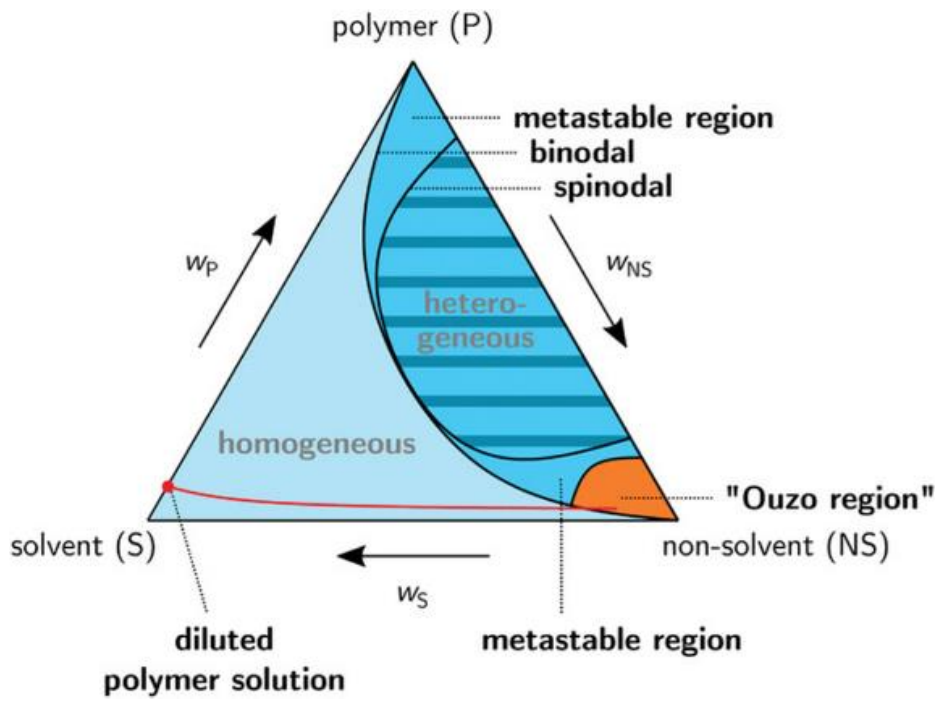

Figure 10 Ternary phase diagram of polymer, solvent and non-solvent showing the regions including ouzo region.(Adapted from Gericke et al, ${ }^{79}$ Copyright from 2020 WILEY-VCH Verlag GmbH \& Co.)

Cellulose derivatives, including $\mathrm{CA}$, cellulose propionate, cellulose butyrate, cellulose phthalate, cellulose stearate, cellulose tosylate, cellulose hexanoate, cellulose laurate, EC, CMC and so on, have been utilized to prepare nanoparticles by nanoprecipitation via dialysis or dropping techniques. ${ }^{77,80-86}$ It was found that nanoparticles of CA prepared by dropping the 
polymer solution into non-solvent are smaller in size than those prepared by dropping nonsolvent to polymer solution. Irregular precipitation occurs when the concentration is higher than the critical concentration. ${ }^{75}$ Nanoparticles fabricated from cellulose alkyl esters, including cellulose stearoyl, lauroyl and caproyl esters have been investigated. ${ }^{80} \mathrm{CSE}$ with a high content of stearoyl groups lead to crystalline nanoparticles with reversible temperature-responsive properties. Cellulose carboxylate/tosylate mixed esters have been synthesized and prepared into nanoparticles by nanoprecipitation via dropping technique. ${ }^{81}$ EC nanoparticles prepared by nanoprecipitation have been reported as stabilizers for super stable foams and Pickering emulsions. ${ }^{83,86,87}$ The interfacial self-assembly of EC nanoparticles in other systems have also been investigated. ${ }^{84,85}$ Nanoparticles from EC made by nanoprecipitation method have also been applied in drug delivery. ${ }^{88}$ HPC and hydroxyethylcellulose (HEC) have been fabricated into prodrugs with fluoroquinolone antibiotic ofloxacin via dialysis technique. ${ }^{89}$ Nanoparticles from cellulose acetate phthalate have been made via dropping and dialysis techniques with reactive carboxyl groups readily to covalently and adsorptively couple various functional moieties such as drugs, antibodies, dyes and so on. ${ }^{90-94}$ Martin Obst et al. synthesized hydrophobic amino cellulose derivatives, which were labelled with FITC and made into nanoparticles via nanoprecipitation. ${ }^{95}$ These labelled nanoparticles have potential application for labelling biomolecules in bioassays. Cheng et al utilized aminocellulose as reducing agent to prepare highly stable silver nanoparticles in aqueous media. The resultant silver colloids showed antibacterial functions. ${ }^{96}$ Wiegand et al prepared nanoparticles from aminocellulose carbamates, which demonstrated enhanced antimicrobial activity and biocompatibility. ${ }^{97}$ Nikolajski et al. reported nanoparticles from highly functionalized 6-deoxy-6-( $\omega$ aminoalkyl)aminocellulosecarbamates via dialysis. The nanoparticles were labelled with rhodamine B isothiocyanate. These functionalized nanoparticles can be easily uptaken by various cells without transfection reagents..$^{98}$

Moreover, smart and stimuli-responsive nanoparticles from cellulose derivatives have also been reported. Li et al reported multi-responsive nanoparticles from cellulose derivatives, which presented in water as nanoparticles with disulfide bonds linkage and dissolved when the disulfide bonds were reduced into thiols. Meanwhile the immobilized rhodamine spiroamide on cellulose 
derivatives enables the reversible fluorescence with the stimuli of UV irradiation, temperature or pH. ${ }^{99}$ Wang et al reported $\mathrm{pH}-$ responsive nanoparticles with switchable sizes from ionic cellulose derivatives. Cellulose was firstly modified with 10-undecenoyl chloride, which had a reactive double bond in the end. Ionic thiols were then coupled to the reactive end via thiol-ene reaction to obtain ionic cellulose derivatives. The cellulose derivatives functionalized with tertiary amine showed $\mathrm{pH}$ responsiveness with tunable sizes of the particles. ${ }^{100}$

\subsubsection{Nanoemulsions}

Nanoemulsions, also referred as miniemulsions, are thermodynamically instable but kinetically stable liquid-in-liquid dispersions. ${ }^{101,102}$ The size of the droplets in nanoemulsion is in the range of around 20-500 $\mathrm{nm}$. Nanoemulsions can generally be obtained by high energy methods and low energy methods. Nanoparticles can be formed by utilizing nanoemulsions as templates. Polymers including cellulose derivatives can be firstly dissolved in organic solvent and mix with a suitable non-solvent to form nanoemulsions. The solvent can be removed to obtain nanoparticles. ${ }^{75,103}$ Compared with nanoprecipitation, nanoparticles prepared from nanoemulsions have their benefits and limitations. On one hand, the size and size distribution of nanoparticles from nanoemulsions can be defined with the modification of the external factors such as the type or amount of surfactant, the strength or time of energy input. ${ }^{75,103}$ On the other hand, the nanoparticles made from nanoemulsions usually have surfactant on the surfaces while the nanoparticles made from nanoprecipitation have "naked" surfaces readily for surface-modification. ${ }^{103}$ In addition, the nanoemulsion method require consideration of solvents that nonmiscible with the nonsolvent.

EC nanoparticles prepared via emulsification and solvent evaporation method have been applied for various drug delivery. ${ }^{104-106} \mathrm{CA}$, cellulose propionate and cellulose butylate with a narrow size distribution have been made via nanoemulsion method..$^{75}$ cellulose acetate phthalate nanoparticles coupled with drug or dye have been made via emulsion technique. ${ }^{107}$

\subsubsection{Other methods}

In addition to the methods mentioned above, flash nanoprecipitation (also referred as rapid 
precipitation) has also been explored for the preparation of nanoparticles from cellulose derivatives. ${ }^{108-112}$ In flash nanoprecipitation, a microfluidic device named multi-inlet vortex mixer is applied to realize the simultaneous rapid mixing of multi-components from multistreams. These components can contain polymer solution, non-solvent, surfactant and loading substances such as drug, dye and so on. The size and size distribution of nanoparticles made from flash nanoprecipitation can be tuned by the rate of each stream and the turbulence inside the mixer which is quantified by Reynold number. ${ }^{108,109}$ This method is suitable for the encapsulation of functional substances into the nanoparticles. Celllose derivatives including carboxymethyl cellulose acetate butyrate, cellulose acetate propionate and hydroxypropylmethyl cellulose acetate succinate have been made into nanoparticles with curcumin loading by flash nanoprecipitation using multi-inlet vortex mixer. ${ }^{109} \mathrm{CMC}$, modified by grafting PEG and various drugs has also been made into nanoparticles using either flash nanoprecipitation or microfluidic devices. ${ }^{112-115}$

Modified nanoprecipitation has been reported via adding solvents as modifier into nonsolvent, which is further utilized as dispersive media for nanoprecipitation. Nanoparticles made from CA by using this method are smaller in size than those made from standard methods. ${ }^{78}$ Functional composite nanoparticles from hydrophobic CA with hydrophilic hydroxyethyl cellulose, CMC, and amino cellulose have been made by nanoprecipitation using hydrophilic solutions as dispersive media. ${ }^{116}$

Aerosol flow reactor is a simple and efficient method to obtain dry nanoparticles without further purification of nanoparticles. The polymer solution is atomized to generate nanosized droplet, which pass through a heated tubular laminar flow reactor with carrier gas. The dry nanoparticles are collected after the solvent evaporatation. Cellulose -graft-polyacrylamide and cellulosegraft-poly (N, N-dimethylacrylamide) have been prepared by single-electron-transfer living radical polymerization. Nanoparticles were produced from these cellulose-g-copolymers via aerosol flow reactor method. ${ }^{117}$

Other examples to obtain nanoparticles from cellulose derivatives usually involve the consideration of their specific characteristics. Pure cellulose nanoparticles have been made via hydrolysis of trimethylsilyl cellulose in water via dialysis technique. ${ }^{118}$ Diblock copolymers 
from cellulose derivatives carrying a hydrophobic alkyne chain and pyrene groups selfassembled into nanoparticles in non-solvent. The obtained nanoparticles had a core-shell structure with a hydrophobic core and hydrophilic shell. ${ }^{119}$ Hybrid complexed nanoparticles were obtained by coating the surface of magnetic nanoparticles with amino cellulose, followed by complexation with $\mathrm{CuBr}$. The hybrid complexed nanoparticles were used to catalyze the atom transfer radical polymerization (ATRP) of styrene. Polystyrene with a narrow molecular weight distribution and low $\mathrm{Cu}$ contents were obtained. The catalyst can be isolated after reaction and reused for further reaction. ${ }^{120}$

\subsubsection{Nanostructured films/membranes}

\subsubsection{Coating from nanoparticle colloids}

Cellulose derivatives can be made into nanoparticles using above-mentioned methods. The ensuing nanoparticle colloids can then be made into films with intriguing properties. For instance, CSE were firstly made into nanoparticles via nanoprecipitation. The resultant CSE nanoparticles were fabricated into superhydrophobic and self-cleaning films via various techniques, e.g. spin-coating, spray-coating and solvent-casting. ${ }^{82}$ This functional film is applicable to various surfaces. Conversly, slippery surfaces were also obtianed using this method. ${ }^{121}$ CLE was firstly made into nanoparticles via nanoprecipitation, which was then made into nanoporous films via spray-coating. Slippery surfaces were manufactured by subsequent infusing the nanoporous films with perfluoropolyether. Water, organic liquids and ionic liquids slide from the CLE slippery surfaces with a sliding angle smaller than $10^{\circ}$. Water drops impacting on the CLE slippery surface bound off without adhesion. The CLE slippery surface also showed anti-ice properties with delayed ice crystallization at $-10{ }^{\circ} \mathrm{C}$. Magnetic liquid drops can be shifted on the CLE slippery surface by using a magnet. This slippery surface has potential application for window coating and open microfluidic devices.

\subsubsection{Lithographic techniques}

Lithographic techniques provide nanostructures with high resolution, thus can be applied in various high-tech areas. Microcontact printing (also referred as nanoimprinting lithography) 
has been utilized to achieve nanostructured substrates from a variety of materials, such as glass, silicon, gold, metals/oxides, polymers. The nanostructured substrates can then be biofunctionalized with monolayers of amino(organo)polysiloxanes and aminocellulose derivatives for versatile bioapplications. ${ }^{122}$ Dore et al. used HPC as a biocompatible, biodegradable and water-processable resist for nanoimprinting lithography. ${ }^{123}$ HPC was patterned into nano-sized arrays by using a hot plate and an elastomeric stamp (Figure 11). Silicon photonic arrays and metal nanoparticle arrays were fabricated via combining HPC and traditional nanofabrication techniques, like spincasting, reactive ion etching and metal lift off. The combination of HPC resist and traditional nanofabrication resists provided more possibilities for advanced nanofabrication. Espinha et al fabricated photonic and plasmonic structures from HPC via soft nanoimprinting lithography. ${ }^{124}$ Photonic crystal films were produced from HPC with patterned lattice of cylindrical holes by hot embossing or replica moulding. HPC films patterned with distinct size of the holes generate photonic films with various structural colors. HPC plasmonic crystals were subsequently obtained from patterned photonic HPC films by metal coating. The obtained plasmonic crystals were further applied for the enhancement of dye photoluminescence with the signal strengthened approximately tenfold. The plasmonic resonance were also used to amplify the signal of Raman scattering.

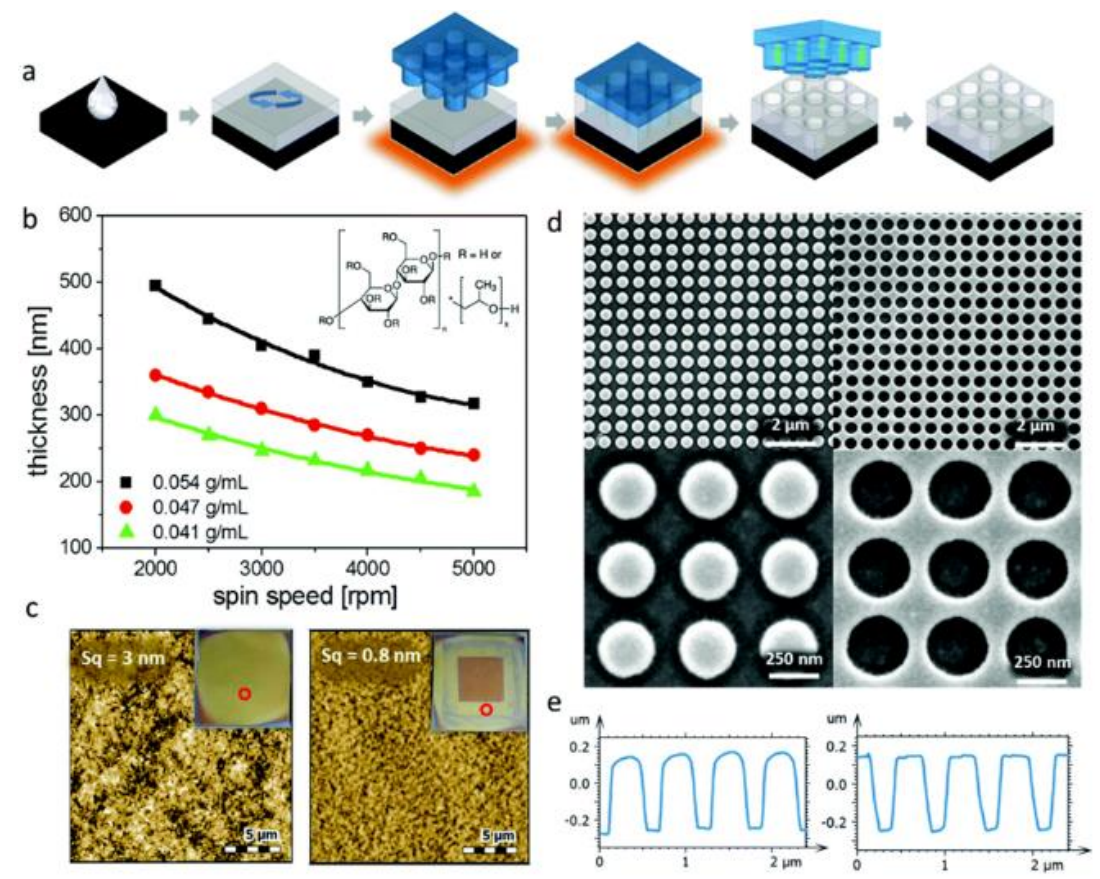

Figure 11 Thermal nanoimprinting to pattern HPC on glass and silicon substrates. (Adapted from Dore 
et al ${ }^{123}$ Copyright from The Royal Society of Chemistry 2018)

Park et al reported transparent antifouling film with nanoneedle array pattern from CA coated with 2-methacryloryloxyethyl phosphorylcholine (MPC). ${ }^{125}$ The nanoneedle patterns of CA were prepared by replica moulding. CA is a cellulose derivative with biocompatibility and biodegradability since it can be produced from living organisms and can be hydrolyzed by enzymes. The nanostructured surface with sharp tips can physically destroy the cell membrane of bacterial and result in anti-bacterial properties. MPC is a biomimic antifouling material, which can form a hydration layer by electrostatic interactions. The combination of CA with nanoneedle patterns coated with MPC resulted in transparent, flexible and biocompatible film with remarkable resistance to bacteria. This film has potential application in biomedical devices to prevent device-associated infections.

Archim Wolfberger et al developed patterned cellulose thin films in nanoscale with photolithography techniques from the trimethylsilyl cellulose with UV irradiation and photo acid generator for the desilylation. ${ }^{126}$ Positive and negative type cellulose can be obtained by using this method. A $32 \mathrm{~nm}$ thin cellulose film from the photochemical regeneration was applied as gate dielectrics for OTFT with good performance.

\subsubsection{Self-assembly}

Nanostructured films from the self-assembly of cellulose derivatives via Langmuir-Blodgett (LB) techniques, layer by layer (LBL) methods, electrostatic interaction, complexation, as well as the self-assembly driven by the intrinsic properties of cellulose derivatives have been widely reported. Sakakibara et al reported LB films from cellulose derivatives containing porphyrins, which were utilized to construct photo current generation systems based on cellulose. The selfquenching of porphyrins in excited state within the LB films were suppressed due to the separation of porphyrins with a distance of approx. $1.0 \mathrm{~nm}$ on cellulose backbone. ${ }^{127}$ They also reported the nanorods from pheophorbide-appending cellulose with the confined space at the air-water interface for light-harvest. These nanorods were made into films with drop-casting and LB technique. The resultant films showed red-shifted absorption than their counterparts in 
solution. ${ }^{128}$ Various nanostructures from self-assembly of Azoacetoxypropylcellulose (AzoAPC) have been reported by Susete N. Fernandes et al. ${ }^{129}$ They fabricated Azoacetoxypropylcellulose (AzoAPC) films by LB technique by using the dilute solution of AzoAPC. The AFM images demonstrated stiff micelles with a diameter of $30 \mathrm{~nm}$ dispersed in a soft matrix. Other versatile nanostructures including round aggregates, filaments and lamellar can be obtained by spincoating of AzoAPC solution by tuning the concentration.

Gutierrez et al developed nanostructured cellulose triacetate (CTA) films based on the selfassembly of PEO-b-PPO-b-PEO (EPE) block copolymer. ${ }^{130}$ The PEO blocks interacts favorably with CTA while the PPO blocks remains immiscible with CTA. Thus, microphase separation occurred to generate nanostructured EPE/CTA composite films. Spherical and worm-like nanostructures were observed by tuning the ratio between EPE and CTA. Wei et al designed the amphiphilic cellulose derivatives that self-assembled into nano-sized micelles in water. Cellulose were firstly modified with hydrophobic chains with various chain length to obtain cellulose octanoate, cellulose laurate and cellulose stearate. The three cellulose esters with hydrophobic chains were further modified with sulfate groups as hydrophilic moieties. The amphiphilic cellulose derivatives self-assembled into nanosized micelles in water. ${ }^{131}$

Altam et al reported nanostructured cellulose derivative-lanthanide complex films with fluorescent color by hierarchical assembly. ${ }^{132}$ Negative-charged CMC and positive-charged quaternized cellulose (QC) were utilized for the assembly. CMC @Ln complex nanoparticles were firstly prepared by tuning the $\mathrm{pH}$ value and the ratio between $\mathrm{CMC}$ and lanthanide ion. The fluorescent films were then obtained via LBL assembly of negative-charged CMC@Ln complex nanoparticles and positive-charged QC. Three kinds of lanthanide ion, $\mathrm{Ce}^{3+}, \mathrm{Eu}^{3+}$, and $\mathrm{Tb}^{3+}$ were applied for the complex films, resulting in blue, green and red fluorescent colors, respectively. More plentiful colors were obtained via tuning the content of $\mathrm{Ce}, \mathrm{Tb}$ and $\mathrm{Eu}$ in the films. These nanostructured fluorescent films assembled by complexation and electrostatic interactions have potential applications in luminescence and catalysis. Similarly, antibacterial nanocomposite films have also been reported by using LBL assembly of silver nanoparticles coated with positive-charged aminocellulose and negative-charged hyaluronic acid. ${ }^{133}$ 


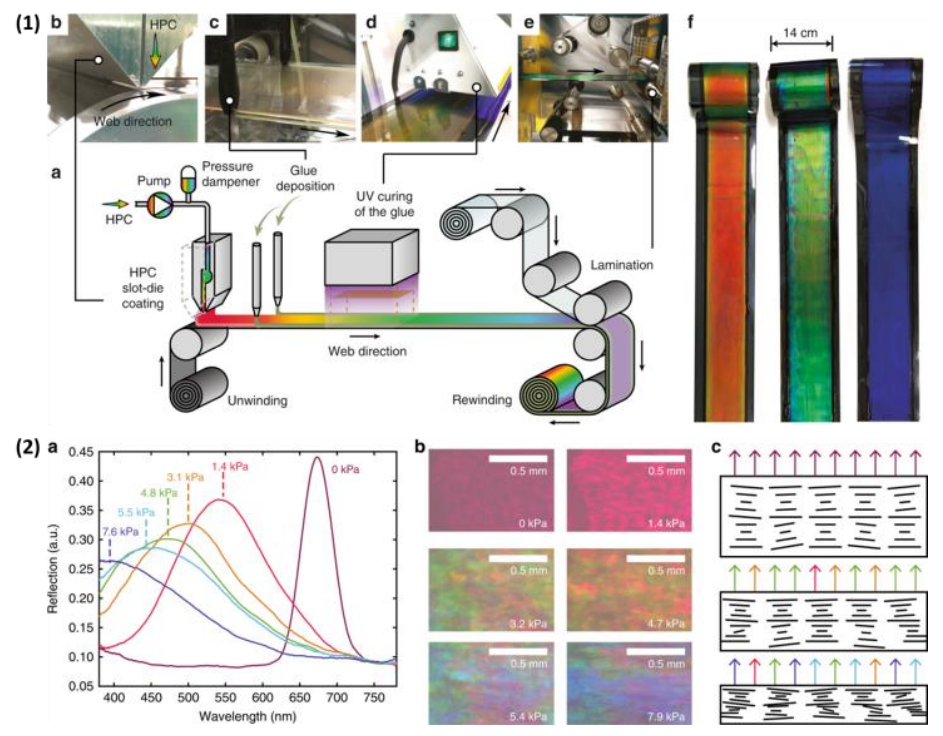

Figure 12 (1) Roll to roll fabrication of HPC photonic laminates (2) HPC laminates respond to pressure loads with varied colors due to the local mis-aligned cholesteric liquid crystal nanostructures upon compression. (adapted from ${ }^{134}$ Copyright from Springer Nature Limited 2018)

Liang et al presented pressure-responsive photonic laminates from HPC. ${ }^{134}$ HPC is a cellulose derivative, which can self-assembly into helical nanostructures in water with a cholesteric liquidcrystalline mesophase. The helical nanostructures interact with visible light and produce vivid colors from Bragg reflections. Roll to roll technique was applied for the fabrication of the photonic laminates with distinct colors tuned by using HPC of various concentrations (Figure 12). The laminates respond to pressure with varied microscopic colors due to the local disorder of the HPC helicoids under pressure loads (Figure 12).

Moreover, aminocellulose self-assembly into various adhesive nanostructured monolayers on plentiful substrates. The nanostructures can be firmly immobilized on substrates, which can withstand rinsing with solvents or even solutions under ultrasound treatment. Versatile coupling reactions with aminocellulose have been reported for the immobilization of biomolecule species, such as enzymes, immunoproteins, DNA sequences, aptamers and cells. Thus, the modified surfaces can be widely applied for biofunctional substrates, biochips and sensor chips. $^{135}$ 


\subsubsection{Nanocomposite films}

Nanocomposite films, fabricated by blending functional nanoscaled fillers and cellulose derivatives, give rise to excellent properties coupled from multiple components. Nanocomposite films, fabricated by blending of HPC and nanoscaled filler AGO demonstrated anti-bacterial properties. ${ }^{136}$ AGO was formed by coupling graphene oxide with silver-covered $\mathrm{ZnO}$ nanoparticles. The anti-bacteria property enabled their application as biological wounddressing material. Sehaqui et al developed a nanostructured biocomposite with high toughness by coating cellulose nanofibers (NFC) network with ductile hydroxyethyl cellulose (HEC) matrix. ${ }^{137}$ The resultant composite films showed remarkably improved mechanical properties. At a volume ratio of NFC at $45 \%$, the toughness of the nanocomposite is more than doubled compared with that of cellulose nanopaper. The NFC network with good load-carrying ability also provided favorable resistance to creep. Rincon-Iglesias et al reported nanocomposite films by blending water-soluble cellulose derivatives including methyl cellulose (MC), HPC, and $\mathrm{NaCMC}$ with cobalt ferrite $\left(\mathrm{CoFe}_{2} \mathrm{O}_{4}\right)$ nanoparticles by doctor blade coating. ${ }^{138}$ Nanoparticles were homogeneously dispersed after mechanical agitation and a large loading of nanoparticles as high as $50 \mathrm{wt} \%$ can be applied. The nanocomposite films remain magnetically active with potential application as magnetic sensors. Moreover, the matrix solutions behaved shearthinning properties, which enabled their application as $2 \mathrm{D}$ printing inks. ${ }^{139}$

\subsubsection{Other nanostructured materials}

Other nanostructured materials, such as nanofibers and aerogels, can be obtained from cellulose derivatives, e.g. CA, aminocellulose, via electro-spinning, sol-gel method etc. The obtained nanostructured materials were widely applied for functional surfaces, separation, and thermalinsulating and so on.

Anna Thorvaldsson et al reported the hydrophobic surface from textile cellulose microfiber covered with electrospun CA nanofiber, followed by plasma treatment. ${ }^{140}$ The elctrospun CA nanofiber created rough and large surface area for the cellulose microfibers. Further plasma treatment with trifluoromethane resulted in the fluorine attachment to the nanofiber surfaces in the forms of $\mathrm{C}-\mathrm{F}, \mathrm{CF}_{3}$, and $\mathrm{CH}_{2}-\mathrm{CF}_{2}$. Thus, the plasma treated surface showed 
superhydrophobicity with water contact angle larger than $150^{\circ}$. Anitha et al reported electrospun fibrous membrane of $\mathrm{CA}$ with $\mathrm{ZnO}$ nanoparticles embedded. ${ }^{141}$ TEM images show the $\mathrm{ZnO}$ nanoparticles attached on the surface of $\mathrm{CA}$ fibers in the membrane. The embedded $\mathrm{ZnO}$ nanoparticles transformed the wettability of $\mathrm{CA}$ fibrous membranes from hydrophilic to hydrophobic with water contact angle increased from $47^{\circ}$ to $124^{\circ}$. The hydrophobic property endowed the $\mathrm{ZnO}$ embedded $\mathrm{CA}$ fibrous membrane with antibacterial properties. Nanofibers from amino-functionalized cellulose blended with polyvinyl alcohol prepared via electrospinning also showed antimicrobial activities. ${ }^{142}$ Arslan et al developed superhydrophobic nanofibrous mat via electrospinning of perfluoro-modified CA, which was applied for the separation of oil/water. ${ }^{143}$ Aerogel of CA have been fabricated by Fischer et al via sol-gel method. ${ }^{144}$ Wet gels were obtained via the crosslinking of CA with polyisocyanate by urethane bonds. Nanoporous aerogel was achieved by following drying with supercritical carbon dioxide. The aerogel based on $\mathrm{CA}$ demonstrated comparable thermal-insulating properties with commercial polyurethane and super-insulating material silica aerogel.

\section{Objective}

Conventional nanostructured materials are usually constructed by blending nanosized functional fillers within polymer matrices, grafting organic ligands on inorganic nanoparticles, self-assembly of block copolymers, or using opal materials with core-shell nanoparticles. Most reported nanostructured materials were based on synthetic polymers while cellulose derivatives are still rare for these purposes. Using cellulose derivatives, instead of conventional polymers of fossil origin to construct nanostructured materials has its advantages. On one hand, it alleviates energy depletion and benefits the environment and sustainable society. On the other hand, nanostructured materials fabricated from cellulose derivatives has potential to achieve comparable or even superior performances compared with those from conventional polymers. Moreover, it also has great potential to construct novel nanostructures and broaden their applications when take the unique structures and properties of cellulose derivatives into account. The aim of this study is to explore novel nanostructured materials, including nanoparticles and 
nanostructured membranes, from cellulose derivatives, which includes:

(1) Scoping the optimal method, the most suitable functional groups and DS for the synthesis of cellulose derivatives with required functions and properties.

(2) Constructing nanostructured materials, including nanoparticles and nanostructured membranes from cellulose derivatives.

(3) Exploring novel properties of the nanostructured materials constructed from the obtained cellulose derivatives, replacing or surpassing conventional nanostructured materials.

(4) Investigation into the properties of nanostructured materials from cellulose derivatives and the mechanism behind them, including nano- and microstructures, as well as the interactions between polymer chains.

(5) Providing suggestive new strategies for future design and applications of nanostructured materials from cellulose derivatives.

\section{Results and discussion}

\subsection{Swelling behaviors of surface-modified CUE-NPs}

As reported in Publication 1, CUE was synthesized in pyridine under heterogeneous conditions. ${ }^{100}{ }^{13} \mathrm{C}$ and ${ }^{1} \mathrm{H}$ NMR spectra verified that 10 -undecenoyl moieties were successfully grafted to cellulose backbone. ${ }^{145,146}$ The DS was calculated to be 3 based on the results of ${ }^{1} \mathrm{H}$ NMR spectra. CUE-NPs were fabricated via nanoprecipitation with dropping technique. ${ }^{80} \mathrm{CUE}$ solutions in THF of $4 \mathrm{mg} / \mathrm{ml}$ or $10 \mathrm{mg} / \mathrm{ml}$ were added drop by drop to ethanol or methanol (5 or 10 times of volume of THF solution) under agitation. The ensuing CUE-NPs demonstrated narrow size distribution with PDI $<0.15$. The sizes of CUE-NPs can be affected by the concentration of CUE solutions, the category of non-solvent as dispersant and the volume ratios of polymer solution/dispersant. A smaller volume ratio of solution/dispersant or a higher concentration of CUE solutions gave rise to larger CUE-NPs. Additionally, CUE-NPs fabricated using ethanol as dispersant were larger than those using methanol as dispersant. The CUE-NPs were further surface-modified via thiol-ene reaction. To obtain NPs with distinct 
surface functionalities, three thiols, namely, ODT, MPA and $\mathrm{CA}^{\prime}$, were used. Corresponding surface-modified CUE-NPs were denoted as CUE-NPs-ODT, CUE-NPs-MPA, and CUE-NPs$\mathrm{CA}^{\prime}$, respectively. The obtained NPs were dialyzed to remove residue thiols and THF, followed by drying for elemental analysis. According to the elemental analysis results, the amount of ODT, MPA, and $\mathrm{CA}^{\prime}$ functional moieties were very low $\left(\sim 10^{-4}\right.$ mol per gram dry NPs). Considering the DS of 3 for CUE and sufficient amounts of thiols added, the modification should only occur on the surface of CUE-NPs while most of the vinyl groups inside the NPs were not accessible.

All CUE-NPs maintained their narrow size distribution with PDI $<0.15$ after surfacemodification. CUE-NPs-ODT and CUE-NPs-MPA showed a minor increase of NPs size while CUE-NPs-CA demonstrated an obvious size increase after surface-modification. This prominent increase of diameter of CUE-NPs-CA should ascribe to improved interactions between CA moieties and ethanol or methanol via hydrogen bonds. The sizes of all surfacemodified CUE-NPs increased substantially after dialysis, which indicated that swelling existed during dialysis since the modified moieties also interacted with ethanol or methanol. Our investigation of swelling behaviors was then designed by stepwise adding corresponding swelling solvents and measuring the sizes and PDI after equilibrium. Swelling solvents, which interact well with the functional moieties was chosen: THF for CUE-NPs-ODT and CUE-NPsMPA, while water for CUE-NPs-CA'. In order to eliminate the influence of dialysis process on the analysis of swelling, analysis of swelling modes of surface-modified CUE-NPs were based on normalized Z-average diameters.
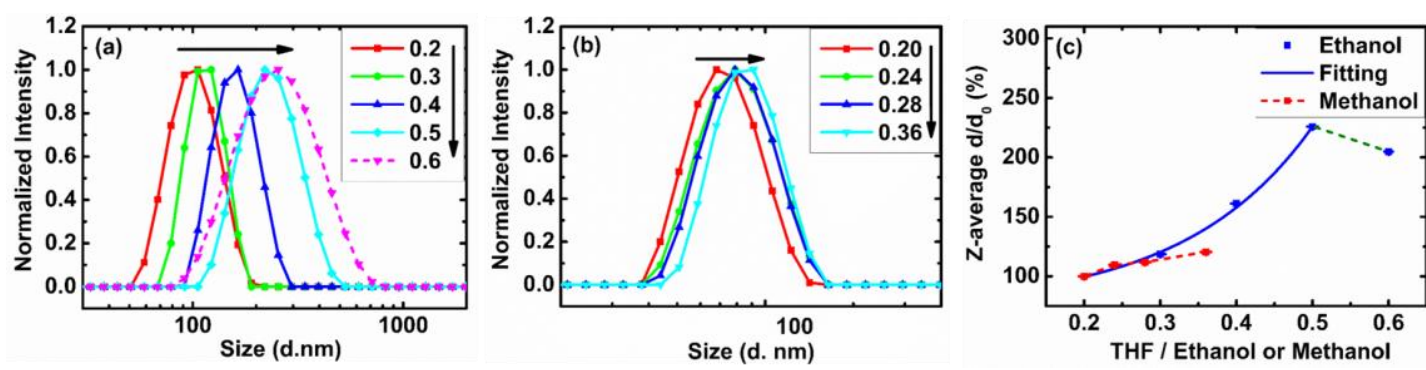

Figure 13. The swelling behavior of CUE-NPs-ODT. $(a, b)$ DLS curves of CUE-NPs-ODT with various volume ratios of THF to ethanol (a) or methanol (b) in dispersant, respectively. The numbers in the insets represent the volume ratios of THF to ethanol or methanol in the dispersants, respectively. (c) 
Development of normalized Z-average diameters of CUE-NPs-ODT versus the volume ratios of THF to ethanol or methanol in dispersant.

In ethanol dispersion, the Z-average diameters of CUE-NPs-ODT increased stepwise from 98 $\mathrm{nm}$ to $221 \mathrm{~nm}$ with $\mathrm{PDI}<0.1$, with rising volume ratios of $\mathrm{THF} / \mathrm{ethanol}\left(\mathrm{V}_{\mathrm{THF} / \text { ethanol }}\right)$ from 0.2 to 0.5 (Figure 13a). When $\mathrm{V}_{\mathrm{THF} / \text { ethanol }}$ increased to 0.6 , the size of CUE-NPs-ODT decreased. However, the DLS curves did not shift to smaller size, only the size distribution becoming wider with PDI of 0.26. This fact indicated the over-swelling or even bursting of CUE-NPs-ODT with high amount of THF in the mixture. In methanol dispersion, the Z-average diameter of CUENPs-ODT increased stepwise from $70 \mathrm{~nm}$ to $84 \mathrm{~nm}$ with PDI $<0.1$, with rising volume ratios of THF/methanol ( $\mathrm{V}_{\mathrm{THF} / \text { methanol }}$ ) from 0.2 to 0.36 (Figure $\left.13 \mathrm{~b}\right)$. When more THF was added, the samples were inappropriate for DLS analysis. The swelling extent of CUE-NPs-ODT in methanol dispersant was quite limited. The swelling trend line of CUE-NPs-ODT in ethanol dispersant was fitted with an exponential function (Figure 13c). The sizes of NPs increased with

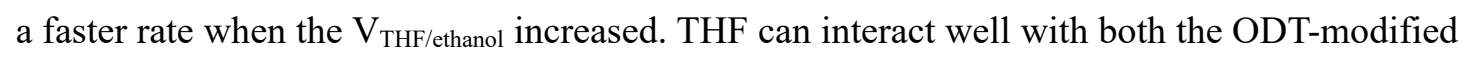
outer part and the interior part of CUE-NPs-ODT, estimated by the fact that both CUE and CSE are well soluble in THF. ${ }^{80,100}$ However, the non-polar ODT moieties at the surface of CUE-NPsODT were in a constrictive state surrounded by a lot of polar solvent in dispersant, thus a steady increase of NPs size was observed at the beginning of the swelling. When more THF with lower polarity added to the system, the ODT moieties turned into an outstretched state, providing more cavities for THF to penetrate into the interior of CUE-NPs-ODT. Therefore, a rapid growth of NPs sizes was demonstrated with higher $\mathrm{V}_{\mathrm{THF} / \text { ethanol. }}$
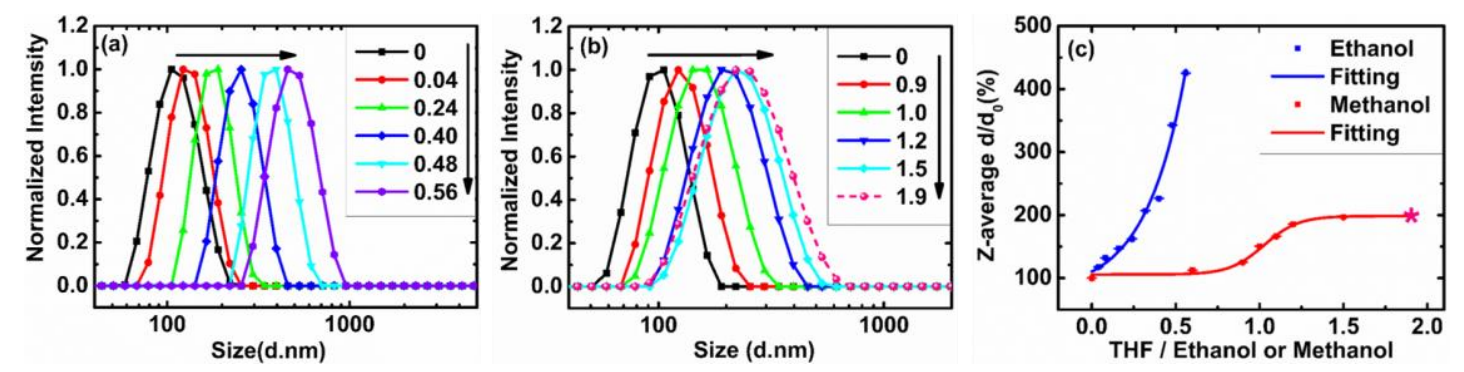

Figure 14 The swelling behavior of CUE-NPs-MPA. (a, b) DLS curves of CUE-NPs-MPA with various volume ratios of THF to ethanol (a) or methanol (b) in dispersant, respectively. The numbers in the insets 
represent the ratios of THF to ethanol and methanol in dispersant, respectively. (c) Development of normalized Z-average diameters of CUE-NPs-MPA versus the volume ratios of THF to ethanol or methanol in dispersant.

In ethanol dispersion, the Z-average diameter of CUE-NPs-MPA increased stepwise from 109 $\mathrm{nm}$ to $463 \mathrm{~nm}$ with $\mathrm{V}_{\mathrm{THF} / \text { ethanol }}$ increased from 0 to 0.56 (Figure 14a). With more THF added, the sample became inappropriate for DLS analysis. The swelling trend line of CUE-NPs-MPA was also fitted to an exponential function (Figure 14c), which was similar with that of CUE-NPsODT in ethanol dispersion. However, the swelling extent was much larger and the increasing rate of the diameters was much faster. THF interact well with both the MPA-modified surface layer and the interior of CUE-NPs-MPA, indicated by the good solubility of both CUE and CUE-MPA in THF. ${ }^{100}$ At the beginning, only the surface-modified part was highly swollen due to the interaction between MPA moieties and THF. Subsequently, with the presence of more THF, the interior part also participated in the swelling process. Thus, the swelling rate became faster. In methanol dispersion, the Z-average diameter of CUE-NPs-MPA increased stepwise from $99 \mathrm{~nm}$ to $124 \mathrm{~nm}$ with $\mathrm{PDI}<0.1$, with $\mathrm{V}_{\mathrm{THF}}$ /methanol increased from 0 to 0.9 (Figure 14b). With $\mathrm{V}_{\mathrm{THF}}$ /methanol further increased to 1.2 , the Z-average diameter increased rapidly to $184 \mathrm{~nm}$ with PDI increased to 0.15 . When $\mathrm{V}_{\mathrm{THF}}$ /methanol further increased to 1.5 , the Z-average diameter increased slowly to $194 \mathrm{~nm}$ and the PDI increased to $\sim 0.2$. When $\mathrm{V}_{\mathrm{THF} / \text { methanol increased further }}$ to 1.9 , The Z-average diameter increased only slightly to $197 \mathrm{~nm}$ with the PDI increased to 0.25 . For higher content of THF in the dispersant, the sample was too polydisperse for analysis. The swelling trend line of CUE-NPs-MPA in methanol was fitted to a sigmoid function (Figure 14c). The NPs formed in methanol dispersant should be tighter in structure, which could be deduced from the fact that CUE-NPs formed in ethanol had larger sizes than those formed in methanol using the same preparation conditions. This phenomenon should originate from the smaller viscosity of methanol than that of ethanol $\left(0.54\right.$ versus 1.07 at $\left.25{ }^{\circ} \mathrm{C}\right) .{ }^{147}$ Thus, THF (with viscosity of 0.46 at $\left.25{ }^{\circ} \mathrm{C}\right)^{147}$ from CUE solution diffused faster in methanol than in ethanol during nanoprecipitation, resulting in CUE-NPs with tighter structure..$^{74,148,149}$ This tight structure made a "barrier" for penetration of THF at the starting stage and the swelling rate is 
rather slow. After that, the rate was much faster because the NP became structurally loose enough for THF to penetrate. After this phase, the swelling rate turned to be slow again due to the saturation of the cavities in CUE-NPs-MPA.
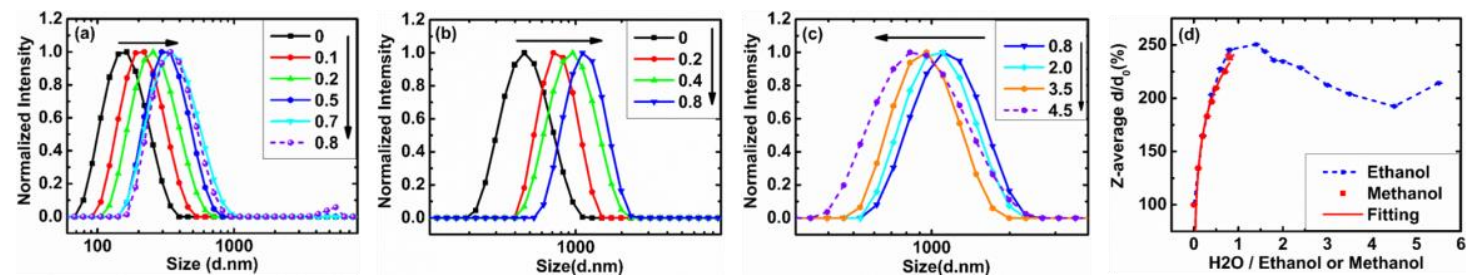

Figure 15 The swelling behavior of CUE-NPs-CA'. (a) DLS curves of CUE-NPs-CA' with various volume ratios of $\mathrm{H}_{2} \mathrm{O}$ to methanol in dispersant. (b, c) DLS curves of CUE-NPs-CA' with various volume ratios of $\mathrm{H}_{2} \mathrm{O}$ to ethanol in dispersant between 0-0.8 (b) and 0.8-4.5 (c). The numbers in the insets represent the ratio of $\mathrm{H} 2 \mathrm{O}$ to methanol or ethanol in dispersant. (d) Development of normalized Zaverage diameters of CUE-NPs-CA versus the volume ratios of $\mathrm{H}_{2} \mathrm{O}$ to ethanol or methanol in dispersant.

In methanol dispersion, the Z-average diameter of CUE-NPs-CA' increased stepwise from 151 $\mathrm{nm}$ to $339 \mathrm{~nm}$ and the PDI remained $\sim 0.1$, with rising volume ratios of water to methanol ( $\mathrm{V}_{\text {water/methanol }}$ ) from 0 to 0.7 (Figure 15a). With $\mathrm{V}_{\text {water/methanol }}$ further increased to 0.8 , the DLS curve did not shift to larger size. However, a small new peak at $\sim 5000 \mathrm{~nm}$ revealed, which indicated the presence of aggregates. In ethanol dispersion, the Z-average diameter of CUENPs-CA' increased from $444 \mathrm{~nm}$ to $1090 \mathrm{~nm}$ and the PDI remained $<0.1$, with rising volume ratios of the $\mathrm{H}_{2} \mathrm{O}$ to ethanol $\left(\mathrm{V}_{\text {water/ethanol }}\right)$ from 0 to 0.8 (Figure $\left.15 \mathrm{~b}\right)$. With further rising $\mathrm{V}_{\text {water/ethanol }}$ from 0.8 to 4.5 , the $\mathrm{Z}$-average diameter of CUE-NPs-CA' decreased gradually from $1090 \mathrm{~nm}$ to $854 \mathrm{~nm}$ and the PDI remained $<0.1$ (Figure 15c). The swelling mode in ethanol dispersant was fitted to a logarithmic function (Figure 15d). The swelling rate became slower and slower with increasing content of water in dispersant. This should originate from the fact that the interaction between water and surface-attached amino groups of CUE-NPs-CA' is strong via hydrogen bond, ${ }^{150}$ while the interaction between $\mathrm{H}_{2} \mathrm{O}$ and the interior part of CUENPs-CA' is inferior, predicted from the poor solubility of CUE in $\mathrm{H}_{2} \mathrm{O} .{ }^{100}$ Therefore, $\mathrm{H}_{2} \mathrm{O}$ can penetrate and swell the outer layers containing $\mathrm{CA}^{\prime}$ groups with a fast rate. The swelling slows down when water is approaching the inner part where the interactions became weak. Too much 
water in methanol dispersion caused aggregation of CUE-NPs-CA' in methanol. In contrast, more water could be added into ethanol dispersant with the NPs dispersion staying stable with the size decreasing. The shrinking of CUE-NPs-CA' with high amount of water in ethanol dispersion should originate from the inferior interaction with the interior part of NPs.

\subsection{Self-compounded multifunctional nanocomposite membranes}

In Publication 2, CCi with DS of 0.6, 1.0, 2.0 were synthesized in DMAc/LiCl under homogeneous conditions while CCi with DS of 2.8 was synthesized in pyridine under heterogeneous conditions (Figure 16a). ${ }^{100,151}{ }^{13} \mathrm{C}$ and ${ }^{1} \mathrm{H}$ NMR spectra showed signals from both cellulose backbone and cinnamoyl groups. ${ }^{146,152,153}$ The DS of obtained CCi was calculated according to previously reported method based on elemental analysis results. ${ }^{154}$

Novel self-compounded CCi nanocomposite membranes were obtained via facile solutioncasting method. The ensuing CCi membranes were composed of two discrepant morphologies: CCi-NPs and CCi polymer matrix (Figure 16b). As shown in SEM images (Figure 16c), The cross-section overview demonstrated the compact microstructure of $\mathrm{CCi}_{0.6}, \mathrm{CCi}_{1.0}$ and $\mathrm{CCi}_{2.0}$ membranes while aggregates were observed in $\mathrm{CCi}_{2.8}$ membranes. CCi-NPs with diameter of 40-60 $\mathrm{nm}$ were either firmly embedded in the CCi polymer matrix or tightly fused with adjacent NPs for $\mathrm{CCi}_{0.6}, \mathrm{CCi}_{1.0}$ and $\mathrm{CCi}_{2.0}$ membranes.

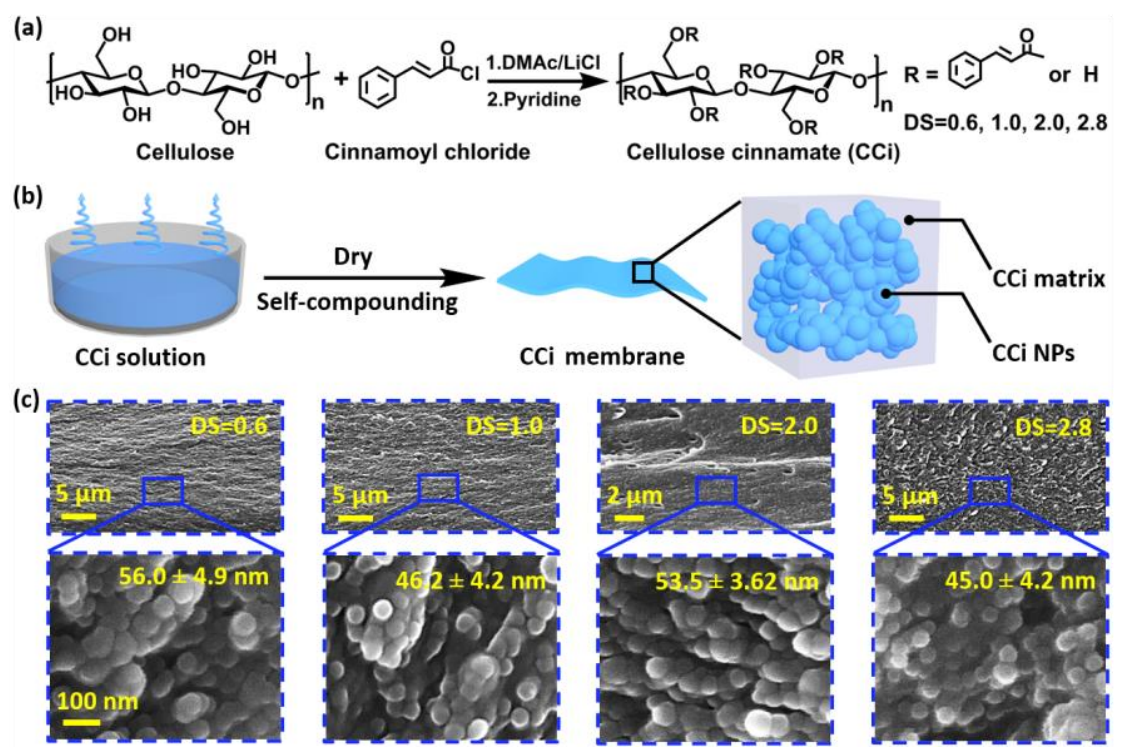

Figure 16 Fabrication of self-compounded nanocomposite membranes from cellulose cinnamate (CCi). 
(a) Synthesis of CCi with DS of 0.6, 1.0, 2.0 in DMAc/LiCl under homogeneous conditions and CCi with DS of 2.8 in pyridine under heterogeneous conditions. (b) Schematic diagram for the fabrication of self-compounded nanocomposite CCi membranes via solvent-casting method. (c) SEM images showing the overview and high magnification cross-section of self-compounded nanocomposite membranes. Insets show the DSs of CCi, scale bars and diameters of NPs.

The small sizes of NPs and their homogeneous dispersion in the matrix resulted in the high transparency of self-compounded CCi nanocomposite membranes (Figure 17a and 17b). Higher transparency was obtained from membranes of CCi with lower DS (Figure 17a). The transparency of $\mathrm{CCi}_{0.6}$ membranes reached $86 \%-90 \%$ in visible region, while that of $\mathrm{CCi}_{1.0}$

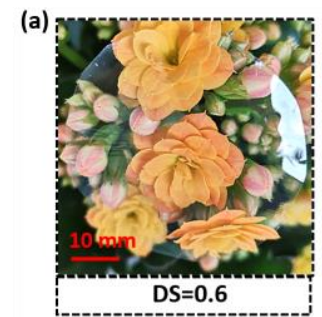

(b)
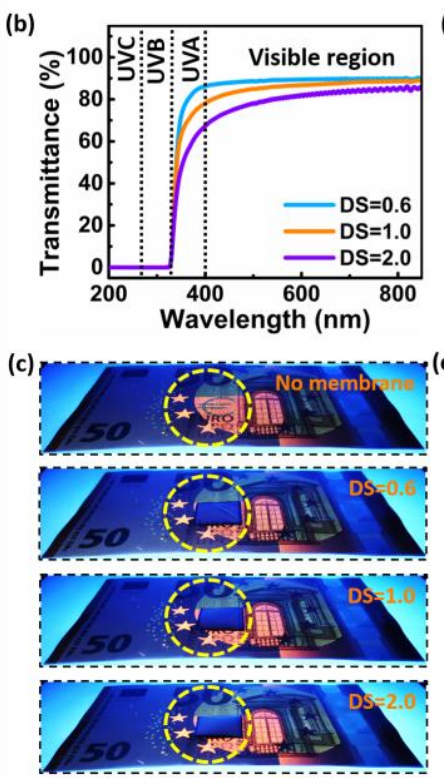

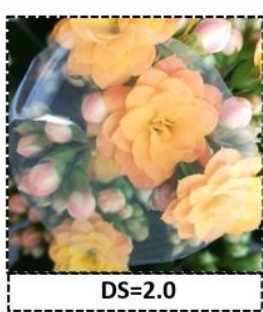

(d)
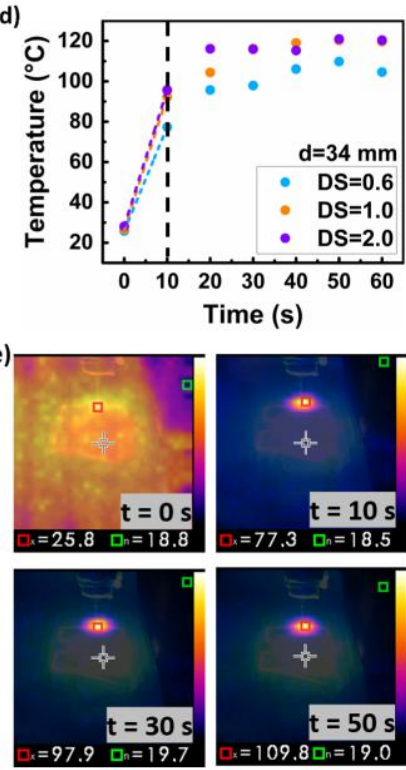

Figure 17 Optical properties, UV-shielding functions and photothermal conversion functions of selfcompounded CCi nanocomposite membranes. (a) Representative photographic images displaying the transparency, and (b) Transmittance of self-compounded nanocomposite CCi membranes (c) UVshielding functions and (d) Time-dependent temperature of self-compounded CCi nanocomposite 
membranes under UV irradiation. (e) Representative IR images of self-compounded CCi nanocomposite membranes with DS of 0.6 before UV irradiation and after UV irradiation of $10 \mathrm{~s}, 30 \mathrm{~s}$ and $50 \mathrm{~s}$.

and $\mathrm{CCi}_{2.0}$ membranes was $78 \%-89 \%$ and $67 \%-83 \%$, respectively (Figure 17b). Additionally, self-compounded CCi nanocomposite membranes demonstrated UV-shielding functions with total block of UVB $(280-320 \mathrm{~nm})$ and UVC $(<280 \mathrm{~nm})$, while the UVA (320$400 \mathrm{~nm}$ ) light was also partially blocked (Figure 17b). As an example, the anti-counterfeiting mark of Euro under $254 \mathrm{~nm}$ UV light can be perfectly blocked by $\mathrm{CCi}_{0.6}, \mathrm{CCi}_{1.0}$ and $\mathrm{CCi}_{2.0}$ membranes (Figure 17c). Moreover, the self-compounded CCi nanocomposite membranes showed remarkable photothermal functions. Under UV irradiation, the temperatures of the membranes increased rapidly in the first $10 \mathrm{~s}$. Then, it continued to increase gradually with longer time (Figure 17d). For instance, with $34 \mathrm{~mm}$ distance between membranes and UV sources, the temperature of $\mathrm{CCi}_{0.6}, \mathrm{CCi}_{1.0}$ and $\mathrm{CCi}_{2.0}$ membranes increased rapidly within the first $10 \mathrm{~s}$ from room temperature to $77{ }^{\circ} \mathrm{C}, 92{ }^{\circ} \mathrm{C}$ and $96{ }^{\circ} \mathrm{C}$ with a rate of $5.2{ }^{\circ} \mathrm{C} / \mathrm{s}, 6.6^{\circ} \mathrm{C} / \mathrm{s}$, and $6.8^{\circ} \mathrm{C} / \mathrm{s}$, respectively. After $60 \mathrm{~s}$, the temperatures of $\mathrm{CCi}_{0.6}, \mathrm{CCi}_{1.0}$ and $\mathrm{CCi}_{2.0}$ membranes increased further with longer time and reached $105{ }^{\circ} \mathrm{C}, 120^{\circ} \mathrm{C}$ and $120{ }^{\circ} \mathrm{C}$, respectively. Figure 17e presents the representative IR images of the self-compounded $\mathrm{CCi}_{0.6}$ nanocomposite membranes before and after UV irradiation of $10 \mathrm{~s}, 30 \mathrm{~s}$, and $50 \mathrm{~s} . \mathrm{CCi}_{2.8}$ membranes were not discussed here due to mechanical brittleness. 
(a)

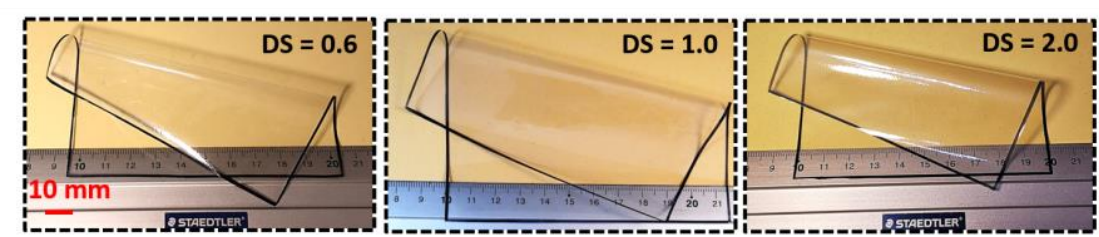

(b)

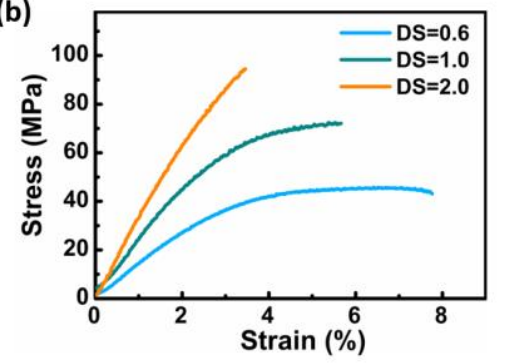

(c)

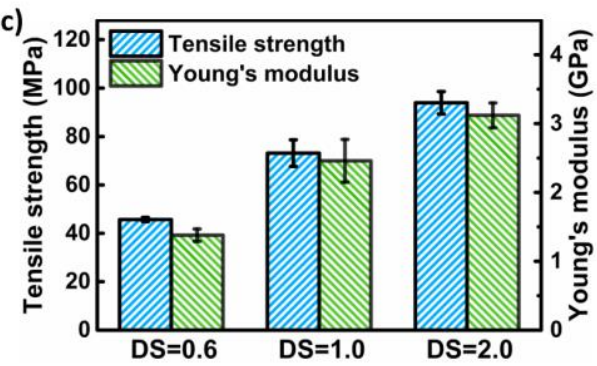

(d)

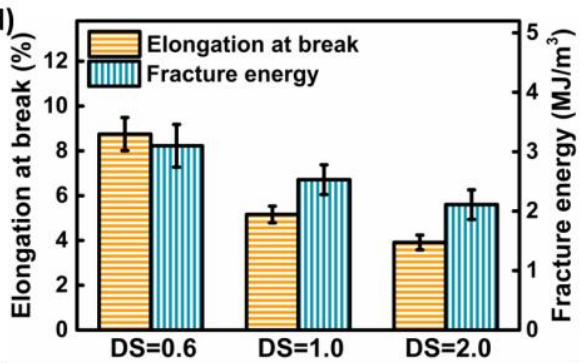

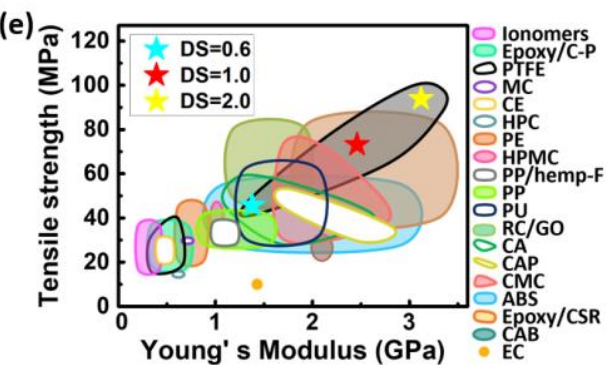

Figure 18 Static mechanical properties of self-compounded nanocomposite membranes fabricated from

CCi with DS of 0.6, 1.0 and 2.0. (a) Representative images showing the mechanical flexibility, (b) Stressstrain curves, (c) Tensile strength and Young's moduli and (d) Elongation at break and fracture energy of self-compounded nanocomposite membranes from CCi with various DSs. (e) Tensile strength and Young's moduli of self-compounded $\mathrm{CCi}_{0.6}, \mathrm{CCi}_{1.0}$ and $\mathrm{CCi}_{2.0}$ nanocomposite membranes, in comparison with a few common synthetic polymers, cellulose derivatives and composites.

The self-compounded nanocomposite membranes with the unique compact structure and perfect compatibility guaranteed the superior mechanical properties of CCi membranes (Figure 18a-18e). $\mathrm{CCi}_{0.6}, \mathrm{CCi}_{1.0}$ and $\mathrm{CCi}_{2.0}$ membranes were mechanically robust and flexible (Figure 18a-18d). $\mathrm{CCi}_{2.0}$ membranes were strong and stiff with a tensile strength of $93.9 \pm 4.6 \mathrm{MPa}$ and Young's modulus of $3.1 \pm 0.2 \mathrm{GPa}$. $\mathrm{CCi}_{2.0}$ membranes broke at an elongation of $3.9 \pm 0.3 \%$ with a fracture energy of $2.1 \pm 0.3 \mathrm{MJ} / \mathrm{m}^{3}$. The stress-strain curve of $\mathrm{CCi}_{2.0}$ membranes demonstrated only elastic characteristics until break without plastic features. Distinct from $\mathrm{CCi}_{2.0}$ membranes, $\mathrm{CCi}_{0.6}$ membranes were relatively ductile and tough with an elongation at break of $8.8 \pm 0.7 \%$ and fracture energy of $3.1 \pm 0.4 \mathrm{MJ} / \mathrm{m}^{3}$. The tensile strength and the Young's moduli of $\mathrm{CCi}_{0.6}$ membranes were $45.7 \pm 0.9 \mathrm{MPa}$ and $1.4 \pm 0.1 \mathrm{GPa}$, respectively. The 
stress-strain curve of $\mathrm{CCi}_{0.6}$ membranes encompassed both elastic and plastic regions connected with a yielding strain of around $3.0 \%$. The strength, stiffness, ductileness and toughness of $\mathrm{CCi}_{1.0}$ membranes lay intermediately between those of $\mathrm{CCi}_{0.6}$ and $\mathrm{CCi}_{2.0}$ membranes with tensile strength, Young's moduli, elongation at break and fracture energy of $72.8 \pm 5.1 \mathrm{MPa}, 2.5 \pm 0.3$ GPa, $5.2 \pm 0.4 \%$ and $2.5 \pm 0.3 \mathrm{MJ} / \mathrm{m}^{3}$, respectively. The development of stress-strain curve for $\mathrm{CCi}_{1.0}$ membranes was also between those of $\mathrm{CCi}_{0.6}$ and $\mathrm{CCi}_{2.0}$ membranes with an elastic region and a short plastic region.

Self-compounded CCi nanocomposite membranes showed comparable or superior mechanical properties with high tensile strength and Young's moduli (Figure 18e), compared with reported materials fabricated from common synthetic polymers including PE, PP, PTFE, ABS, thermoplastic PU, ionomers; ${ }^{155}$ other cellulose derivatives, such as cellulose fatty acid esters, cellulose acetate, methyl cellulose, ethyl cellulose and carboxymethyl cellulose; ${ }^{156-164}$ and composites, such as epoxy/coconut shell particles, regenerated cellulose/graphite oxides, $\mathrm{PP} /$ hemp fibers, epoxy/core shell rubber. ${ }^{165-168}$

According to dynamic mechanical thermal analysis (Figure 19), the storage moduli, loss moduli and damping factor maintained invariable in a time length of more than 4 hours at $25{ }^{\circ} \mathrm{C}, 30 \%$ RH with a frequency of $10 \mathrm{~Hz}$ (Figure 19a), demonstrating that CCi nanostructured
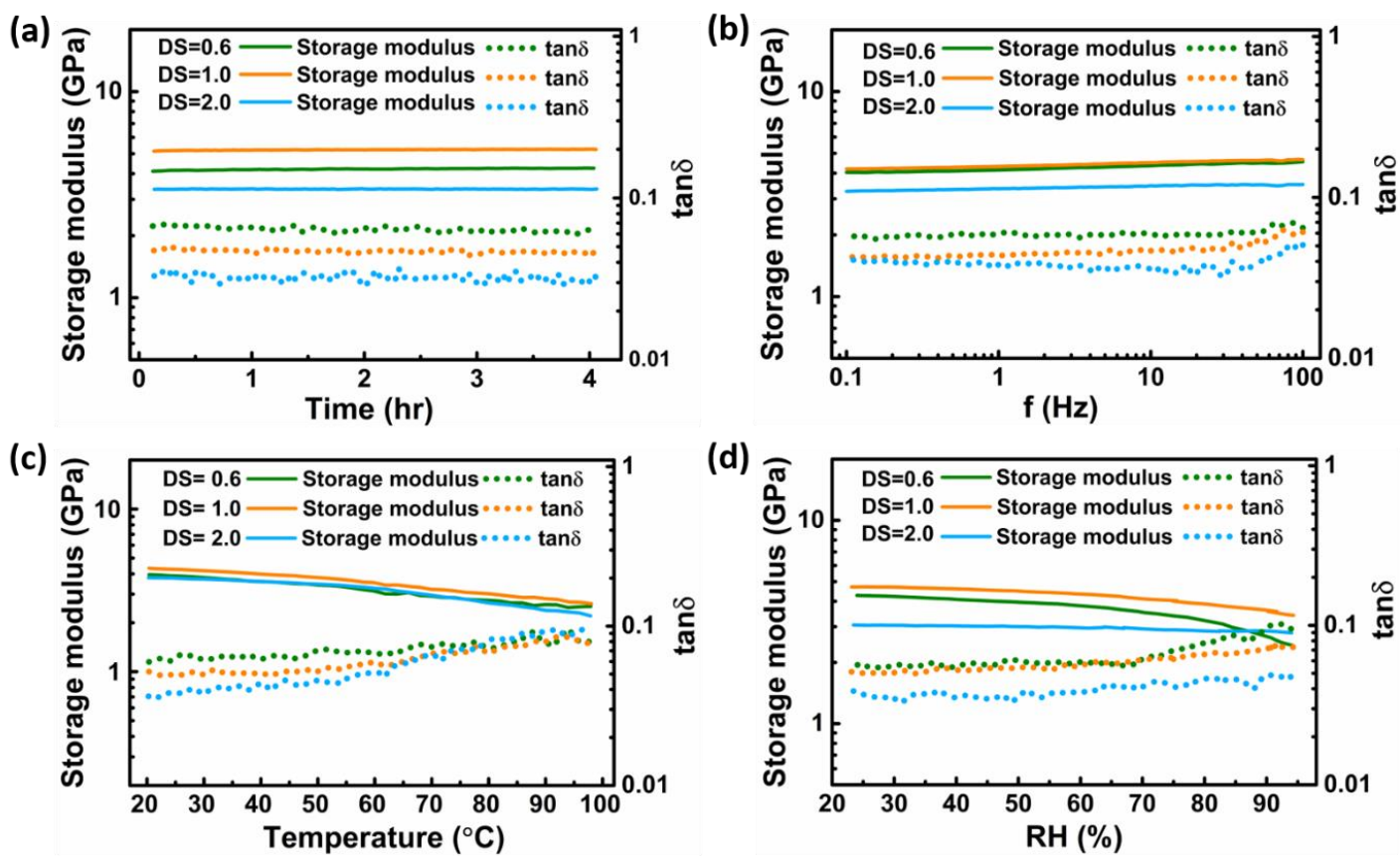

Figure 19 Dynamic mechanical thermal analysis of self-compounded CCi nanocomposite membranes. 
(a) time scanning curves at $25^{\circ} \mathrm{C}, 30 \% \mathrm{RH}$ with a frequency of $10 \mathrm{~Hz}$, (b) frequency scanning curves at $25^{\circ} \mathrm{C}, 30 \% \mathrm{RH}$, (c) temperature scanning curves at $30 \% \mathrm{RH}$ with a frequency of $10 \mathrm{~Hz}$ and (d) humidity scanning curves at $25^{\circ} \mathrm{C}$, with a frequency of $10 \mathrm{~Hz}$.

membranes were highly stable materials at a given condition. The storage moduli of all selfcompounded CCi nanocomposite membranes only increased in a small range when frequency varied from $0.1 \mathrm{~Hz}$ to $100 \mathrm{~Hz}$ (Figure 19b), which implied the favorable coupling of CCi chains within both phases as well as at their interfaces. Otherwise, weak interactions/linkages should provide higher mobility of $\mathrm{CCi}$ polymer chains. Thus, vastly varying time for relaxation are needed when the frequency vary in a wide range, resulting in large variation of storage moduli. ${ }^{169}$

The storage moduli decreased with the increase of temperature due to the increased flexibility and mobility of CCi polymer chains. Though high temperature can impair the mechanical properties of CCi membranes, all self-compounded CCi nanocomposite membranes showed storage moduli larger than $2 \mathrm{GPa}$ even at temperature of $98^{\circ} \mathrm{C}$ with a humidity of $30 \% \mathrm{RH}$ (Figure 19c), demonstrating excellent thermal resistance. The thermal resistance of CCi membranes were also confirmed by thermal gravimetric analysis, $\mathrm{CCi}_{0.6}, \mathrm{CCi}_{1.0}, \mathrm{CCi}_{2.0}$ and $\mathrm{CCi}_{2.8}$ start to decompose at around $291{ }^{\circ} \mathrm{C}, 306{ }^{\circ} \mathrm{C}, 335^{\circ} \mathrm{C}$, and $348{ }^{\circ} \mathrm{C}$, respectively.

Cellulose-based materials usually suffer from humidity sensitivity. The storage moduli of $\mathrm{CCi}_{0.6}$ membranes decreased remarkably from $4.3 \mathrm{GPa}$ to $2.4 \mathrm{GPa}$ while that of $\mathrm{CCi}_{1.0}$ membranes reduced from 4.7 GPa to 3.4 GPa when relative humidity increased from $24 \% \mathrm{RH}$ to $94 \% \mathrm{RH}$ (Figure $19 \mathrm{~d}$ ). $\mathrm{CCi}_{0.6}, \mathrm{CCi}_{1.0}$ and $\mathrm{CCi}_{2.0}$ membranes would adsorb water molecules with hydrophilic wettability. Membranes fabricated from CCi with lower DS could adsorb much more water. The adsorbed water molecules could build hydrogen bonds with CCi chains, disrupting the previously existing hydrogen bonds and facilitate the mobility of CCi chains. Consequently, the storage moduli decrease. However, the humidity influence on CCi membranes was only obvious at high RH (> $80 \% \mathrm{RH})$ and can be much minimized for CCi membranes with a high DS, for instance, the storage moduli of $\mathrm{CCi}_{2.0}$ membranes only decreased from 3.1 GPa to $2.8 \mathrm{GPa}$ when humidity increased from $21 \% \mathrm{RH}$ to $94 \% \mathrm{RH}$ (Figure 
$19 d)$.

In addition to the thermal and humidity resistance, $\mathrm{CCi}$ membranes with compact structure also demonstrated excellent gas/oil barrier properties. $\mathrm{CCi}_{0.6}, \mathrm{CCi}_{1.0}$ and $\mathrm{CCi}_{2.0}$ membranes demonstrated water vapor permeability of $(1.331 \pm 0.111) \times 10^{-11} \mathrm{~g} \cdot \mathrm{m}^{-1} \cdot \mathrm{s}^{-1} \cdot \mathrm{Pa}^{-1},(1.345 \pm 0.123)$ $\times 10^{-11} \mathrm{~g} \cdot \mathrm{m}^{-1} \cdot \mathrm{s}^{-1} \cdot \mathrm{Pa}^{-1}$ and $(0.94 \pm 0.03) \times 10^{-11} \mathrm{~g} \cdot \mathrm{m}^{-1} \cdot \mathrm{s}^{-1} \cdot \mathrm{Pa}^{-1}$, respectively, which are lower than reported water barrier materials fabricated from synthetic polymers, such as EVA ${ }^{170}$ and HNBR $;{ }^{170}$ biopolymers, such as $\mathrm{RC}^{171}$ and amylose; ${ }^{172}$ as well as their composites, such as $\mathrm{MC} / \mathrm{rGO},{ }^{173} \mathrm{CRC} / \mathrm{GO},{ }^{174} \mathrm{CMC} / \mathrm{ST} / \mathrm{CNC},{ }^{175}$ ST/sorbital, ${ }^{176}$ SPI/PVA/glycerol, ${ }^{177}$ and CG/CNC. ${ }^{178}$ The oxygen permeability of $\mathrm{CCi}_{0.6}, \mathrm{CCi}_{1.0}$ and $\mathrm{CCi}_{2.0}$ membranes were $(8.48 \pm 2.39)$ $\times 10^{-13} \mathrm{~cm}^{3} \cdot \mathrm{cm} / \mathrm{cm}^{2} \cdot \mathrm{s} \cdot \mathrm{cmHg}, \quad 5.11 \times 10^{-11} \quad \mathrm{~cm}^{3} \cdot \mathrm{cm} / \mathrm{cm}^{2} \cdot \mathrm{s} \cdot \mathrm{cmHg}$ and $5.22 \times 10^{-11}$ $\mathrm{cm}^{3} \cdot \mathrm{cm} / \mathrm{cm}^{2} \cdot \mathrm{s} \cdot \mathrm{cmHg}$, respectively, which are comparable or even much lower than oxygen barrier materials fabricated from synthetic polymers, including LDPE, ${ }^{179} \mathrm{PU},{ }^{180}$ and PVAc; ${ }^{180}$ cellulose derivatives, such as $\mathrm{EC}^{181}$ and $\mathrm{CA}^{182}$ as well as composites, such as $\mathrm{CA} / \mathrm{LDH},{ }^{182}$ PS/graphene, ${ }^{183}$ Nylon/silicate, ${ }^{184}$ and CG/CNC. ${ }^{178}$ Furthermore, the oil permeabilities were as low as $0.358 \pm 0.026 \mathrm{~g} \mathrm{~mm} \mathrm{~m}^{-2}$ day $^{-1}, 0.813 \pm 0.020 \mathrm{~g} \mathrm{~mm} \mathrm{~m}^{-2}$ day $^{-1}$ and $0.008 \pm 0.003 \mathrm{~g} \mathrm{~mm}$ $\mathrm{m}^{-2}$ day $^{-1}$ for self-compounded $\mathrm{CCi}_{0.6}, \mathrm{CCi}_{1.0}$ and $\mathrm{CCi}_{2.0}$ nanocomposite membranes, respectively, which were comparable or much lower in comparison with those reported for oil packaging, including SRC/sorbitol ${ }^{185}$ and $\mathrm{CS} / \mathrm{cm}-\mathrm{CNC} .{ }^{186}$ 


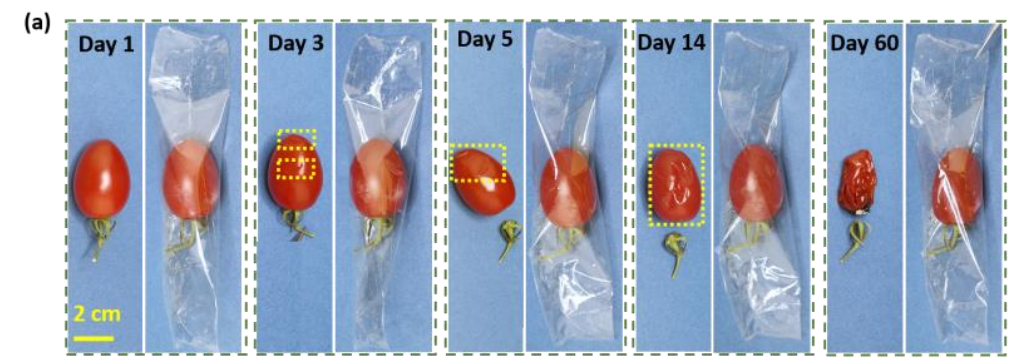

(b)

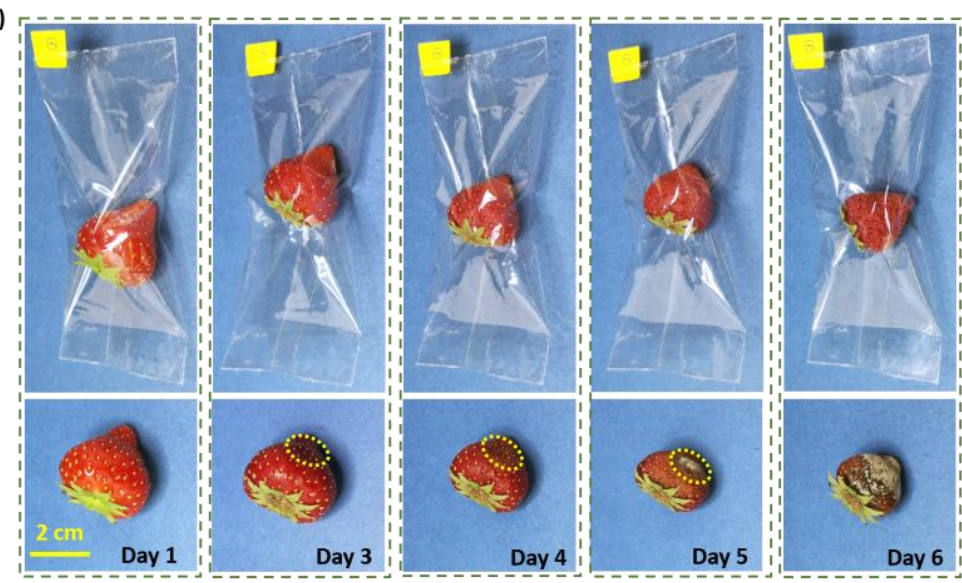

Figure 20 Self-compounded CCi nanocomposite membranes with DS of 0.6 applied as packaging materials for (a) mini-date vine tomatoes and (b) strawberries. The non-packaged and packaged minidate vine tomatoes were stored in an environment with temperature of $23-25^{\circ} \mathrm{C}$ and $\mathrm{RH}$ of $70-80 \%$, while the strawberries were stored in ambient environment with room temperature and RH of 30-40\%. The yellow dashed rectangles in (a) denote the wilted area of non-packaged mini-date vine tomatoes, while the yellow dashed circles in (b) denote the areas with mold spoilage of non-packaged strawberries.

Self-compounded CCi nanocomposite membranes with DS of 0.6 were applied to package mini-date vine tomatoes (Figure 20a) and strawberries (Figure 20b). The non-packaged minidate vine tomatoes wilted the third day and the vine dropped off on the fifth day. The withering of non-packaged mini-date vine tomatoes went on with prolonged time, while no significant withering or vine dropping were observed from the packaged ones even after 2 weeks. After 60 days, the non-packaged mini-date vine tomatoes were completely shriveled while the packaged ones maintained in relatively fresh state with only minor water loss. The non-packaged strawberries became dark in color the third day and the darkening went on with longer time. A small area with mold spoilage appeared on the surface of the non-packaged strawberries the third day, which became larger the fourth day and hoary in color the fifth day. The sizes of non- 
packaged strawberries had a sharp decrease with prolonged time due to severe water loss. In contrast, the packaged strawberries maintained relatively bright in color without any spotted area and the sizes decreased in a slower rate. Thus, we successfully integrated multiple excellent properties in self-compounded nanocomposites with only one chemical constituent, which showed promising application potential, e.g. as packaging materials.

\subsection{CCi hydroplastic polymer as eco-friendly hydrosetting plastics}

Based on the results from Publication 2, the humidity sensitivity of CCi membranes, especially those with low DS, inspired the development of a new type of plastics: hydroplastics, as shown in Publication 3. CCi with DS of 0.27 was synthesized in DMAc/ $\mathrm{LiCl}$ under homogeneous conditions. ${ }^{151,187}$ Its chemical structure was confirmed by using ${ }^{13} \mathrm{C}$ and ${ }^{1} \mathrm{H}$ NMR spectra. ${ }^{146,152,153}$ With facile solvent casting of $\mathrm{CCi}_{0.27}$ solutions, $\mathrm{CCi}_{0.27}$ membranes were obtained with self-compounded nanocomposite structure. SEM images showed that CCi-NPs with a diameter of $(42.0 \pm 3.2) \mathrm{nm}$ evenly dispersed in CCi matrix.

(a)

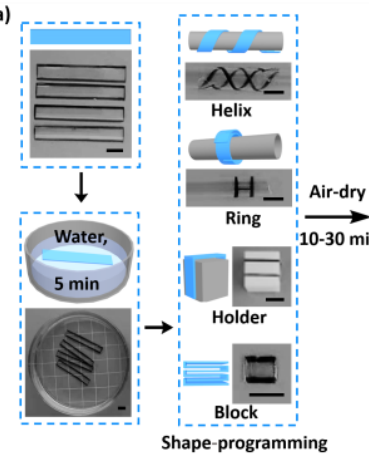

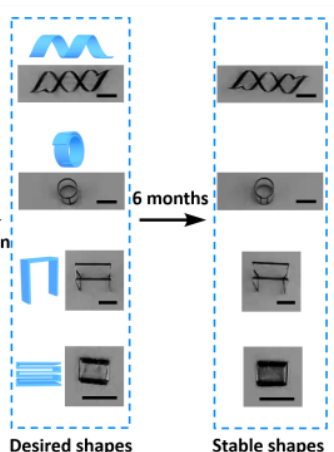

Stable shapes (b)

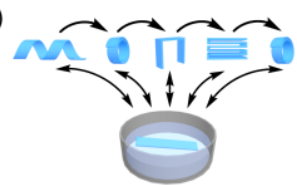

(d)

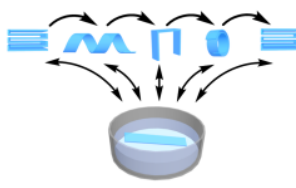

(c)

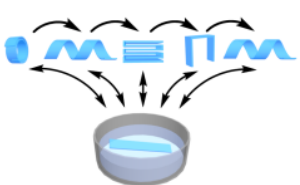

(e)

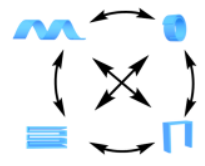

Figure 21 Sustainable and highly facile hydrosetting shape-programming of $\mathrm{CCi}_{0.27}$ membranes. (a) Schematic diagram and experimental demonstration for programming $\mathrm{CCi}$ strips into diverse 2D/3D shapes via the hydrosetting method and their shape stability, scale bars: $5 \mathrm{~mm}$. CCi membrane strips with a dimension of $30 \mathrm{~mm} \times 5 \mathrm{~mm}$ were stroked by colored mark pens on the edges for clarity. (b-d) Schematic flow charts showing the continuous programming of the same CCi membrane strip into versatile shapes in diverse sequences via the hydrosetting process. (e) A summary chart exemplifying the reversible and random transformation of CCi membrane from one 2D/3D shape to other diverse 2D/3D shapes via the facile hydrosetting shape-programming. 
$\mathrm{CCi}_{0.27}$ membranes could be easily transformed into diverse $2 \mathrm{D} / 3 \mathrm{D}$ shapes via the facile and sustainable hydrosetting method (Figure 21a). The hydrosetting process comprised of (1) the immersion of $\mathrm{CCi}_{0.27}$ membrane strips in water for 5 min that allowed the programming into desired shapes in wet state, and (2) following air-drying in the ambient environment for 10-30 min until constant weights. To fix the shapes, assistant molds were used only as templates, such as a cylinder or a cube. After drying, self-standing membranes were fixed in distinct shapes, for instance, helix, ring, holder and block, which were exactly the desired shapes as programmed in the wet state. These fixed shapes were stable and maintained for a long term of more than 6 months at environment with designated RH.

Moreover, the shapes of $\mathrm{CCi}_{0.27}$ membranes could be sequentially programmed and fixed into versatile $2 \mathrm{D} / 3 \mathrm{D}$ shapes in diverse sequences by using hydrosetting method. For example, they were programmed into four exemplarily demonstrated shapes (helix, ring, holder and block) with distinct sequences and diverse orders (Figure 21b-21d). As well, these shapes could be transformed into each other reversibly and arbitrarily (Figure 21e). Furthermore, one $\mathrm{CCi}_{0.27}$ membrane strip could be continuously reprogrammed and fixed in distinct $2 \mathrm{D} / 3 \mathrm{D}$ shapes for at least 15 cycles without fatigue via the facile hydrosetting process, which demonstrated the sustainable reusability of these nanocomposite $\mathrm{CCi}_{0.27}$ membranes with extended life-cycles.

(a)

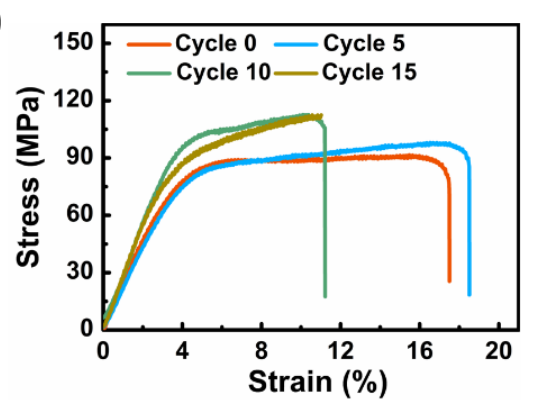

(c)

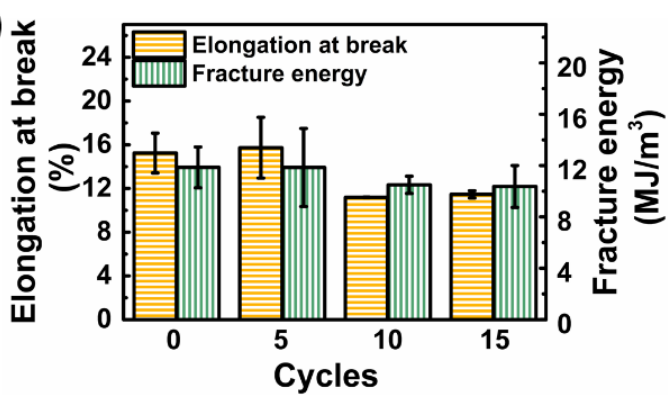

(b)

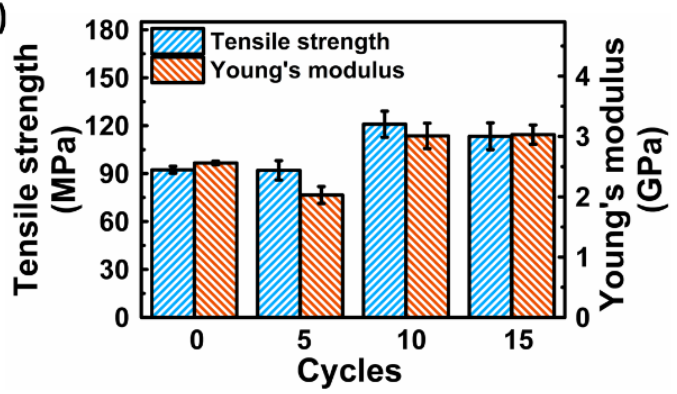

(d)

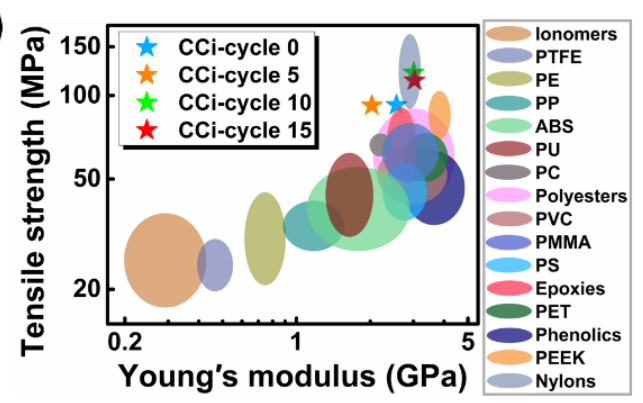


Figure 22 Static mechanical properties of hydroplastic $\mathrm{CCi}_{0.27}$ membranes. (a) stress-strain curves, (b) tensile strength and Young's modulus, (c) elongation at break and fracture energy of as-prepared CCi membranes (Cycle 0) as well as those after 5, 10 and 15 times of shape-programming (Cycle 5, 10 and 15) via hydrosetting. (d) tensile strengths and Young's moduli of CCi hydroplastics membranes compared with currently widely-used thermoplastic and thermosetting plastics. ${ }^{155}$

Static mechanical properties of dried as-prepared $\mathrm{CCi}_{0.27}$ membranes (Cycle 0 ) as well as those after 5,10 and 15 times of shape-programming (Cycle 5, 10 and 15) via hydrosetting method were analyzed (Figure 22a-22c). The as-prepared membranes were stiff, strong and tough with a tensile strength of $92.37 \pm 2.18 \mathrm{MPa}$, Young's modulus of $2.56 \pm 0.03 \mathrm{GPa}$, elongation at break of $(15.24 \pm 1.82) \%$ and fracture energy of $11.86 \pm 1.59 \mathrm{MJ} / \mathrm{m}^{3}$. After 5 times of hydrosetting shape changes, the tensile strength, Young's modulus, elongation at break and fracture energy of $\mathrm{CCi}_{0.27}$ membrane strips maintained at $92.03 \pm 6.06 \mathrm{MPa}, 2.03 \pm 0.14 \mathrm{GPa}$, $(15.73 \pm 2.78) \%$ and $11.85 \pm 3.04 \mathrm{MJ} / \mathrm{m}^{3}$, respectively. After 10 times of hydrosetting shape changes, the $\mathrm{CCi}_{0.27}$ membranes became slightly stiffer and stronger with trivial sacrifice of ductility and toughness. The tensile strength and Young's modulus slightly increased to 120.89 $\pm 8.19 \mathrm{MPa}$ and $3.01 \pm 0.21 \mathrm{GPa}$, while the elongation at break and fracture energy deceased to $(11.19 \pm 0.02) \%$ and $10.50 \pm 0.67 \mathrm{MJ} / \mathrm{m}^{3}$, respectively. These mechanical properties did not show substantial change with the shape-programming further increased to 15 cycles. The $\mathrm{CCi}_{0.27}$ membranes showed similar tensile strength and Young's modulus of $113.35 \pm 8.38 \mathrm{MPa}$ and $3.03 \pm 0.16 \mathrm{GPa}$, and the elongation at break and fracture energy also remained around $11.46 \pm 0.33 \%$ and $10.37 \pm 1.63 \mathrm{MJ} / \mathrm{m}^{3}$ compared to those after 10 cycles. Thus, dried $\mathrm{CCi}_{0.27}$ membranes maintained their mechanical properties after 10 hydrosetting processes, although varied from the initial state. Compared with currently widely-used thermoplastic materials, such as PE, PP, PET, PVC and thermosetting plastic materials including epoxies and phenolics, as-prepared $\mathrm{CCi}_{0.27}$ membranes as well as those after 5,10 , and 15 cycles of hydrosetting shape-programming showed comparable or superior tensile strengths and Young's moduli (Figure 22d). ${ }^{155}$ 
(a)

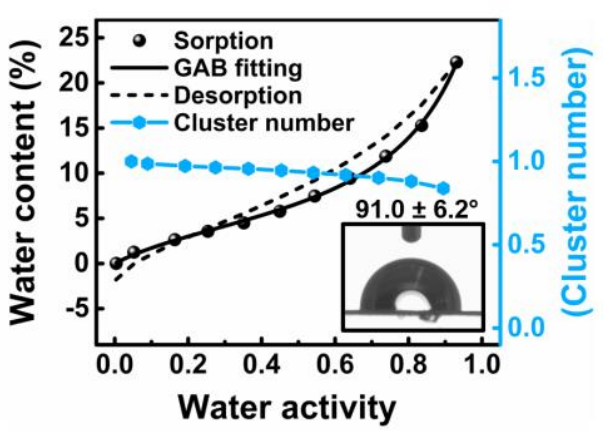

(c)

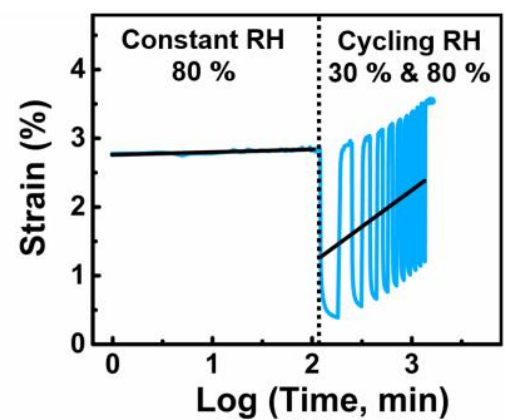

(b)

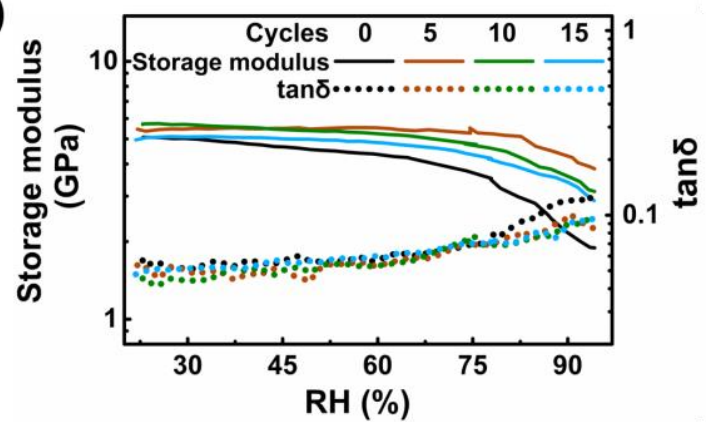

(d)

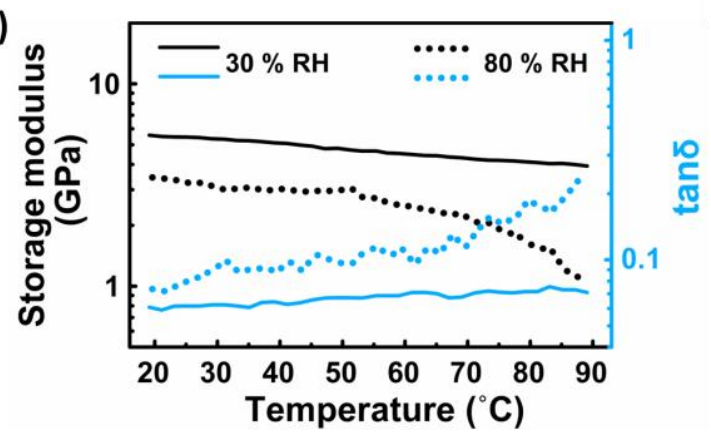

Figure 23 Significant effect of water on the properties of hydroplastic CCi membranes. (a) Dynamic water vapor sorption isotherm of as-prepared CCi membranes, fitting of sorption curve according to GAB model and calculated cluster number of water in dependence of water activity. Inset shows the static water contact angle on a CCi membrane. (b) Humidity sweep with $\mathrm{RH}$ increasing rate of $2 \% / \mathrm{min}$ at $25^{\circ} \mathrm{C}$ and frequency of $10 \mathrm{~Hz}$ for as-prepared $\mathrm{CCi}$ membranes (Cycle 0 ) as well as those after 5, 10 and 15 times of shape-programming (Cycle 5, 10 and 15) via hydrosetting processes. (c) Mechano-sorptive creep behaviors of as-prepared $\mathrm{CCi}$ membranes at $25{ }^{\circ} \mathrm{C}$ with a constant stress of $1.5 \mathrm{MPa}$ measured under constant $\mathrm{RH}$ of $80 \%$ and subsequently under cycling RH with repeating change of RH between $30 \%$ and $80 \%$ with cycling time of $2 \mathrm{~h}$. The samples were preconditioned for 30 min at $25{ }^{\circ} \mathrm{C}$ and $80 \%$ RH before loading. (d) Temperature sweep with temperature increasing rate of $0.5^{\circ} \mathrm{C} / \mathrm{min}$ and frequency of $10 \mathrm{~Hz}$ of as-prepared CCi membranes at RH of $30 \%$ and $80 \%$. Dynamic mechanical thermal analysis was implemented within linear viscoelastic region of CCi membranes.

To further reveal the hydroplastic properties of $\mathrm{CCi}_{0.27}$ membranes, their water vapor sorption behavior was analyzed. The water vapor sorption at low RH ranges rose only very slowly. At $\mathrm{RH}>60 \%$, the sorption increased faster and the equilibrated water content reached $22 \%$ at $93 \%$ RH (Figure 23a). The sorption curve was fitted to the Guggenheim-Anderson-de Boer (GAB) model, which is usually expressed as: ${ }^{188}$ 


$$
M=\frac{C K M_{0} a_{w}}{\left(1-K a_{w}\right)\left(1-K a_{w}+C K a_{w}\right)}
$$

According to the fitting results, water vapor sorption starts with monolayer sorption at low RH region with the occupation of primary sorption sites. Then it increased without a "knee" point, which indicated the significant overlap of the coverage of monolayer and the beginning of multilayer water sorption. The water sorption at high RH range was mainly due to the multilayer water sorption. Water cluster number was also calculated with the following equation: ${ }^{189}$

$$
N_{C}=-\left(1-\varphi_{1}\right) \times\left(\frac{\varphi_{1}}{M_{0} C}\left(-2 C K a_{w}+2 K a_{w}+C-2\right)-1\right)
$$

The water cluster number decreased from 1 to 0.84 when water activity increased from 0.01 to 0.93, indicating no water clustering during the water sorption process $\mathrm{CCi}_{0.27}$ membranes.

The storage moduli of $\mathrm{CCi}_{0.27}$ membranes decreased gradually with increasing $\mathrm{RH}$ from $23 \%$ to $78 \%$ (Figure 23b). Then, it dropped drastically when the RH further rose to $93 \%$. Correspondingly, the damping factors of as-prepared $\mathrm{CCi}_{0.27}$ membranes increased gently in the $\mathrm{RH}$ range of $23 \%-78 \%$ and intensely when RH further increased to $93 \%$. According to the DVS data and the fitting results, the water content of $\mathrm{CCi}_{0.27}$ membranes was $13.2 \%$ at $78 \%$ RH with multilayer water sorption. Thus, CCi chain mobility increased drastically only with the presence of a large amount of multilayer water sorption.

The programmed shapes of $\mathrm{CCi}_{0.27}$ membranes maintain long term stable in environments with constant RH while the shapes gradually changed with varied RH. The shape changes under varied $\mathrm{RH}$ should be closely related to the mechano-sorptive creep of $\mathrm{CCi}_{0.27}$ membranes (Figure 23c) The strain was almost constant at $80 \%$ RH with very slight increase from $2.78 \%$ to $2.84 \%$ under constant load of $1.5 \mathrm{MPa}$. However, the stain increased in a relatively higher rate under cycling RH of $30 \%$ and $80 \% \mathrm{RH}$. The relatively stable stain at constant $\mathrm{RH}$ and increased strain with cycling RH coincides with the shape stability under constant RH and the shape instability under varied RH. This mechano-sorptive creep behavior can generally be attributed to the sorption-induced stress gradients within $\mathrm{CCi}_{0.27}$ membranes. ${ }^{190,191}$ As well, the hydroplastic $\mathrm{CCi}_{0.27}$ membranes at a fixed $\mathrm{RH}$ also showed temperature-dependent thermoplastic properties, while the performance highly depended on the RH (Figure 23d). At $30 \% \mathrm{RH}$, the storage moduli decreased steadily ( $24 \%$ ) with increasing temperature from $20{ }^{\circ} \mathrm{C}$ to $88{ }^{\circ} \mathrm{C}$, which was accompanied by a slight increase (25\%) of damping factor. This 
indicates the higher mobility of CCi polymer chains in membranes at higher temperature. This trend is greatly enhanced at $80 \% \mathrm{RH}$ with drastic decrease of storage moduli (around $69 \%$ ) and prominent increase of damping factor $(96 \%)$. This greatly enhanced thermo-dependent reduction of the storage moduli at $80 \% \mathrm{RH}$ further approved the significant impact of high $\mathrm{RH}$ on the mechanical properties and thus the hydroplastic character of $\mathrm{CCi}_{0.27}$ membranes.

Based on the results shown above, the interaction between water molecules and CCi polymer chains strongly affected the mechanical properties of hydroplastic $\mathrm{CCi}_{0.27}$ membranes. $\mathrm{CCi}$ membranes adsorbed water molecules first as monolayer then as multilayers, when immersed in water. When the water sorption content exceeds $\sim 13.2 \%$ with multilayer water, the mobility of $\mathrm{CCi}$ chains increases prominently allowing for shape changes. Subsequent drying leads to water desorption and the formation of programmed shapes with decrease of CCi polymer chain mobility. This hydrosetting shape-programming process is reversible and sustainable thanks to the reversible increase and decrease of plasticity of CCi polymer chains with water sorption and desorption. The reversible and highly facile hydrosetting process on hydroplastics provided an eco-friendly, sustainable method for processing and engineering plastics as well as extending their lifetimes.

\section{General conclusion and perspectives}

As shown in the above study, nanostructured materials from cellulose derivatives have attracted substantial research interest. Cellulose, with an annual production of $\sim 75$ billion tons globally, ${ }^{192}$ is the most abundant biopolymer on earth, offering an almost inexhaustible resource as the raw material. The biocompatibility and biodegradability of cellulose derivatives also provide attractive perspectives for eco-friendly nanostructured materials and their applications in diverse fields. Compared with conventional nanomaterials and synthetic polymers, the unique properties of cellulose derivatives offer a variety of novel nanostructured materials with distinct structures and intriguing properties, which allows the extension and even the revolution of nanostructured materials in fabrication, processing as well as their applications.

As demonstrated in Publication 1, the swelling behaviors of surface-modified CUE-NPs were investigated via adding swelling solvents and subsequent assessment with DLS. The 
investigation revealed that the swelling behaviors of surface modified CUE-NPs depend highly on the interactions between the swelling solvents and the CUE-NPs. Good interactions between both the outer part and inner part of the surface-modified CUE-NPs gave rise to an exponential increase of the sizes of NPs when increasing the volume of swelling solvents. Good interactions with only the outer part and inferior interactions with the inner part resulted in a logarithmic increase of the sizes with the volume increase of swelling solvents. Moreover, a nonsolvent with a smaller viscosity as dispersant resulted in CUE-NPs with tighter structure, which caused difficulties of swelling at the starting stage. In addition, solvents have inferior interactions with the NPs can cause the shrinking of CUE-NPs after swelling.

In Publication 2, self-compounded CCi nanocomposite membranes were obtained via facile solvent casting method. CCi polymers chains self-compounded into two distinct morphologies: CCi-NPs and $\mathrm{CCi}$ polymer matrix in the obtained membranes. $\mathrm{CCi}_{0.6}, \mathrm{CCi}_{1.0}$ and $\mathrm{CCi}_{2.0}$ membranes demonstrated compact structure with CCi-NPs either firmly embedded in CCi matrix or tightly fused with adjacent CCi-NPs while agglomerates were observed in $\mathrm{CCi}_{2.8}$ membranes. The self-compounded compact structure and perfect compatibility resulted in CCi membranes with high-strength, exceptional gas/oil barrier properties, excellent thermal/humidity resistance as well as outstanding UV-shielding and photothermal conversion functions. CCi membranes demonstrated a high strength and Young's modulus of $94.0 \mathrm{MPa}$ and 3.1 GPa, respectively. The water vapor, oxygen and oil permeabilities were as low as $(0.94 \pm$ $0.03) \times 10^{-11} \mathrm{~g} \cdot \mathrm{m} \cdot \mathrm{m}^{-2} \cdot \mathrm{s}^{-1} \cdot \mathrm{Pa}^{-1},(8.48 \pm 2.39) \times 10^{-13} \mathrm{~cm}^{3} \cdot \mathrm{cm} / \mathrm{cm}^{2} \cdot \mathrm{s} \cdot \mathrm{cmHg}$ and $0.008 \pm 0.003$ $\mathrm{g} \cdot \mathrm{mm} \cdot \mathrm{m}^{-2} \cdot \mathrm{day}^{-1}$, respectively. The storage moduli remain higher than $2.0 \mathrm{Gpa}$ even at $98{ }^{\circ} \mathrm{C}$ and decreased only less than $10 \%$ when RH increased from $21 \% \mathrm{RH}$ to $94 \% \mathrm{RH}$. The membranes also demonstrated fully block of the UVB and UVC light and partial block of UVA light. The temperature of the membrane can increase from room temperature to $120^{\circ} \mathrm{C}$ within 1 min under UV irradiation.

In publication 3, the humidity sensitivity of cellulose derivatives with low DS was explored and a novel type of plastics: hydroplastics, was developed. Self-compounded $\mathrm{CCi}_{0.27}$ membranes showed hydroplastic properties: capable of being programmed into various shapes via a facile, eco-friendly hydrosetting method. The programmed shapes maintain stable for 
more than 6 months. Moreover, the same piece of $\mathrm{CCi}_{0.27}$ membrane can be sequentially programmed into diverse shapes. e.g. helix, ring, holder and block, by using this hydrosetting method. As a result, the programmed shapes can be transformed from one to another reversibly and arbitrarily. Thus, $\mathrm{CCi}_{0.27}$ membranes turned out to be an eco-friendly plastic with sustainable cellulose as raw materials, capable of being processed with a facile, green method and reused with extended life-cycles.

In conclusion, nanostructured materials, including colloidal nanoparticles (Publication 1) and solid-state nanocomposite membranes (Publication 2 and 3) were constructed from cellulose derivatives, i.e. CUE and CCi. All the results demonstrate that cellulose derivatives are very promising for constructing nanostructured materials with unique and superior properties. Surface modification provided an effective route for the adjustment of swelling molds of CUENPs (Publication 1). Broader extension can be applied to other cellulose derivatives, other surface-modifications and correspondingly other versatile swelling solvents. Future research on NPs from cellulose derivatives is anticipated to provide more detailed information about their structure, properties, functionalization, and their adjustment for real applications. Other methods, including nano-emulsion, flash nanoprecipitation, aerosol flow reactor etc. for the fabrication of NPs from cellulose derivatives are waiting for further development. The proposed mechanisms of formation of nanoparticles in molecular scale is anticipated to be verified or amended for deeper understanding of the process. For instance, the interactions between cellulose derivatives and solvents could be further calculated/computed with some proper models if the inner and surface constitutes of the NPs and the molecular structure of cellulose derivatives in both layers are more strictly defined.

Self-compounded nanostructured membranes from cellulose derivatives provided a new perspective to obtain membranes with multiple superior properties (Publication 2). The selfcompounding phenomenon is supposed to be extended from cellulose to other bio-based materials for materials design and their applications. More investigation about the formation and mechanism of this novel self-compounding process are anticipated. The role of $\pi-\pi$ interactions, hydrogen bonds played in the formation of this unique nanostructure and their corresponding properties can be explored further. Other interactions, such as complex 
interactions, electrostatic interactions, van der waals forces etc., and structures, such as crystalline structures and liquid crystalline structures, can possibly be utilized for the construction of self-compounded nanocomposites. Some new nano-/microstructures and corresponding properties could be anticipated with the different interactions. And some interesting applications could be explored with these structures and properties.

The hydroplastics provided new perspectives for ecofriendly plastics. Other hydroplastics from various hydroplastic polymers with green production, processing and reusability are anticipated. Deeper understanding of the mechanisms of hydroplastics and the optimization of the hydroplastic properties would endow the hydroplastics with improved performance for real applications. More interesting designs with diverse dimensions and shapes of hydroplastics and their hydrosetting shape-programming properties are also beneficial for their real applications. The investigation of the interactions between water molecules and hydroplastic polymers in molecular or atomic scale would provide more information for the theoretical development of hydroplastic plastics. With further understanding of hydroplastic polymer and their hydroplastic behaviors, the new type of plastics can be further developed for real applications in our daily life.

\section{References}

1 Popa, V. Polysaccharides in medicinal and pharmaceutical applications. (Smithers Rapra, 2011).

2 Heinze, T., El Seoud, O. A. \& Koschella, A. Cellulose derivatives: synthesis, structure, and properties. (Springer, 2018).

3 Vandamme, E., De Baets, S., Vanbaelen, A., Joris, K. \& De Wulf, P. Improved production of bacterial cellulose and its application potential. Polym. Degrad. Stab. 59, 93-99, (1998).

4 Jonas, R. \& Farah, L. F. Production and application of microbial cellulose. Polym. Degrad. Stab. 59, 101-106, (1998).

5 Yoshinaga, F., Tonouchi, N. \& Watanabe, K. Research progress in production of bacterial cellulose by aeration and agitation culture and its application as a new industrial material. Biosci. Biotechnol. Biochem 61, 219-224, (1997). 
6 Zhou, S., Nyholm, L., Strømme, M. \& Wang, Z. Cladophora cellulose: unique biopolymer nanofibrils for emerging energy, environmental, and life science applications. Acc. Chem. Res. 52, 2232-2243, (2019).

7 Hirose, E., Kimura, S., Itoh, T. \& Nishikawa, J. Tunic morphology and cellulosic components of pyrosomas, doliolids, and salps (Thaliacea, Urochordata). Biol. Bull 196, 113-120, (1999).

8 Hon, D.-S. Chemical modification of lignocellulosic materials. (Marcel Dekker, Inc, 1995).

9 Payen, A. Memoir on the composition of the tissue of plants and of woody material. $C R$ Biol 7, 1052-1056, (1838).

10 Qi, H. Novel functional materials based on cellulose. (Springer, 2017).

11 Kondo, T. The relationship between intramolecular hydrogen bonds and certain physical properties of regioselectively substituted cellulose derivatives. J. Polym. Sci. Polym. Phys. 35, 717-723, (1997).

12 Liang, C. \& Marchessault, R. Infrared spectra of crystalline polysaccharides. I. Hydrogen bonds in native celluloses. J. Polym. Sci. 37, 385-395, (1959).

13 Michell, A. J. Second derivative F.t.-i.r. spectra of celluloses I and II and related mono-and oligo-saccharides. Carbohydr. Res. 173, 185-195, (1988).

14 Kamide, K., Okajima, K., Kowsaka, K. \& Matsui, T. CP/MASS (cross-polarization/magic angle sample spinning] carbon-13 NMR spectra of cellulose solids: an explanation by the intramolecular hydrogen bond concept. Polym. J. 17, 701-706, (1985).

15 Krässig, H. A. Cellulose: structure, accessibility and reactivity. (Gordon and Breach Science Publ., 1993).

16 Nishiyama, Y., Langan, P. \& Chanzy, H. Crystal structure and hydrogen-bonding system in cellulose I $\beta$ from synchrotron X-ray and neutron fiber diffraction. J. Am. Chem. Soc. 124, 9074-9082, (2002).

17 Nishiyama, Y., Sugiyama, J., Chanzy, H. \& Langan, P. Crystal structure and hydrogen bonding system in cellulose I $\alpha$ from synchrotron X-ray and neutron fiber diffraction. $J$. Am. Chem. Soc. 125, 14300-14306, (2003).

18 Wyman, C. et al. Polysaccharides: structural diversity and functional versatility. (Dekker, 
New York, 2005).

19 Tashiro, K. \& Kobayashi, M. Theoretical evaluation of three-dimensional elastic constants of native and regenerated celluloses: role of hydrogen bonds. Polymer 32, 1516-1526, (1991).

20 Atalla, R. H. \& Vanderhart, D. L. Native cellulose: a composite of two distinct crystalline forms. Science 223, 283-285, (1984).

21 Jarvis, M. Cellulose stacks up. Nature 426, 611-612, (2003).

22 Isogai, A., Usuda, M., Kato, T., Uryu, T. \& Atalla, R. H. Solid-state CP/MAS carbon-13 NMR study of cellulose polymorphs. Macromolecules 22, 3168-3172, (1989).

23 Horii, F., Yamamoto, H., Kitamaru, R., Tanahashi, M. \& Higuchi, T. Transformation of native cellulose crystals induced by saturated steam at high temperatures. Macromolecules 20, 2946-2949, (1987).

24 Kono, H., Numata, Y., Erata, T. \& Takai, M. ${ }^{13} \mathrm{C}$ and ${ }^{1} \mathrm{H}$ resonance assignment of mercerized cellulose II by two-dimensional MAS NMR spectroscopies. Macromolecules 37, 5310-5316, (2004)

25 Wada, M. et al. Improved structural data of cellulose $\mathrm{III}_{\mathrm{I}}$ prepared in supercritical ammonia. Macromolecules 34, 1237-1243, (2001).

26 Sarko, A., Southwick, J. \& Hayashi, J. Packing analysis of carbohydrates and polysaccharides. 7. Crystal structure of cellulose $\mathrm{III}_{\mathrm{I}}$ and its relationship to other cellulose polymorphs. Macromolecules 9, 857-863, (1976).

27 Gardiner, E. S. \& Sarko, A. Packing analysis of carbohydrates and polysaccharides. 16. The crystal structures of celluloses $\mathrm{IV}_{\mathrm{I}}$ and $\mathrm{IV}_{\mathrm{II}}$. Can. J. Chem. 63, 173-180, (1985).

28 Zugenmaier, P. Conformation and packing of various crystalline cellulose fibers. Prog. Polym. Sci 26, 1341-1417, (2001).

29 Mantanis, G., Young, R. \& Rowell, R. Swelling of compressed cellulose fiber webs in organic liquids. Cellulose 2, 1-22, (1995).

30 Eckelt, J., Richardt, D., Schuster, K. C. \& Wolf, B. A. Thermodynamic interactions of natural and of man-made cellulose fibers with water. Cellulose 17, 1079-1093, (2010).

31 Schleicher, H. \& Philipp, B. Effect of activation on the reactivity of cellulose. Papier 
(Bingen, Germany) 34, 550-555, (1980).

32 Hartley, I., Kamke, F. \& Peemoeller, H. Cluster theory for water sorption in wood. Wood Sci. Technol. 26, 83-99, (1992).

33 Despond, S., Espuche, E., Cartier, N. \& Domard, A. Hydration mechanism of polysaccharides: a comparative study. J. Polym. Sci. Polym. Phys. 43, 48-58, (2005).

34 Humeres, E., Mascayano, C., Riadi, G. \& González-Nilo, F. Molecular dynamics simulation of the aqueous solvation shell of cellulose and xanthate ester derivatives. $J$. Phys. Org. Chem. 19, 896-901, (2006).

35 Rao, V. \& Foster, J. F. An addition complex between carbohydrates and dimethyl sulfoxide as revealed by proton magnetic resonance. J. Phys. Chem. 69, 656-658, (1965).

36 Casu, B., Reggiani, M., Gallo, G. \& Vigevani, A. Hydrogen bonding and conformation of glucose and polyglucoses in dimethyl-sulphoxide solution. Tetrahedron 22, 3061-3083, (1966).

37 Ko, H., Kim, Y. \& Shim, G. Evidences that $\beta$-lactose forms hydrogen bonds in DMSO. Bull. Korean Chem. Soc. 26, 2001-2006, (2005).

38 Kasbekar, G. \& Neale, S. The swelling of cellulose in aqueous solutions of certain acids and salts with measurements of the vapour pressures, densities and viscosities of these solutions. Trans. Faraday Soc. 43, 517-528, (1947).

39 Chedin, J. \& Marsaudon, A. Progress in the understanding of liquid reaction mediums, and interpretation of their reactions with cellulosic fibers: mercerization-nitration. Chim Ind (Paris) 71, 55-68, (1954).

40 Ellefsen, Ø., Gjönnes, J. \& Norman, N. Changes in the crystalline structure of cellulose caused by treatment of cotton and wood pulps with concentrated hydrochloric acid. Nor Skogind 13, 411-421, (1959).

41 Bucher, H. Zu den Vorgängen bei der Pergamentierung von Zellstoff mit Schwefelsäure. Das Papier 11, 125-133, (1957).

42 Champetier, G. Addition compounds of cellulose. Ann. Chim. Appl. 20, 5-96, (1933).

43 Dinand, E., Vignon, M., Chanzy, H. \& Heux, L. Mercerization of primary wall cellulose and its implication for the conversion of cellulose I $\rightarrow$ cellulose II. Cellulose 9, 7-18, 
(2002).

44 Cotton, F. A., Wilkinson, G., Murillo, C. A., Bochmann, M. \& Grimes, R. Advanced inorganic chemistry. (Wiley New York, 1988).

45 Hess, K. \& Gundermann, u. J. The effect of liquid ammonia on cellulose fibers (formation from ammonia-cellulose I, ammonia-cellulose II and cellulose III). Ber Dtsch Chem Ges $B$ 70, 1788-1790, (1937).

46 Vigo, T. L. Textile processing and properties: Preparation, dyeing, finishing and performance. (Elsevier, 2013).

47 El Seoud, O. A., Nawaz, H. \& Arêas, E. P. Chemistry and applications of polysaccharide solutions in strong electrolytes/dipolar aprotic solvents: an overview. Molecules 18, 12701313, (2013).

48 Schroeder, L. R. \& Haigh, F. C. Gel permeation chromatographic analysis of cellulose and wood pulp polysaccharides. (1979).

49 Rosenau, T., Potthast, A. \& Kosma, P. in Polysaccharides II, Trapping of reactive intermediates to study reaction mechanisms in cellulose chemistry. 153-197 (Springer, 2006).

50 Marson, G. A. \& El Seoud, O. A. A novel, efficient procedure for acylation of cellulose under homogeneous solution conditions. J. Appl. Polym. Sci. 74, 1355-1360, (1999).

51 El Seoud, O. A., Marson, G. A., Ciacco, G. T. \& Frollini, E. An efficient, one-pot acylation of cellulose under homogeneous reaction conditions. Macromol. Chem. Phys. 201, 882$889,(2000)$.

52 El Seoud, O. A. \& Heinze, T. in Polysaccharides I, Organic esters of cellulose: new perspectives for old polymers. 103-149 (Springer, 2005).

53 Morgenstern, B. \& Kammer, H.-W. Solvation in cellulose-LiCl-DMAc solutions. Trends in polymer Science 3, 87-91, (1996).

54 Heinze, T. et al. Effective preparation of cellulose derivatives in a new simple cellulose solvent. Macromol. Chem. Phys. 201, 627-631, (2000).

55 Kostag, M., Liebert, T., El Seoud, O. A. \& Heinze, T. Efficient cellulose solvent: quaternary ammonium chlorides. Macromol. Rapid Commun. 34, 1580-1584, (2013). 
56 Kostag, M., Liebert, T. \& Heinze, T. Acetone-based cellulose solvent. Macromol. Rapid Commun. 35, 1419-1422, (2014).

57 Yanagisawa, M., Shibata, I. \& Isogai, A. SEC-MALLS analysis of cellulose using LiCl/1, 3-dimethyl-2-imidazolidinone as an eluent. Cellulose 11, 169-176, (2004).

58 Köhler, S. \& Heinze, T. New solvents for cellulose: dimethyl sulfoxide/ammonium fluorides. Macromol. Biosci. 7, 307-314, (2007).

59 Casarano, R., Pires, P. A. \& El Seoud, O. A. Acylation of cellulose in a novel solvent system: Solution of dibenzyldimethylammonium fluoride in DMSO. Carbohydr. Polym. 101, 444-450, (2014).

60 Gericke, M., Fardim, P. \& Heinze, T. Ionic liquids — promising but challenging solvents for homogeneous derivatization of cellulose. Molecules 17, 7458-7502, (2012).

61 Heinze, T. \& Liebert, T. Unconventional methods in cellulose functionalization. Prog. Polym. Sci 26, 1689-1762, (2001).

62 Bain, A. D., Eaton, D. R., Hux, R. A. \& Tong, J. P. An NMR study of the interactions between cadoxen and saccharides. Carbohydr. Res. 84, 1-12, (1980).

63 Nehls, I., Wagenknecht, W. \& Philipp, B. C-13-NMR spectroscopic studies of cellulose in various solvent systems. Cell. Chem. Technol. 29, 243-251, (1995).

64 Klemm, D., Heinze, T., Philipp, B. \& Wagenknecht, W. New approaches to advanced polymers by selective cellulose functionalization. Acta Polym. 48, 277-297, (1997).

65 Liebert, T., Klemm, D. \& Heinze, T. Synthesis and carboxymethylation of organo-soluble trifluoroacetates and formates of cellulose. J. Macromol. Sci. A 33, 613-626, (1996).

66 Law, R. C. in Macromol. Symp. 255-266 (Wiley Online Library, 2004).

67 Gericke, M., Schlufter, K., Liebert, T., Heinze, T. \& Budtova, T. Rheological properties of cellulose/ionic liquid solutions: from dilute to concentrated states. Biomacromolecules 10, 1188-1194, (2009).

68 Gericke, M., Liebert, T., Seoud, O. A. E. \& Heinze, T. Tailored media for homogeneous cellulose chemistry: ionic liquid/co-solvent mixtures. Macromol. Mater. Eng. 296, 483493, (2011).

69 Regiani, A. M., Frollini, E., Marson, G. A., Arantes, G. M. \& El Seoud, O. A. Some aspects 
of acylation of cellulose under homogeneous solution conditions. J. Polym. Sci. Polym. Chem. 37, 1357-1363, (1999).

70 Possidonio, S., Fidale, L. C. \& El Seoud, O. A. Microwave-assisted derivatization of cellulose in an ionic liquid: An efficient, expedient synthesis of simple and mixed carboxylic esters. J. Polym. Sci. Polym. Chem. 48, 134-143, (2010).

71 Clayden, J., Greeves, N., Warren, S. \& Wothers, P. Organic chemistry. (Oxford university press, 2001).

72 Schubert, S., Delaney Jr, J. T. \& Schubert, U. S. Nanoprecipitation and nanoformulation of polymers: from history to powerful possibilities beyond poly(lactic acid). Soft Matter 7, 1581-1588, (2011).

73 Chronopoulou, L., Fratoddi, I., Palocci, C., Venditti, I. \& Russo, M. V. Osmosis based method drives the self-assembly of polymeric chains into micro- and nanostructures. Langmuir 25, 11940-11946, (2009).

74 Aubry, J., Ganachaud, F., Cohen Addad, J.-P. \& Cabane, B. Nanoprecipitation of polymethylmethacrylate by solvent shifting: 1. Boundaries. Langmuir 25, 1970-1979, (2009).

75 Wondraczek, H., Petzold-Welcke, K., Fardim, P. \& Heinze, T. Nanoparticles from conventional cellulose esters: evaluation of preparation methods. Cellulose 20, 751-760, (2013).

76 Lepeltier, E., Bourgaux, C. \& Couvreur, P. Nanoprecipitation and the "Ouzo effect": Application to drug delivery devices. Adv. Drug Deliv. Rev. 71, 86-97, (2014).

77 Geissler, A., Biesalski, M., Heinze, T. \& Zhang, K. Formation of nanostructured cellulose stearoyl esters via nanoprecipitation. J. Mater. Chem. A 2, 1107-1116, (2014).

78 Kulterer, M. R. et al. Nanoprecipitation of cellulose acetate using solvent/nonsolvent mixtures as dispersive media. Colloids Surf. A Physicochem. Eng. Asp. 375, 23-29, (2011).

79 Gericke, M., Schulze, P. \& Heinze, T. Nanoparticles based on hydrophobic polysaccharide derivatives-formation principles, characterization techniques, and biomedical applications. Macromol. Biosci., e1900415, (2020).

80 Zhang, K., Geissler, A. \& Heinze, T. Reversibly crystalline nanoparticles from cellulose 
alkyl esters via nanoprecipitation. Part. Part. Syst. Charact. 32, 258-266, (2015).

81 Ferreira, D. C., Bastos, G. S., Pfeifer, A., Heinze, T. \& El Seoud, O. A. Cellulose carboxylate/tosylate mixed esters: synthesis, properties and shaping into microspheres. Carbohydr. Polym. 152, 79-86, (2016).

82 Geissler, A., Chen, L., Zhang, K., Bonaccurso, E. \& Biesalski, M. Superhydrophobic surfaces fabricated from nano- and microstructured cellulose stearoyl esters. ChemComm 49, 4962-4964, (2013).

83 Jin, H. et al. Super stable foams stabilized by colloidal ethyl cellulose particles. Soft Matter 8, 2194-2205, (2012).

84 Bizmark, N., Ioannidis, M. A. \& Henneke, D. E. Irreversible adsorption-driven assembly of nanoparticles at fluid interfaces revealed by a dynamic surface tension probe. Langmuir 30, 710-717, (2014).

85 Bizmark, N. \& Ioannidis, M. A. Effects of ionic strength on the colloidal stability and interfacial assembly of hydrophobic ethyl cellulose nanoparticles. Langmuir 31, 92829289, (2015).

86 Bizmark, N. \& Ioannidis, M. A. Ethyl cellulose nanoparticles at the alkane-water interface and the making of pickering emulsions. Langmuir 33, 10568-10576, (2017).

87 Han, Y., Bizmark, N., Abukhdeir, N. M. \& Ioannidis, M. A. Dynamics of ethyl cellulose nanoparticle self-assembly at the interface of a nematic liquid crystal droplet. Phys. Chem. Chem. Phys. 19, 24955-24960, (2017).

88 Duarah, S., Durai, R. D. \& Narayanan, V. B. Nanoparticle-in-gel system for delivery of vitamin C for topical application. Drug Deliv. Transl. Res. 7, 750-760, (2017).

89 Amin, M. et al. Cellulose ether derivatives: a new platform for prodrug formation of fluoroquinolone antibiotics. Cellulose 22, 2011-2022, (2015).

90 Schulze, P. et al. Incorporation of hydrophobic dyes within cellulose acetate and acetate phthalate based nanoparticles. Macromol. Chem. Phys. 217, 1823-1833, (2016).

91 Garg, A., Rai, G., Lodhi, S., Jain, A. P. \& Yadav, A. K. In-vitro and in-vivo assessment of dextran-appended cellulose acetate phthalate nanoparticles for transdermal delivery of 5 fluorouracil. Drug Deliv. 23, 1525-1535, (2016). 
92 Schulze, P., Gericke, M. \& Heinze, T. Reactive nanoparticles with activated ester moieties from cellulose acetate phthalate derivatives. Cellulose 26, 475-490, (2018).

93 Sahle, F. F., Gerecke, C., Kleuser, B. \& Bodmeier, R. Formulation and comparative in vitro evaluation of various dexamethasone-loaded $\mathrm{pH}$-sensitive polymeric nanoparticles intended for dermal applications. Int. J. Pharm. 516, 21-31, (2017).

94 Date, A. A. et al. Thermosensitive gel containing cellulose acetate phthalate-efavirenz combination nanoparticles for prevention of HIV-1 infection. J. Biomed. Nanotechnol. 11, 416-427, (2015).

95 Obst, M. \& Heinze, T. Simple synthesis of reactive and nanostructure forming hydrophobic amino cellulose derivatives. Macromol. Mater. Eng. 301, 65-70, (2016).

96 Cheng, F., Betts, J. W., Kelly, S. M., Schaller, J. \& Heinze, T. Synthesis and antibacterial effects of aqueous colloidal solutions of silver nanoparticles using aminocellulose as a combined reducing and capping reagent. Green Chem. 15, 989, (2013).

97 Wiegand, C., Nikolajski, M., Hipler, U. C. \& Heinze, T. Nanoparticle formulation of AEA and BAEA cellulose carbamates increases biocompatibility and antimicrobial activity. Macromol. Biosci. 15, 1242-1251, (2015).

98 Nikolajski, M., Wotschadlo, J., Clement, J. H. \& Heinze, T. Amino-functionalized cellulose nanoparticles: preparation, characterization, and interactions with living cells. Macromol. Biosci. 12, 920-925, (2012).

99 Li, W., Wang, W., Yang, Y. \& Zhang, K. Redox-responsive, reversibly fluorescent nanoparticles from sustainable cellulose derivatives. J. Mater. Chem. A 2, 13675-13681, (2014).

100 Wang, Y., Heinze, T. \& Zhang, K. Stimuli-responsive nanoparticles from ionic cellulose derivatives. Nanoscale 8, 648-657, (2016).

101 Gupta, A., Eral, H. B., Hatton, T. A. \& Doyle, P. S. Nanoemulsions: formation, properties and applications. Soft Matter 12, 2826-2841, (2016).

102 Anton, N. \& Vandamme, T. F. Nano-emulsions and micro-emulsions: clarifications of the critical differences. Pharm. Res. 28, 978-985, (2011).

103 Anton, N., Benoit, J. P. \& Saulnier, P. Design and production of nanoparticles formulated 
from nano-emulsion templates-a review. J. Control. Release 128, 185-199, (2008).

104 Ravikumara, N. R., Madhusudhan, B., Nagaraj, T. S., Hiremat, S. R. \& Raina, G. Preparation and evaluation of nimesulide-loaded ethylcellulose and methylcellulose nanoparticles and microparticles for oral delivery. J. Biomater. Appl. 24, 47-64, (2009).

105 El-Habashy, S. E., Allam, A. N. \& El-Kamel, A. H. Ethyl cellulose nanoparticles as a platform to decrease ulcerogenic potential of piroxicam: formulation and in vitro/in vivo evaluation. Int. J. Nanomed. 11, 2369-2380, (2016).

106 Balzus, B. et al. Formulation and ex vivo evaluation of polymeric nanoparticles for controlled delivery of corticosteroids to the skin and the corneal epithelium. Eur. J. Pharm. Biopharm. 115, 122-130, (2017).

107 Mandal, S. et al. Cellulose acetate phthalate and antiretroviral nanoparticle fabrications for HIV pre-exposure prophylaxis. Polymers 9, (2017).

108 Vedula, V. B., Chopra, M., Joseph, E. \& Mazumder, S. Preparation and characterization of nanoparticles of carboxymethyl cellulose acetate butyrate containing acyclovir. Appl. Nanosci. 6, 197-208, (2015).

109 Chopra, M., Jain, R., Dewangan, A. K., Varkey, S. \& Mazumder, S. Design of curcumin loaded polymeric nanoparticles-optimization, formulation and characterization. J. Nanosci. Nanotechnol. 16, 9432-9442, (2016).

110 Dewangan, A. K., Perumal, Y., Pavurala, N., Chopra, K. \& Mazumder, S. Preparation, characterization and anti-inflammatory effects of curcumin loaded carboxymethyl cellulose acetate butyrate nanoparticles on adjuvant induced arthritis in rats. $J$ Drug Deliv Sci Technol 41, 269-279, (2017).

111 Mazumder, S., Dewangan, A. K. \& Pavurala, N. Enhanced dissolution of poorly soluble antiviral drugs from nanoparticles of cellulose acetate based solid dispersion matrices. Asian J. Pharm. 12, 532-541, (2017).

112 Bteich, J. et al. Using flash nanoprecipitation to produce highly potent and stable cellax nanoparticles from amphiphilic polymers derived from carboxymethyl cellulose, polyethylene glycol, and cabazitaxel. Mol. Pharm. 14, 3998-4007, (2017).

113 Yang, Y., Roy, A., Zhao, Y., Undzys, E. \& Li, S. D. Comparison of tumor penetration of 
podophyllotoxin-carboxymethylcellulose conjugates with various chemical compositions in tumor spheroid culture and in vivo solid tumor. Bioconjugate Chem. 28, 1505-1518, (2017).

114 Roy, A. et al. Selective targeting and therapy of metastatic and multidrug resistant tumors using a long circulating podophyllotoxin nanoparticle. Biomaterials 137, 11-22, (2017).

115 Ernsting, M. J., Tang, W. L., MacCallum, N. \& Li, S. D. Synthetic modification of carboxymethylcellulose and use thereof to prepare a nanoparticle forming conjugate of docetaxel for enhanced cytotoxicity against cancer cells. Bioconjugate Chem. 22, 24742486, (2011).

116 Kulterer, M. R. et al. Functional polysaccharide composite nanoparticles from cellulose acetate and potential applications. Adv. Funct. Mater. 22, 1749-1758, (2012).

117 Hiltunen, M. S., Raula, J. \& Maunu, S. L. Tailoring of water-soluble cellulose-gcopolymers in homogeneous medium using single-electron-transfer living radical polymerization. Polym. Int. 60, 1370-1379, (2011).

118 Kostag, M., Köhler, S., Liebert, T. \& Heinze, T. Pure Cellulose Nanoparticles from Trimethylsilyl Cellulose. Macromol. Symp. 294, 96-106, (2010).

119 Enomoto-Rogers, Y., Kamitakahara, H., Yoshinaga, A. \& Takano, T. Synthesis of diblock copolymers with cellulose derivatives 4 . Self-assembled nanoparticles of amphiphilic cellulose derivatives carrying a single pyrene group at the reducing-end. Cellulose 18, 1005-1014, (2011).

120 Fidale, L. C. et al. Hybrid $\mathrm{Fe}_{3} \mathrm{O}_{4} @$ amino cellulose nanoparticles in organic mediaheterogeneous ligands for atom transfer radical polymerizations. J. Colloid Interface Sci. 390, 25-33, (2013).

121 Chen, L., Geissler, A., Bonaccurso, E. \& Zhang, K. Transparent slippery surfaces made with sustainable porous cellulose lauroyl ester films. ACS Appl. Mater. Interfaces 6, 69696976, (2014).

122 Jung, A., Wolters, B. \& Berlin, P. (Bio)functional surface structural design of substrate materials based on self-assembled monolayers from aminocellulose derivatives and amino(organo)polysiloxanes. Thin Solid Films 515, 6867-6877, (2007). 
123 Dore, C., Osmond, J. \& Mihi, A. A water-processable cellulose-based resist for advanced nanofabrication. Nanoscale 10, 17884, (2018).

124 Espinha, A. et al. Hydroxypropyl cellulose photonic architectures by soft nanoimprinting lithography. Nat Photonics 12, 343-348, (2018).

125 Park, H.-H. et al. Cellulose acetate nanoneedle array covered with phosphorylcholine moiety as a biocompatible and sustainable antifouling material. Cellulose 26, 8775-8788, (2019).

126 Wolfberger, A. et al. Photolithographic patterning of cellulose: a versatile dual-tone photoresist for advanced applications. Cellulose 22, 717-727, (2015).

127 Sakakibara, K., Ogawa, Y. \& Nakatsubo, F. First cellulose Langmuir-Blodgett films toward photocurrent generation systems. Macromol. Rapid Commun. 28, 1270-1275, (2007).

128 Sakakibara, K. et al. Light-harvesting nanorods based on pheophorbide-appending cellulose. Biomacromolecules 14, 3223-3230, (2013).

129 Fernandes, S. N. et al. Cellulose-based nanostructures for photoresponsive surfaces. Cellulose 23, 465-476, (2015).

130 Gutierrez, J. et al. Transparent nanostructured cellulose acetate films based on the self assembly of PEO-b-PPO-b-PEO block copolymer. Carbohydr. Polym. 165, 437-443, (2017).

131 Wei, Y., Cheng, F., Hou, G. \& Sun, S. Amphiphilic cellulose: surface activity and aqueous self-assembly into nano-sized polymeric micelles. React. Funct. Polym. 68, 981-989, (2008).

132 Altam, A. A. et al. Cellulose derivative-lanthanide complex film by hierarchical assembly process. Carbohydr. Polym. 168, 240-246, (2017).

133 Francesko, A. et al. Bottom-up layer-by-layer assembling of antibacterial freestanding nanobiocomposite films. Biomacromolecules 19, 3628-3636, (2018).

134 Liang, H. L. et al. Roll-to-roll fabrication of touch-responsive cellulose photonic laminates. Nat. Commun. 9, 4632, (2018).

135 Heinze, T., Siebert, M., Berlin, P. \& Koschella, A. Biofunctional materials based on amino cellulose derivatives - a nanobiotechnological concept. Macromol. Biosci. 16, 10-42, 
(2016).

136 Wang, Y. et al. Graphene oxide-IPDI-Ag/ZnO@hydroxypropyl cellulose nanocomposite films for biological wound-dressing applications. ACS Omega 4, 15373-15381, (2019).

137 Sehaqui, H., Zhou, Q. \& Berglund, L. A. Nanostructured biocomposites of high toughness - a wood cellulose nanofiber network in ductile hydroxyethylcellulose matrix. Soft Matter 7, 7342-7350, (2011).

138 Rincon-Iglesias, M., Lizundia, E. \& Lanceros-Mendez, S. Water-soluble cellulose derivatives as suitable matrices for multifunctional materials. Biomacromolecules 20, 2786-2795, (2019).

139 Rincon-Iglesias, M., Delgado, A., Perinka, N., Lizundia, E. \& Lanceros-Mendez, S. Waterbased 2D printing of magnetically active cellulose derivative nanocomposites. Carbohydr. Polym. 233, 115855, (2020).

140 Thorvaldsson, A. et al. Superhydrophobic behaviour of plasma modified electrospun cellulose nanofiber-coated microfibers. Cellulose 19, 1743-1748, (2012).

141 Anitha, S., Brabu, B., Thiruvadigal, D. J., Gopalakrishnan, C. \& Natarajan, T. S. Optical, bactericidal and water repellent properties of electrospun nano-composite membranes of cellulose acetate and ZnO. Carbohydr. Polym. 87, 1065-1072, (2012).

142 Roemhild, K., Wiegand, C., Hipler, U. C. \& Heinze, T. Novel bioactive aminofunctionalized cellulose nanofibers. Macromol. Rapid Commun. 34, 1767-1771, (2013).

143 Arslan, O., Aytac, Z. \& Uyar, T. Superhydrophobic, hybrid, electrospun cellulose acetate nanofibrous mats for oil/water separation by tailored surface modification. ACS Appl. Mater. Interfaces 8, 19747-19754, (2016).

144 Fischer, F., Rigacci, A., Pirard, R., Berthon-Fabry, S. \& Achard, P. Cellulose-based aerogels. Polymer 47, 7636-7645, (2006).

145 Dais, P. \& Perlin, A. S. Assignment of the O-acetyl carbonyl carbon atoms of cellulose triacetate via 2D, long-range, proton-carbon chemical-shift-correlation data. Carbohydr. Res. 181, 233-235, (1988).

146 Meng, X., Matson, J. B. \& Edgar, K. J. Olefin cross-metathesis as a source of polysaccharide derivatives: Cellulose $\omega$-carboxyalkanoates. Biomacromolecules 15, 177- 
187, (2014).

147 Lide, D. R. CRC Handbook of Chemistry and Physics (CRC press, 2004).

148 Aschenbrenner, E. et al. Using the polymeric ouzo effect for the preparation of polysaccharide-based nanoparticles. Langmuir 29, 8845-8855, (2013).

149 Thioune, O., Fessi, H., Devissaguet, J. \& Puisieux, F. Preparation of pseudolatex by nanoprecipitation: influence of the solvent nature on intrinsic viscosity and interaction constant. Int. J. Pharm. 146, 233-238, (1997).

150 Sterpone, F., Stirnemann, G., Hynes, J. T. \& Laage, D. Water hydrogen-bond dynamics around amino acids: the key role of hydrophilic hydrogen-bond acceptor groups. J. Phys. Chem. B 114, 2083-2089, (2010).

151 Samaranayake, G. \& Glasser, W. G. Cellulose derivatives with low DS. I. A novel acylation system. Carbohydr. Polym. 22, 1-7, (1993).

152 Edgar, K. J., Heinze, T. \& Buchanan, C. M. Polysaccharide materials: Performance by design. (American Chemical Society Washington DC, USA, 2009).

153 Dai, J. \& Kim, J. C. Photo and thermal properties of cinnamoyl Pluronic F-127. Polym. Int. 63, 501-506, (2014).

154 Vaca-Garcia, C., Borredon, M. E. \& Gaseta, A. Determination of the degree of substitution (DS) of mixed cellulose esters by elemental analysis. Cellulose 8, 225-231, (2001).

155 Ashby, M. F. Materials Selection in Mechanical Design. (Elsevier Ltd, 2011).

156 Bastos, M. d. S. R. et al. Physical and mechanical testing of essential oil-embedded cellulose ester films. Polym. Test. 49, 156-161, (2016).

157 Willberg-Keyriläinen, P., Vartiainen, J., Harlin, A. \& Ropponen, J. The effect of side-chain length of cellulose fatty acid esters on their thermal, barrier and mechanical properties. Cellulose 24, 505-517, (2016).

158 Espinoza-Herrera, N., Pedroza-Islas, R., San Martín-Martinez, E., Cruz-Orea, A. \& Tomás, S. A. Thermal, Mechanical and Microstructures Properties of Cellulose Derivatives Films: A Comparative Study. Food Biophys. 6, 106-114, (2010).

159 Uddin, M. E. et al. Preparation and enhanced mechanical properties of non-covalentlyfunctionalized graphene oxide/cellulose acetate nanocomposites. Compos. B. Eng. 90, 
223-231, (2016).

160 Heredia-Guerrero, J. A. et al. Cellulose-polyhydroxylated fatty acid ester-based bioplastics with tuning properties: Acylation via a mixed anhydride system. Carbohydr. Polym. 173, 312-320, (2017)

161 Wang, W., Liang, T., Bai, H., Dong, W. \& Liu, X. All cellulose composites based on cellulose diacetate and nanofibrillated cellulose prepared by alkali treatment. Carbohydr. Polym. 179, 297-304, (2018).

162 Biswas, A. et al. Preparation and Characterization of Carboxymethyl Cellulose Films with Embedded Essential Oils. J. Mater. Sci. Res. 7, 16, (2018).

163 Rynkowska, E. et al. The Effect of Reactive Ionic Liquid or Plasticizer Incorporation on the Physicochemical and Transport Properties of Cellulose Acetate Propionate-Based Membranes. Polymers 10, 86, (2018).

164 Hypoelae, R., Husson, I. \& Sundholm, F. Evaluation of physical properties of plasticized ethyl cellulose films cast from ethanol solution part 1. Int. J. Pharm. 133, 161-170, (1996).

165 Quan, D. \& Ivankovic, A. Effect of core-shell rubber (CSR) nano-particles on mechanical properties and fracture toughness of an epoxy polymer. Polymer 66, 16-28, (2015).

166 Han, D., Yan, L., Chen, W., Li, W. \& Bangal, P. R. Cellulose/graphite oxide composite films with improved mechanical properties over a wide range of temperature. Carbohydr. Polym. 83, 966-972, (2011).

167 Sarki, J., Hassan, S. B., Aigbodion, V. S. \& Oghenevweta, J. E. Potential of using coconut shell particle fillers in eco-composite materials. J. Alloys Compd. 509, 2381-2385, (2011).

168 Ragoubi, M., Bienaimé, D., Molina, S., George, B. \& Merlin, A. Impact of corona treated hemp fibres onto mechanical properties of polypropylene composites made thereof. Ind. Crops and Prod. 31, 344-349, (2010).

169 Bandyopadhyay, A., De Sarkar, M. \& Bhowmick, A. K. Polymer-filler interactions in solgel derived polymer/silica hybrid nanocomposites. J. Polym. Sci. Polym. Phys. 43, 23992412, (2005).

170 Wolińska-Grabczyk, A. et al. Gas and water vapor transport properties of mixed matrix membranes containing 13X zeolite. J. Membr. Sci. 526, 334-347, (2017). 
171 Bedane, A. H., Eić, M., Farmahini-Farahani, M. \& Xiao, H. Water vapor transport properties of regenerated cellulose and nanofibrillated cellulose films. J. Membr. Sci. 493, 46-57, (2015).

172 Colussi, R. et al. Acetylated rice starches films with different levels of amylose: Mechanical, water vapor barrier, thermal, and biodegradability properties. Food Chem. 221, 1614-1620, (2017)

173 Liu, H., Liu, C., Peng, S., Pan, B. \& Lu, C. Effect of polyethyleneimine modified graphene on the mechanical and water vapor barrier properties of methyl cellulose composite films. Carbohydr. Polym. 182, 52-60, (2018).

$174 \mathrm{Li}$, L. et al. Robust cellulose nanocomposite films based on covalently cross-linked network with effective resistance to water permeability. Carbohydr. Polym. 211, 237-248, (2019).

175 El Miri, N. et al. Bio-nanocomposite films reinforced with cellulose nanocrystals: Rheology of film-forming solutions, transparency, water vapor barrier and tensile properties of films. Carbohydr. Polym. 129, 156-167, (2015).

176 Al-Hassan, A. A. \& Norziah, M. H. Starch-gelatin edible films: Water vapor permeability and mechanical properties as affected by plasticizers. Food Hydrocoll. 26, 108-117, (2012).

$177 \mathrm{Su}$, J.-F. et al. Moisture sorption and water vapor permeability of soy protein isolate/poly(vinyl alcohol)/glycerol blend films. Ind. Crops Prod. 31, 266-276, (2010).

178 Cao, L. et al. An edible oil packaging film with improved barrier properties and heat sealability from cassia gum incorporating carboxylated cellulose nano crystal whisker. Food Hydrocoll. 98, 105251, (2020).

179 Ali Dadfar, S. M., Alemzadeh, I., Reza Dadfar, S. M. \& Vosoughi, M. Studies on the oxygen barrier and mechanical properties of low density polyethylene/organoclay nanocomposite films in the presence of ethylene vinyl acetate copolymer as a new type of compatibilizer. Mater. Des. 32, 1806-1813, (2011).

180 Semsarzadeh, M. A. \& Ghalei, B. Characterization and gas permeability of polyurethane and polyvinyl acetate blend membranes with polyethylene oxide-polypropylene oxide block copolymer. J. Membr. Sci. 401-402, 97-108, (2012). 
181 Yang, D. et al. "Green" films from renewable resources: properties of epoxidized soybean oil plasticized ethyl cellulose films. Carbohydr. Polym. 103, 198-206, (2014).

182 Dou, Y. et al. Transparent, Flexible Films Based on Layered Double Hydroxide/Cellulose Acetate with Excellent Oxygen Barrier Property. Adv. Funct. Mater. 24, 514-521, (2014).

183 Compton, O. C., Kim, S., Pierre, C., Torkelson, J. M. \& Nguyen, S. T. Crumpled graphene nanosheets as highly effective barrier property enhancers. Adv. Mater. 22, 4759-4763, (2010).

184 Russo, G. M., Simon, G. P. \& Incarnato, L. Correlation between Rheological, Mechanical, and Barrier Properties In New copolyamide-based nanocomposite films. Macromolecules 39, 3855-3864, (2006).

185 Farhan, A. \& Hani, N. M. Characterization of edible packaging films based on semirefined kappa-carrageenan plasticized with glycerol and sorbitol. Food Hydrocoll. 64, 48$58,(2017)$.

$186 \mathrm{Ma}, \mathrm{X}$. et al. Hydrophilic modification of cellulose nanocrystals improves the physicochemical properties of cassava starch-based nanocomposite films. LWT 86, 318$326,(2017)$.

187 Zhang, K. et al. Moisture-responsive films of cellulose stearoyl esters showing reversible shape transitions. Sci. Rep. 5, 11011, (2015).

188 Rao, M. A., Rizvi, S. S., Datta, A. K. \& Ahmed, J. Engineering properties of foods. (CRC press, 2014).

189 Zhang, Z., Britt, I. J. \& Tung, M. A. Water absorption in EVOH films and its influence on glass transition temperature. J. Polym. Sci., Part B: Polym. Phys. 37, 691-699, (1999).

190 Habeger, C. C. \& Coffin, D. W. The role of stress concentrations in acceleration creep and sorption-induced physical aging. J. Pulp Pap. Sci. 26, 145-157, (2000).

191 Habeger, C. C., Coffin, D. W. \& Hojjatie, B. Influence of humidity cycling parameters on the moisture-accelerated creep of polymeric fibers. J. Polym. Sci., Part B: Polym. Phys. 39, 2048-2062, (2001).

192 Khalil, H. A. et al. Production and modification of nanofibrillated cellulose using various mechanical processes: a review. Carbohydr. Polym. 99, 649-665, (2014). 


\section{Appendix}

Author's peer-reviewed publications 


\title{
Modular Adjustment of Swelling Behaviors of Surface-Modified Solvent-Responsive Polymeric Nanoparticles Based on Cellulose 10- Undecenoyl Ester
}

\author{
Jiaxiu Wang and Kai Zhang*(i) \\ Wood Technology and Wood Chemistry, Georg-August-University of Goettingen, Büsgenweg 4, D-37077 Göttingen, Germany
}

Supporting Information

\begin{abstract}
Functional polymeric nanoparticles (NPs) have attracted intense interest because of their broad applications. However, most of them focused on characteristics, behaviors, properties, or functionalities of the NPs, while neglecting the interaction between NPs and solvents and thus the influence of solvents on the physical-chemical properties of NPs. In this paper, NPs based on cellulose 10-undecenoyl ester with total substitution of hydroxyl groups by undecenoyl moieties were prepared in various organic dispersants via nanoprecipitation. These NPs were further surface-modified with diverse functionalities via thiol-ene reactions on the terminal vinyl groups of undecenoyl moieties. The swelling behaviors of the resultant surface-modified NPs were systematically investigated via adding corresponding swelling solvents to the dispersions, fitting the swelling modes to different types of functions, and analyzing the factors influencing the swelling processes. It is concluded that different interactions including hydrogen bond interaction between swelling solvents and surface-modified outer layers as well as nonmodified interior parts of NPs are essential for different swelling trends. The swelling extents and tolerant capacities for swelling solvents in dispersant could be affected by the characters of dispersants, the surface functionalities of NPs, and the interaction between them. Thus, our investigation provides a general understanding of the swelling behaviors of surface-modified solvent-responsive NPs derived from polymeric cellulose derivatives.
\end{abstract}

\section{INTRODUCTION}

Functional polymeric nanoparticles (NPs) have been the research interest over recent decades owing to their broad application in bioscience including drug delivery, biosensor, cell/tissue labels, targeting, diagnostics, and many others. ${ }^{1-4}$ The advantages of polysaccharide-based NPs for biological applications are widely recognized, primarily because of the nature of biogenic polysaccharides, which better fulfill the criteria of nontoxic, nonimmunogenic, and biodegradable characters, compared to synthetic polymers. ${ }^{5-8}$

Among various methods for the preparation of NPs derived from polysaccharides, nanoprecipitation as a postshaping method stands out as an easy and effective experimental method. ${ }^{9-14}$ When a polymer solution is added to a nonsolvent (miscible with the solvent) in excess amount, a stable and homogeneous dispersion of polymeric NPs will be spontaneously formed. Thus, nanoprecipitation is also mentioned as a solvent-shifting, solvent exchange, or solvent replacement process, which principally based on the "ouzo effect". ${ }^{12,15-19}$ Moreover, a little energy input is needed for this process, which makes this method especially suitable for the preparation of NPs based on diverse polymers or for imbedding drugs, sensitive molecules, or compounds within the NPs, such as using cellulose derivatives, poly(lactic acid), and poly(D,L-lacticco-glycolic acid). ${ }^{20-23}$ For this purpose, functional compounds could be integrated into NPs by blending them in the polymer solvent before nanoprecipitation. ${ }^{23,24}$ For the application of polymeric NPs in the field of nanomedicine, the size of polymeric NPs should be well-controlled because it can directly affect the cellular uptake as well as the pharmacokinetic and pharmacodynamic properties. ${ }^{25,26}$ For instance, the formation of protein "corona" can also be influenced by the particle size, when polymeric NPs with desired functions are introduced into biological systems. ${ }^{27}$ Therefore, it is critical to control the size of polymeric NPs for diverse biomedical applications. Polymeric NPs can swell or shrink due to multifarious environmental conditions during their application in biological surroundings. ${ }^{28,29}$ The swelling phenomenon of NPs based on polymethylmethacrylate with different acetone volumes in the disperse medium has already been observed. ${ }^{16}$

To better control the size of polymeric NPs, several methods have been developed. Polymeric NPs derived from intrinsically stimuli-responsive polymers can change their sizes depending on the stimuli, such as those derived from poly $(\mathrm{N}-$ isopropylacrylamide) depending on the temperature. ${ }^{30}$ The sizes of polymeric NPs could also be changed by incorporating

Received: November 24, 2017

Revised: February 15, 2018

Published: March 14, 2018 
stimuli-responsive moieties along the polymeric backbones, such as azobenzene groups, which led to NPs with lightswitchable sizes. ${ }^{31} \mathrm{Ku}$ et al. reported the adjustment of the internal morphology and the overall shape of self-assembled particles based on block copolymers using size-controlled Au NP surfactants. ${ }^{32}$ A further approach is to modify the surface layer of NPs with stimuli-responsive compounds or to fabricate multilayer polymeric NPs, which enables the change of the NP sizes using corresponding triggers. ${ }^{33-35}$ In particular, this approach allows the surface modification of NPs derived from polysaccharides, which can be prepared via nanoprecipitation.

There have been many reports focusing on the approaches for the formation, characterization, functionalization, and size control of NPs to promote their applications, for example, in biomedical fields. However, the interaction between these NPs and dispersing solvents and the influence of the solvents on the properties of NPs were mostly neglected. ${ }^{36,37}$ Within this context, the swelling behaviors of polymeric NPs in corresponding dispersing solvents need to be systematically investigated. This not only serves to gather deeper comprehension of their dynamic structure and explore proper methods for size control but also allows us to understand the effect of the surface functionalities on the overall behaviors of polysaccharide-derived NPs, which has rarely been studied.

Herein, we used NPs based on cellulose 10-undecenoyl ester (CUE)-derived polymers for the detailed investigation of their swelling behaviors. The surfaces of these NPs were modified with diverse functional groups, whereas the interior of NPs not. For this purpose, we synthesized a CUE with a degree of substitution of 3 , that is, complete substitution of hydroxyl groups at the cellulose backbone by undecenoyl groups under heterogeneous condition. Then, NPs of CUE were obtained via nanoprecipitation by adding their solution in tetrahydrofuran (THF) into ethanol or methanol as nonsolvents. Because of the presence of $\mathrm{C}=\mathrm{C}$ double bonds of undecenoyl groups, the resulting NPs were further surface-modified with various thiols via a thiol-ene click reaction to endow NPs with diverse surface functionalities. The NPs containing surface-attached functional groups are responsive to specific solvents. The swelling behaviors of the surface-modified NPs were further systematically investigated via adding corresponding swelling solvents to the dispersions, fitting the swelling trends to distinct types of functions and subsequent analysis of the swelling processes.

\section{EXPERIMENTAL SECTION}

Materials. Commercial microcrystalline cellulose (MCC) with a particle size of $50 \mu \mathrm{m}$ and a degree of polymerization of $\sim 275$ and cysteamine (CA, $\geq 98 \%$ ) were purchased from Sigma-Aldrich Chemie GmbH (Steinheim, Germany). 3Mercaptopropionic acid (MPA, $\geq 98 \%$ ) and 1-octadecanethiol (ODT) were purchased from Merck KGaA (Darmstadt, Germany). Pyridine ( $\geq 99 \%)$ was purchased from abcr $\mathrm{GmbH}$ (Karlsruhe, Germany). THF ( $\geq 99 \%)$ was purchased from Bernd Kraft GmbH (Duisburg, Germany). Ethanol ( $\geq 99 \%)$ and methanol $(\geq 99.8 \%)$ were purchased from Th. Geyer $\mathrm{GmbH} \&$ Co. KG (Renningen, Germany). Deionized water was used in all experiments. All chemicals were used without further treatment.

Synthesis of CUE. CUE was synthesized as reported before. ${ }^{11} \mathrm{MCC}$ was first dried at $103{ }^{\circ} \mathrm{C}$ at $10 \mathrm{mbar}$ overnight. Then, $1 \mathrm{~g}$ of dried MCC was mixed with $30 \mathrm{~mL}$ of pyridine in a $100 \mathrm{~mL}$ three-necked flask. The temperature of the mixture was raised to $100{ }^{\circ} \mathrm{C}$ under agitation, and $8.4 \mathrm{~mL}$ of 10 -undecenoyl chloride (corresponding to a molar ratio of 10-undecenoyl chloride to hydroxyl groups in cellulose of $2: 1$ ) was added. The temperature of the mixture was maintained at $100{ }^{\circ} \mathrm{C}$ for $1 \mathrm{~h}$ with agitation. After the reaction, the mixture was added into $200 \mathrm{~mL}$ of methanol, leading to a precipitated product. After the centrifugation of $5000 \mathrm{rpm}$ at $4{ }^{\circ} \mathrm{C}$ for $20 \mathrm{~min}$, the supernatant is discarded and the precipitate was dissolved in a low amount of THF. Purified CUE was obtained after repeated dissolution in THF and precipitation in methanol several times. Finally, CUE was dissolved in THF and stored in dark at $4{ }^{\circ} \mathrm{C}$. The resulting CUE product is well-soluble in THF and dichloromethane, whereas not soluble in ethanol, methanol, or water. $^{11,38,39}$

Formation and Surface Modification of NPs of CUE (CUE-NPs). CUE-NPs were prepared by using a nanoprecipitation dropping technique. ${ }^{40}$ For this purpose, CUE was dissolved in THF at the concentration of $4 \mathrm{mg} / \mathrm{mL}$ (for CUE-NPs-MPA, CUE-NPs-CA in ethanol and methanol dispersants, and CUE-NPs-ODT in methanol dispersant) or $10 \mathrm{mg} / \mathrm{mL}$ (for CUE-NPs-ODT in ethanol dispersant). Then, the THF solutions of CUE were added dropwise to the excess volume of ethanol or methanol (for CUE-NPs-ODT, the volume ratio of ethanol or methanol to the THF solution of CUE was 5:1; for CUE-NPs-MPA and CUE-NPs-CA, the volume ratio of ethanol or methanol to the THF solution of CUE was 10:1) under magnetic stirring of $500 \mathrm{rpm}$ at room temperature, leading to opalescent CUE-NP dispersions. The lower amount of nonsolvent for CUE-NPs-ODT was chosen due to the instable dispersions after the introduction of ODT onto the CUE-NP surface. The $Z$-average diameters and polydispersity index (PDI) of resulting CUE-NPs are listed in Table 1.

Table 1. Z-Average Diameters $(d)$ and PDI of CUE-NPs Fabricated under Diverse Conditions Using the CUE Solution of $5 \mathrm{mg} / \mathrm{mL}$ THF

$\begin{array}{lcccc} & \begin{array}{c}Z \text {-average } \\ d(\mathrm{~nm}) \\ \left(1: 5^{a}\right)\end{array} & \text { PDI }\left(1: 5^{a}\right) & \begin{array}{c}Z \text {-average } \\ d(\mathrm{~nm}) \\ \left(1: 10^{a}\right)\end{array} & \text { PDI }\left(1: 10^{a}\right) \\ \text { dispersant } & 87.8 \pm 0.5^{b} & 0.14 \pm 0.01 & 45.1 \pm 0.3 & 0.05 \pm 0.01 \\ \text { ethanol } & 63.6 \pm 0.2 & 0.07 \pm 0.01 & 39.4 \pm 0.1 & 0.13 \pm 0.01\end{array}$

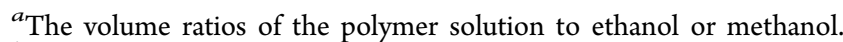

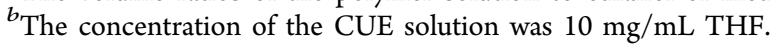

The CUE-NPs were further modified by using a UV-initiated thiol-ene click reaction. ${ }^{41}$ To obtain surface-modified CUENPs, MPA (with a molar ratio of thiol group to double bond of 2:1) or CA (with a molar ratio of thiol group to double bond of $1: 1$ ) or ODT (with a molar ratio of thiol group to double bond of 1:2) was first added to the CUE-NP dispersions. Then, the sample was irradiated with UV light (a wavelength of 320-400 $\mathrm{nm}$ and an intensity of $0.1 \mathrm{~W} \mathrm{~cm}^{-2}$ ) at room temperature for 2 $\mathrm{h}$ (for CUE-NPs-MPA and CUE-NPs-ODT) or $2 \mathrm{~h}$ and 20 min (for CUE-NPs-CA) under agitation. Finally, the subsequent mixture was repeatedly dialyzed for CUE-NPsMPA and CUE-NPs-CA in ethanol or methanol to remove THF and the nonreacted MPA or CA residue, respectively. Because of the instability of CUE-NPs-ODT after the dialysis in ethanol or methanol, no dialysis was employed after surface modification using ODT. To minimize the remaining ODT molecules in the CUE-NPs-ODT dispersion system, only 0.5 
Table 2. Z-Average Diameters $(d)$ and PDI of CUE-NPs Fabricated in Different Dispersants after Surface Modification

\begin{tabular}{llccc}
\multicolumn{1}{c}{ NPs } & dispersant & Z-average $d(\mathrm{~nm})$ & PDI & Z-average $d(\mathrm{~nm})$ after dialysis \\
CUE-NPs-ODT & ethanol & $97.7 \pm 0.3$ & $0.05 \pm 0.01$ & $a$ \\
CUE-NPs-ODT & methanol & $69.7 \pm 0.1$ & $0.06 \pm 0.01$ & $a$ \\
CUE-NPs-MPA & ethanol & $57.4 \pm 0.3$ & $0.02 \pm 0.01$ & $108.8 \pm 0.6$ \\
CUE-NPs-MPA & methanol & $40.3 \pm 0.5$ & $0.13 \pm 0.01$ & $98.8 \pm 0.8$ \\
CUE-NPs-CA & ethanol & $118.9 \pm 1$ & $0.04 \pm 0.01$ & $444.0 \pm 1.6$ \\
CUE-NPs-CA & methanol & $129.2 \pm 1.2$ & $0.09 \pm 0.01$ & $0.02 \pm 0.01$
\end{tabular}

${ }^{a}$ No dialysis was implemented after surface modification.

mol ODT per mole olefin groups was added to the system for the surface modification reaction. The $Z$-average diameters and PDI of NPs after surface modifications are listed in Table 2.

Characterization. Nuclear Magnetic Resonance Spectroscopy. The liquid state ${ }^{1} \mathrm{H}$ and ${ }^{13} \mathrm{C}$ NMR spectroscopy of CUE in deuterated chloroform was obtained by using a Bruker DRX 500 spectrometer (Bruker, BioSpin GmbH; Ettlingen, Germany) with a frequency of $500 \mathrm{MHz}$ for ${ }^{1} \mathrm{H}$ NMR and 125 $\mathrm{MHz}$ for ${ }^{13} \mathrm{C} \mathrm{NMR}$. One hundred fifty scans were collected for ${ }^{1} \mathrm{H}$ NMR spectroscopy, whereas 20000 scans were accumulated for ${ }^{13} \mathrm{C}$ NMR spectroscopy. The repetition delay was $5 \mathrm{~s}$ for ${ }^{1} \mathrm{H}$ NMR and $1 \mathrm{~s}$ for ${ }^{13} \mathrm{C}$ NMR.

Elemental Analysis. Elemental analysis was performed on an elemental analyzer Vario EL III CHN instrument from Elementar (Hanau, Germany). The analyzed results and the amount of ODT, MPA, and CA functional moieties calculated from these results are shown in Table S1.

Dynamic Light Scattering. For the size and size distribution measurement of NPs, the dynamic light scattering (DLS) analysis $^{42-44}$ was implemented on a Zetasizer Nano ZS instrument (Malvern Ltd, UK). The thoroughly cleaned quartz cuvette (Starna, Pfungstadt, Germany) filled with $1 \mathrm{~mL}$ of NP dispersions was used for the measurement. Each sample was scanned three times at $25^{\circ} \mathrm{C}$, and the average values were taken as the final result.

Scanning Electron Microscopy. The images of NPs were obtained by exploiting a scanning electron microscopy (SEM) Leo SUPRA 35 instrument (Carl Zeiss SMT GmbH, Oberkochen, Germany). The samples were prepared by dropping $15 \mu \mathrm{L}$ of diluted NP dispersions on silicon wafers and following drying at room temperature. A layer of carbon (with a maximal thickness of $10 \mathrm{~nm}$ ) was vacuum-coated on the surface of the samples before the observation.

\section{RESULTS AND DISCUSSION}

Synthesis and Formation of NPs. CUE was synthesized by modifying MCC with 10-undecenoyl chloride in pyridine under heterogeneous reaction conditions (Figure 1). ${ }^{11}$ According to the NMR spectrum (Figure S1), 10-undecenoyl groups were successfully introduced into the cellulose chain. Within the ${ }^{13} \mathrm{C}$ NMR spectrum, the signals at 138 and $113 \mathrm{ppm}$ originate from the olefin groups. Three peaks from 170 to 172 ppm are derived from the carbonyl groups at three different positions in the anhydroglucose units. ${ }^{45,46}$ The signals from 20 to $40 \mathrm{ppm}$ are attributed to the other carbons in the 10 undecenoyl groups, whereas the signals between 60 and 120 ppm are ascribed to the carbons of cellulose backbone. ${ }^{46}$ Within the ${ }^{1} \mathrm{H}$ NMR spectrum, the signals at 4.8 and $5.7 \mathrm{ppm}$ are derived from hydrogen within the olefin moiety. The signals from 3.2 to $5.5 \mathrm{ppm}$ (except the signal at $4.8 \mathrm{ppm}$ ) represent hydrogen on the cellulose backbone. The degree of substitution ascribed to 10-undecenoyl groups in CUE was calculated to be

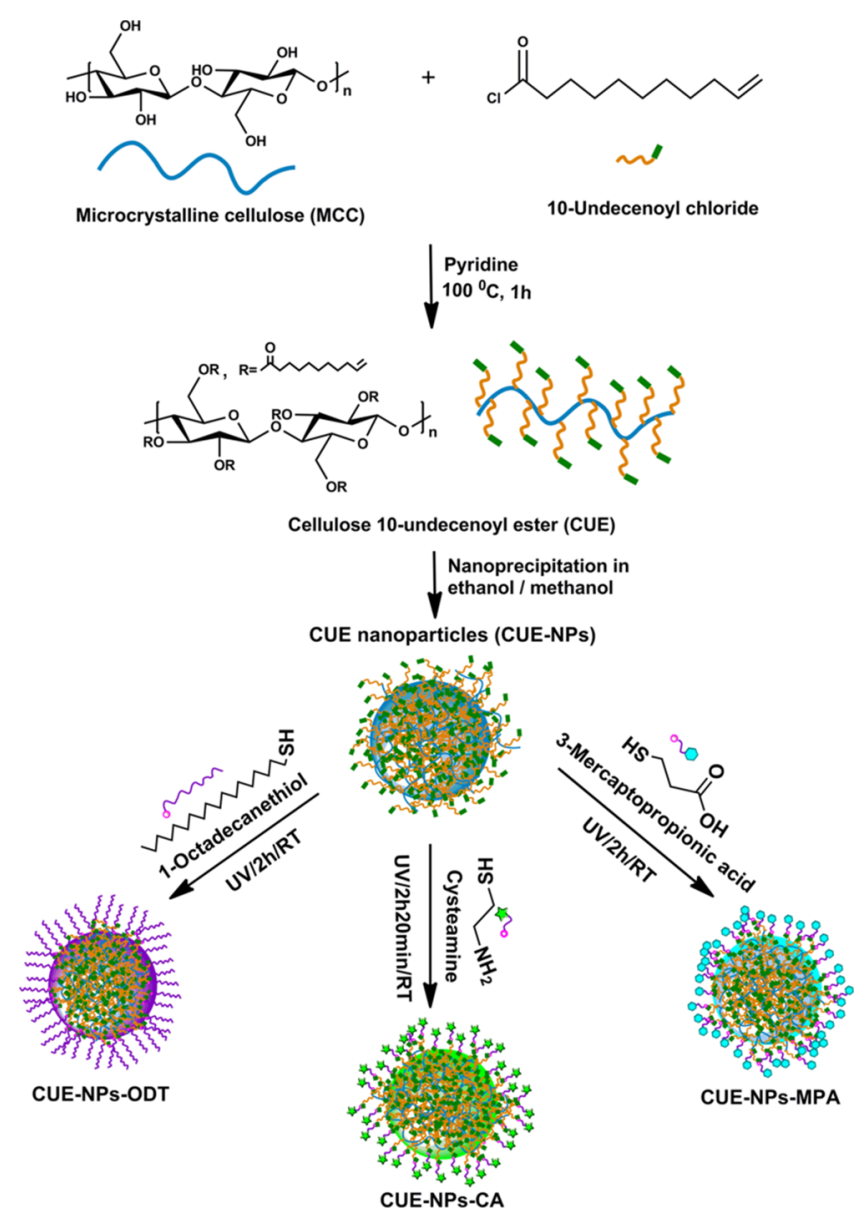

Figure 1. Schematic representation for the synthesis of CUE with a degree of substitution of 3 and the surface modification of the CUENPs prepared via nanoprecipitation.

3 based on the results of the ${ }^{1} \mathrm{H}$ NMR spectrum of CUE (Supporting Information).

CUE-NPs were prepared by exploiting a nanoprecipitation dropping technique. ${ }^{40}$ For this purpose, the CUE solution in THF of 4 or $10 \mathrm{mg} / \mathrm{mL}$ was added drop by drop to excess ethanol or methanol ( 5 or 10 times of the volume of the THF solution) under agitation of $500 \mathrm{rpm}$. The opalescent color of resulting dispersions indicates the formation of CUE-NPs. It should be noted that CUE-NPs can also be made in water dispersion. However, CUE-NPs were more stable when dispersed in methanol or ethanol than in water. Moreover, compared with the most conventional NPs formed in water, we extended the field of nanoprecipitation for the preparation of cellulose-based NPs by exploiting organic solvents as dispersants. 

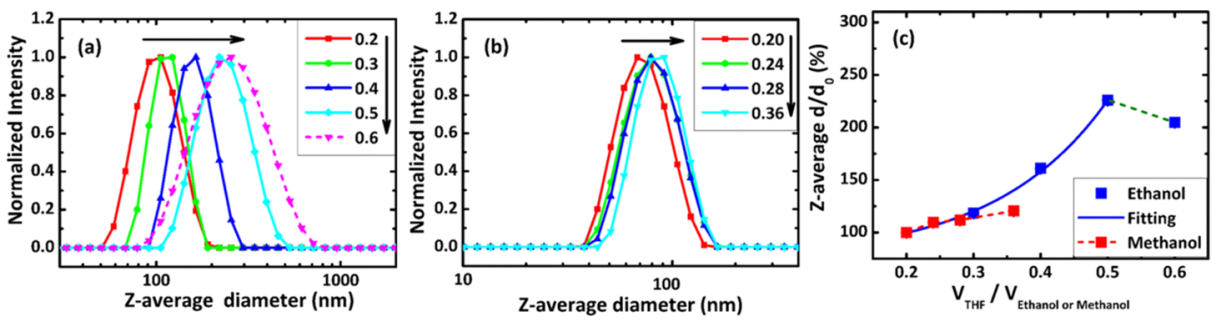

\begin{tabular}{cccc} 
(d) & \multicolumn{4}{l}{} \\
\hline $\mathrm{V}_{\text {THF }} / \mathrm{V}_{\text {Ethanol }}$ & Z-average $\mathrm{d}(\mathrm{nm})$ & $\mathrm{PDI}$ & $\mathrm{d} / \mathrm{d}_{0}(\%)$ \\
\hline 0.2 & $97.7 \pm 0.3$ & $0.05 \pm 0.01$ & $100 \pm 0.1$ \\
0.3 & $115.8 \pm 0.7$ & $0.03 \pm 0.01$ & $118.6 \pm 0.1$ \\
0.4 & $157.4 \pm 1.6$ & $0.02 \pm 0.01$ & $161.2 \pm 0.1$ \\
0.5 & $220.6 \pm 0.6$ & $0.05 \pm 0.01$ & $225.9 \pm 0.1$ \\
0.6 & $200.1 \pm 2.4$ & $0.26 \pm 0.01$ & $204.9 \pm 0.1$ \\
\hline
\end{tabular}

\begin{tabular}{cccc}
\hline \multicolumn{5}{l}{ e) } \\
$\mathrm{V}_{\text {THF }} / \mathrm{V}_{\text {Methanol }}$ & Z-average $\mathrm{d}(\mathrm{nm})$ & $\mathrm{PDI}$ & $\mathrm{d} / \mathrm{d}_{0}(\%)$ \\
\hline 0.2 & $69.7 \pm 0.1$ & $0.06 \pm 0.01$ & $100 \pm 0.1$ \\
0.24 & $76.5 \pm 0.3$ & $0.07 \pm 0.01$ & $109.6 \pm 0.1$ \\
0.28 & $78.0 \pm 0.3$ & $0.05 \pm 0.01$ & $111.9 \pm 0.1$ \\
0.36 & $84.1 \pm 0.5$ & $0.05 \pm 0.01$ & $120.5 \pm 0.1$ \\
\hline
\end{tabular}
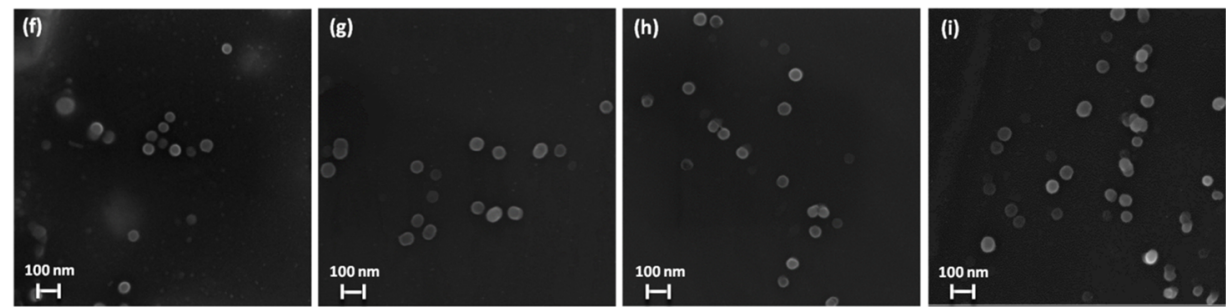

Figure 2. Swelling behavior of CUE-NPs-ODT. $(a, b)$ DLS curves of CUE-NPs-ODT with various volume ratios of THF to ethanol (a) or methanol (b) in dispersant. The numbers in the insets represent the volume ratios of THF to ethanol or methanol in the dispersants. (c) Development of normalized $Z$-average diameters of CUE-NPs-ODT vs the volume ratios of THF to ethanol or methanol in dispersant. (d,e) $Z$ Average diameters, PDI, and normalized Z-average diameters of CUE-NPs-ODT with various volume ratios of THF to ethanol (d) or methanol (e) in dispersant. ( $f, g$ ) Representative SEM images of original CUE-NPs-ODT (f) and swollen CUE-NPs-ODT ( $g$, with the volume ratio of THF/ ethanol of 0.5$)$ in ethanol dispersant. $(h, i)$ Representative SEM images of original CUE-NPs-ODT $(h)$ and swollen CUE-NPs-ODT (i, with the ratio of $\mathrm{THF} / \mathrm{methanol}$ of 0.36 ) in methanol dispersant.

Table 1 shows the $Z$-average diameters and PDI of CUE-NPs fabricated in different dispersants. It is obvious that size distributions of CUE-NPs are quite narrow with PDIs less than 0.15. Moreover, the Z-average diameters of CUE-NPs were highly affected by the concentration of CUE solutions, the dispersant as ethanol or methanol, and the volume ratios of polymer solution/dispersant. Generally, larger NPs are obtained using a lower volume ratio of solution/dispersant for the nanoprecipitation process or a higher concentration of CUE solutions (Table 1). Furthermore, with the same concentration of CUE solutions and the same ratio of dispersant to solution, CUE-NPs formed in ethanol are generally larger than those formed in methanol.

Surface Modifications of CUE-NPs. The CUE-NPs were further modified via a UV-induced thiol-ene click reaction without initiator participation. To obtain NPs with different surface functionalities, three thiols were used for the modification, namely, ODT with a long hydrocarbon chain, MPA with a terminal carboxyl group, and CA with a terminal amino group. The corresponding modified NPs were named CUE-NPs-ODT, CUE-NPs-MPA, and CUE-NPs-CA, respectively (Figure 1). Elemental analysis was performed after dialysis for the determination of the contents of sulfur on the modified NPs, which was used to calculate the amount of ODT, MPA, and CA moieties on the surface-modified NPs. According to the contents of sulfur, the amounts ascribed to ODT, MPA, and CA functional moieties were calculated to be $4.37 \times 10^{-4}$, $3.40 \times 10^{-4}, 7.01 \times 10^{-4} \mathrm{~mol}$ per gram dry NPs, respectively. For the NPs in methanol dispersion, the amounts ascribed to ODT, MPA, and CA functional moieties were calculated to be $3.49 \times 10^{-4}, 2.74 \times 10^{-4}, 3.65 \times 10^{-4}$ mol per gram dry NPs, respectively (Table S1). These values are rather low, considering the degree of substitution of 3 for olefin groups in CUE. Because the amounts of thiols added to the dispersions were sufficient, it can therefore be supposed that only the olefin groups on the surface of the NPs participated in the reaction. In comparison, most of the alkene groups inside the NPs were not accessible toward the UV-induced thiol-ene reaction.

Table 2 exhibits the $Z$-average diameters and PDI of NPs after surface modifications. All NPs maintained their narrow distribution with PDIs less than 0.15. A minor increase in NPs diameter (less than $10 \mathrm{~nm}$ ) is observed for CUE-NPs-ODT and CUE-NPs-MPA compared with those before surface modification. However, CUE-NPs-CA exhibits a much more obvious size increase to $118.9 \pm 1 \mathrm{~nm}$ in ethanol or $129.2 \pm 1.2$ $\mathrm{nm}$ in methanol, which is about three times of those before surface modifications (Table 2). This significant increase should be due to the fact that the modification of NPs in ethanol obtained a higher amount of functional groups than those in methanol (Table S1). As mentioned above, dialysis processes were implemented in ethanol or methanol to remove excess thiols and THF to get pure surface-modified NPs. The sizes of NPs increased after the dialysis processes are shown in Table 2. Swelling could happen during these solvent-changing processes considering that the modified MPA and CA moieties could also have interaction with ethanol or methanol to a certain extent. To eliminate the influence of dialysis process on swelling, our investigation of swelling behaviors was all based on normalized $Z$-average diameters.

Swelling Modes. To investigate swelling behaviors of the surface-modified NPs, various swelling solvents corresponding to the characteristics of the modification moieties were added 

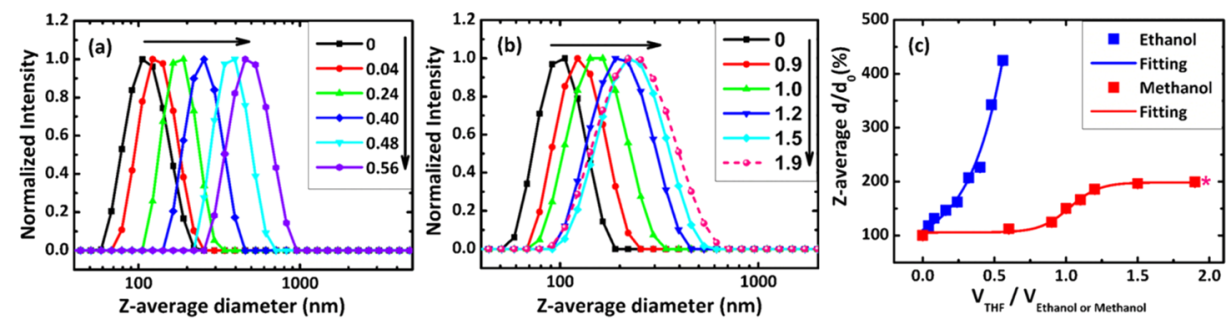

\begin{tabular}{lccc} 
(d) & & & \\
\hline $\mathrm{V}_{\text {THF }} / \mathrm{V}_{\text {Ethanol }}$ & Z-average $\mathrm{d}(\mathrm{nm})$ & $\mathrm{PDI}$ & $\mathrm{d} / \mathrm{d}_{0}(\%)$ \\
\hline 0 & $108.8 \pm 0.6$ & $0.05 \pm 0.01$ & $100 \pm 0.1$ \\
0.04 & $128.1 \pm 0.8$ & $0.04 \pm 0.02$ & $117.7 \pm 0.1$ \\
0.24 & $176.4 \pm 1.7$ & $0.01 \pm 0.01$ & $162.1 \pm 0.1$ \\
0.40 & $246.4 \pm 2.8$ & $0.02 \pm 0.01$ & $226.5 \pm 0.1$ \\
0.48 & $372.8 \pm 3.3$ & $0.01 \pm 0.01$ & $342.7 \pm 0.1$ \\
0.56 & $462.6 \pm 7.4$ & $0.07 \pm 0.01$ & $425.2 \pm 0.1$ \\
\hline
\end{tabular}

\begin{tabular}{cccc}
\hline \multicolumn{5}{l}{$(\mathrm{e})$} & & \\
\hline $\mathrm{V}_{\text {THF }} / \mathrm{V}_{\text {Methanol }}$ & Z-average $\mathrm{d}(\mathrm{nm})$ & $\mathrm{PDI}$ & $\mathrm{d} / \mathrm{d}_{0}(\%)$ \\
\hline 0 & $98.8 \pm 0.8$ & $0.02 \pm 0.01$ & $100 \pm 0.1$ \\
0.9 & $123.7 \pm 0.6$ & $0.05 \pm 0.02$ & $125.2 \pm 0.1$ \\
1.0 & $148.6 \pm 1.7$ & $0.06 \pm 0.01$ & $150.4 \pm 0.1$ \\
1.2 & $183.5 \pm 0.6$ & $0.15 \pm 0.01$ & $185.8 \pm 0.1$ \\
1.5 & $194.1 \pm 0.4$ & $0.22 \pm 0.01$ & $196.5 \pm 0.1$ \\
1.9 & $196.7 \pm 1.4$ & $0.25 \pm 0.01$ & $199.1 \pm 0.1$ \\
\hline
\end{tabular}
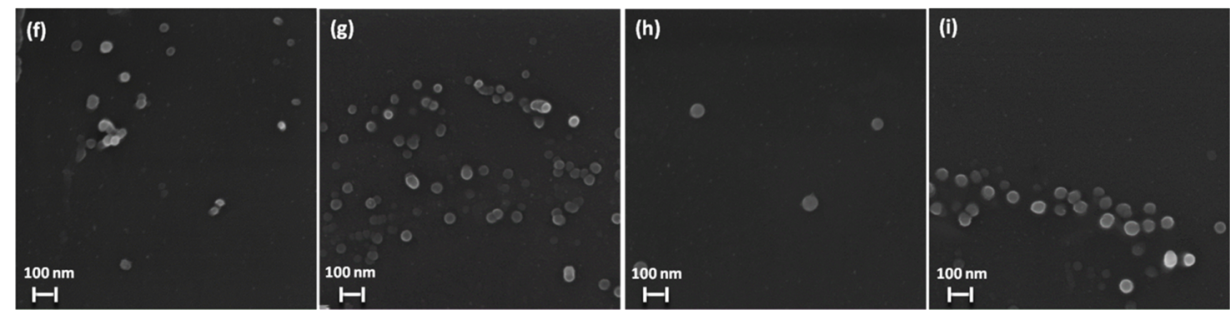

Figure 3. Swelling behavior of CUE-NPs-MPA. (a,b) DLS curves of CUE-NPs-MPA with various volume ratios of THF to ethanol (a) or methanol (b) in dispersant. The numbers in the insets represent the ratios of THF to ethanol and methanol in dispersant. (c) Development of normalized Z-average diameters of CUE-NPs-MPA vs the volume ratios of THF to ethanol or methanol in dispersant. (d,e) Z-Average diameters, PDI, and normalized $Z$-average diameters of CUE-NPs-MPA with various volume ratios of THF to ethanol $(d)$ or methanol $(e)$ in dispersant. $(f, g)$ Representative SEM images of original CUE-NPs-MPA (f) and swollen CUE-NPs-MPA (g, with the volume ratio of THF/ethanol of 0.48) in ethanol dispersant. $(h, i)$ Representative SEM images of original CUE-NPs-MPA $(h)$ and swollen CUE-NPs-MPA (i, with the volume ratio of $\mathrm{THF} /$ methanol of 1.5) in methanol dispersant.

step by step to NP dispersions. The swelling solvents with strong interaction with the functional moieties were chosen, so that a progressive and steady increase of the NP size could be observed and analyzed: THF as the swelling solvent for CUENPs-ODT and CUE-NPs-MPA, whereas $\mathrm{H}_{2} \mathrm{O}$ for CUENPs-CA. This proposal was based on previous reports that CUE, cellulose stearoyl esters (CSEs), and cellulose 11-((3carboxyl)ethylthio)undecanoate (CUE-MPA) can be welldissolved in THF, whereas CUE and CSE have poor solubility in ethanol, methanol, and water. ${ }^{11,40}$ Although cellulose 11-((2aminoethyl)thio) undecanoate (CUE-CA) can be dissolved in methanol and was not able to dissolve in water. ${ }^{11}$ We chose water as a swelling solvent for CUE-NPs-CA, considering that water can interact well with amino groups via hydrogen bond. ${ }^{47}$ DLS analysis was performed to trace the change of particle sizes and size distributions of swollen NPs. Samples were analyzed at least $5 \mathrm{~h}$ later after adding swelling solvents, to ensure that the swelling processes reached equilibrium states.

The swelling behaviors of CUE-NPs-ODT within the mixtures with various ratios of THF to ethanol or methanol are demonstrated based on the DLS analysis (Figure 2). For ethanol dispersion, the $Z$-average diameter of CUE-NPs-ODT increased gradually from 98 to $221 \mathrm{~nm}$ and the PDI remained lower than 0.1, with rising volume ratios of THF/ethanol from 0.2 to 0.5 (Figure $2 \mathrm{a}, \mathrm{d}$ ). With even higher volume ratio of THF/ethanol up to 0.6, the Z-average diameter of CUE-NPsODT decreased but the DLS curves did not shift to the left side and only the size distribution became wider. In particular, the PDI rose to 0.26 simultaneously. These facts indicate an overswelling and even bursting of CUE-NPs-ODT at the high content of THF in the mixture. For methanol dispersion, the $Z$ average diameter of CUE-NPs-ODT increased gradually from 70 to $84 \mathrm{~nm}$ and the PDI remained lower than 0.1, with rising volume ratios of THF/methanol from 0.2 to 0.36 (Figure $2 b, e$ ). The tolerance range of THF fraction in the methanol dispersant was quite small, and the ratio of THF to methanol could only maximally reach 0.36 . When more THF was added to the dispersant, the sample was not proper for DLS analysis. In comparison, the THF content in the ethanol dispersant could reach the volume ratio of THF/ethanol of 0.5 .

To manifest the swelling extent and swelling trend of CUENPs-ODT, normalized $Z$-average diameters of swollen CUE$\mathrm{NPs}-\mathrm{ODT}$ were obtained by dividing the $Z$-average diameters of swollen CUE-NPs-ODT by the original CUE-NPs-ODT right after the surface modification. The development of the normalized average NP diameters depending on the volume ratios of THF to ethanol or methanol was demonstrated in Figure 2c. It is obvious that the swollen extent of CUE-NPsODT in methanol dispersant was quite limited. The $Z$-average diameter only maximally increased to $121 \%$ of that of the original CUE-NPs-ODT. However, CUE-NPs-ODT in ethanol dispersion exhibited a larger swelling extent, and the $Z$-average diameter was able to increase up to $226 \%$ of that of the original CUE-NPs-ODT. The swelling trend line of CUENPs-ODT in ethanol dispersant was fitted with an exponential function (the parameters of the function in the Supporting Information). The $Z$-average diameters of NPs increased with a faster rate when the ratio of THF to ethanol increased. It is supposed that THF can interact well with both the ODTmodified outer part and the interior of CUE-NPs-ODT, 
estimated by the fact that both CUE and CSE have a good solubility in THF. ${ }^{11,40}$ However, the nonpolar ODT moieties at the surface of CUE-NPs-ODT are in a constrictive state surrounded by a lot of polar solvent (ethanol or methanol) in dispersant. Therefore, the free space on the surface is highly limited by the constrictive ODT moieties, which results in a steady increase of the NP sizes during the swelling process with a smaller volume ratio of THF to ethanol (Figure 2c, marked with blue line). When more THF with lower polarity added to the system, the ODT moieties turned into an outstretched state, providing more cavities for THF to penetrate into the interior of CUE-NPs-ODT. Therefore, a rapid growth of NP sizes was demonstrated, when more THF was added to this system during the following stages of the swelling process (Figure 2c).

Figure $2 \mathrm{f}-\mathrm{i}$ shows the SEM images of original and swollen CUE-NPs-ODT in ethanol and methanol. Because all NPs are measured in the dried state, they show similar sizes. This fact confirms that the size evolution of CUE-NPs-ODT during the swelling process truly originated from the swelling solvents, but not from aggregation or other processes. The size of swollen CUE-NPs-ODT recovered after drying, and no depressed area on the surface is visible, which may originate from the fact that the swollen chains in the NPs have the sufficient flexibility to recover after drying.

The swelling behaviors of CUE-NPs-MPA with various volume ratios of THF to ethanol or methanol are demonstrated based on the DLS analysis in Figure 3. For ethanol dispersion, the $Z$-average diameters of CUE-NPs-MPA increased from 109 to $463 \mathrm{~nm}$ with enhancing volume ratios of THF to ethanol from 0 to 0.56 (Figure $3 \mathrm{a}, \mathrm{d}$ ). With even higher THF content in dispersant, the sample became not proper for DLS analysis. The swelling trend line rose until the diameter reached $425 \%$ of that of the original CUE-NPs-MPA (Figure 3c). The swelling trend line of CUE-NPs-MPA was also fitted to an exponential function (the parameters for the function in the Supporting Information), which was similar with that of CUENPs-ODT in ethanol dispersion. However, the swelling extent was much larger, and the increasing rate of the diameters was much faster. Nevertheless, the swelling process could be similar to that of CUE-NPs-ODT, that is, THF interact well with both the MPA-modified surface layer and partly with the interior of CUE-NPs-MPA, indicated by the good solubility of both CUE and CUE-MPA in THF. ${ }^{11}$ At the beginning, only the surfacemodified part was highly swollen because of the interaction between MPA moieties and THF. Subsequently, with the presence of more THF, the interior part also participated in the swelling process.

For methanol dispersion, the swelling of CUE-NPs-MPA was rather weak. The $Z$-average diameters of CUE-NPs-MPA increased from 99 to $124 \mathrm{~nm}$ and the PDI maintained lower than 0.1 , with rising volume ratios of THF to methanol from 0 to 0.9 (Figure $3 \mathrm{~b}, \mathrm{e}$ ). The normalized $Z$-average diameters only increased to $125 \%$ of the original CUE-NPs-MPA (Figure 3c). However, with even higher volume ratios of THF to methanol from 0.9 to 1.2 , the $Z$-average diameters increased rapidly to $184 \mathrm{~nm}$ and the PDI stayed lower than 0.15 . The normalized $Z$ average diameters increased to $186 \%$. After that, the increasing rate of the size of NPs became very slow again. With even higher volume ratios of THF to methanol from 1.2 to 1.5 , the $Z$-average diameters increased only slightly from 184 to $194 \mathrm{~nm}$ and the PDI increased to around 0.2. The normalized $Z$-average diameters increased from $186 \%$ slightly to $196 \%$ of the original
CUE-NPs-MPA. During all the swelling processes of CUENPs-MPA in methanol with rising volume ratios of THF/ methanol from 0 to 1.5 , the DLS curves shifted gradually to the right side with larger sizes. Thus, the swelling trend line of CUE-NPs-MPA in methanol is totally different than that of CUE-NPs-MPA in ethanol. Instead of swelling in an exponential mode, the swelling trend line of CUE-NPs-MPA in methanol showed an S-shape curve (Figure 3c) and was fitted to a characteristic sigmoid function (parameters of the function in the Supporting Information).

However, when the volume ratio of $\mathrm{THF} / \mathrm{methanol}$ increased further to 1.9, the DLS curve maintained almost at the same place. The Z-average diameter of CUE-NPs-MPA increased only slightly from 194 to $197 \mathrm{~nm}$ and the PDI increased to 0.25 . For even higher content of THF in the dispersant, the sample was too polydisperse for the analysis. For the sigmoid increase of the normalized average size of CUENPs-MPA in methanol dispersant, it was assumed that at the beginning, it was more difficult for THF to permeate into the NPs. On one hand, the interaction between THF and MPAmodified surface part is not as strong as that between THF and the nonpolar long alkane chains. ${ }^{40,48}$ On the other hand, the NPs formed in methanol dispersant would be tighter in the structure, which could be deduced from the fact that using the same preparation conditions, including the same concentration of CUE solution in THF, the same ratio of THF to ethanol or methanol, and the same agitation rate, and the CUE-NPs formed in ethanol generally have bigger sizes than those formed in methanol (Table 1). This phenomenon may originate from the fact that the viscosity of methanol is smaller than that of ethanol $\left(0.54\right.$ vs 1.07 at $\left.25{ }^{\circ} \mathrm{C}\right)$. During the process of nanoprecipitation, THF (with a viscosity of 0.46 at $25^{\circ} \mathrm{C}$ ) ${ }^{48}$ in the CUE solution can diffuse faster in methanol than in ethanol, resulting in CUE-NPs with a tighter structure. This phenomenon that higher viscosity leads to larger NPs during nanoprecipitation has also been observed for other polymers. $12,49-51$

During the swelling processes in methanol dispersant, THF probably need to overcome a "barrier" at the starting stage and the swelling rate is rather slow. After that, the rate was much faster because the NP became loose enough for THF to penetrate in. After this phase, the swelling rate turned to be slow again owing to the saturation of the cavities in CUE-NPsMPA. Noticeably, the swelling extent of CUE-NPs-MPA in ethanol dispersant was much larger than that in methanol dispersant: $425 \%$ of original CUE-NPs-MPA for ethanol dispersant compared with $197 \%$ for methanol dispersant. As comparison, the swelling extent of CUE-NPs-ODT in ethanol dispersant was also larger than that in methanol dispersant, $226 \%$ versus $121 \%$ of original CUE-NPs-ODT. This phenomenon indicates different structures within the CUENPs formed in ethanol and methanol dispersions. During the nanoprecipitation process, ethanol with a higher viscosity provides lower speed for THF to diffuse out of the initial particles that were formed instantly after dropping. ${ }^{12,16,49}$ Therefore, CUE-NPs will be formed more slowly than those in methanol, which should provide more possibilities for the entanglement of polymer chains and therefore higher entanglement densities within NPs. Higher entanglement densities could make the NPs more rigid in structure and thus could result in larger swelling extent before the bursting of NPs, because the surface functionalities are still the same for CUE-NPs-MPA. 

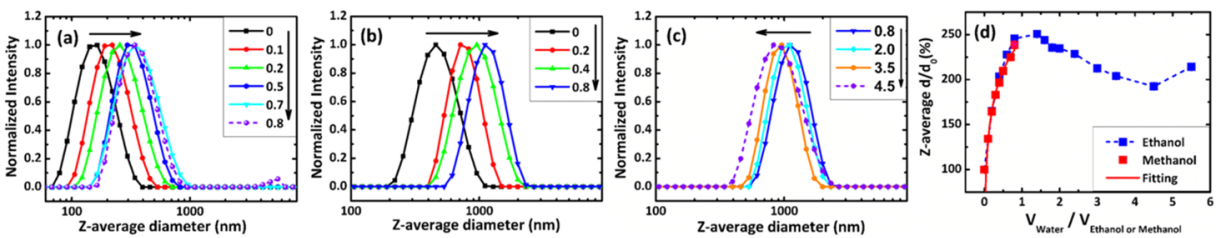

\begin{tabular}{cccc}
\multicolumn{5}{l}{ (e) } \\
\hline $\mathrm{V}_{\text {water }} / \mathrm{N}_{\text {Methanol }}$ & Z-averaged $(\mathrm{nm})$ & $\mathrm{PDI}$ & $\mathrm{d} / \mathrm{d}_{0}(\%)$ \\
\hline 0 & $150.6 \pm 0.6$ & $0.11 \pm 0.02$ & $100 \pm 0.1$ \\
0.1 & $202.2 \pm 2.1$ & $0.12 \pm 0.03$ & $134.3 \pm 0.1$ \\
0.2 & $247.3 \pm 2.3$ & $0.12 \pm 0.01$ & $164.2 \pm 0.1$ \\
0.5 & $315.6 \pm 2.5$ & $0.10 \pm 0.02$ & $209.6 \pm 0.1$ \\
0.7 & $338.6 \pm 4.0$ & $0.12 \pm 0.03$ & $224.8 \pm 0.1$ \\
0.8 & $358.9 \pm 3.5$ & $0.15 \pm 0.02$ & $238.3 \pm 0.1$ \\
\hline
\end{tabular}

\begin{tabular}{cccc} 
(f) \\
\hline $\mathrm{V}_{\text {water }} / \mathrm{V}_{\text {Ethanol }}$ & Z-averaged $(\mathrm{nm})$ & $\mathrm{PDI}$ & $\mathrm{d} / \mathrm{d}_{0}(\%)$ \\
\hline 0 & $444.0 \pm 1.6$ & $0.07 \pm 0.02$ & $100 \pm 0.1$ \\
0.2 & $732.8 \pm 12.3$ & $0.06 \pm 0.02$ & $165.1 \pm 0.1$ \\
0.4 & $902.4 \pm 12.0$ & $0.07 \pm 0.03$ & $203.2 \pm 0.1$ \\
0.8 & $1090 \pm 22.9$ & $0.07 \pm 0.02$ & $245.5 \pm 0.1$ \\
2.0 & $1042 \pm 22.8$ & $0.04 \pm 0.02$ & $234.7 \pm 0.1$ \\
3.5 & $905.7 \pm 3.7$ & $0.05 \pm 0.03$ & $204.0 \pm 0.1$ \\
4.5 & $854.2 \pm 14.7$ & $0.06 \pm 0.04$ & $192.4 \pm 0.1$ \\
\hline
\end{tabular}
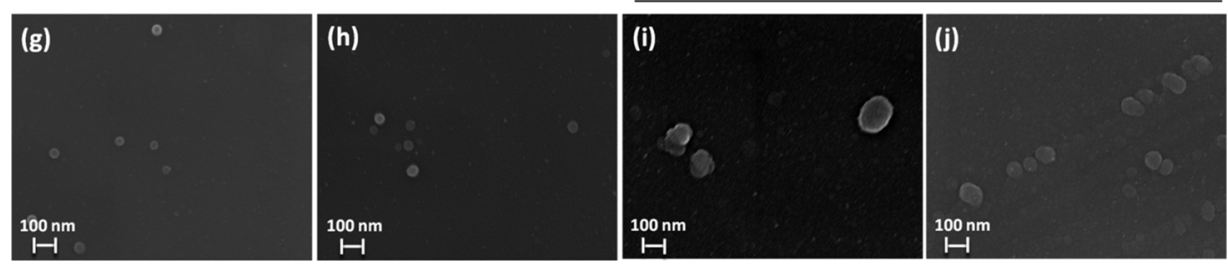

Figure 4. Swelling and shrinking behavior of CUE-NPs-CA. (a) DLS curves of CUE-NPs-CA with various volume ratios of $\mathrm{H}_{2} \mathrm{O}$ to methanol in dispersant. $(b, c)$ DLS curves of CUE-NPs-CA with various volume ratios of $\mathrm{H}_{2} \mathrm{O}$ to ethanol in dispersant between $0-0.8$ (b) and $0.8-4.5$ (c). The numbers in the insets represent the ratio of $\mathrm{H}_{2} \mathrm{O}$ to methanol or ethanol in dispersant. (d) Development of normalized $Z$-average diameters of CUENPs-CA vs the volume ratios of $\mathrm{H}_{2} \mathrm{O}$ to ethanol or methanol in dispersant. (e,f) $Z$-average diameters, $\mathrm{PDI}$, and normalized $Z$-average diameters of CUE-NPs-CA with various volume ratios of $\mathrm{H}_{2} \mathrm{O}$ to methanol (e) or ethanol (f) in dispersant. (g,h) Representative SEM images of original CUENPs-CA (g) and swollen CUE-NPs-CA ( $h$, with the volume ratio of $\mathrm{H}_{2} \mathrm{O}$ /methanol of 0.6 ) in methanol dispersant. (i,j) Representative SEM images of original CUE-NPs-CA (i) and swollen CUE-NPs-CA ( $j$, with the volume ratio of $\mathrm{H}_{2} \mathrm{O}$ /ethanol of 0.6) in ethanol.

However, the tolerant capacity of THF for CUE-NPs-MPA in methanol was much better than that in ethanol. A volume ratio of THF to methanol of up to 1.9 was still possible for stable CUE-NPs-MPA dispersion, whereas the highest volume ratio of THF to ethanol was only 0.56 for the stable CUENPs-MPA dispersion in ethanol. These phenomena jointly showed that the swelling of NPs was not only dependent on the ratio of swelling solvent in the dispersant but also the inherent nature of both the dispersant and the NPs. Figure $3 \mathrm{f}-\mathrm{i}$ shows the SEM images of original and swollen CUE-NPs-MPA in ethanol and methanol. Similar to CUE-NPs-ODT, all NPs exhibited similar sizes after drying and no depressed area on the surface is visible for swollen CUE-NPs-MPA.

The swelling behaviors of CUE-NPs-CA with various ratios of water to ethanol or methanol with corresponding DLS data are exhibited in Figure 4. For methanol dispersion, the $Z$ average diameter of CUE-NPs-CA increased from 151 to 339 $\mathrm{nm}$ and the PDI remained around 0.1, with rising volume ratios of $\mathrm{H}_{2} \mathrm{O}$ to methanol from 0 to 0.7 (Figure $4 \mathrm{a}, \mathrm{e}$ ). With further increasing the volume ratio of $\mathrm{H}_{2} \mathrm{O}$ to methanol up to 0.8 , the DLS curve did not shift to the right side, whereas a new small peak revealed at around $5000 \mathrm{~nm}$. This new peak indicates the presence of aggregates. Thus, the content of $\mathrm{H}_{2} \mathrm{O}$ in the stable NP dispersion could only be elevated up to the volume ratio of 0.7 , and the $Z$-average diameter became $225 \%$ of original CUENPs-CA (Figure 4d,e).

For ethanol dispersion, the $Z$-average diameter of CUENPs-CA increased from 444 to $1090 \mathrm{~nm}$ and the PDI remained below 0.1, with rising volume ratios of $\mathrm{H}_{2} \mathrm{O}$ to ethanol from 0 to 0.8 (Figure $4 \mathrm{~b}, \mathrm{f}$ ). The $Z$-average diameter became $246 \%$ of original CUE-NPs-CA (Figure 4d,f). With further rising the volume ratio of $\mathrm{H}_{2} \mathrm{O}$ to ethanol from 0.8 to 4.5 , the $Z$-average diameter of CUE-NPs-CA decreased gradually from 1090 to $854 \mathrm{~nm}$ and the PDI remained below 0.1 (Figure 4c). The normalized $Z$-average diameter shrank slightly from 246 to $192 \%$ of the original CUE-NPs-CA.

The swelling trend lines of CUE-NPs-CA in both ethanol and methanol dispersant proceeded similarly in a logarithmic way. The swelling mode in ethanol dispersant was fitted to a logarithmic function (the parameters of the function in the Supporting Information). The swelling rate became slower and slower with increasing content of $\mathrm{H}_{2} \mathrm{O}$ in dispersant, which is completely different from that of CUE-NPs-ODT and CUENPs-MPA in ethanol. This difference might originate from the fact that the interaction between $\mathrm{H}_{2} \mathrm{O}$ and surface-attached amino groups of CUE-NPs-CA is strong via hydrogen bond, ${ }^{47}$ whereas the interaction between $\mathrm{H}_{2} \mathrm{O}$ and the interior part of CUE-NPs-CA is not preferred, predicted from the poor solubility of CUE in $\mathrm{H}_{2} \mathrm{O}$. ${ }^{11}$ Therefore, $\mathrm{H}_{2} \mathrm{O}$ can penetrate into and swell the layers containing CA groups. This process will proceed until all possible amino groups underwent the interaction with water molecules. The interaction between the nonmodified interior part of the NPs and $\mathrm{H}_{2} \mathrm{O}$ is negligible, and the swelling rate became slower again. Finally, the maximal swelling extents of CUE-NPs-CA in ethanol and methanol dispersions were almost the same comparing the normalized diameters (Figure 4d-f).

However, too much water in methanol dispersion caused significant aggregation of CUE-NPs-CA. In contrast, more water could be added into the ethanol dispersant while maintaining the NP dispersion stable. The presence of high amount of water resulted in continuous shrinking of CUENPs-CA. According to SEM images of original and swollen CUE-NPs-CA shown in Figure $4 \mathrm{~g}-\mathrm{j}$, the size of swollen CUENPs-CA in methanol dispersant did not vary significantly compared with the original ones. For CUE-NPs-CA in ethanol 


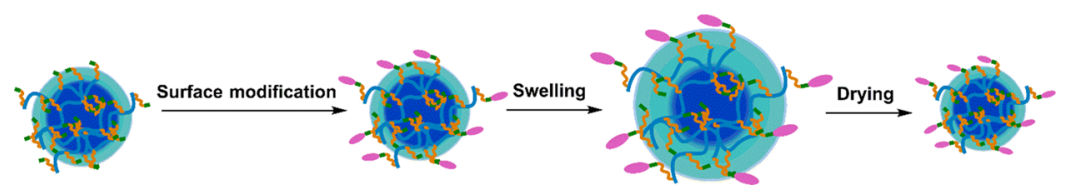

Figure 5. Schematic illustration for the evolution of surface-modified CUE-NPs during swelling and drying process. Elliptic symbols: functional groups introduced on the NP surface via the thiol-ene reactions.

dispersant, a slight deformation was observed for both original and swollen NPs after drying. This should be due to larger sizes of the original CUE-NPs-CA in ethanol, which already have been swollen right after the dialysis following the surface modification (Table 2) and were partially deformed during drying.

Thus, these diverse swelling modes of CUE-NPs-ODT, CUE-NPs-MPA, and CUE-NPs-CA indicate that different interactions including hydrogen bond interaction between swelling solvents and modified outer layers of NPs as well as nonmodified interior parts of NPs are the key factors affecting the swelling processes of polymeric NPs. Primarily, even the surface functionalities on NPs resulting in different exterior constituents provide possibilities to modify swelling behaviors of polymeric NPs and to change their responsive properties against diverse solvents. A general overview about the swelling process of these surface-modified NPs can thus be illustrated as in Figure 5. Moreover, the dispersing medium can strongly affect the swelling processes of NPs. The physical structural difference within NPs, originating from nanoprecipitation processes by using different dispersants, also plays a role for varied swelling modes of NPs. The swelling extents and tolerant capacities of swelling solvents depend not only on the various interactions between swelling solvents and different parts of NPs but also on the inherent nature of the dispersants and the surface functionalities of NPs. Such surface-modified functional NPs will find diverse applications in distinct fields, for example, for the separation of miscible solvents according to their swelling behaviors, as the delivery system in biological fields and also in other colloidal systems, or as a nanoabsorber for the removal of certain components. On the basis of our results shown above, the factors influencing the swelling processes and a proper combination of starting polymers, dispersing solvents, and swelling solvents need to be considered as total to fit a certain application surrounding. All of the results acquired here open a window for further investigation of the readily dynamic characters of polymeric NPs as colloids and their specific behaviors under distinct conditions. This includes the questions, such as how polymeric NPs via nanoprecipitation are formed, how such polymeric NPs really look like, and how to control their properties. ${ }^{12,24,52,53}$ These aspects are of great importance for not only the theoretical progress but also broader applications of NPs. ${ }^{4,17,24}$

\section{CONCLUSIONS}

In conclusion, we successfully prepared diverse surfacemodified NPs via nanoprecipitation and subsequent thiolene click reaction. We extended the nanoprecipitation approach for the preparation of cellulose-based NPs by using organic solvents as dispersants. Their unique responsive swelling behaviors against distinct solvents were systematically investigated via adding corresponding swelling solvents to respective dispersions, fitting the swelling modes with particular functions, and analyzing the factors influencing the swelling processes. It is found that these surface-modified NPs in different dispersants have disparate swelling modes. The different interactions including hydrogen bond interaction between swelling solvents and surface-modified layers as well as the nonmodified interior parts of NPs are crucial factors for their specific swelling modes. Various physical structures of NPs formed in different dispersants using ethanol or methanol also play a role. Furthermore, the swelling extent and the tolerant capacity of swelling solvents can vary in a large range regarding to functional moieties on modified NPs and dispersants for these NPs, which depend on the inherent physical characters of dispersants and NPs as well as the interaction between them. The understanding about the swelling behaviors of polymeric NPs derived from cellulose derivatives would intrigue the interest for the further exploration of physical characteristics of such NPs, which is of great importance for promoting both the theoretical progress and broad applications of NPs.

\section{ASSOCIATED CONTENT}

\section{S Supporting Information}

The Supporting Information is available free of charge on the ACS Publications website at DOI: 10.1021/acs.jpcc.7b11521.

Detailed information about NMR spectrum of synthesized CUE, elemental analysis results of surface-modified CUE-NPs, the viscosity and refractive index of diverse dispersions of surface-modified CUE-NPs for DLS analysis, and fitting functions of different swelling modes (PDF)

\section{AUTHOR INFORMATION}

\section{Corresponding Author}

*E-mail: kzhang1@uni-goettingen.de. Phone: +49-551-394505. ORCID $\odot$

Kai Zhang: 0000-0002-5783-946X

Notes

The authors declare no competing financial interest.

\section{ACKNOWLEDGMENTS}

K.Z. thanks Fonds der Chemischen Industrie (FCI) and GeorgAugust-University of Goettingen for the start-up funding as well as Anschubfinanzierung (Funding for the Promotion of Young Academics of University of Goettingen) for the financial support. J.W. appreciates the financial support provided by China Scholarship Council (CSC) for her $\mathrm{PhD}$ grant. We gratefully thank Ralf Gerke from Institute of Organic and Biomolecular Chemistry in Georg-August-University of Goettingen for providing kind help for the measurement of refractive index of mixed solvents.

\section{REFERENCES}

(1) Karimi, M.; Zangabad, P. S.; Baghaee-Ravari, S.; Ghazadeh, M.; Mirshekari, H.; Hamblin, M. R. Smart Nanostructures for Cargo 
Delivery: Uncaging and Activating by Light. J. Am. Chem. Soc. 2017, 139, 4584-4610.

(2) Obst, K.; et al. Protein Corona Formation on Colloidal Polymeric Nanoparticles and Polymeric Nanogels: Impact on Cellular Uptake, Toxicity, Immunogenicity, and Drug Release Properties. Biomacromolecules 2017, 18, 1762-1771.

(3) Allen, T. M.; Cullis, P. R. Drug Delivery Systems: Entering the Mainstream. Science 2004, 303, 1818-1822.

(4) Langer, R. Drug Delivery and Targeting. Nature 1998, 392, 5-10.

(5) Liu, Z.; Jiao, Y.; Wang, Y.; Zhou, C.; Zhang, Z. PolysaccharidesBased Nanoparticles as Drug Delivery Systems. Adv. Drug Delivery Rev. 2008, 60, 1650-1662.

(6) Nitta, S.; Numata, K. Biopolymer-Based Nanoparticles for Drug/ Gene Delivery and Tissue Engineering. Int. J. Mol. Sci. 2013, 14, $1629-1654$.

(7) Boddohi, S.; Kipper, M. J. Engineering Nanoassemblies of Polysaccharides. Adv. Mater. 2010, 22, 2998-3016.

(8) Klemm, D.; Heublein, B.; Fink, H.-P.; Bohn, A. Cellulose: Fascinating Biopolymer and Sustainable Raw Material. Angew. Chem., Int. Ed. 2005, 44, 3358-3393.

(9) Vauthier, C.; Bouchemal, K. Methods for the Preparation and Manufacture of Polymeric Nanoparticles. Pharm. Res. 2009, 26, 10251058.

(10) Stainmesse, S.; Orecchioni, A.-M.; Nakache, E.; Puisieux, F.; Fessi, H. Formation and Stabilization of a Biodegradable Polymeric Colloidal Suspension of Nanoparticles. Colloid Polym. Sci. 1995, 273, 505-511.

(11) Wang, Y.; Heinze, T.; Zhang, K. Stimuli-Responsive Nanoparticles from Ionic Cellulose Derivatives. Nanoscale 2016, 8, 648657.

(12) Aschenbrenner, E.; Bley, K.; Koynov, K.; Makowski, M.; Kappl, M.; Landfester, K.; Weiss, C. K. Using the Polymeric Ouzo Effect for the Preparation of Polysaccharide-Based Nanoparticles. Langmuir 2013, 29, 8845-8855.

(13) Hornig, S.; Heinze, T.; Hesse, S.; Liebert, T. Novel Nanoparticles Based on Dextran Esters with Unsaturated Moieties. Macromol. Rapid Commun. 2005, 26, 1908-1912.

(14) Liebert, T.; Hornig, S.; Hesse, S.; Heinze, T. Nanoparticles on the Basis of Highly Functionalized Dextrans. J. Am. Chem. Soc. 2005, 127, 10484-10485.

(15) Vitale, S. A.; Katz, J. L. Liquid Droplet Dispersions Formed by Homogeneous Liquid-Liquid Nucleation: "The Ouzo Effect". Langmuir 2003, 19, 4105-4110.

(16) Aubry, J.; Ganachaud, F.; Addad, J.-P. C.; Cabane, B. Nanoprecipitation of Polymethylmethacrylate by Solvent Shifting: 1 . Boundaries. Langmuir 2009, 25, 1970-1979.

(17) Brick, M. C.; Palmer, H. J.; Whitesides, T. H. Formation of Colloidal Dispersions of Organic Materials in Aqueous Media by Solvent Shifting. Langmuir 2003, 19, 6367-6380.

(18) Van Keuren, E.; Georgieva, E.; Adrian, J. Kinetics of the Formation of Organic Molecular Nanocrystals. Nano Lett. 2001, 1, 141-144.

(19) Schrade, A.; Cao, Z.; Landfester, K.; Ziener, U. Preparation of Raspberry-Like Nanocapsules by the Combination of Pickering Emulsification and Solvent Displacement Technique. Langmuir 2011, 27, 6689-6700.

(20) Lepeltier, E.; Bourgaux, C.; Couvreur, P. Nanoprecipitation and the "Ouzo Effect": Application to Drug Delivery Devices. Adv. Drug Delivery Rev. 2014, 71, 86-97.

(21) Bilati, U.; Allémann, E.; Doelker, E. Development of a Nanoprecipitation Method Intended for the Entrapment of Hydrophilic Drugs into Nanoparticles. Eur. J. Pharm. Sci. 2005, 24, 67-75.

(22) Kulterer, M. R.; Reischl, M.; Reichel, V. E.; Hribernik, S.; Wu, M.; Köstler, S.; Kargl, R.; Ribitsch, V. Nanoprecipitation of Cellulose Acetate Using Solvent/Nonsolvent Mixtures as Dispersive Media. Colloids Surf., A 2011, 375, 23-29.

(23) Kulterer, M. R.; Reichel, V. E.; Kargl, R.; Köstler, S.; Sarbova, V.; Heinze, T.; Stana-Kleinschek, K.; Ribitsch, V. Functional Poly- saccharide Composite Nanoparticles from Cellulose Acetate and Potential Applications. Adv. Funct. Mater. 2012, 22, 1749-1758.

(24) Lince, F.; Marchisio, D. L.; Barresi, A. A. Strategies to Control the Particle Size Distribution of Poly-Epsilon-Caprolactone Nanoparticles for Pharmaceutical Applications. J. Colloid Interface Sci. 2008, 322, 505-515.

(25) Kulkarni, S. A.; Feng, S.-S. Effects of Particle Size and Surface Modification on Cellular Uptake and Biodistribution of Polymeric Nanoparticles for Drug Delivery. Pharm. Res. 2013, 30, 2512-2522.

(26) Gaitzsch, J.; Appelhans, D.; Wang, L.; Battaglia, G.; Voit, B. Synthetic Bio-Nanoreactor: Mechanical and Chemical Control of Polymersome Membrane Permeability. Angew. Chem., Int. Ed. 2012, $51,4448-4451$.

(27) Shang, L.; Nienhaus, K.; Nienhaus, G. Engineered Nanoparticles Interacting with Cells: Size Matters. J. Nanobiotechnol. 2014, 12, 5.

(28) Blanazs, A.; Massignani, M.; Battaglia, G.; Armes, S. P.; Ryan, A. J. Tailoring Macromolecular Expression at Polymersome Surfaces. Adv. Funct. Mater. 2009, 19, 2906-2914.

(29) Broz, P.; Driamov, S.; Ziegler, J.; Ben-Haim, N.; Marsch, S.; Meier, W.; Hunziker, P. Toward Intelligent Nanosize Bioreactors: A PH-Switchable, Channel-Equipped, Functional Polymer Nanocontainer. Nano Lett. 2006, 6, 2349-2353.

(30) Hsiue, G.-H.; Hsu, S.-H.; Yang, C.-C.; Lee, S.-H.; Yang, I. K. Preparation of Controlled Release Ophthalmic Drops, for Glaucoma Therapy Using Thermosensitive Poly-N-isopropylacrylamide. Biomaterials 2002, 23, 457-462.

(31) Anwar, N.; Willms, T.; Grimme, B.; Kuehne, A. J. C. LightSwitchable and Monodisperse Conjugated Polymer Particles. ACS Macro Lett. 2013, 2, 766-769.

(32) Ku, K. H.; Shin, J. M.; Kim, M. P.; Lee, C.-H.; Seo, M.-K.; Yi, G.R.; Jang, S. G.; Kim, B. J. Size-Controlled Nanoparticle-Guided Assembly of Block Copolymers for Convex Lens-Shaped Particles. J. Am. Chem. Soc. 2014, 136, 9982-9989.

(33) Wu, T.; Zou, G.; Hu, J.; Liu, S. Fabrication of Photoswitchable and Thermotunable Multicolor Fluorescent Hybrid Silica Nanoparticles Coated with Dye-Labeled Poly(N-Isopropylacrylamide) Brushes. Chem. Mater. 2009, 21, 3788-3798.

(34) Kim, S.-H.; Shum, H. C.; Kim, J. W.; Cho, J.-C.; Weitz, D. A. Multiple Polymersomes for Programmed Release of Multiple Components. J. Am. Chem. Soc. 2011, 133, 15165-15171.

(35) Lee, S. M.; Bae, Y. C. Swelling Behaviors of Doubly Thermosensitive Core-Shell Nanoparticle Gels. Macromolecules 2014, 47, 8394-8403.

(36) Chatrabhuti, S.; Chirachanchai, S. Chitosan Core-Corona Nanospheres: A Convenient Material to Tailor $\mathrm{PH}$ and Solvent Responsive Magnetic Nanoparticles. Polymer 2013, 54, 4318-4324.

(37) Katsura, C.; Nobukawa, S.; Sugimoto, H.; Nakanishi, E.; Inomata, K. Solvent-Responsive Coloring Behavior of Colloidal Crystal Films Consisting of Cross-Linked Polymer Nanoparticles. Colloid Polym. Sci. 2017, 295, 1709-1715.

(38) Hansen, C. M. The Universality of the Solubility Parameters. Ind. Eng. Chem. Prod. Res. Dev. 1969, 8, 2.

(39) Van Krevelen, D. W. Properties of Polymers; Elsevier: Amsterdam, The Netherlands, 2009.

(40) Zhang, K.; Geissler, A.; Heinze, T. Reversibly Crystalline Nanoparticles from Cellulose Alkyl Esters via Nanoprecipitation. Part. Part. Syst. Charact. 2015, 32, 258-266.

(41) Lowe, A. B. Thiol-Ene "Click" Reactions and Recent Applications in Polymer and Materials Synthesis. Polym. Chem. 2010, 1, 17-36.

(42) Hassan, P. A.; Rana, S.; Verma, G. Making Sense of Brownian Motion: Colloid Characterization by Dynamic Light Scattering. Langmuir 2015, 31, 3-12.

(43) Meng, Z.; Hashmi, S. M.; Elimelech, M. Aggregation Rate and Fractal Dimension of Fullerene Nanoparticles via Simultaneous Multiangle Static and Dynamic Light Scattering Measurement. J. Colloid Interface Sci. 2013, 392, 27-33. 
(44) Lim, J.; Yeap, S. P.; Che, H. X.; Low, S. C. Characterization of Magnetic Nanoparticle by Dynamic Light Scattering. Nanoscale Res. Lett. 2013, 8, 381.

(45) Dais, P.; Perlin, A. S. Assignment of the O-Acetyl Carbonyl Carbon Atoms of Cellulose Triacetate via 2d Long-Range ProtonCarbon Chemical-Shift-Correlation Data. Carbohydr. Res. 1988, 181, 233-235.

(46) Meng, X.; Matson, J. B.; Edgar, K. J. Olefin Cross-Metathesis as a Source of Polysaccharide Derivatives: Cellulose $\omega$-Carboxyalkanoates. Biomacromolecules 2014, 15, 177-187.

(47) Sterpone, F.; Stirnemann, G.; Hynes, J. T.; Laage, D. Water Hydrogen-Bond Dynamics around Amino Acids: The Key Role of Hydrophilic Hydrogen-Bond Acceptor Groups. J. Phys. Chem. B 2010, 114, 2083-2089.

(48) Lide, D. R. CRC Handbook of Chemistry and Physics, 85th ed.; CRC Press: Boca Raton, FL, 2004.

(49) Thioune, O.; Fessi, H.; Devissaguet, J. P.; Puisieux, F. Preparation of Pseudolatex by Nanoprecipitation: Influence of the Solvent Nature on Intrinsic Viscosity and Interaction Constant. Int. J. Pharm. 1997, 146, 233-238.

(50) Dong, Y.; Feng, S.-S. Methoxy Poly(ethylene glycol)-Poly(lactide) (MPEG-PLA) Nanoparticles for Controlled Delivery of Anticancer Drugs. Biomaterials 2004, 25, 2843-2849.

(51) Mistlberger, G.; Koren, K.; Scheucher, E.; Aigner, D.; Borisov, S. M.; Zankel, A.; Pölt, P.; Klimant, I. Multifunctional Magnetic Optical Sensor Particles with Tunable Sizes for Monitoring Metabolic Parameters and as a Basis for Nanotherapeutics. Adv. Funct. Mater. 2010, 20, 1842-1851.

(52) Beck-Broichsitter, M.; Rytting, E.; Lebhardt, T.; Wang, X.; Kissel, T. Preparation of Nanoparticles by Solvent Displacement for Drug Delivery: A Shift in the "Ouzo Region" Upon Drug Loading. Eur. J. Pharm. Sci. 2010, 41, 244-253.

(53) Müller, R. H.; Radtke, M.; Wissing, S. A. Solid Lipid Nanoparticles (SLN) and Nanostructured Lipid Carriers (NLC) in Cosmetic and Dermatological Preparations. Adv. Drug Delivery Rev. 2002, 54, S131-S155. 
Supporting Information

Modular Adjustment of Swelling Behaviors of Surface-Modified SolventResponsive Polymeric Nanoparticles Based on Cellulose 10-Undecenoyl Ester

Jiaxiu Wangt, Kai Zhang ${ }^{*}$

+ Wood Technology and Wood Chemistry, Georg-August-University of Goettingen, Büsgenweg 4, D-37077 Göttingen, Germany.

${ }^{*}$ Corresponding author

Tel: +49-551-394505

E-mail:kzhang1@uni-goettingen.de 


\section{NMR spectroscopy}

(a)

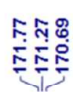

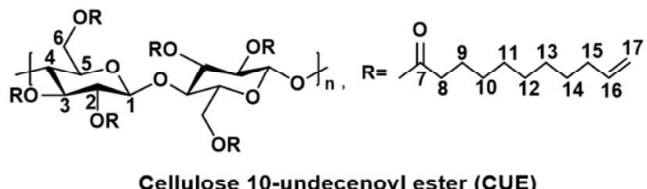

$\mathrm{CDCl}_{3}$

Cellulose 10-undecenoyl ester (CUE)

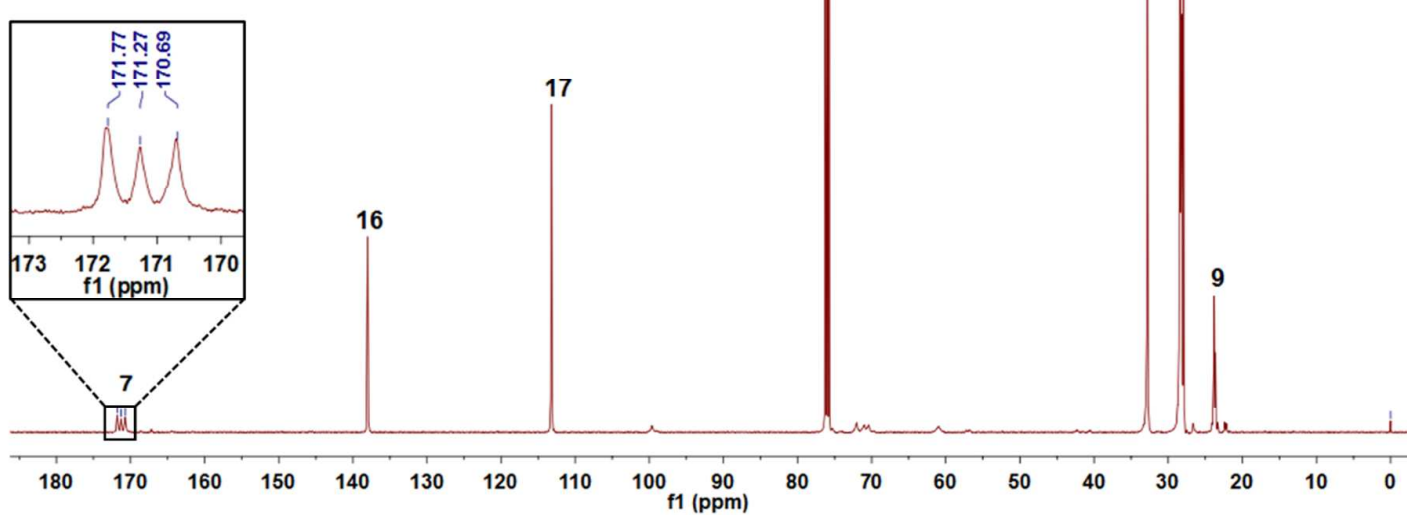

(b)

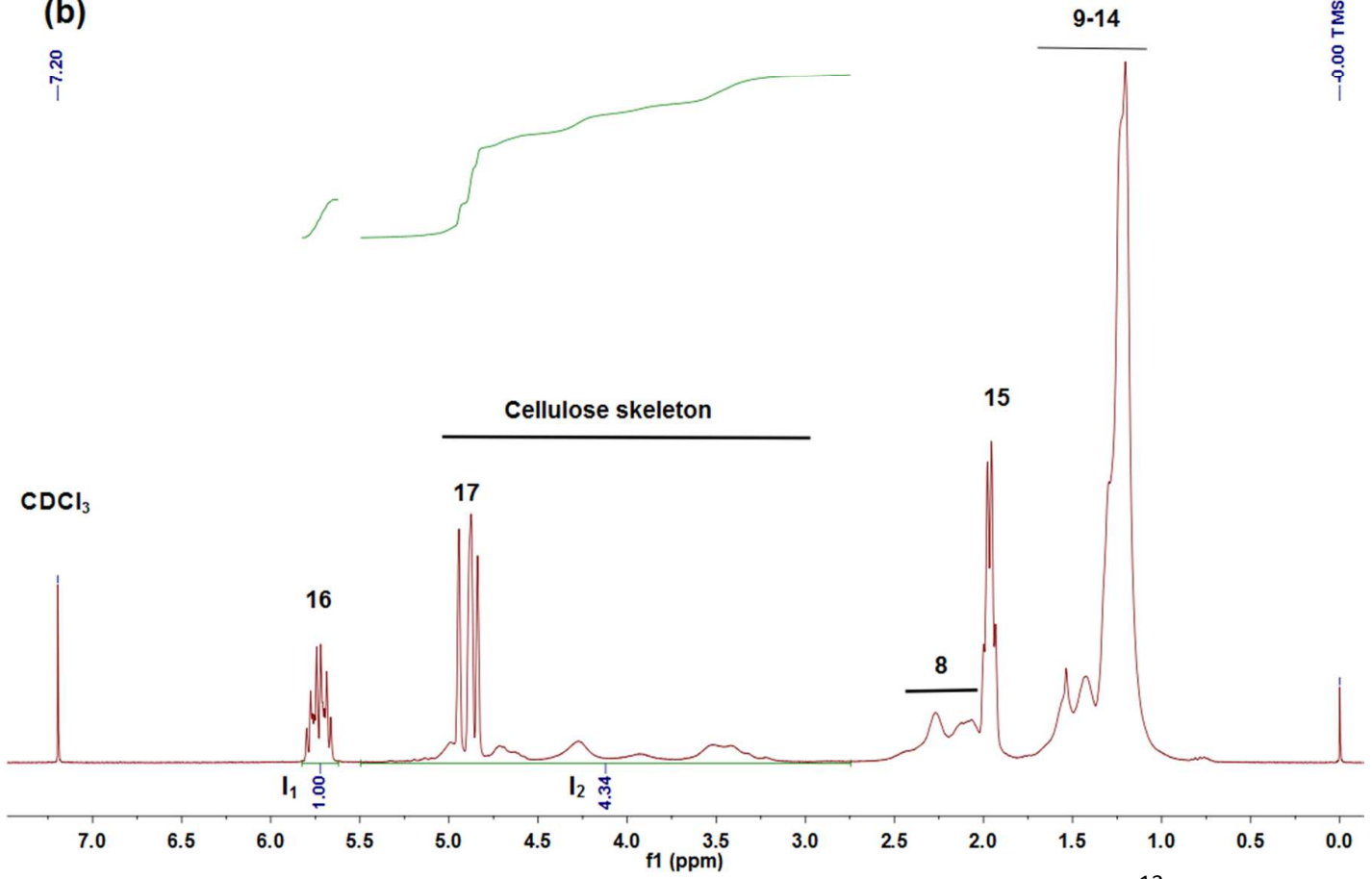

Figure S1. The NMR spectra of cellulose 10-undecenoyl ester (CUE): (a) ${ }^{13} \mathrm{C}$ NMR spectrum and (b) ${ }^{1} \mathrm{H}$ NMR spectrum in $\mathrm{CDCl}_{3}$. 
According to the NMR spectrum shown above, the 10-undecenoyl groups are present on the cellulose chains. For the ${ }^{13} \mathrm{C}$ NMR spectrum, the signals at $138 \mathrm{ppm}$ and $113 \mathrm{ppm}$ originate from the olefin groups. The three signal peaks from $170 \mathrm{ppm}$ to $172 \mathrm{ppm}$ derive from the carbonyl groups representing three different positions in an anhydroglucose unit (AGU). ${ }^{1-2}$ And the signals from 20 to $40 \mathrm{ppm}$ come from other carbons in the 10-undecenoyl group while the small signal peaks from $60 \mathrm{ppm}$ to $120 \mathrm{ppm}$ are ascribed to the carbons of cellulose backbone. ${ }^{2}$ All hydrogen signals from both cellulose chain and 10-undecenoyl moiety present in the ${ }^{1} \mathrm{H}$ NMR spectrum. The signals at 4.8 and $5.7 \mathrm{ppm}$ correspond to the hydrogen from olefin moiety. Signals from $3.2 \mathrm{ppm}$ to $5.5 \mathrm{ppm}$ except that at $4.8 \mathrm{ppm}$ represent the cellulose backbone. The integration of the hydrogen signal around 5.7 corresponding to proton from $\mathrm{C} 16$ were defined as $I_{1}$. The signal from $3.2 \mathrm{ppm}$ to $5.5 \mathrm{ppm}$ were defined as $I_{2} \cdot I_{2}-2 I_{1}$ represent the proton from cellulose backbone. The degree of substitution (DS) of 10-undecenoyl group in the synthesized CUE can be calculated with formula (1):

$$
\frac{D S}{7}=\frac{I_{1}}{I_{2}-2 I_{1}}
$$

With the value of $I_{1}=1$ and $I_{2}=4.34$, the DS of synthesized CUE was calculated to be 3 , which indicates that all the hydroxyl groups in the cellulose backbone were substituted with 10undecenoyl groups. 


\section{Elemental analysis}

Table S1. Determined content of sulfurs via elemental analysis and the calculated amount of functional moieties in dry surface-modified nanoparticles prepared in different dispersions.

\begin{tabular}{cccc}
\hline NPs & Dispersion & Content of Sulfur (\%) & $\begin{array}{c}\text { Amount of Functional } \\
\text { Moieties }\left(\times 10^{-4} \mathbf{~ m o l} / \mathbf{g}\right)\end{array}$ \\
\hline CUE-NPs-ODT & Ethanol & 1.40 & 4.37 \\
CUE-NPs-ODT & Methanol & 1.12 & 3.49 \\
CUE-NPs-MPA & Ethanol & 1.09 & 3.40 \\
CUE-NPs-MPA & Methanol & 0.88 & 2.74 \\
CUE-NPS-CA & Ethanol & 2.25 & 7.01 \\
CUE-NPS-CA & Methanol & 1.17 & 3.65 \\
\hline
\end{tabular}

\section{Viscosity and refractive index of solvent mixtures}

Mixed solvents with two components were used as dispersants during the swelling processes of the surface-modified swollen CUE-NPs. Calibrated viscosity and refractive index of the mixed solvents were needed for the accurate DLS analysis. The viscosity was calculated with the following Arrhenius formula:

$$
\ln \eta_{i d}=X_{1} \ln \eta_{1}+X_{2} \ln \eta_{2}
$$

where $\eta_{i d}$ is the ideal viscosity of binary mixed solvents. $X_{i}, \eta_{i}$ are the mole fraction and viscosity of pure components. ${ }^{3}$ The refractive index was measured directly by using a 
refractometer. To ensure the accuracy of the measurement, pure solvents (ethanol, methanol, THF and water) were measured at first, and the results were calibrated with the ideal values. Then the mixed solvents were measured and calibrated. The calculated viscosity and refractive index of the mixed solvents were shown in table S2-S4.

Table S2. The viscosity and refractive index of the dispersions for CUE-NP-ODT with different THF to ethanol/methanol ratios at $25^{\circ} \mathrm{C}$.

\begin{tabular}{cccccc}
\hline $\begin{array}{c}\mathbf{V}_{\mathrm{THF}} / \\
\mathbf{V}_{\text {Ethanol }}\end{array}$ & $\begin{array}{c}\text { Viscosity } \\
(\mathbf{c P})\end{array}$ & $\begin{array}{c}\text { Refractive } \\
\text { Index }\end{array}$ & $\begin{array}{c}\mathrm{V}_{\mathrm{THF}} / \\
\mathrm{V}_{\text {Methanol }}\end{array}$ & $\begin{array}{c}\text { Viscosity } \\
(\mathbf{c P})\end{array}$ & $\begin{array}{c}\text { Refractive } \\
\text { Index }\end{array}$ \\
\hline 0.2 & 0.9372 & 1.367 & 0.2 & 0.5385 & 1.342 \\
0.3 & 0.8980 & 1.370 & 0.24 & 0.5368 & 1.343 \\
0.4 & 0.8645 & 1.373 & 0.28 & 0.5353 & 1.344 \\
0.5 & 0.8356 & 1.375 & 0.36 & 0.5323 & 1.348 \\
0.6 & 0.8104 & 1.377 & & & \\
\hline
\end{tabular}


Table S3. The viscosity and refractive index of the dispersions for CUE-NP-MPA with different THF to ethanol/methanol ratios at $25^{\circ} \mathrm{C}$.

\begin{tabular}{cccccc}
\hline $\begin{array}{c}\mathbf{V}_{\text {THF }} / \\
\mathbf{V}_{\text {Ethanol }}\end{array}$ & $\begin{array}{c}\text { Viscosity } \\
(\mathbf{c P})\end{array}$ & $\begin{array}{c}\text { Refractive } \\
\text { Index }\end{array}$ & $\begin{array}{c}\mathrm{V}_{\mathrm{THF}} / \\
\mathbf{V}_{\text {Methanol }}\end{array}$ & $\begin{array}{c}\text { Viscosity } \\
\text { (cP) }\end{array}$ & $\begin{array}{c}\text { Refractive } \\
\text { Index }\end{array}$ \\
\hline 0 & 1.04 & 1.361 & 0 & 0.5476 & 1.328 \\
0.04 & 1.0162 & 1.361 & 0.9 & 0.5170 & 1.365 \\
0.24 & 0.9207 & 1.368 & 1.0 & 0.5148 & 1.367 \\
0.4 & 0.8645 & 1.372 & 1.2 & 0.5108 & 1.371 \\
0.48 & 0.8410 & 1.374 & 1.5 & 0.5058 & 1.375 \\
0.56 & 0.8201 & 1.376 & 1.9 & 0.5029 & 1.377 \\
\hline
\end{tabular}

Table S4. The viscosity and refractive index of the dispersions for CUE-NP-CA with different $\mathrm{H}_{2} \mathrm{O}$ to ethanol/methanol ratios at $25^{\circ} \mathrm{C}$.

\begin{tabular}{cccccc}
\hline $\begin{array}{c}\mathbf{V}_{\mathrm{H} 2 \mathrm{O}} \\
/ \mathrm{V}_{\text {Ethanol }}\end{array}$ & $\begin{array}{c}\text { Viscosity } \\
(\mathbf{c P})\end{array}$ & $\begin{array}{c}\text { Refractive } \\
\text { Index }\end{array}$ & $\begin{array}{c}\mathrm{V}_{\mathrm{H} 2 \mathrm{O}} \\
/ \mathrm{V}_{\text {Methanol }}\end{array}$ & $\begin{array}{c}\text { Viscosity } \\
(\mathbf{c P})\end{array}$ & $\begin{array}{c}\text { Refractive } \\
\text { Index }\end{array}$ \\
\hline 0 & 1.04 & 1.361 & 0 & 0.5476 & 1.328 \\
0.2 & 0.9771 & 1.363 & 0.1 & 0.5982 & 1.333 \\
0.4 & 0.9508 & 1.362 & 0.2 & 0.6359 & 1.336 \\
0.8 & 0.9274 & 1.358 & 0.4 & 0.6880 & 1.339 \\
2.0 & 0.9063 & 1.349 & 0.5 & 0.7067 & 1.340 \\
3.5 & 0.8987 & 1.343 & 0.7 & 0.7354 & 1.340 \\
4.5 & 0.8963 & 1.340 & 0.8 & 0.7465 & 1.340 \\
\hline
\end{tabular}




\section{Fitting of the swelling curves of surface-modified CUE-NPs}

Different swelling modes of surface-modified CUE-NPs were fitted to diverse functions.

The swelling trend lines of CUE-NPs-ODT and CUE-NPs-MPA in ethanol dispersion were fitted with the following exponential function:

$$
y=A_{1} * e^{\left(\frac{x}{t}\right)}+y_{0}
$$

For CUE-NPs-ODT, $A_{1}, t$ and $y_{0}$ are $7.73 \pm 3.59,0.17 \pm 0.02$ and $74.20 \pm 8.68$. The $\mathrm{R}^{2}$ for the fitting is 0.999;

For CUE-NsP-MPA, $A_{1}, t$ and $y_{0}$ are $33.30 \pm 14.12,0.24 \pm 0.04$ and $76.95 \pm 19.47$. The $\mathrm{R}^{2}$ for the fitting is 0.977 .

The swelling trend line of CUE-NPs-MPA in methanol dispersion was fitted with the following sigmoidal function:

$$
y=A_{2}+\frac{A_{1}-A_{2}}{1+e^{\frac{x-x_{0}}{t}}}
$$

where $A_{1}, A_{2}, x_{0}$ and $t$ were $105.61 \pm 3.55,198.46 \pm 2.94,1.03 \pm 0.02$ and $0.10 \pm 0.02$. The $\mathrm{R}^{2}$ for the fitting is 0.988 . 
The swelling trend line of CUE-NPs-CA in ethanol dispersion was fitted to a logarithmic function:

$$
\mathrm{y}=\mathrm{a}-\mathrm{b} * \ln (x+c)
$$

where $\mathrm{a}, \mathrm{b}$ and $c$ are $243.93 \pm 2.91,-48.94 \pm 6.74$, and $-2.04 \pm 0.03$. The $\mathrm{R}^{2}$ for the fitting is 0.988 .

\section{References}

(1) Dais, P.; Perlin, A. S. Assignment of the O-Acetyl Carbonyl Carbon Atoms of Cellulose Triacetate via 2d Long-Range Proton-Carbon Chemical-Shift-Correlation Data. Carbohydr. Res. $1988,181,233-235$.

(2) Meng, X.; Matson, J. B.; Edgar, K. J. Olefin Cross-Metathesis as a Source of Polysaccharide Derivatives: Cellulose w-Carboxyalkanoates. Biomacromolecules 2014, 15, 177-187.

(3) Anantaraman, A. V. Thermodynamics of Solvent Mixtures. I. Density and Viscosity of Binary Mixtures of N-Methylpyrrolidinone-Tetrahydrofuran and Propylene CarbonateAcetonitrile. Can. J. Chem. 1986, 64, 46-50. 


\section{Self-compounded Nanocomposites: Toward Multifunctional Membranes with Superior Mechanical, Gas/oil Barrier, UV-shielding and Photothermal Conversion Properties}

Jiaxiu Wang, ${ }^{1}$ Yu Cao, ${ }^{2,3}$ Bea Jaquet, ${ }^{4}$ Christoph Gerhard, ${ }^{4}$ Wei Li, ${ }^{5}$ Xiaodong Xia,,${ }^{2,6 *}$ Judith E. Rauschendorfer, ${ }^{7}$ Philipp Vana ${ }^{7}$ and Kai Zhang $^{1 *}$

${ }^{1}$ Wood Technology and Wood Chemistry, Department of Wood Technology and Wood-based Composites, Georg-August-University of Göttingen, Büsgenweg 4, D37077, Göttingen, Germany

${ }^{2}$ School of Food Science and Technology, National Engineering Research Center of Seafood, Dalian Polytechnic University, Dalian, Liaoning 116034, China

${ }^{3}$ Beijing Advanced Innovation Center for Food Nutrition and Human Health, College of Food Science and Nutritional Engineering, China Agricultural University, Beijing, 100083, China

${ }^{4}$ Faculty of Engineering and Health, University of Applied Sciences and Arts, VonOssietzky-Straße 99, D-37085, Göttingen, Germany 
${ }^{5}$ Key Laboratory of Bio-based Material Science and Technology of Ministry of Education, Northeast Forestry University, Hexing Road 26, Harbin 150040, China.

${ }^{6}$ College of Food Science and Engineering, Sino-US Joint Research Center, Northwest A\&F University, Shaanxi 712100, China

${ }^{7}$ Institute of Physical Chemistry, Georg-August-University of Göttingen, Tammannstraße 6, D-37077, Göttingen, Germany

*Corresponding authors:

Kai Zhang

Email: kai.zhang@uni-goettingen.de

Xiaodong Xia

Email: foodscixiaodong@yahoo.com

KEYWORDS: Self-compounding, nanocomposite, mechanical, barrier, photothermal conversion, UV-shielding 


\section{ABSTRACT}

Nanocomposites combine multiple favorable properties to achieve intriguing functionalities, but the formation of nanocomposites with only one constituent with the inclusion of multiple superior properties is still not known. Here, novel multifunctional self-compounded nanocomposite membranes from one single polymer - cellulose cinnamate (CCi) with multiple outstanding properties are reported. The selfcompounded membranes contain two distinct morphologies as $\mathrm{CCi}$ nanoparticles $(\mathrm{CCi}-$ NPs) and CCi polymer matrix, while CCi-NPs are either firmly embedded in CCi matrix or fused with adjacent CCi-NPs. The unique self-compounded nanostructure endows the membranes with a tensile strength of $94 \mathrm{MPa}$ and Young's modulus of 3.1 GPa. The water vapor permeability, oxygen permeability and oil permeability reach as low as $(0.94 \pm 0.03) \times 10^{-11} \mathrm{~g} \mathrm{~m}^{-1} \mathrm{~s}^{-1} \mathrm{~Pa}^{-1},(8.48 \pm 2.39) \times 10^{-13} \mathrm{~cm}^{3} \cdot \mathrm{cm} / \mathrm{cm}^{2} \cdot \mathrm{s} \cdot \mathrm{cmHg}$ and $0.008 \pm 0.003 \mathrm{~g} \mathrm{~mm} \mathrm{~m}{ }^{-2} \mathrm{day}^{-1}$, respectively. Moreover, self-compounded CCi nanocomposite membranes also demonstrate UV-shielding and photothermal conversion properties. UVB and UVC light are entirely blocked while UVA light is also highly blocked. The temperature increases from room temperature to $120{ }^{\circ} \mathrm{C}$ within 1 min under UV irradiation. In addition, $\mathrm{CCi}$ membranes also show remarkable thermal and humidity resistance. Based on these outstanding properties, $\mathrm{CCi}$ membranes are applied as food packaging materials. This work offers a new avenue to construct nanocomposites with multiple superior properties from one constituent, which is promising for diverse applications. 


\section{INTRODUCTION}

Nanocomposite materials, capable of coupling multiple properties including electronic, optical, mechanical and transport properties, possess unique advantages over single materials. Exceptional performance in a host of intriguing applications ranging from flexible energy storage devices, ultrafast selective ion transport to electronic artificial skins and more efficient catalysts have been achieved with nanocomposite materials. ${ }^{1-4}$ Most nanocomposite materials are fabricated via embedding functional nanofillers including nanowires, nanofibers, nanoparticles (NPs) and nanoflakes, such as metal-/covalent organic frameworks, carbon nanotubes and graphene, into polymer matrices. ${ }^{5-8}$ Usually, the functional nanofillers endowed the nanocomposite materials with the featured functions, such as reinforcement, conductivity, selectivity and so on, while polymer matrices provide fundamental properties, such as film formation and processability.

Though high-performance materials have been achieved by using such multicomponent nanocomposites, distinct properties of nanofillers and polymer matrices often lead to incompatibility problems. The incompatibility can cause the aggregation of nanofillers and processing challenges, impeding the integral performance of resultant nanocomposites. To alleviate these problems, chemical modifications including covalent bonding and non-covalent bonding, such as hydrogen bonding, $\pi-\pi$ interactions, van der Waals force and electrostatic interactions, have been employed for achieving better compatibility between nanofillers and polymer matrix. ${ }^{1,}$ 
${ }^{8-9}$ For instance, graphene nanosheets were covalently or noncovalently functionalized to enhance the interactions between graphene nanosheets and polyurethane, for the improvement of mechanical properties of the nanocomposite materials. However, such modifications can impair the intrinsic properties of nanofillers or polymer matrix, and thus are only limited to improve the properties of nanocomposites.

For the real applications of advanced nanocomposite materials, multiple processing steps or further integration of additional materials are often required to achieve multiple exceptional functions. Nevertheless, it is often the case that the addition of more components or further processing can impair the properties of other components, leading to the degradation of the whole performance of the nanocomposite materials. To obtain groundbreaking breakthrough for the prominent performance improvement of nanocomposite materials, novel nanoscale structures and new operational principles are often required. For example, granular phase-separated nanostructures with deformable NPs, coupled with intermolecular multiple hydrogen bonds gave rise to supertough polymeric composites. ${ }^{10}$ Nanocoatings with exceptional mechanical, barrier, and flame-retardant properties were achieved by constructing a nacre-like compact structure with well-aligned nanosheets, coupled with the cross-linking between the nanosheets and polymer matrix. ${ }^{11}$ Until now, nanocomposite materials evolved from one single compound has hardly been reported. Integrating multiple properties in nanocomposites with only one single compound is even more challenging. 
Herein, we report a novel nanocomposite membrane from only one single polymer, cellulose cinnamate (CCi), by using a facile drying-driven self-compounding process. The resultant membranes were compact in structure, with two distinct morphologies: CCi nanoparticles (CCi-NPs) and CCi polymer matrix, which are highly compatible with each other. The self-compounded CCi nanocomposite membranes demonstrated superior mechanical properties with high tensile strength and Young's modulus. Moreover, the self-compounded $\mathrm{CCi}$ nanocomposite membranes demonstrated remarkable UV-shielding properties, photothermal conversion properties, excellent thermal stability and humidity resistance, as well as exceptional gas (both water vapor and oxygen)/oil barrier properties and were applied as packaging materials.

\section{RESULTS AND DISCUSSION}

CCi can have diverse DSs based on the content of cinnamoyl moieties on cellulose backbone. In this study, $\mathrm{CCi}_{0.6}, \mathrm{CCi}_{1.0}$ and $\mathrm{CCi}_{2.0}$ were synthesized via esterification of cellulose by cinnamoyl chloride in DMAc/LiCl under homogeneous conditions. ${ }^{12}$

CCi2.8 was synthesized in pyridine under heterogeneous conditions (Figure. 1a). ${ }^{13}$ The chemical structures of obtained CCi were verified by $13 \mathrm{C}$ and $1 \mathrm{H}$ NMR spectra according to the signals from both cellulose backbone and cinnamoyl groups (Figure. S1). DS of obtained CCi was calculated according to previously reported method based on elemental analysis (Table S1).${ }^{14} \mathrm{CCi}_{0.6}$ and $\mathrm{CCi}_{1.0}$ are well soluble in DMSO, while $\mathrm{CCi}_{2.0}$ and $\mathrm{CCi}_{2.8}$ in THF. Self-compounded nanocomposite $\mathrm{CCi}$ membranes with thicknesses of $10-20 \mu \mathrm{m}$ were fabricated by facile solvent casting of $10 \mathrm{mg} / \mathrm{ml} \mathrm{CCi}$ 
solutions. Subsequent drying in vacuum oven at $80{ }^{\circ} \mathrm{C}$ was required for $\mathrm{CCi} 0.6$ and $\mathrm{CCi}_{1.0}$, while $\mathrm{CCi}_{2.0}$ and $\mathrm{CCi}_{2.8}$ were dried in ambient atmosphere at room temperature. All CCi membranes are comprised of two distinct topographies: dispersing CCi-NPs and CCi polymer as continuous matrix, despite of distinct DSs and discrepant drying conditions (Figure. 1b, c). In other words, dissolved CCi polymer chains in solutions (one phase) self-compounded into two distinct phases in the drying process. This selfcompounding process gave rise to the novel nanocomposite membranes originating from one single raw material.

(a)

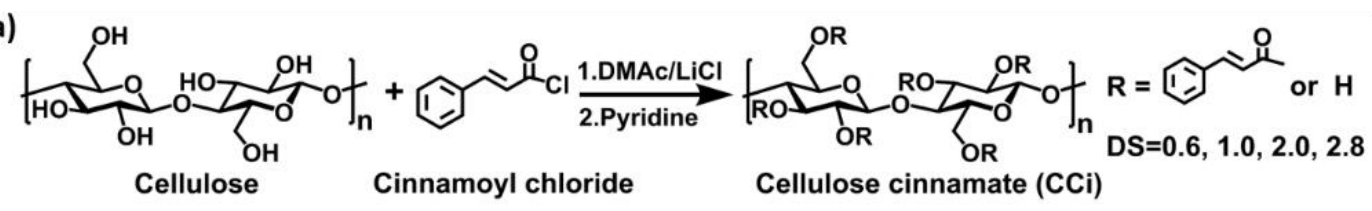

(b)

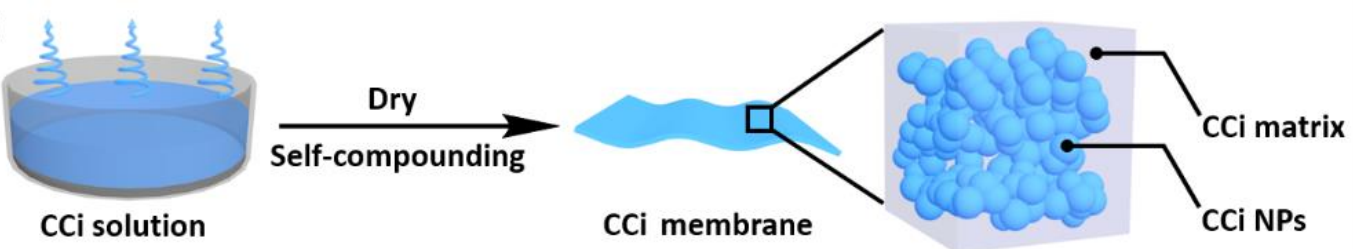

(c)
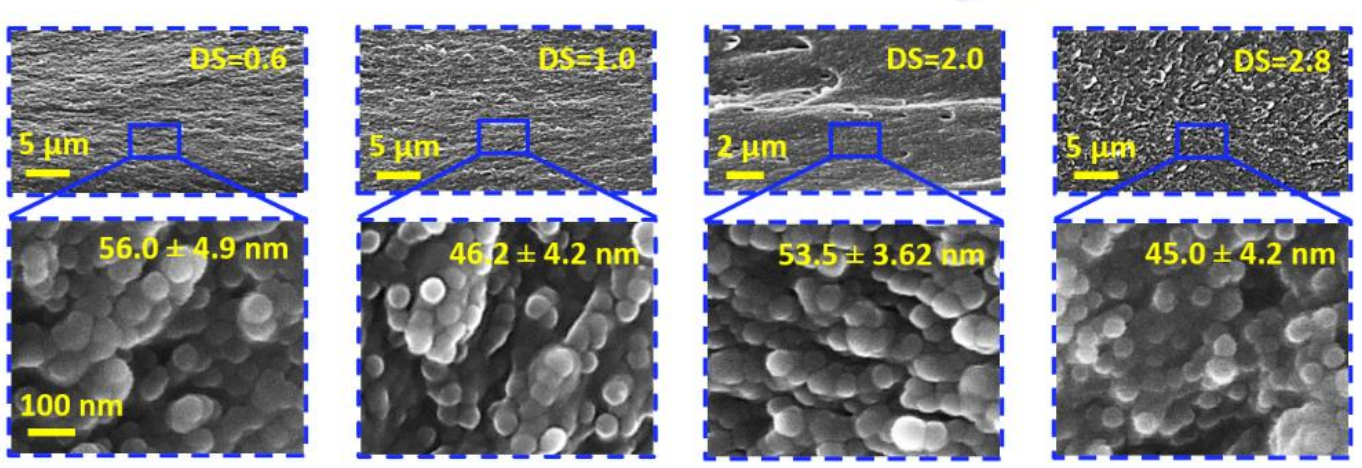

Figure 1. Fabrication of self-compounded nanocomposite membranes from cellulose cinnamate (CCi). (a) Synthesis of CCi with degree of substitution (DS) of 0.6, 1.0, 2.0 in DMAc/LiCl under homogeneous conditions and $\mathrm{CCi}$ with DS of 2.8 in pyridine under heterogeneous conditions. (b) Schematic diagram for the fabrication of self- 
compounded $\mathrm{CCi}$ nanocomposite membranes via solvent-casting method. Obtained CCi membranes contain two discrepant phases: CCi nanoparticles (CCi-NPs) and CCi polymer matrix. (c) Scanning electronic microscopy (SEM) images showing the overview and high magnification cross-section of self-compounded nanocomposite membranes fabricated from CCi with DS of 0.6, 1.0, 2.0 and 2.8. Self-compounded CCi membranes with DS of 0.6, 1.0 and 2.0 are compact in structure, while agglomerates are present in CCi membranes with DS of 2.8. Insets show the scale bars and diameters of NPs. See Figure. S2 for the surface images of the self-compounded CCi nanocomposite membranes.

As shown in SEM images, cross-section overviews showed the compact microstructures of $\mathrm{CCi}_{0.6}, \mathrm{CCi}_{1.0}$ and $\mathrm{CCi}_{2.0}$ membranes, while agglomerates were observed in $\mathrm{CCi}_{2.8}$ membranes (Figure. 1c). Some small oval-shaped voids with the length of $\sim 600 \mathrm{~nm}$ were visible in $\mathrm{CCi}_{2.0}$ and $\mathrm{CCi}_{2.8}$ membranes (Figure. 1c). These voids should originate from the rapid evaporation of THF during the drying processes. According to the high magnification cross-section images, CCi-NPs with a diameter of around $40-60 \mathrm{~nm}$ and CCi polymer matrix were observed for all CCi membranes (Figure. 1c). The CCi-NPs were either firmly embedded in the CCi polymer matrix or tightly fused with adjacent NPs. The surfaces of all membranes were highly smooth without flaws, bumps or cracks, while the surfaces of $\mathrm{CCi}_{2.0}$ and $\mathrm{CCi}_{2.8}$ occasionally contained nanoscale voids (Figure. S2). The highly smooth surfaces should originate from the unique self-compounded compact structure and the superior compatibility 
between the two distinct phases. This unique self-compounded nanocomposite structure should emanate from the particular characters of CCi polymers. On one hand, the benzene rings on the side chains should inclined to pile up or stack with each other due to $\pi-\pi$ interactions, preferring the formation of CCi-NPs. On the other hand, cellulose main chains are inherently rigid due to the $\beta$-glycosidic bonds and tendency of forming intramolecular hydrogen bonds, ${ }^{15}$ which result in continuous matrix phase, despite of alleviation of intramolecular hydrogen bonds to diverse extents due to the substitution of hydroxyl groups by cinnamoyl groups.

(a)

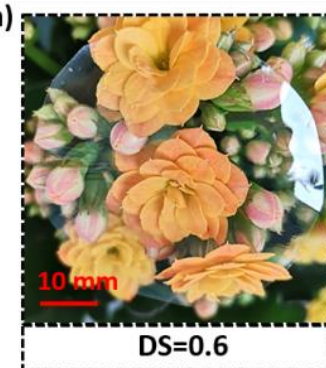

(b)

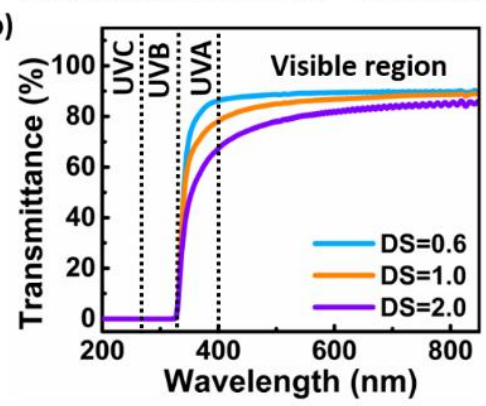

(c)
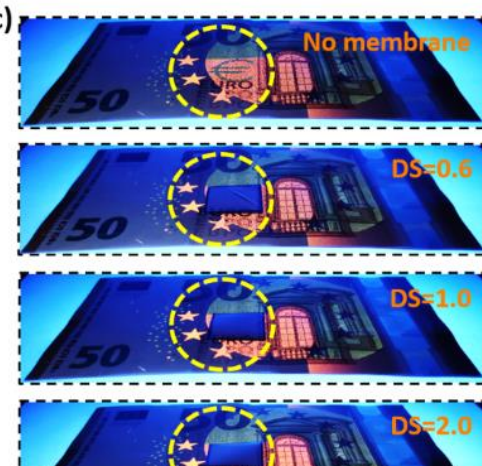
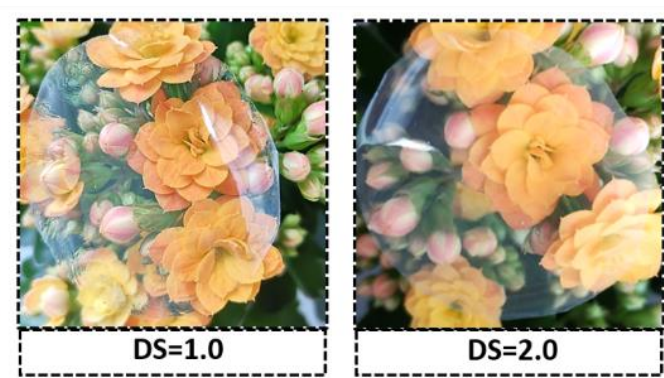

(d)
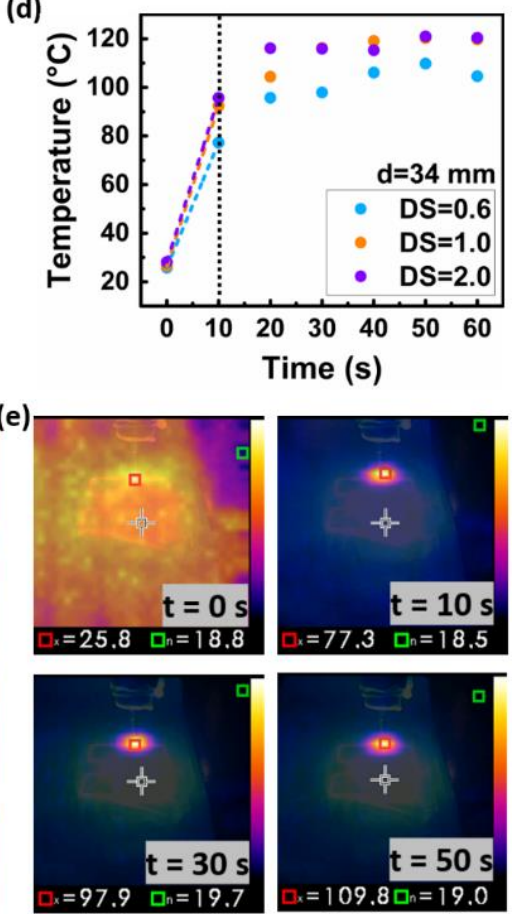
Figure 2. Transmittance, UV-shielding functions and photothermal conversion properties of self-compounded CCi nanocomposite membranes. (a) Representative photographic images displaying the transparency, and (b) Transmittance of selfcompounded CCi nanocomposite membranes with DS of 0.6, 1.0 and 2.0. See Figure. S3a, b for reflectance and reflection haze. (c) UV-shielding functions and (d) Timedependent temperature of self-compounded CCi nanocomposite membranes with DS of 0.6, 1.0 and 2.0 under UV irradiation. (e) Representative IR images of selfcompounded CCi nanocomposite membranes with DS of 0.6 before UV irradiation and after UV irradiation of $10 \mathrm{~s}, 30 \mathrm{~s}$ and $50 \mathrm{~s}$. The images of UV-shielding functions in (c) were obtained under $254 \mathrm{~nm}$ UV source. The time-dependent temperatures (d) were measured with a distance of $34 \mathrm{~mm}$ between the membranes and the UV sources. The dashed color lines in (d) show the temperature increasing rate of CCi membranes in the first 10 s. See Figure. S3c for the time-dependent temperature of self-compounded CCi nanocomposite membranes measured with a distance of $75 \mathrm{~mm}$. The $\mathrm{CCi}$ membranes with DS of 2.8 were mechanically brittle (Figure. S3d) and not discussed hereafter.

The small sizes of NPs and their homogeneous dispersion in the matrix resulted in the high transparency of self-compounded CCi nanocomposite membranes (Figure. 2a, b). Higher transparency was obtained from CCi membranes with lower DS (Figure. 2a). The transparency of $\mathrm{CCi} 0.6$ membranes reached $86 \%$ - $90 \%$ in visible region, while that of $\mathrm{CCi}_{1.0}$ and $\mathrm{CCi}_{2.0}$ membranes was $78 \%-89 \%$ and $67 \%-83 \%$, respectively (Figure. 2b). The voids inside and on the surfaces of the $\mathrm{CCi}_{2.0}$ membranes provide 
more opportunities for light scattering (Figure. 1c and S2), and thus their transparency became lower than that of $\mathrm{CCi}_{0.6}$ and $\mathrm{CCi}_{1.0}$ membranes. The $\mathrm{CCi}_{0.6}$ and $\mathrm{CCi}_{1.0}$ membranes demonstrated reflection around $10 \%$ while $\mathrm{CCi}_{2.0}$ membranes demonstrated reflection of around $5 \%$ (Figure. S3a). All self-compounded CCi nanocomposite membranes demonstrated obvious reflection haze with the value of 6.52 $\pm 0.16,23.16 \pm 2.36$ and $19.12 \pm 3.95$ for $\mathrm{CCi}_{0.6}, \mathrm{CCi}_{1.0}$ and $\mathrm{CCi}_{2.0}$ membranes, respectively (Figure. S3b). Additionally, self-compounded $\mathrm{CCi}$ nanocomposite membranes demonstrated UV-shielding functions with total block of UVB (280-320 $\mathrm{nm})$ and UVC ( $<280 \mathrm{~nm})$, while the UVA (320-400 nm) light was also highly blocked (Figure. 2b). As UVC is blocked naturally by ozonosphere and UVB is considered much harmful to human than UVA, CCi membranes possess high potential to be used as UV-shielding materials. As an example, the anti-counterfeiting mark of Euro under $254 \mathrm{~nm}$ UV light can be perfectly blocked by $\mathrm{CCi} 0.6, \mathrm{CCi}_{1.0}$ and $\mathrm{CCi}_{2.0}$ membranes (Figure. 2c). Moreover, the self-compounded CCi nanocomposite membranes showed remarkable photothermal properties. Under UV irradiation, the temperatures of the membranes increased rapidly in the first $10 \mathrm{~s}$. Then, it continued to increase gradually with longer time (Figure. 2d and S3c). For instance, with $75 \mathrm{~mm}$ distance between CCi membranes and UV sources, the temperatures of self-compounded $\mathrm{CCi}_{0.6}, \mathrm{CCi}_{1.0}$ and $\mathrm{CCi} 2.0$ nanocomposite membranes increased within the first $10 \mathrm{~s}$ from room temperature to $35{ }^{\circ} \mathrm{C}, 37{ }^{\circ} \mathrm{C}$ and $41{ }^{\circ} \mathrm{C}$ with a rate of $0.7^{\circ} \mathrm{C} / \mathrm{s}, 0.8^{\circ} \mathrm{C} / \mathrm{s}$, and $1.6^{\circ} \mathrm{C} / \mathrm{s}$, respectively (Figure. S3c). After $60 \mathrm{~s}$, the temperatures of $\mathrm{CCi} 0.6, \mathrm{CCi}_{1.0}$ and $\mathrm{CCi}_{2.0}$ membranes increased further with ongoing time and reached $44{ }^{\circ} \mathrm{C}, 43{ }^{\circ} \mathrm{C}$ and $48{ }^{\circ} \mathrm{C}$, respectively 
(Figure. S3c). Furthermore, with $34 \mathrm{~mm}$ distance between membranes and UV sources, the temperature of self-compounded $\mathrm{CCi}_{0.6}, \mathrm{CCi}_{1.0}$ and $\mathrm{CCi}_{2.0}$ nanocomposite membranes increased within the first $10 \mathrm{~s}$ from room temperature rapidly to $77^{\circ} \mathrm{C}, 92$ ${ }^{\circ} \mathrm{C}$ and $96{ }^{\circ} \mathrm{C}$ with a rate of $5.2{ }^{\circ} \mathrm{C} / \mathrm{s}, 6.6^{\circ} \mathrm{C} / \mathrm{s}$, and $6.8{ }^{\circ} \mathrm{C} / \mathrm{s}$, respectively. After $60 \mathrm{~s}$, the temperatures of self-compounded $\mathrm{CCi}_{0.6}, \mathrm{CCi}_{1.0}$ and $\mathrm{CCi}_{2.0}$ nanocomposite membranes increased further with longer time and reached $105^{\circ} \mathrm{C}, 120^{\circ} \mathrm{C}$ and $120^{\circ} \mathrm{C}$, respectively (Figure. 2d). Thus, the temperatures of self-compounded CCi membranes with higher DS increased with a higher rate in the first $10 \mathrm{~s}$ and reached a higher temperature after UV irradiation of $60 \mathrm{~s}$. Decreasing the distance between the membranes and the UV sources allows the temperatures to increase in a much faster way and to reach a much higher temperature after $60 \mathrm{~s} \mathrm{UV} \mathrm{irradiation.} \mathrm{Figure.} \mathrm{2e} \mathrm{presents} \mathrm{the} \mathrm{representative} \mathrm{IR}$ images of the self-compounded $\mathrm{CCi}_{0.6}$ nanocomposite membranes before and after UV irradiation of $10 \mathrm{~s}, 30 \mathrm{~s}$, and $50 \mathrm{~s}$. The remarkable photothermal properties imply versatile potential applications of $\mathrm{CCi}$ membranes, such as heat collection materials, desalination, sewage treatment, photothermal actuation, steam power generation and so on. $\mathrm{CCi}_{2.8}$ membranes were not discussed here due to mechanical brittleness (Figure. S3d). 
(a)

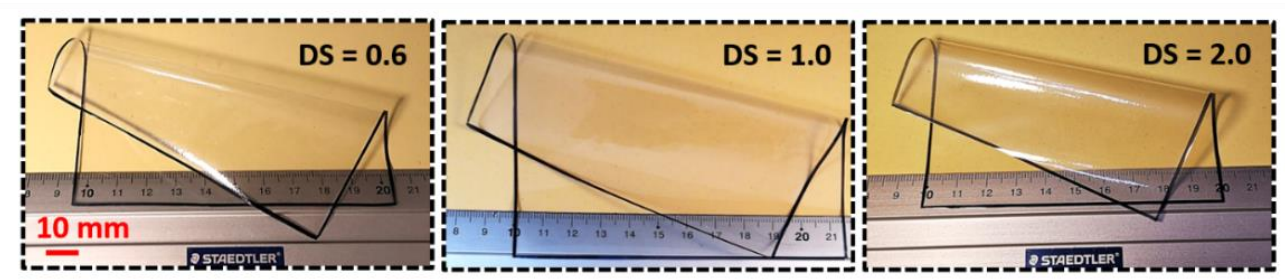

(b)

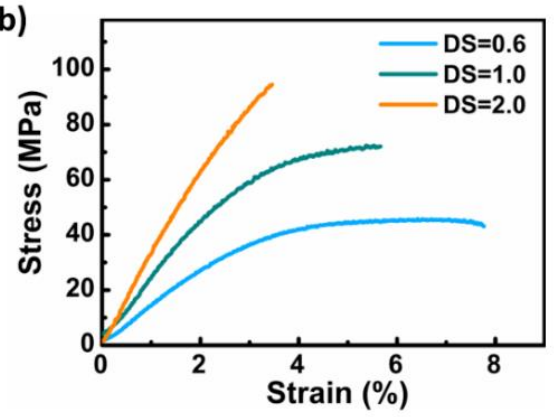

(d)

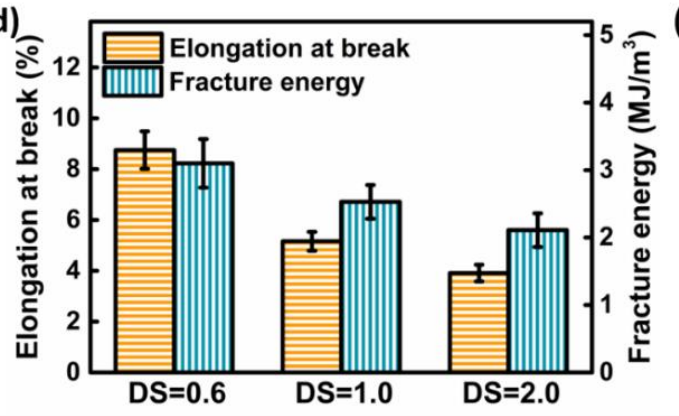

(c)
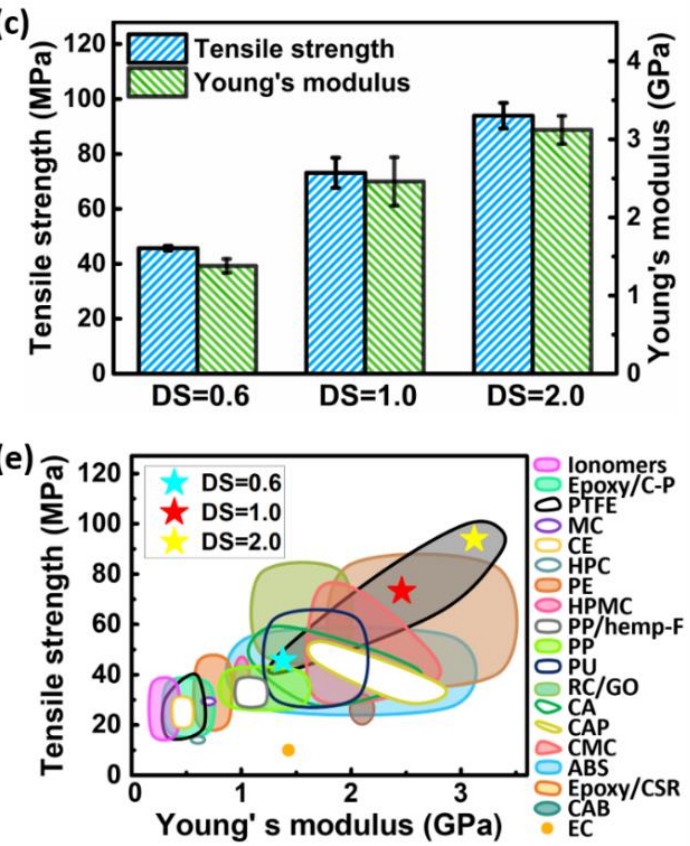

Figure 3. Static mechanical properties of self-compounded nanocomposite membranes fabricated from CCi with DS of 0.6, 1.0 and 2.0. (a) Representative images showing the mechanical flexibility, (b) Stress-strain curves, (c) Tensile strength and Young's moduli and (d) Elongation at break and fracture energy of self-compounded nanocomposite membranes from CCi with various DSs. (e) Tensile strength and Young's moduli of self-compounded $\mathrm{CCi} 0.6, \mathrm{CCi}_{1.0}$ and $\mathrm{CCi}_{2.0}$ nanocomposite membranes, in comparison with a few common synthetic polymers, cellulose derivatives and composites. Ionomers, ${ }^{16}$ Epoxy/C-P: epoxy/coconut shell particles, ${ }^{17}$ PTFE: polytetrafluoroethylene, ${ }^{16} \mathrm{MC}$ : methyl cellulose, ${ }^{18} \mathrm{CE}$ : cellulose fatty acid esters, ${ }^{19}$ HPC: hydroxypropyl cellulose,${ }^{18} \mathrm{PE}$ : polyethylene, ${ }^{16} \mathrm{HPMC}$ : hydroxypropyl methylcellulose,${ }^{18} \mathrm{PP}$ : polypropylene, ${ }^{16} \mathrm{PP} /$ hemp-F: polypropylene/hemp fibers, ${ }^{20} \mathrm{PU}$ : 
polyurethane, ${ }^{16} \mathrm{RC} / \mathrm{GO}$ : regenerated cellulose/graphite oxide, ${ }^{21} \mathrm{CA}$ : cellulose acetate, ${ }^{22-25} \mathrm{CAP}$ : cellulose acetate propionate. ${ }^{22,26} \mathrm{CMC}$ : carboxymethyl cellulose, ${ }^{18,}$ ${ }^{27} \mathrm{ABS}$ : acrylonitrile butadiene styrene, ${ }^{16}$ Epoxy/CSR: epoxy/core-shell rubber. ${ }^{28} \mathrm{CAB}$ : cellulose acetate butyrate, ${ }^{22}$ EC: ethyl cellulose. ${ }^{29}$

The self-compounded nanocomposite membranes with the unique compact structure and perfect compatibility guaranteed the superior mechanical properties of $\mathrm{CCi}$ membranes (Figure. 3a-d). $\mathrm{CCi}_{0.6}, \mathrm{CCi}_{1.0}$ and $\mathrm{CCi}_{2.0}$ self-compounded nanocomposite membranes were mechanically robust and flexible, readily to be rolled or deformed (Figure. 3a). $\mathrm{CCi}_{2.0}$ membranes were strong and stiff with a tensile strength of $93.9 \pm$ 4.6 $\mathrm{MPa}$ and Young's modulus of $3.1 \pm 0.2 \mathrm{GPa}$. $\mathrm{CCi}_{2.0}$ membranes broke at an elongation of $3.9 \pm 0.3 \%$ with a fracture energy of $2.1 \pm 0.3 \mathrm{MJ} / \mathrm{m} 3$. The stress-strain curve of $\mathrm{CCi}_{2.0}$ membranes demonstrated only elastic characteristics until break without plastic features. Distinct from $\mathrm{CCi}_{2.0}$ membranes, $\mathrm{CCi}_{0.6}$ membranes were relatively ductile and tough with an elongation at break of $8.8 \pm 0.7 \%$ and fracture energy of 3.1 $\pm 0.4 \mathrm{MJ} / \mathrm{m} 3$. The tensile strength and the Young's moduli of CCi 0.6 membranes were $45.7 \pm 0.9 \mathrm{MPa}$ and $1.4 \pm 0.1 \mathrm{GPa}$, respectively. The stress-strain curve of $\mathrm{CCi}_{0.6}$ membranes encompassed both elastic and plastic regions connected with a yielding strain of around $3.0 \%$. The strength, stiffness, ductileness and toughness of $\mathrm{CCi}_{1.0}$ membranes lay intermediately between those of $\mathrm{CCi}_{0.6}$ and $\mathrm{CCi}_{2.0}$ membranes with tensile strength, Young's moduli, elongation at break and fracture energy of $72.8 \pm 5.1$ 
$\mathrm{MPa}, 2.5 \pm 0.3 \mathrm{GPa}, 5.2 \pm 0.4 \%$ and $2.5 \pm 0.3 \mathrm{MJ} / \mathrm{m} 3$, respectively. The development of stress-strain curve for $\mathrm{CCi}_{1.0}$ membranes was also between those of $\mathrm{CCi}_{0.6}$ and $\mathrm{CCi}_{2.0}$ membranes with an elastic region and a short plastic region. The mechanical properties of $\mathrm{CCi}_{2.8}$ membranes were not measured due to the obvious mechanical brittleness (Figure. S3d).

Self-compounded CCi nanocomposite membranes showed comparable or superior mechanical properties with high tensile strength and Young's moduli (Figure. 3d), compared with reported materials fabricated from common synthetic polymers including PE, PP, PTFE, ABS, thermoplastic PU, ionomers; ${ }^{16}$ other cellulose derivatives, such as cellulose fatty acid esters, cellulose acetate, methyl cellulose, ethyl cellulose and carboxymethyl cellulose; ${ }^{18-19}, 22-27,29$ and composites, such as epoxy/coconut shell particles, regenerated cellulose/graphite oxides, PP/hemp fibers, epoxy/core shell rubber. ${ }^{17,} 20-21,28$ These exceptional mechanical properties of CCi membranes should be ascribed to the unique self-compounded nanocomposite structures. All self-compounded nanocomposite membranes were compact in structure with CCi-NPs firmly embedded in continuous CCi matrix or fused with adjacent NPs (Figure. 1c). First, the compact microstructures indicate the perfect compatibility of the two phases in self-compounded nanocomposite membranes in comparison to conventional nanocomposites with at least two chemical constituents. In particular, these polymeric NPs with the average diameters of around $50 \mathrm{~nm}$ assure sufficient surface areas for the interaction with the continuous matrix. This favorable compatibility and enlarged surface area alleviate premature failures, offer effective 
stress transfer at interfaces and consequently increase the ultimate strength. Second, the $\mathrm{CCi}$ matrix should be reinforced and toughed by CCi-NPs with entangled and coiled polymer chains, which efficiently dissipate the deformation energy and relax the stress, resulting in better stress transfer and effective resistance to failure. Third, the fused CCi-NPs provide enhanced linkages between NPs, resulting in reinforcement of the CCi-NPs phase to withstand higher loading. Moreover, the compact microstructure and fused NPs could be favorable for the improved molecular interactions including hydrogen bonds and $\pi-\pi$ interactions in both phases as well as at their interfaces due to the reduced distances between CCi polymer chains. Therefore, the self-compounded nanostructure strengthened CCi membranes based on the efficient combination of two distinct morphologies, while the intermolecular interactions including hydrogen bonds and $\pi-\pi$ interactions could also play an important role in adjusting the mechanical properties. 

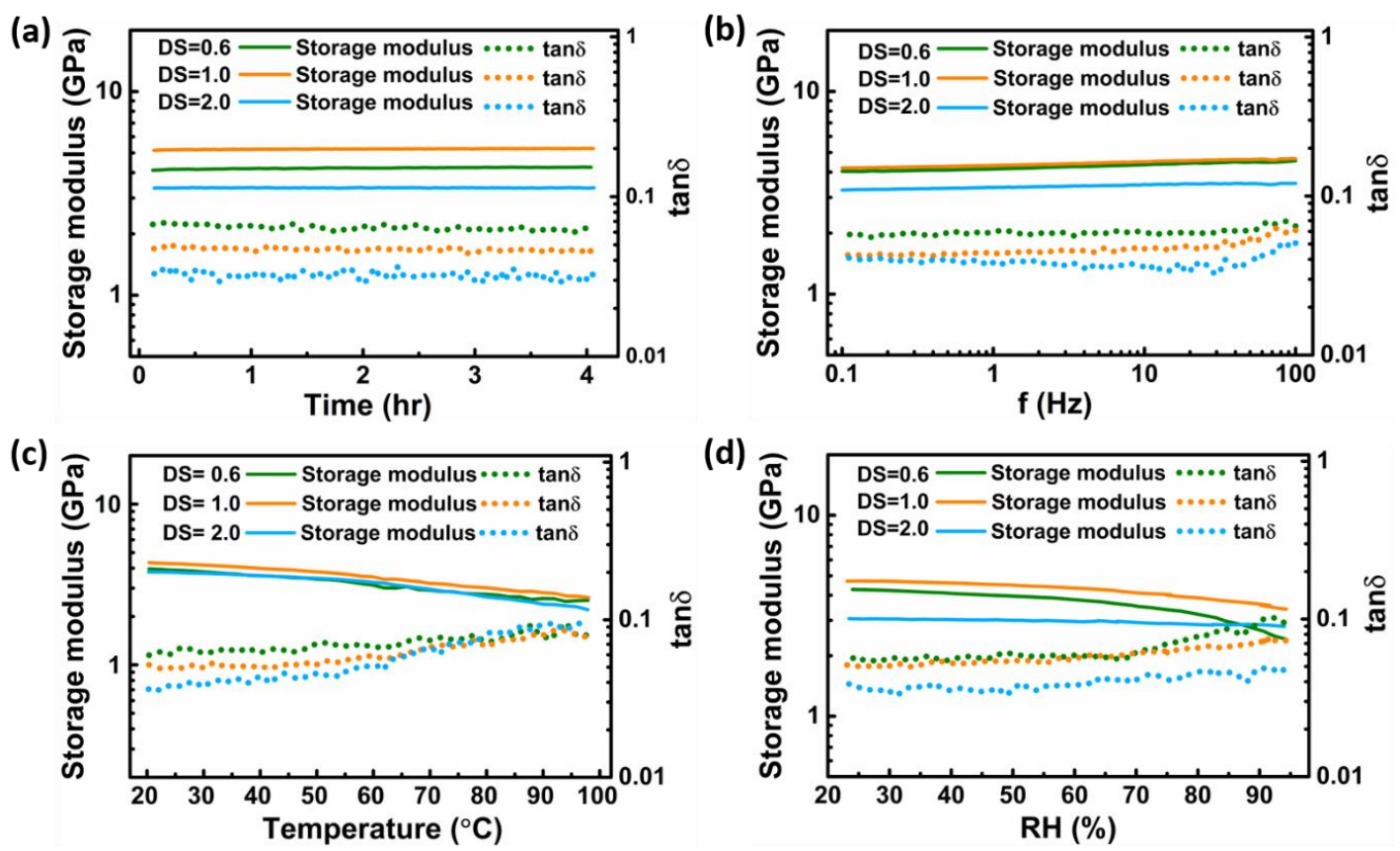

Figure 4. CCi nanocomposite membranes with various DSs. (a) Time sweep at $25^{\circ} \mathrm{C}$, $30 \%$ RH with a frequency of $10 \mathrm{~Hz}$, (b) Frequency sweep at $25^{\circ} \mathrm{C}, 30 \% \mathrm{RH}$, (c) Temperature sweep at $30 \% \mathrm{RH}$ with a frequency of $10 \mathrm{~Hz}$ and temperature increasing rate of $2{ }^{\circ} \mathrm{C} / \mathrm{min}$, and (d) Humidity sweep at $25^{\circ} \mathrm{C}$, with a frequency of $10 \mathrm{~Hz}$. For clarity, only the storage modulus and damping factor were demonstrated. See Figure. S4 for corresponding curves of loss modulus.

DMTA was further implemented to obtain deeper understanding on the mechanical properties of self-compounded $\mathrm{CCi}$ nanocomposite membranes (Figure. 4). The storage moduli, loss moduli and damping factor maintained invariable in a time length of more than $4 \mathrm{hr}$ at $25{ }^{\circ} \mathrm{C}$ and $30 \% \mathrm{RH}$ at a frequency of $10 \mathrm{~Hz}$, demonstrating that nanostructured $\mathrm{CCi}$ membranes were highly stable at a given condition (Figure. $4 \mathrm{a}$ and S4a). The great stability of all CCi membranes under static and dynamic loads verified 
the stiffness and robustness of the self-compounded nanostructures, which can withstand deformations without becoming fatigue for long time. This mechanical stability should benefit from the self-compounded compact structures and the high compatibility between the two phases. $\mathrm{CCi} 0.6, \mathrm{CCi}_{1.0}$ and $\mathrm{CCi}_{2.0}$ membranes showed storage moduli of $4.2 \mathrm{GPa}, 5.2 \mathrm{GPa}$ and $3.4 \mathrm{GPa}$, respectively. The voids in $\mathrm{CCi}_{2.0}$ membranes, as shown in Figure. 1c, should account for the corresponding low storage modulus. The decrease of loss modulus and damping factor with the increase of DS indicated stronger interactions between CCi chains (Figure. 4 and S4), which verified the effectiveness of newly introduced $\pi-\pi$ interactions after substitution. This was in accordance with the static mechanical properties. For instance, $\mathrm{CCi}$ membranes with higher DS demonstrated higher tensile strength and Young's moduli.

The storage moduli of all self-compounded CCi nanocomposite membranes only increased in a small range $(\sim 10 \%)$, when frequency was elevated from $0.1 \mathrm{~Hz}$ to 100 $\mathrm{Hz}$ (Figure. 4b). This fact implied the favorable coupling of $\mathrm{CCi}$ chains within both phases as well as at their interfaces, in other words, the superior compatibility of the two morphologies. Otherwise, weak interactions/linkages should provide higher mobility of CCi polymer chains. Thus, vastly varying time for the relaxation are needed, when the frequency varies in a wide range, resulting in large variation of storage moduli. ${ }^{30}$

The storage moduli decreased with increasing temperature due to higher flexibility and mobility of $\mathrm{CCi}$ polymer chains, which were verified via the obviously rising 
damping factor (Figure. 4c). With the temperature increased from $20{ }^{\circ} \mathrm{C}$ to $98{ }^{\circ} \mathrm{C}$, the storage moduli decreased from 4.0 GPa to $2.5 \mathrm{GPa}$, from $4.3 \mathrm{GPa}$ to $2.6 \mathrm{GPa}$ and from 3.8 GPa to $2.2 \mathrm{GPa}$ for $\mathrm{CCi}_{0.6}, \mathrm{CCi}_{1.0}$ and $\mathrm{CCi}_{2.0}$ membranes, respectively. Though high temperature can impair the mechanical properties of $\mathrm{CCi}$ membranes, all selfcompounded CCi nanocomposite membranes showed storage moduli larger than $2 \mathrm{GPa}$ even at temperature of $98{ }^{\circ} \mathrm{C}$ with a humidity of $30 \% \mathrm{RH}$, demonstrating excellent thermal resistance. The thermal resistance of $\mathrm{CCi}$ membranes was also approved by TGA (Figure. S5a). $\mathrm{CCi}_{0.6}, \mathrm{CCi}_{1.0}, \mathrm{CCi}_{2.0}$ and $\mathrm{CCi}_{2.8}$ start to decompose at around 291 ${ }^{\circ} \mathrm{C}, 306^{\circ} \mathrm{C}, 335^{\circ} \mathrm{C}$, and $348^{\circ} \mathrm{C}$, respectively. The thermal resistance of CCi membranes guarantees their versatile applications over a wide temperature range.

Cellulose-based materials usually suffer from humidity sensitivity, which impedes their applications especially in humid environments. Figure. 4d demonstrated the influence of humidity on mechanical properties of self-compounded $\mathrm{CCi}$ nanocomposite membranes. The storage moduli of self-compounded CCi 0.6 membranes decreased remarkably from $4.3 \mathrm{GPa}$ to $2.4 \mathrm{GPa}$ with increasing relative humidity from $24 \% \mathrm{RH}$ to $94 \% \mathrm{RH}$, while that of self-compounded $\mathrm{CCi}_{1.0}$ membranes reduced from 4.7 $\mathrm{GPa}$ to $3.4 \mathrm{GPa}$. All self-compounded $\mathrm{CCi}$ nanocomposite membranes demonstrated hydrophilic wettability, with static water contact angle of $70 \pm 2^{\circ}, 66 \pm$ $3^{\circ}$ and $84 \pm 3^{\circ}$, for $\mathrm{CCi}_{0.6}, \mathrm{CCi}_{1.0}$ and $\mathrm{CCi}_{2.0}$ membranes, respectively (Figure. $\mathbf{S 5 c}$ ). In fact, the introduced cinnamoyl groups were too short to generate hydrophobic membranes, even those with a high DS of 2.0. In comparison, long chain aliphatic hydrocarbyl groups resulted in hydrophobic films, even with a low DS of $0.3 .{ }^{31}$ 
Therefore, hydrophilic CCi membranes still can adsorb water molecules, in particular CCi membranes with lower DS. For instance, the equilibrated mass change of $\mathrm{CCi}_{0.6}$ membranes reached $13.1 \%$ at $93 \% \mathrm{RH}$, while that of $\mathrm{CCi}_{1.3}$ and $\mathrm{CCi}_{2.2}$ membranes were only $4.5 \%$ and $2.4 \%$, respectively (Figure. S5b). The adsorbed water molecules could build hydrogen bonds with the residual hydroxyl groups on CCi chains, disrupt the previously existing hydrogen bonds and facilitate the mobility of $\mathrm{CCi}$ chains. Consequently, the storage moduli decreased and the damping factors increased. However, the humidity influence on CCi membranes was only obvious at high RH (> $80 \% \mathrm{RH}$ ) as shown in Figure. $4 \mathrm{~d}$ and can be much minimized for CCi membranes with a high DS. For instance, the mechanical properties of $\mathrm{CCi}_{2.0}$ membranes demonstrated much improved humidity resistance, with storage moduli decreased only from $3.1 \mathrm{GPa}$ to $2.8 \mathrm{GPa}$, when humidity increased from $21 \% \mathrm{RH}$ to $94 \% \mathrm{RH}$ (Figure. $4 \mathrm{~d}$ ). The superior humidity resistance of $\mathrm{CCi}_{2.0}$ membranes guaranteed their applications in humid environments. 
(a)

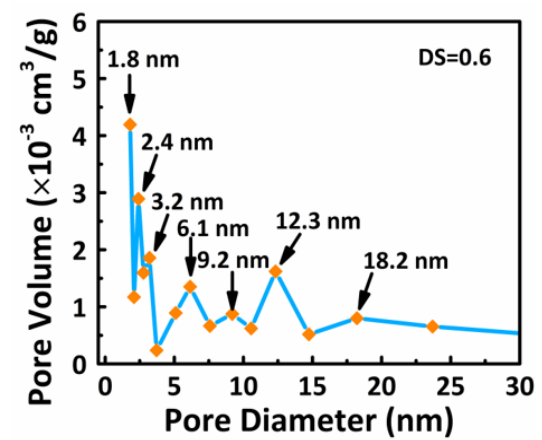

(b)

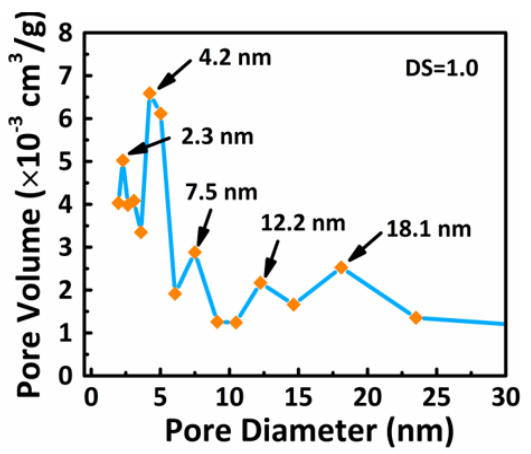

(c)

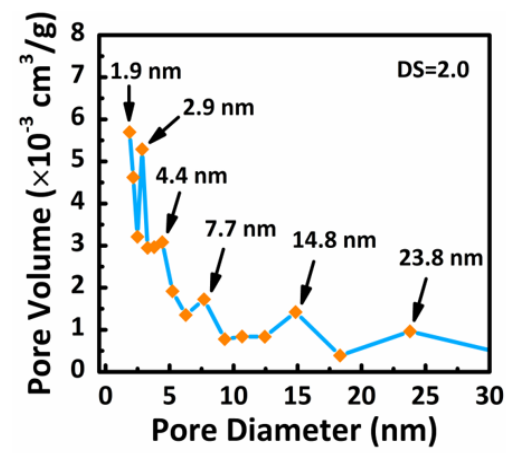

(d)

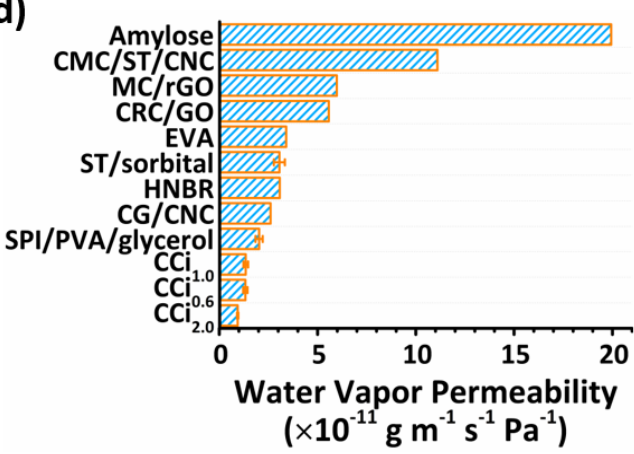

(e)

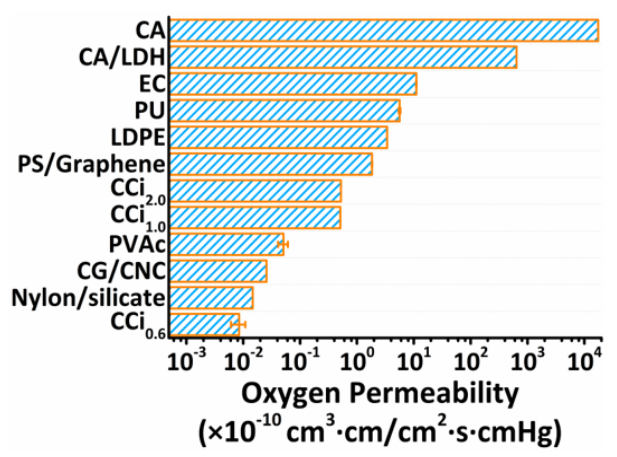

(f)

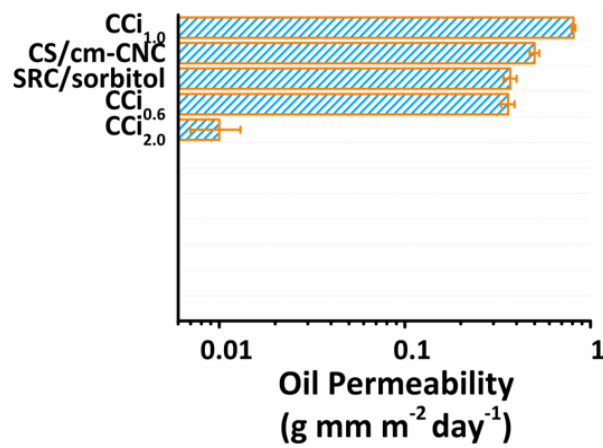

Figure 5. $(\mathrm{a}, \mathrm{b}, \mathrm{c})$ Pore size distribution of self-compounded CCi nanocomposite membranes with DS of (a) 0.6, (b) 1.0 and (c) 2.0. (d) Water vapor permeability, (e) Oxygen permeability and (f) Oil permeability of self-compounded CCi nanocomposite membranes with various DSs, in comparison with other reported barrier membranes fabricated from typical synthetic polymers, biopolymers, bio-based polymers and composites. CMC: carboxymethyl cellulose, ST: starch, CNC: cellulose nanocrystals, MC: methyl cellulose, rGO: reduced graphene oxide, CRC: cross-linked regenerated cellulose, GO: graphene oxide, EVA: ethylenevinyl acetate copolymer, HNBR: 
hydrogenated nitrile rubber, ${ }^{32} \mathrm{CG}$ : cassia-gum, SPI: soy protein isolate, PVA: poly(vinyl alcohol), CA: cellulose acetate, LDH: layered double hydroxide, EC: ethyl cellulose, PU: polyurethane, LDPE: low density polyethylene, PS: polystyrene, PVAc: polyvinyl acetate, CS: cassava starch, cm-CNC: carboxymethyl cellulose nanocrystals, SRC: semi-refined kappa-carrageenan. See Table S2 for the corresponding values.

Apart from the mechanical properties, thermal and humidity resistance, BET analysis was further executed to reveal the pore size and surface area of $\mathrm{CCi}$ membranes. The self-compounded nanocomposite $\mathrm{CCi}$ membranes of similar thicknesses possess nanosized pores with pore sizes in the range of 1-25 $\mathrm{nm}$ (Figure. 5a-c). The average pore diameter was $2.1 \mathrm{~nm}, 2.0 \mathrm{~nm}$ and $1.6 \mathrm{~nm}$ for $\mathrm{CCi}_{0.6}, \mathrm{CCi}_{1.0}$, and $\mathrm{CCi}_{2.0}$ membranes, respectively. Accordingly, the corresponding surface areas of CCi ${ }_{0.6}, \mathrm{CCi}_{1.0}$, and $\mathrm{CCi}_{2.0}$ membranes were $5.3 \mathrm{~m}^{2} / \mathrm{g}, 9.0 \mathrm{~m}^{2} / \mathrm{g}$ and $8.5 \mathrm{~m}^{2} / \mathrm{g}$, respectively. The small sizes of pores and surface areas confirmed the compact structure and improved interphases of these self-compounded nanocomposite membranes.

The compact microstructures, the small sizes of pores and small surface areas indicate excellent barrier properties of self-compounded $\mathrm{CCi}$ nanocomposite membranes, as shown by their gas and oil barrier properties. Though hydrophilic in wettability, selfcompounded $\mathrm{CCi}$ nanocomposite membranes demonstrated superior water vapor barrier properties with water vapor permeability of $(1.331 \pm 0.111) \times 10^{-11} \mathrm{~g} \mathrm{~m}^{-1} \mathrm{~s}^{-1} \mathrm{~Pa}^{-}$ ${ }^{1},(1.345 \pm 0.123) \times 10^{-11} \mathrm{~g} \mathrm{~m}^{-1} \mathrm{~s}^{-1} \mathrm{~Pa}^{-1}$ and $(0.94 \pm 0.03) \times 10^{-11} \mathrm{~g} \mathrm{~m}^{-1} \mathrm{~s}^{-1} \mathrm{~Pa}^{-1}$, for 
CCi $0.6, \mathrm{CCi}_{1.0}$ and $\mathrm{CCi}_{2.0}$ membranes, respectively, which are lower than reported water barrier materials fabricated from synthetic polymers, such as $\mathrm{EVA}^{32}$ and $\mathrm{HNBR} ;{ }^{32}$ biopolymers, such as $\mathrm{RC}^{33}$ and amylose; ${ }^{34}$ as well as their composites, such as $\mathrm{MC} / \mathrm{rGO},{ }^{35} \mathrm{CRC} / \mathrm{GO}, 36 \mathrm{CMC} / \mathrm{ST} / \mathrm{CNC},{ }^{37} \mathrm{ST} /$ sorbital $^{38}$ SPI/PVA/glycerol, ${ }^{39}$ and $\mathrm{CG} / \mathrm{CNC}^{40}$ (Figure. 5d). The oxygen permeability of self-compounded CCi0.6, $\mathrm{CCi}_{1.0}$ and $\mathrm{CCi}_{2.0}$ nanocomposite membranes were $(8.48 \pm 2.39) \times 10^{-13} \mathrm{~cm}^{3} \cdot \mathrm{cm} / \mathrm{cm}^{2} \cdot \mathrm{s} \cdot \mathrm{cmHg}$, $5.11 \times 10^{-11} \mathrm{~cm}^{3} \cdot \mathrm{cm} / \mathrm{cm}^{2} \cdot \mathrm{s} \cdot \mathrm{cmHg}$ and $5.22 \times 10^{-11} \mathrm{~cm}^{3} \cdot \mathrm{cm} / \mathrm{cm}^{2} \cdot \mathrm{s} \cdot \mathrm{cmHg}$, respectively, which are comparable or even much lower than oxygen barrier materials fabricated from synthetic polymers, including LDPE, ${ }^{41} \mathrm{PU},{ }^{42}$ and PVAc; ${ }^{42}$ cellulose derivatives, such as $\mathrm{EC}^{43}$ and $\mathrm{CA}^{44}$ as well as composites, such as $\mathrm{CA} / \mathrm{LDH},{ }^{44} \mathrm{PS} /$ graphene, ${ }^{45}$ Nylon/silicate, ${ }^{46}$ and $\mathrm{CG} / \mathrm{CNC}^{40}$ (Figure. 5e). In comparison, the oil permeabilities were as low as $0.358 \pm 0.026 \mathrm{~g} \mathrm{~mm} \mathrm{~m}^{-2}$ day $^{-1}, 0.813 \pm 0.020 \mathrm{~g} \mathrm{~mm} \mathrm{~m}^{-2} \mathrm{day}^{-1}$ and 0.008 $\pm 0.003 \mathrm{~g} \mathrm{~mm} \mathrm{~m}^{-2}$ day $^{-1}$ for self-compounded $\mathrm{CCi} 10.6, \mathrm{CCi}_{1.0}$ and $\mathrm{CCi}_{2.0}$ nanocomposite membranes, respectively, which were comparable or much lower in comparison with those reported for oil packaging, including SRC/sorbitol ${ }^{47}$ and $\mathrm{CS} / \mathrm{cm}-\mathrm{CNC}^{48}$ (Figure. 5f). 
(a)

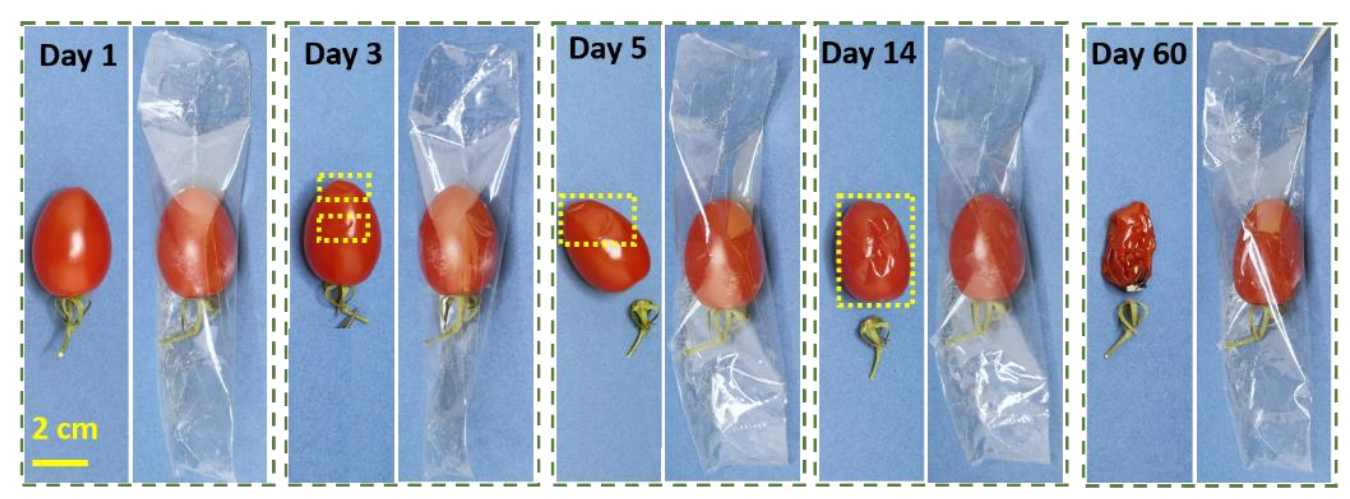

(b)

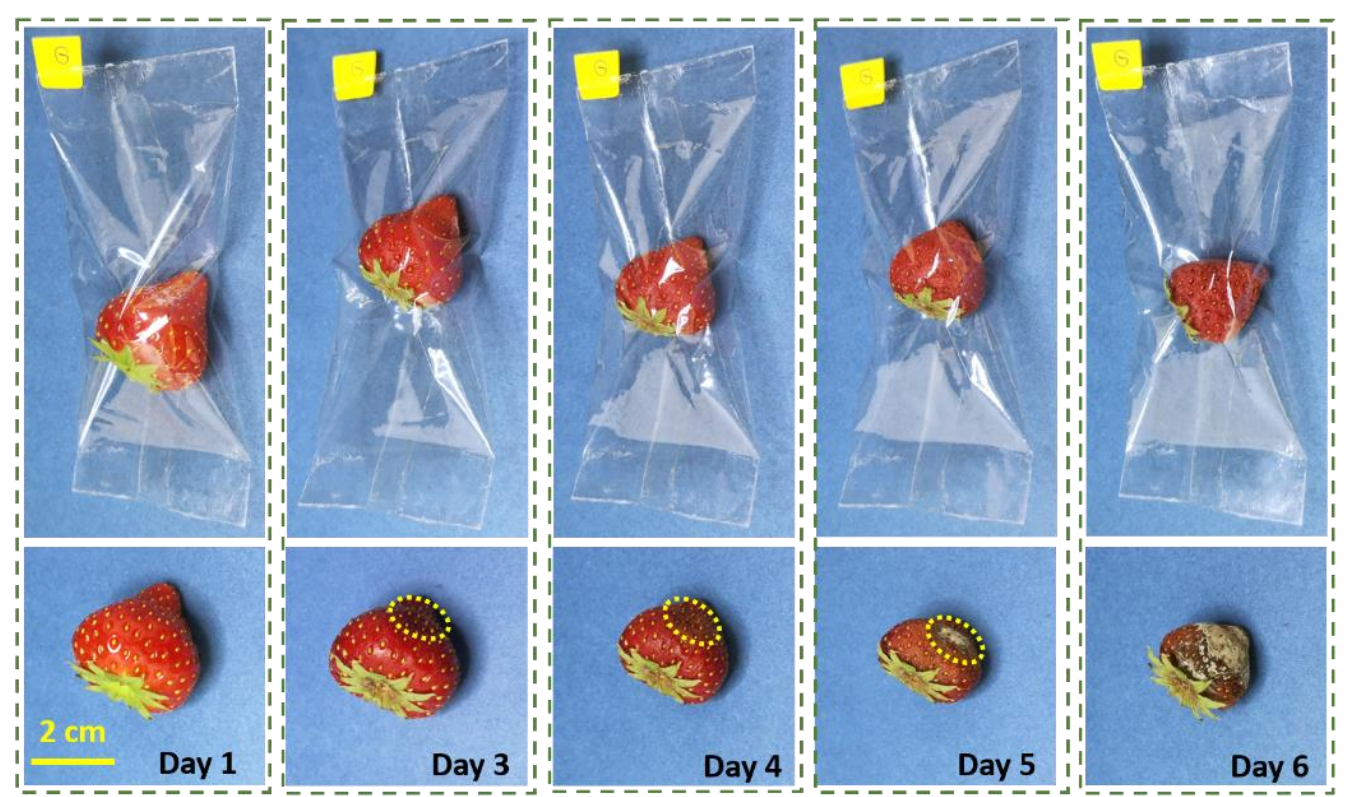

Figure 6. Self-compounded CCi nanocomposite membranes with DS of 0.6 applied as packaging materials for (a) mini-date vine tomatoes and (b) strawberries. The nonpackaged and packaged mini-date vine tomatoes were stored in an environment with temperature of $23-25^{\circ} \mathrm{C}$ and $\mathrm{RH}$ of $70-80 \%$, while the strawberries were stored in ambient environment with room temperature and $\mathrm{RH}$ of 30-40\%. The yellow dashed rectangles in (a) denote the wilted area of non-packaged mini-date vine tomatoes, while the yellow dashed circles in (b) denote the areas with mold spoilage of non-packaged strawberries. 
The self-compounded $\mathrm{CCi}$ nanocomposite membranes demonstrated superior mechanical properties, thermal/humidity resistance, gas/oil barrier properties, which allow them ready for versatile applications, e.g., packaging materials. Self-compounded CCi nanocomposite membranes with DS of 0.6 were applied to package mini-date vine tomatoes (Figure. 6a) and strawberries (Figure. 6b). The non-packaged and packaged mini-date vine tomatoes were stored in an environment with temperature of $23-25{ }^{\circ} \mathrm{C}$ and $\mathrm{RH}$ of $70-80 \%$. The non-packaged mini-date vine tomatoes wilted the third day and the vine dropped off the fifth day. The withering of non-packaged mini-date vine tomatoes went on with prolonged time, while no significant withering or vine dropping were observed from the packaged ones even after 2 weeks. After 60 days, the nonpackaged mini-date vine tomatoes were completely shriveled while the packaged ones maintained in relatively fresh state with only minor water loss. The non-packaged and packaged strawberries were stored in ambient environment with room temperature and RH of 30-40 \% (Figure. 6b). The non-packaged strawberries became dark in color the third day and the darkening went on with longer time. A small area with mold spoilage appeared on the surface of the non-packaged strawberries the third day, which became larger the fourth day and hoary in color the fifth day. The sizes of non-packaged strawberries had a sharp decrease with prolonged time due to severe water loss. In contrast, the packaged strawberries maintained relatively bright in color without any spotted area and the sizes decreased in a slower rate. Thus, we successfully integrated multiple excellent properties in self-compounded nanocomposites with only one 
chemical constituent, which showed promising application potential, e.g., as packaging materials.

\section{CONCLUSIONS}

In conclusion, we discovered novel self-compounded nanocomposite membranes from only one constituent, $\mathrm{CCi}$, via facile solvent casting method. The ensuing membranes were comprised of two distinct morphologies: CCi-NPs and CCi polymer matrix with CCi-NPs either firmly embedded in CCi matrix or fused with adjacent NPs. The self-compounded CCi nanocomposite membranes with compact structure and superior compatibility showed outstanding mechanical properties. $\mathrm{CCi}_{2.0}$ membranes demonstrated high strength and stiffness with a tensile strength and Young's modulus of $94 \mathrm{MPa}$ and $3.1 \mathrm{GPa}$, respectively, which is prominently higher than materials fabricated from some common polymers, cellulose derivatives and composites. DMA measurements verified the stability of the self-compounded nanocomposite structure and the strong coupling of $\mathrm{CCi}$ chains within the NPs, the matrix as well as their interfaces. Moreover, the self-compounded CCi membranes also demonstrated high transparency, remarkable UV-shielding functions and photothermal conversion functions, excellent thermal/humidity resistance and exceptional gas/oil barrier properties. As a result, the CCi membranes were applied as food packaging materials. Moreover, the $\mathrm{CCi}$ membranes are promising to be applied in versatile areas, such as UV-shielding, heat collection, desalination, photothermal actuations and so on. Thus, we constructed nanocomposites from one single constituent integrated with multiple 
excellent properties. Our work provides a new available route to achieve nanocomposites with less constituents and multiple outstanding properties.

\section{ASSOCIATED CONTENT}

\section{Supporting Information}

The Supporting Information is available free of charge at

Materials and methods, NMR spectra, elemental analysis results of CCi. Surface SEM images, reflection, reflection haze, loss modulus, TGA, DVS and contact angle of CCi membranes.

\section{AUTHOR INFORMATION}

\section{Corresponding Authors}

Kai Zhang - Wood Technology and Wood Chemistry, Department of Wood Technology and Wood-based Composites, Georg-August-University of Göttingen, Buesgenweg 4, D-37077, Goettingen, Germany;

\section{Email: kai.zhang@uni-goettingen.de}

Xiaodong Xia - School of Food Science and Technology, National Engineering Research Center of Seafood, Dalian Polytechnic University, Dalian, Liaoning, 116034 China; College of Food Science and Engineering, Sino-US Joint Research Center, Northwest A\&F University, Shaanxi, 712100, China; 
Email: foodscixiaodong@yahoo.com

\section{Authors}

Jiaxiu Wang - Wood Technology and Wood Chemistry, Department of Wood Technology and Wood-based Composites, Georg-August-University of Göttingen, Büsgenweg 4, D-37077, Göttingen, Germany

Yu Cao - School of Food Science and Technology, National Engineering Research Center of Seafood, Dalian Polytechnic University, Dalian, Liaoning, 116034 China; Beijing Advanced Innovation Center for Food Nutrition and Human Health, College of Food Science and Nutritional Engineering, China Agricultural University, Beijing, 100083, China

Bea Jaquet - Faculty of Engineering and Health, University of Applied Sciences and Arts, Von-Ossietzky-Straße 99, 37085 Göttingen, Germany

Christoph Gerhard - Faculty of Engineering and Health, University of Applied Sciences and Arts, Von-Ossietzky-Straße 99, 37085 Göttingen, Germany

Wei Li - Key Laboratory of Bio-based Material Science and Technology of Ministry of Education, Northeast Forestry University, Hexing Road 26, Harbin 150040, P. R. China.

Judith Elisabeth Rauschendorfer - Institute of Physical Chemistry, Georg-AugustUniversity of Göttingen, Tammannstraße 6, D-37077, Göttingen, Germany

Philipp Vana - Institute of Physical Chemistry, Georg-August-University of Göttingen, Tammannstraße 6, D-37077, Göttingen, Germany 


\section{Notes}

The authors declare no competing financial interest.

\section{ACKNOWLEDGMENTS}

K.Z. thanks the German Research Foundation (DFG) and Lower Saxony Ministry of Science and Culture for the project INST186/1281-1/FUGG. J.X.W. thanks the Chinese Scholarship Council (CSC) for the financial support of her PhD study. All authors thank Mr. Lukas Emmerich for the DVS measurement.

\section{REFERENCES}

(1)Choudhury, S.; Mangal, R.; Agrawal, A.; Archer, L. A. A Highly Reversible RoomTemperature Lithium Metal Battery Based on Crosslinked Hairy Nanoparticles. Nat. Commun. 2015, 6, 10101 .

(2)Zhang, H.; Hou, J.; Hu, Y.; Wang, P.; Ou, R.; Jiang, L.; Liu, J. Z.; Freeman, B. D.; Hill, A. J.; Wang, H. Ultrafast Selective Transport of Alkali Metal Ions in Metal Organic Frameworks with Subnanometer Pores. Sci. $A d v$. 2018, 4, eaaq0066.

(3) Someya, T.; Bao, Z.; Malliaras, G. G. The Rise of Plastic Bioelectronics. Nature 2016, 540, 379-385.

(4) Arandiyan, H.; Dai, H.; Ji, K.; Sun, H.; Li, J. Pt Nanoparticles Embedded in Colloidal Crystal Template Derived 3d Ordered Macroporous $\mathrm{Ce}_{0.6} \mathrm{Zr}_{0.3} \mathrm{y}_{0.1} \mathrm{O}_{2}$ : Highly Efficient Catalysts for Methane Combustion. ACS Catalysis 2015, 5, 1781-1793.

(5)Liang, J.; Li, L.; Chen, D.; Hajagos, T.; Ren, Z.; Chou, S. Y.; Hu, W.; Pei, Q. Intrinsically Stretchable and Transparent Thin-Film Transistors Based on Printable Silver Nanowires, Carbon Nanotubes and an Elastomeric Dielectric. Nat. Commun. 2015, 6, 1-10.

(6)Denny, M. S.; Moreton, J. C.; Benz, L.; Cohen, S. M. Metal-Organic Frameworks for Membrane-Based Separations. Nat. Rev. Mater. 2016, 1, 1-17.

(7)Bet-moushoul, E.; Mansourpanah, Y.; Farhadi, K.; Tabatabaei, M. TiO2 Nanocomposite 
Based Polymeric Membranes: A Review on Performance Improvement for Various Applications in Chemical Engineering Processes. Chem. Eng. J. 2016, 283, 29-46.

(8)Kinloch, I. A.; Suhr, J.; Lou, J.; Young, R. J.; Ajayan, P. M. Composites with Carbon Nanotubes and Graphene: An Outlook. Science 2018, 362, 547-553.

(9)Eckert, A.; Rudolph, T.; Guo, J.; Mang, T.; Walther, A. Exceptionally Ductile and Tough Biomimetic Artificial Nacre with Gas Barrier Function. Adv. Mater. 2018, 30, 1802477.

(10) Song, P.; Xu, Z.; Dargusch, M. S.; Chen, Z. G.; Wang, H.; Guo, Q. Granular Nanostructure: A Facile Biomimetic Strategy for the Design of Supertough Polymeric Materials with High Ductility and Strength. Adv. Mater. 2017, 29, 1704661.

(11) Ding, F.; Liu, J.; Zeng, S.; Xia, Y.; Wells, K. M.; Nieh, M.-P.; Sun, L. Biomimetic Nanocoatings with Exceptional Mechanical, Barrier, and Flame-Retardant Properties from Large-Scale Coassembly. Sci. Adv. 2017, 3, e1701212.

(12) Samaranayake, G.; Glasser, W. G. Cellulose Derivatives with Low DS. I. A Novel Acylation System. Carbohydr. Polym. 1993, 22, 1-7.

(13) Wang, Y.; Heinze, T.; Zhang, K. Stimuli-Responsive Nanoparticles from Ionic Cellulose Derivatives. Nanoscale 2016, 8, 648-657.

(14) Vaca-Garcia, C.; Borredon, M.-E.; Gaseta, A. Determination of the Degree of Substitution (DS) of Mixed Cellulose Esters by Elemental Analysis. Cellulose 2001, 8, 225231.

(15) Krässig, H. A. Cellulose: Structure, Accessibility and Reactivity. Gordon and Breach Science Publ.: 1993.

(16) Ashby, M. F. Materials Selection in Mechanical Design. Elsevier Ltd: 2011.

(17) Sarki, J.; Hassan, S. B.; Aigbodion, V. S.; Oghenevweta, J. E. Potential of Using Coconut Shell Particle Fillers in Eco-Composite Materials. J. Alloys Compd. 2011, 509, 23812385.

(18) Espinoza-Herrera, N.; Pedroza-Islas, R.; San Martín-Martinez, E.; Cruz-Orea, A.; Tomás, S. A. Thermal, Mechanical and Microstructures Properties of Cellulose Derivatives Films: A Comparative Study. Food Biophys. 2010, 6, 106-114.

(19) Willberg-Keyriläinen, P.; Vartiainen, J.; Harlin, A.; Ropponen, J. The Effect of Side- 
Chain Length of Cellulose Fatty Acid Esters on Their Thermal, Barrier and Mechanical Properties. Cellulose 2016, 24, 505-517.

(20) Ragoubi, M.; Bienaimé, D.; Molina, S.; George, B.; Merlin, A. Impact of Corona Treated Hemp Fibres onto Mechanical Properties of Polypropylene Composites Made Thereof. Ind. Crops and Prod. 2010, 31, 344-349.

(21) Han, D.; Yan, L.; Chen, W.; Li, W.; Bangal, P. R. Cellulose/Graphite Oxide Composite Films with Improved Mechanical Properties over a Wide Range of Temperature. Carbohydr. Polym. 2011, 83, 966-972.

(22) Bastos, M. d. S. R.; Laurentino, L. d. S.; Canuto, K. M.; Mendes, L. G.; Martins, C. M.; Silva, S. M. F.; Furtado, R. F.; Kim, S.; Biswas, A.; Cheng, H. N. Physical and Mechanical Testing of Essential Oil-Embedded Cellulose Ester Films. Polym. Test. 2016, 49, 156-161.

(23) Uddin, M. E.; Layek, R. K.; Kim, H. Y.; Kim, N. H.; Hui, D.; Lee, J. H. Preparation and Enhanced Mechanical Properties of Non-Covalently-Functionalized Graphene Oxide/Cellulose Acetate Nanocomposites. Compos. B. Eng. 2016, 90, 223-231.

(24) Heredia-Guerrero, J. A.; Goldoni, L.; Benitez, J. J.; Davis, A.; Ceseracciu, L.; Cingolani, R.; Bayer, I. S.; Heinze, T.; Koschella, A.; Heredia, A., et al. CellulosePolyhydroxylated Fatty Acid Ester-Based Bioplastics with Tuning Properties: Acylation Via a Mixed Anhydride System. Carbohydr. Polym. 2017, 173, 312-320.

(25) Wang, W.; Liang, T.; Bai, H.; Dong, W.; Liu, X. All Cellulose Composites Based on Cellulose Diacetate and Nanofibrillated Cellulose Prepared by Alkali Treatment. Carbohydr. Polym. 2018, 179, 297-304.

(26) Rynkowska, E.; Fatyeyeva, K.; Kujawa, J.; Dzieszkowski, K.; Wolan, A.; Kujawski, W. The Effect of Reactive Ionic Liquid or Plasticizer Incorporation on the Physicochemical and Transport Properties of Cellulose Acetate Propionate-Based Membranes. Polymers 2018, 10, 86.

(27) Biswas, A.; Furtado, R. F.; Bastos, M. d. S. R.; Benevides, S. D.; Oliveira, M. d. A.; Boddu, V.; Cheng, H. N. Preparation and Characterization of Carboxymethyl Cellulose Films with Embedded Essential Oils. J. Mater. Sci. Res. 2018, 7, 16.

(28) Quan, D.; Ivankovic, A. Effect of Core-Shell Rubber (CSR) Nano-Particles on 
Mechanical Properties and Fracture Toughness of an Epoxy Polymer. Polymer 2015, 66, 16-28.

(29) Hypoelae, R.; Husson, I.; Sundholm, F. Evaluation of Physical Properties of Plasticized Ethyl Cellulose Films Cast from Ethanol Solution Part 1. Int. J. Pharm. 1996, 133, $161-170$.

(30) Bandyopadhyay, A.; de Sarkar, M.; Bhowmick, A. K. Polymer-Filler Interactions in Sol-Gel Derived Polymer/Silica Hybrid Nanocomposites. J. Polym. Sci. B Polym. Phys. 2005, $43,2399-2412$.

(31) Zhang, K.; Geissler, A.; Standhardt, M.; Mehlhase, S.; Gallei, M.; Chen, L.; Thiele, C. M. Moisture-Responsive Films of Cellulose Stearoyl Esters Showing Reversible Shape Transitions. Sci. Rep. 2015, 5, 11011.

(32) Wolińska-Grabczyk, A.; Kubica, P.; Jankowski, A.; Wójtowicz, M.; Kansy, J.; Wojtyniak, M. Gas and Water Vapor Transport Properties of Mixed Matrix Membranes Containing 13x Zeolite. J. Membr. Sci. 2017, 526, 334-347.

(33) Bedane, A. H.; Eić, M.; Farmahini-Farahani, M.; Xiao, H. Water Vapor Transport Properties of Regenerated Cellulose and Nanofibrillated Cellulose Films. J. Membr. Sci. 2015, 493, 46-57.

(34) Colussi, R.; Pinto, V. Z.; El Halal, S. L. M.; Biduski, B.; Prietto, L.; Castilhos, D. D.; da Rosa Zavareze, E.; Dias, A. R. G. Acetylated Rice Starches Films with Different Levels of Amylose: Mechanical, Water Vapor Barrier, Thermal, and Biodegradability Properties. Food Chem. 2017, 221, 1614-1620.

(35) Liu, H.; Liu, C.; Peng, S.; Pan, B.; Lu, C. Effect of Polyethyleneimine Modified Graphene on the Mechanical and Water Vapor Barrier Properties of Methyl Cellulose Composite Films. Carbohydr. Polym. 2018, 182, 52-60.

(36) Li, L.; Zhou, Z. H.; Yang, B.; Ji, X.; Huang, H. D.; Zhong, G. J.; Xu, L.; Li, Z. M. Robust Cellulose Nanocomposite Films Based on Covalently Cross-Linked Network with Effective Resistance to Water Permeability. Carbohydr. Polym. 2019, 211, 237-248.

(37) El Miri, N.; Abdelouahdi, K.; Barakat, A.; Zahouily, M.; Fihri, A.; Solhy, A.; E1 Achaby, M. Bio-Nanocomposite Films Reinforced with Cellulose Nanocrystals: Rheology of Film-Forming Solutions, Transparency, Water Vapor Barrier and Tensile Properties of Films. 
Carbohydr. Polym. 2015, 129, 156-167.

(38) Al-Hassan, A. A.; Norziah, M. H. Starch-Gelatin Edible Films: Water Vapor Permeability and Mechanical Properties as Affected by Plasticizers. Food Hydrocoll. 2012, 26, $108-117$.

(39) Su, J.-F.; Huang, Z.; Zhao, Y.-H.; Yuan, X.-Y.; Wang, X.-Y.; Li, M. Moisture Sorption and Water Vapor Permeability of Soy Protein Isolate/Poly(vinyl acohol)/Glycerol Blend Films. Ind. Crops Prod. 2010, 31, 266-276.

(40) Cao, L.; Ge, T.; Meng, F.; Xu, S.; Li, J.; Wang, L. An Edible Oil Packaging Film with Improved Barrier Properties and Heat Sealability from Cassia Gum Incorporating Carboxylated Cellulose Nano Crystal Whisker. Food Hydrocoll. 2020, 98, 105251.

(41) Ali Dadfar, S. M.; Alemzadeh, I.; Reza Dadfar, S. M.; Vosoughi, M. Studies on the Oxygen Barrier and Mechanical Properties of Low Density Polyethylene/Organoclay Nanocomposite Films in the Presence of Ethylene Vinyl Acetate Copolymer as a New Type of Compatibilizer. Mater. Des. 2011, 32, 1806-1813.

(42) Semsarzadeh, M. A.; Ghalei, B. Characterization and Gas Permeability of Polyurethane and Polyvinyl Acetate Blend Membranes with Polyethylene OxidePolypropylene Oxide Block Copolymer. J. Membr. Sci. 2012, 401, 97-108.

(43) Yang, D.; Peng, X.; Zhong, L.; Cao, X.; Chen, W.; Zhang, X.; Liu, S.; Sun, R. "Green" Films from Renewable Resources: Properties of Epoxidized Soybean Oil Plasticized Ethyl Cellulose Films. Carbohydr. Polym. 2014, 103, 198-206.

(44) Dou, Y.; Xu, S.; Liu, X.; Han, J.; Yan, H.; Wei, M.; Evans, D. G.; Duan, X. Transparent, Flexible Films Based on Layered Double Hydroxide/Cellulose Acetate with Excellent Oxygen Barrier Property. Adv. Funct. Mater. 2014, 24, 514-521.

(45) Compton, O. C.; Kim, S.; Pierre, C.; Torkelson, J. M.; Nguyen, S. T. Crumpled Graphene Nanosheets as Highly Effective Barrier Property Enhancers. Adv. Mater. 2010, 22, $4759-4763$

(46) Russo, G. M.; Simon, G. P.; Incarnato, L. Correlation between Rheological, Mechanical, and Barrier Properties in New Copolyamide-Based Nanocomposite Films. Macromolecules 2006, 39, 3855-3864. 
(47) Farhan, A.; Hani, N. M. Characterization of Edible Packaging Films Based on SemiRefined Kappa-Carrageenan Plasticized with Glycerol and Sorbitol. Food Hydrocoll. 2017, 64, 48-58.

(48) Ma, X.; Cheng, Y.; Qin, X.; Guo, T.; Deng, J.; Liu, X. Hydrophilic Modification of Cellulose Nanocrystals Improves the Physicochemical Properties of Cassava Starch-Based Nanocomposite Films. LWT 2017, 86, 318-326.

TOC

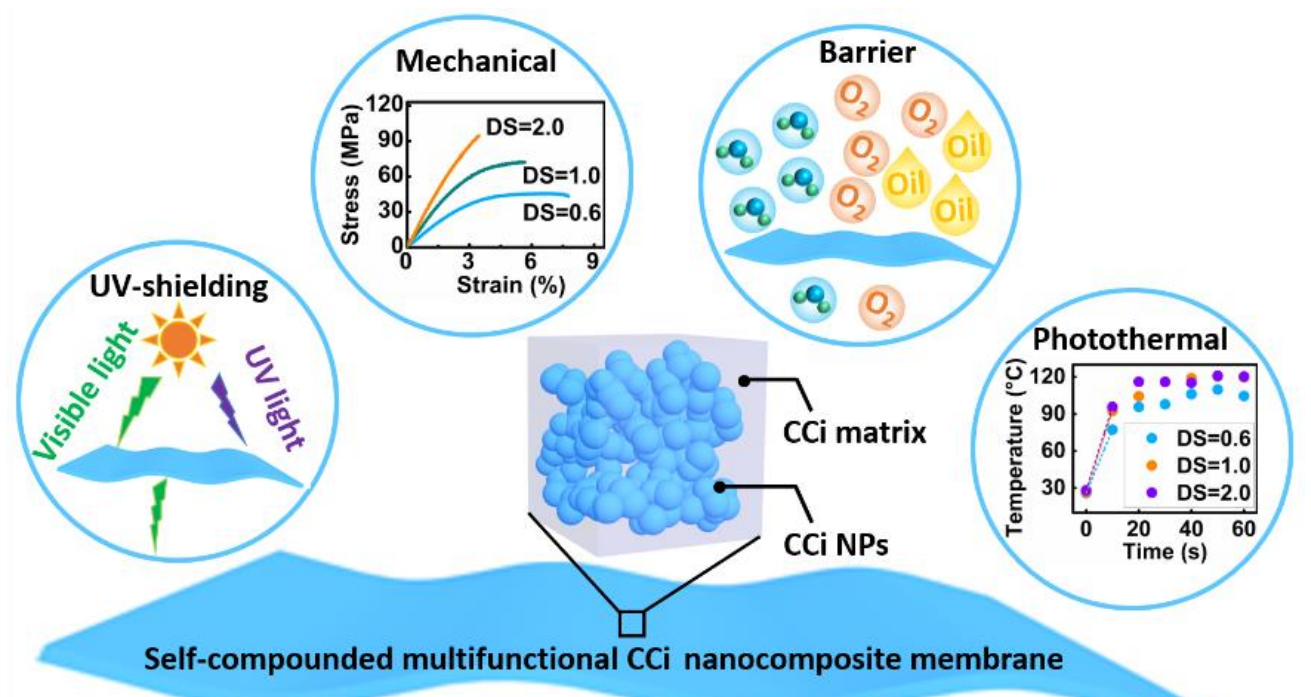




\section{Supporting Information}

\section{Self-compounded Nanocomposites: Toward Multifunctional Membranes with Superior Mechanical, Gas/oil Barrier, UV-shielding and Photothermal Conversion Properties}

Jiaxiu Wang, ${ }^{1}$ Yu Cao, ${ }^{2,3}$ Bea Jaquet,,${ }^{4}$ Christoph Gerhard, ${ }^{4}$ Wei Li, ${ }^{5}$ Xiaodong Xia, $, 2,6^{*}$ Judith E. Rauschendorfer, ${ }^{7}$ Philipp Vana $^{7}$ and Kai Zhang $^{1 *}$

${ }^{1}$ Wood Technology and Wood Chemistry, Department of Wood Technology and Wood-based Composites, Georg-August-University of Göttingen, Büsgenweg 4, D37077, Göttingen, Germany

${ }^{2}$ School of Food Science and Technology, National Engineering Research Center of Seafood, Dalian Polytechnic University, Dalian, Liaoning 116034, China

${ }^{3}$ Beijing Advanced Innovation Center for Food Nutrition and Human Health, College of Food Science and Nutritional Engineering, China Agricultural University, Beijing, 100083, China

${ }^{4}$ Faculty of Engineering and Health, University of Applied Sciences and Arts, VonOssietzky-Straße 99, D-37085, Göttingen, Germany 
${ }^{5}$ Key Laboratory of Bio-based Material Science and Technology of Ministry of

Education, Northeast Forestry University, Hexing Road 26, Harbin 150040, China.

${ }^{6}$ College of Food Science and Engineering, Sino-US Joint Research Center,

Northwest A\&F University, Shaanxi 712100, China

${ }^{7}$ Institute of Physical Chemistry, Georg-August-University of Göttingen,

Tammannstraße 6, D-37077, Göttingen, Germany

*Corresponding authors:

Kai Zhang

Email: kai.zhang@uni-goettingen.de

Xiaodong Xia

Email: foodscixiaodong@yahoo.com 


\section{EXPERIMENTAL SECTION}

Materials. Commercial microcrystalline cellulose (MCC) with particle sizes of $\sim 50$ $\mu \mathrm{m}$ and degree of polymerization of $\sim 270$ was purchased from Sigma-Aldrich Chemie GmbH. N, N-Dimethylacetamide (DMAc, $99.5 \%$ ) and cinnamoyl chloride (98\%) were purchased from J \& K Scientific GmbH. Lithium chloride ( $\mathrm{LiCl}$ ) was purchased from MP Biomedicals, LLC. Pyridine (99 \%) was purchased from abcr GmbH. Dimethylsulfoxide (DMSO, 99.5 \%) was purchased from Carl Roth GmbH \& Co. KG. Methanol (99.8 \%) was purchased from TH. Geyer GmbH \& Co. KG. Tetrahydrofuran (THF, $99.5 \%$ ) was purchased from VWR. Dummy CZ-Si wafer was purchased from MicroChemicals GmbH.

Synthesis of CCi. CCi with degree of substitution (DS) of 0.6, 1.0 and 2.0 (CCi 0.6 , $\mathrm{CCi}_{1.0}$ and $\mathrm{CCi}_{2.0}$ ) were synthesized by acylation of cellulose under homogeneous condition according to previously reported method with modifications. ${ }^{1}$ Briefly, MCC was firstly dried in vacuum oven at $103{ }^{\circ} \mathrm{C}$ overnight. $1 \mathrm{~g}$ dried MCC and $40 \mathrm{ml}$ DMAc were then fed into a $100 \mathrm{ml}$ three-necked flask, which was equipped with a magnetic stir bar and connected to a condenser. The mixture was stirred at $130{ }^{\circ} \mathrm{C}$ for 30 mins, followed by $3 \mathrm{~g} \mathrm{LiCl}$ added. After cooling down to room temperature, a clear cellulose solution was obtained. The solution was then heated to $60^{\circ} \mathrm{C}$ before cinnamoyl chloride $\left(2.00,2.65,4.50 \mathrm{ml}\right.$ for $\mathrm{CCi} 0.6, \mathrm{CCi}_{1.0}$ and $\mathrm{CCi}_{2.0}$, respectively) and pyridine $(2.24,2.98$, $5.07 \mathrm{ml}$ for $\mathrm{CCi}_{0.6}, \mathrm{CCi}_{1.0}$ and $\mathrm{CCi}_{2.0}$, respectively) were dropped into the solution under stirring. The reaction was carried out by maintaining the temperature at $60{ }^{\circ} \mathrm{C}$ for $3 \mathrm{hr}$. $\mathrm{CCi}$ with DS of $2.8\left(\mathrm{CCi}_{2.8}\right)$ was synthesized under heterogeneous condition. ${ }^{2} 1 \mathrm{~g}$ dried 
MCC and $30 \mathrm{ml}$ pyridine were fed into a $100 \mathrm{ml}$ three-necked flask. After raising the temperature to $100{ }^{\circ} \mathrm{C}, 6.00 \mathrm{ml}$ cinnamoyl chloride was added with stir. The mixture was then maintained at $100{ }^{\circ} \mathrm{C}$ for $1 \mathrm{~h}$. The subsequent mixtures were precipitated in methanol. The products were collected by centrifugation and purified by repeatedly dissolution in DMSO or THF and precipitation in methanol. The pure product was dried in vacuum before being dissolved in DMSO or THF for storage.

Nuclear Magnetic Resonance (NMR) Spectroscopy. CCi0.6 and $\mathrm{CCi}_{1.0}$ were dissolved in deuterated DMSO, while $\mathrm{CCi}_{2.0}$ and $\mathrm{CCi}_{2.8}$ were dissolved in chloroform for liquid state ${ }^{1} \mathrm{H}$ and ${ }^{13} \mathrm{C}$ NMR measurement. Spectra were recorded using a NMR spectrometer (Avance III HD, Bruker) with a frequency of $500 \mathrm{MHz}$ for ${ }^{1} \mathrm{H} \mathrm{NMR}$ and $125 \mathrm{MHz}$ for ${ }^{13} \mathrm{C}$ NMR. 65 scans were collected for ${ }^{1} \mathrm{H}$ NMR spectroscopy, whereas 16000 scans were accumulated for 13C NMR spectroscopy. The repetition delay was 5 $\mathrm{s}$ for ${ }^{1} \mathrm{H}$ NMR and $1 \mathrm{~s}$ for ${ }^{13} \mathrm{C}$ NMR.

Elemental Analysis. Elemental analysis was performed on an elemental analyzer (unicube, Elementar). The degree of substitution of CCi was calculated according to previously reported method: ${ }^{3}$

$$
D S=(162.141 \times c-72.066) /(108.099-130.146 \times c)
$$

where $c$ is the carbon content measured by elemental analysis. The elemental analysis results and the calculated DS of CCi were shown in Table S1.

Preparation of CCi Membranes. CCi membranes were prepared by facile solvent casting method. Firstly, a mold was assembled by sandwiching a wafer substrate 
between two blocks of teflon, one of them was cut with a cylindrical hollow area in the center as a container for CCi solutions. The wafer substrate was sonicated in DMSO or THF and deionized water respectively, followed by blow-drying with nitrogen before use. Then, $5 \mathrm{ml}$ of CCi solutions with a concentration of $10 \mathrm{mg} / \mathrm{ml}$ was transferred into the assembled molds. Membranes of $\mathrm{CCi}_{0.6}$ and $\mathrm{CCi}_{1.0}$ were dried from their DMSO solutions at $80{ }^{\circ} \mathrm{C}, 15$ mbar while membranes of $\mathrm{CCi}_{2.0}$ and $\mathrm{CCi}_{2.8}$ were dried from their THF solutions at ambient environment. The dried CCi membranes was peeled from wafer substrate after disassembly of the molds. Obtained membranes were 10-20 $\mu \mathrm{m}$ in thickness.

Scanning Electron Microscopy (SEM). The images of cross-section and surface of CCi membranes were obtained by using a scanning electron microscopy (SUPRA 35, Carl Zeiss SMT GmbH). A layer of carbon (with a thickness of $\sim 10 \mathrm{~nm}$ ) was vacuumcoated on the samples before the observation. The sizes of nanoparticles were measured by using Nano Measure software, 30 nanoparticles were measured to calculate the diameters.

Transmittance, UV-shielding, Reflectance and Reflection Haze. Transmittance and UV-shielding properties of CCi membranes were measured by using a UV-VIS spectrometer (SPECORD 205, Analytik Jena AG). Reflectance was measured with the aid of an UV-VIS spectrometer (Lambda 650, Perkin Elmer) at an angle of incidence of $8^{\circ}$. The reflection haze was determined using a commercial measurement device (Novo-Gloss 20/60/85 Glossmeter, Rhopoint Instruments) according to the standard 
ASTM E430. ${ }^{4}$ Five different measuring points with a spacing of approximately $1 \mathrm{~mm}$ were detected and the mean value was taken as the final data.

Photothermal Conversion Properties. The photothermal conversion properties were determined by monitoring the temperatures of $\mathrm{CCi}$ membranes under continuous UV irradiation with an IR camera (PT-32, Voltcraft) at increments of 10 seconds. The UV irradiation was performed with a commercial UV source (SUPERLITE I 05, LUMATEC). Experiments were performed at two distances between the UV source and the CCi membranes, i.e., $34 \mathrm{~mm}$ and $75 \mathrm{~mm}$.

Static Mechanical Tests. Tensile tests were performed by a microtensile tester (Z3, Grip-Engineering Thümler $\mathrm{GmbH}$ ) equipped with a $50 \mathrm{~N}$ load cell according to standard test method described by ASTM D882-02. ${ }^{5} \mathrm{CCi}$ membranes with a dimension of $20 \mathrm{~mm} \times 10 \mathrm{~mm}$, were loaded into the test machine with a clamp distance of $8.0 \mathrm{~mm}$. The membranes were then subjected to uniaxial extension with a constant rate of 2.0 $\mathrm{mm} / \mathrm{min}$ until rupture. In each case, at least 5 equal samples were measured to ensure accuracy of the results. All measurements were carried out at $20^{\circ} \mathrm{C}$ and $60 \% \mathrm{RH}$. The stress of membranes was calculated by dividing force by cross-section area while the strain $(\%)$ of membranes was defined by $(\mathrm{L}-\mathrm{L} 0) / \mathrm{L} 0 \times 100 \%$, where $\mathrm{L}$ was the instantaneous length and L0 was the initial length of the sample. Toe compensation was performed before the calculation of tensile strength, Young's modulus, elongation at break, and fracture energy according to ASTM D882-02. ${ }^{5}$

Dynamic Mechanical Thermal Analysis (DMTA). DMTA measurements were carried out by using a dynamic mechanical analysis system (GABO EPLEXOR, 
NETZSCH) with a force sensor of 150 N. CCi membranes with a dimension of $20 \mathrm{~mm}$ $\times 10 \mathrm{~mm}$ were loaded into the machine with a clamp distance of $8.0 \mathrm{~mm}$. The measurements were executed with a contact force of $0.5 \mathrm{~N}$, a static strain of $0.5 \%$ and a dynamic strain of $0.1 \%$. All measurements were carried out within the linear elastic region. For each case, 3-5 parallel tests were implemented to ensure that the data collected were reliable.

Thermal Gravimetric Analysis (TGA). Thermal gravimetric analysis (TGA) of CCi membranes were recorded by using a thermo-microbalance (TG 209 F3 Tarsus, $\mathrm{NETZSCH}$ ) in a nitrogen atmosphere. The samples were heated in $\mathrm{A} 12 \mathrm{O} 3$ crucibles that were pyrolytically cleaned at $1000{ }^{\circ} \mathrm{C}$ prior to the measurements. Measurements were carried out in the temperature range of $25-550{ }^{\circ} \mathrm{C}$ with a heating rate of $10 \mathrm{~K} / \mathrm{min}$.

Static Water Contact Angle. The wetting properties of CCi membranes were assessed on a Contact Angle System (OCA 15EC, DataPhysics). Static water contact angles were measured by using the sessile droplet method with dosing volume of $2.0 \mu \mathrm{L}$ and dosing rate of $1.0 \mu \mathrm{L} / \mathrm{s}$. For each membrane, the static water contact angle was acquired by taking the mean from at least 10 equivalent measurements.

Dynamic Vapor Sorption (DVS). Dynamic water vapor sorption behaviors of CCi membranes were assessed with a DVS apparatus (DVS Advantage, Surface Measurement Systems). CCi membranes, with a dimension of $10 \mathrm{~mm} \times 10 \mathrm{~mm}$ and a mass of $14.45 \pm 3.23 \mathrm{mg}$, were prepared for the measurements. The measurements were executed at $20{ }^{\circ} \mathrm{C}$ with $\mathrm{RH}$ first reduced to $0 \%$, until the mass change $(\mathrm{dm} / \mathrm{dt})$ was $<0.002 \%$ min-1 over a period of $10 \mathrm{~min}$ and the initial dry mass was recorded. 
Subsequently, the RH was increased from $5 \%$ to $95 \%$ in $10 \%$ steps (sorption) followed by a decrease to $0 \%$ in reverse order (desorption). During each measurement, the RH was maintained constant, until $\mathrm{dm} / \mathrm{dt}<0.002 \% \mathrm{~min}-1$ over a period of $10 \mathrm{~min}$ and the equilibrated mass was detected. The moisture content at each RH was calculated based on the mass of the membranes in equilibrium.

Brunauer-Emmett-Teller (BET) Surface Analysis. The pore size and surface area of the membranes were determined with a BET surface area analyzer (ASAP 2020, Micrometrics). Nitrogen sorption experiments were carried out at $77 \mathrm{~K}$. The samples were pretreated at $353 \mathrm{~K}$ in vacuum before the measurement. The BET specific surface area was calculated from the adsorption data. The pore size distribution was obtained by using the Barrett-Joyner-Halenda (BJH) model.

Permeability Tests. Water vapor permeability (WVP) was measured by using a gravimetric method according to ASTM E96-00 with modifications. ${ }^{6}$ Five equivalent measurements were carried out at $20{ }^{\circ} \mathrm{C}$. Previously dried glass bottles were loaded with $\sim 20 \mathrm{~g}$ dry $\mathrm{CaCl}_{2}$, and sealed with $\mathrm{CCi}$ membranes for the initial mass measurement. Then the systems were moved to an environment with $75 \% \mathrm{RH}$ and the mass increase $(\Delta \mathrm{m})$ was recorded within time interval $(\Delta \mathrm{t})$. The WVP was calculated with the following equation:

$$
W V P=(\Delta m \times d) /(\Delta t \times S \times P \times \Delta R H)
$$


where $d$ and $S$ denote the thickness and effective area of CCi membranes, respectively. $P$ is the saturated water vapor pressure at $20^{\circ} \mathrm{C} . \Delta R H$ represents the difference of relative humidity between the two sides of the membranes.

Oxygen permeability was measured by a gas permeability tester (VAC-V1, Labthink) according to test standard GB/T1038-2000. The measurements were carried out at 23 ${ }^{\circ} \mathrm{C}$ and $0 \% \mathrm{RH}$.

Oil permeability was measured by using a previous method with modifications. ${ }^{7}$ Five glass bottles were separately loaded with $3.0 \mathrm{ml}$ sunflower oil and sealed with $\mathrm{CCi}$ membranes. The bottles were then put upside down on ten layers of filter paper. The mass increase $(\Delta \mathrm{m})$ of the filter papers was taken after 7 days. The oil permeability was calculated as follows:

$$
\text { Oil Permeability }=(\Delta m \times d) /(S \times \Delta t)
$$

Where $d$ and $S$ denote the thickness and effective area of $\mathrm{CCi}$ membranes, respectively. $\Delta t$ represents the time intervals. 


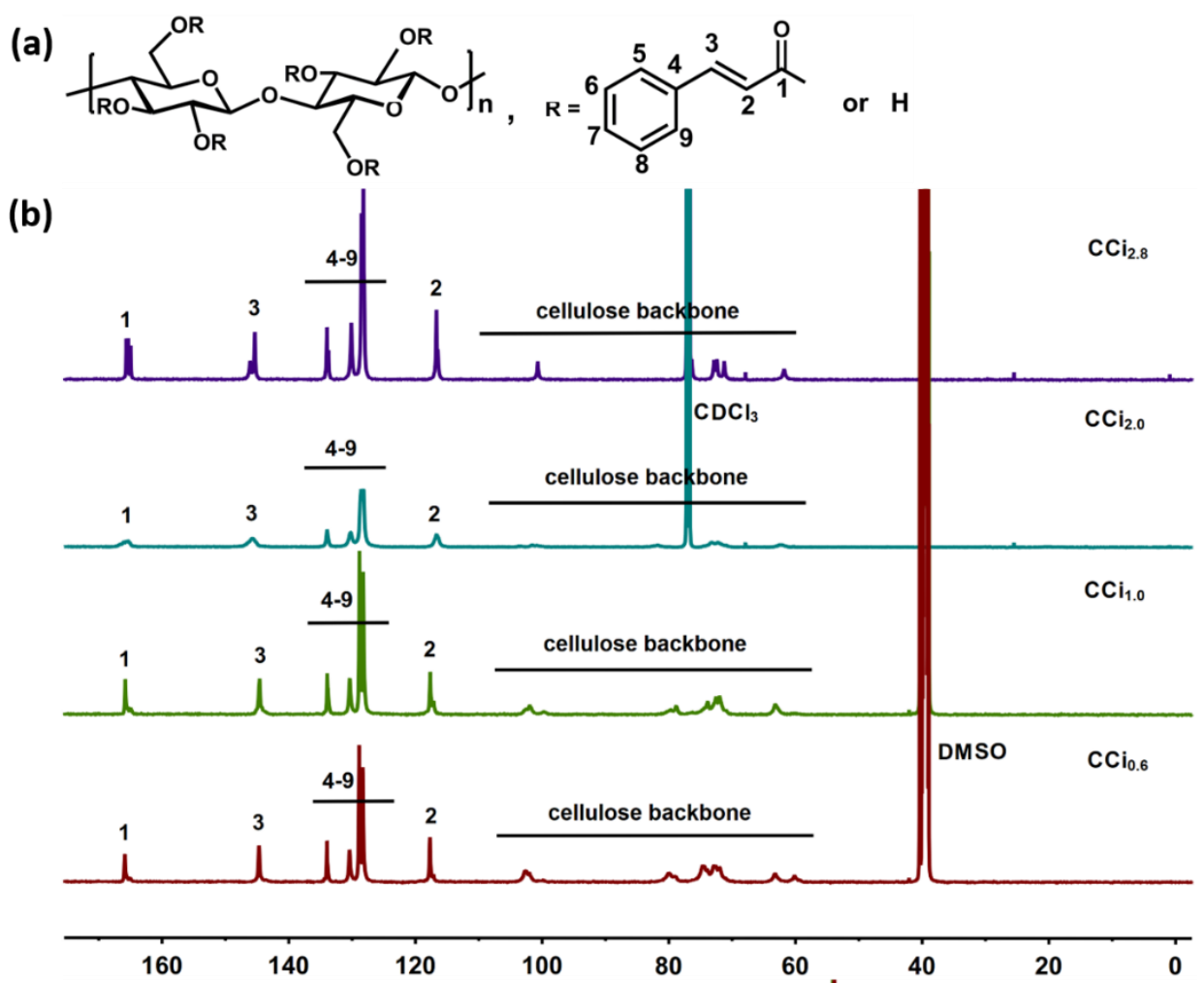

(c)

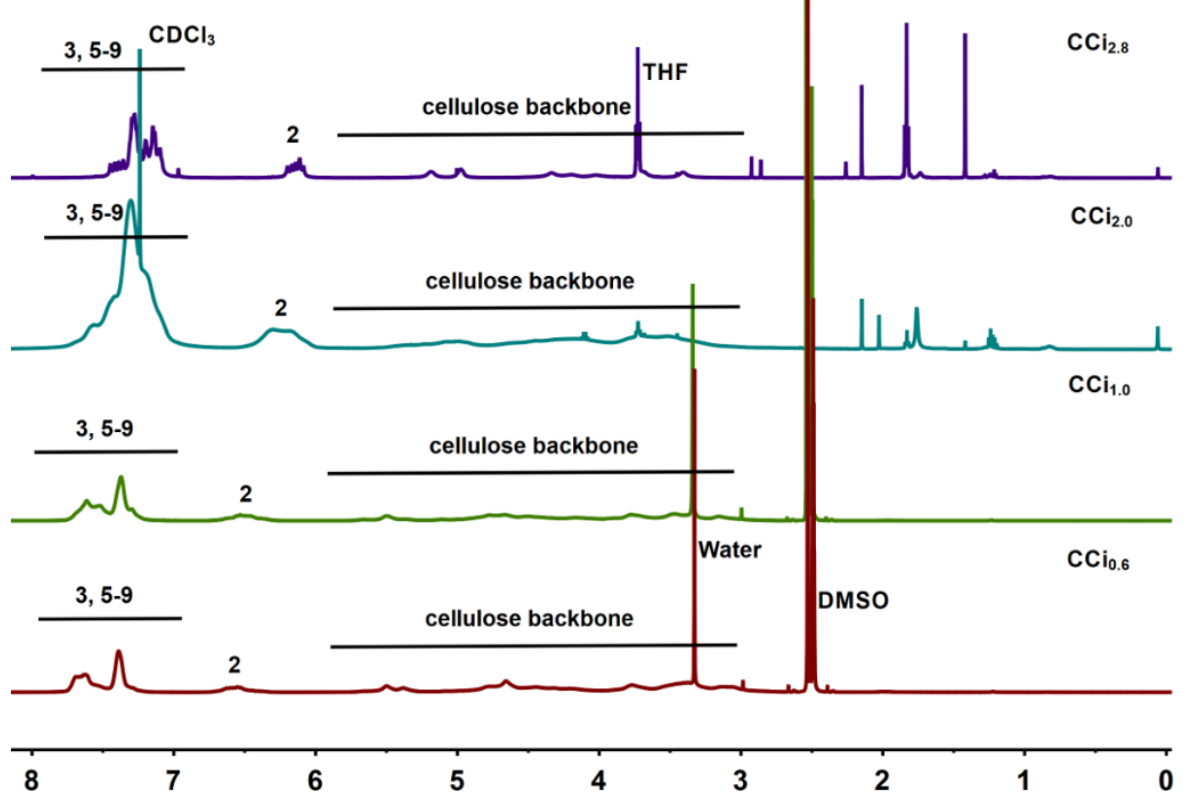

Fig. S1 (a) Molecular formula, (b) ${ }^{13} \mathrm{C}$ NMR and (c) ${ }^{1} \mathrm{H}$ NMR spectra of cellulose cinnamate (CCi) with degree of substitution (DS) of 0.6, 1.0, 2.0 and 2.8 (CCi ${ }_{0.6}, \mathrm{CCi}_{1.0}$, $\mathrm{CCi}_{2.0}$ and $\mathrm{CCi}_{2.8}$ ). CCi0.6 and $\mathrm{CCi}_{1.0}$ were dissolved in DMSO-d6, while $\mathrm{CCi}_{2.0}$ and $\mathrm{CCi}_{2.8}$ were dissolved in $\mathrm{CDCl}_{3}$. 
Signals from both cellulose backbone and cinnamoyl groups were observed from ${ }^{13} \mathrm{C}$ and ${ }^{1} \mathrm{H}$ NMR spectra. Within ${ }^{13} \mathrm{C}$ NMR spectra (Fig. S1b), the peak at $166 \mathrm{ppm}$ denote the carboxyl groups, whereas the signal at around $145 \mathrm{ppm}$ represents the carbon at $\beta$ position and the peak at around $117 \mathrm{ppm}$ originates from the carbon at $\alpha$ position. ${ }^{8}$ The signals from 126 to $135 \mathrm{ppm}$ correspond to the carbon from benzene ring and the small signals from 60 to 110 ppm derive from cellulose backbone. ${ }^{9}$ Within the ${ }^{1} \mathrm{H}$ NMR spectra (Fig. S1c), the signals from 6 to $6.8 \mathrm{ppm}$ denote the hydrogen at $\alpha$ position of carboxyl groups. The peaks from 7 to $7.8 \mathrm{ppm}$ represent the hydrogen at $\beta$ position of carboxyl group and the hydrogen from the benzene ring. ${ }^{10}$ The small peaks from 3.0 to 5.8 originate from cellulose backbone. ${ }^{9}$
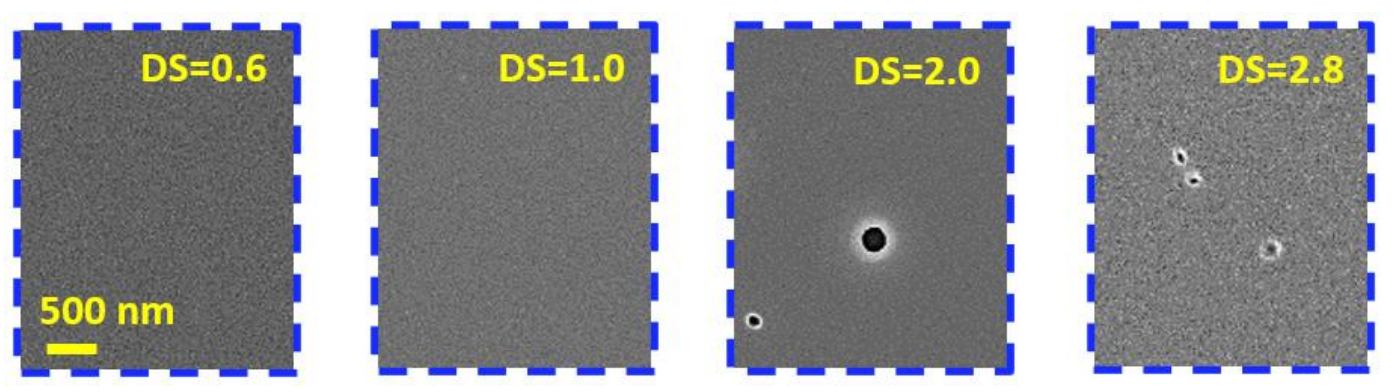

Fig. S2 Scanning electron microscopy (SEM) images showing the surfaces of selfcompounded nanocomposite membranes fabricated from CCi with DS of 0.6, 1.0, 2.0 and 2.8. 
(a)

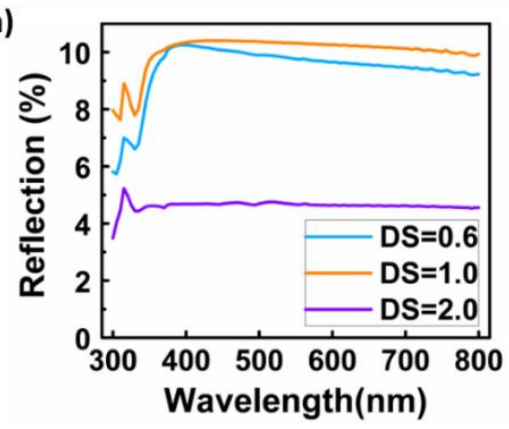

(c)

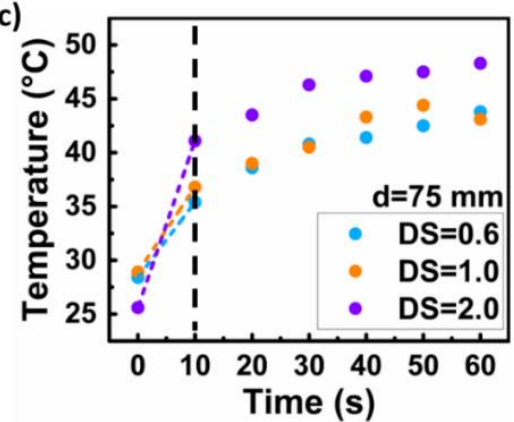

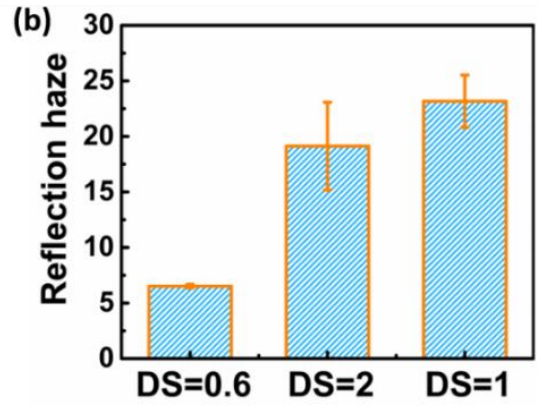

(d)

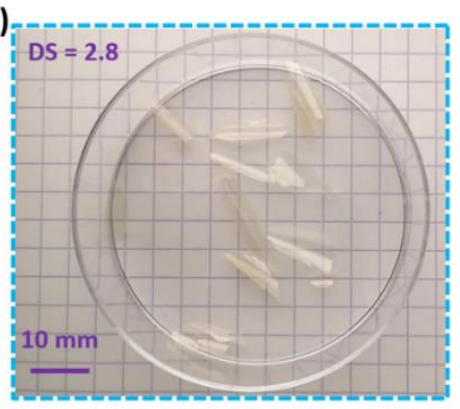

Fig. S3 (a) Reflection, (b) Reflection haze of self-compounded CCi membranes with

DS of $0.6,1.0$ and 2.0, respectively. (c) Time-dependent temperature of selfcompounded CCi membranes under UV irradiation with a distance of $75 \mathrm{~mm}$ between UV sources and membranes. The dashed lines show the temperature increase rate of CCi membranes in the first 10 seconds. (d) Photographic image showing the mechanical brittleness of self-compounded CCi nanocomposite membranes with DS of 2.8 . 
(a)

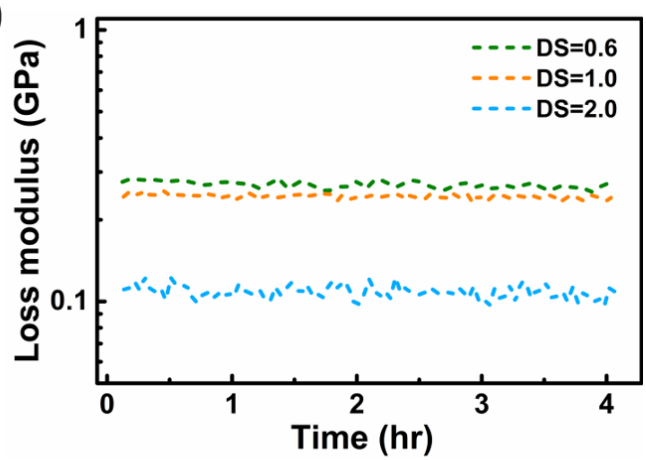

(c)

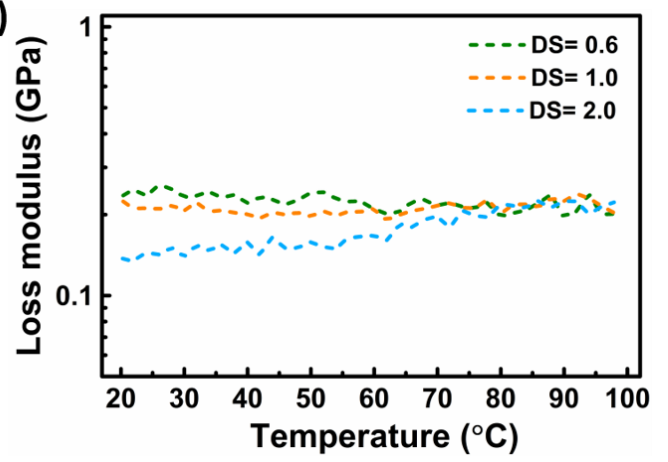

(b)

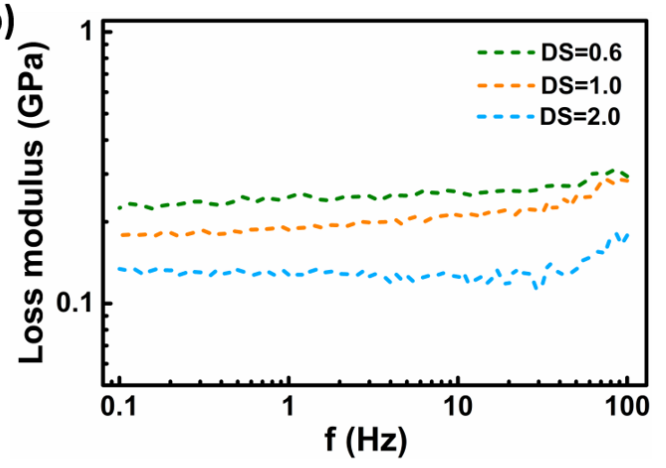

(d)

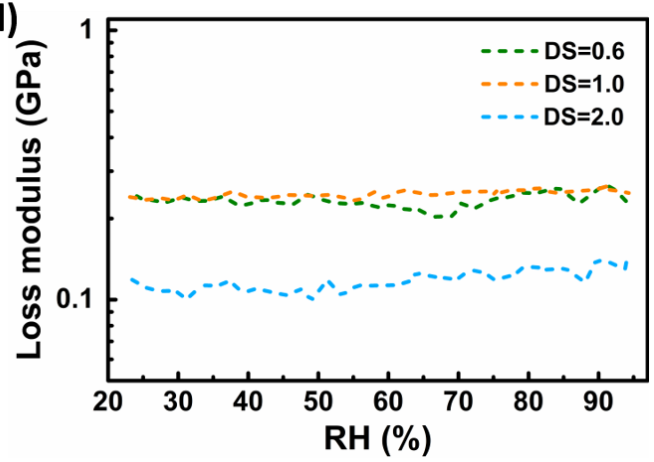

Fig. S4 Loss modulus of self-compounded $\mathrm{CCi}$ nanocomposite membranes with various DSs. (a) time scanning curves at $25^{\circ} \mathrm{C}, 30 \% \mathrm{RH}$ with a frequency of $10 \mathrm{~Hz}$, (b) frequency scanning curves at $25^{\circ} \mathrm{C}, 30 \% \mathrm{RH}$, (c) temperature scanning curves at 30 $\% \mathrm{RH}$ with a frequency of $10 \mathrm{~Hz}$ and temperature increasing rate of $2{ }^{\circ} \mathrm{C} / \mathrm{min}$, and (d) humidity scanning curves at $25^{\circ} \mathrm{C}$, with a frequency of $10 \mathrm{~Hz}$. 

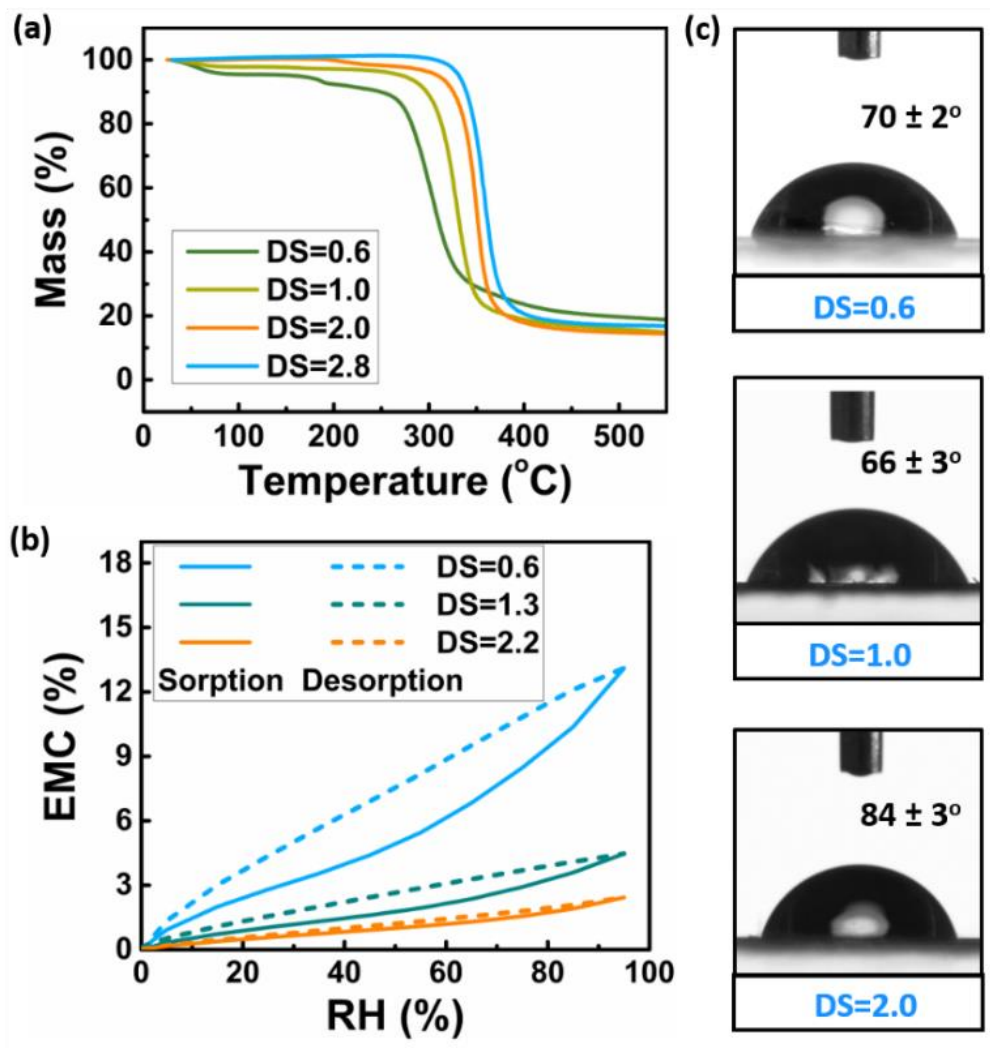

Fig. S5 (a) TGA curves, (b) Dynamic water vapor sorption isotherms and (c) Static water contact angles of self-compounded CCi nanocomposite membranes with various DSs.

Table S1 Elemental analysis results of cellulose cinnamate (CCi).

\begin{tabular}{ccc}
\hline $\mathbf{C ~ ( \% )}$ & H (\%) & DS \\
\hline 56.90 & 5.91 & 0.59 \\
61.36 & 5.50 & 0.97 \\
68.43 & 5.21 & 2.04 \\
71.24 & 5.34 & 2.82 \\
\hline
\end{tabular}


Table S2 Water vapor permeability, oxygen permeability and oil permeability of selfcompounded CCi nanocomposite membranes in comparison with other reported barrier membranes fabricated from synthetic polymers, biopolymers, bio-based polymers and some composites.

\begin{tabular}{|c|c|c|c|}
\hline Materials & $\begin{array}{l}\text { Water vapor permeability } \\
\left(\mathrm{g} \mathrm{m}^{-1} \mathrm{~s}^{-1} \mathrm{~Pa}^{-1}\right)\end{array}$ & $\begin{array}{l}\text { Oxygen permeability } \\
\left(\mathrm{cm}^{3} \cdot \mathrm{cm} / \mathrm{cm}^{2} \cdot \mathrm{s} \cdot \mathrm{cmHg}\right)\end{array}$ & $\begin{array}{l}\text { Oil permeability } \\
\left(\mathrm{g} \mathrm{mm} \mathrm{m}^{-2} \text { day }^{-1}\right)\end{array}$ \\
\hline $\mathrm{MC} / \mathrm{rGO}^{11}$ & $5.98 \times 10^{-11}$ & -- & -- \\
\hline $\mathrm{CRC} / \mathrm{GO}^{12}$ & $5.57 \times 10^{-11}$ & -- & -- \\
\hline $\mathrm{CMC} / \mathrm{ST} / \mathrm{CNC}^{13}$ & $11.1 \times 10^{-11}$ & -- & -- \\
\hline ST/sorbital ${ }^{14}$ & $(3.06 \pm 0.28) \times 10^{-11}$ & -- & -- \\
\hline SPI/PVA/glycerol ${ }^{15}$ & $(2.03 \pm 0.18) \times 10^{-11}$ & -- & -- \\
\hline PLLA/PDLA $^{16}$ & $1.00 \times 10^{-11}$ & -- & -- \\
\hline $\mathrm{RC}^{17}$ & $(2.22-7.12) \times 10^{-11}$ & -- & -- \\
\hline $\mathrm{HNBR}^{18}$ & $3.08 \times 10^{-11}$ & -- & -- \\
\hline $\mathrm{EVA}^{18}$ & $3.41 \times 10^{-11}$ & -- & -- \\
\hline Amylose $e^{19}$ & $19.94 \times 10^{-11}$ & -- & -- \\
\hline $\mathrm{EC}^{20}$ & -- & $(11.1 \pm 0.1) \times 10^{-10}$ & -- \\
\hline $\mathrm{EC} / \mathrm{ESO}^{20}$ & -- & $(4.3 \pm 0.1) \times 10^{-10}$ & -- \\
\hline $\mathrm{CA}^{21}$ & -- & $1.75 \times 10^{-6}$ & -- \\
\hline $\mathrm{CA} / \mathrm{LDH}^{21}$ & -- & $6.4 \times 10^{-8}$ & -- \\
\hline PS/Graphene ${ }^{22}$ & -- & $(1.84 \pm 0.02) \times 10^{-10}$ & -- \\
\hline Nylon ${ }^{23}$ & -- & $2.84 \times 10^{-12}$ & -- \\
\hline Nylon/silicate ${ }^{23}$ & -- & $1.47 \times 10^{-12}$ & -- \\
\hline LDPE $^{24}$ & -- & $3.4 \times 10^{-10}$ & -- \\
\hline LDPE/EVA/OC ${ }^{24}$ & -- & $1.9 \times 10^{-10}$ & -- \\
\hline $\mathrm{PU}^{25}$ & -- & $(5.64 \pm 0.2) \times 10^{-10}$ & -- \\
\hline $\mathrm{PVAc}^{25}$ & -- & $(5.10 \pm 1.0) \times 10^{-12}$ & -- \\
\hline $\mathrm{BPSH}^{26}$ & -- & $1.46 \times 10^{-11}$ & -- \\
\hline SRC/sorbitol ${ }^{27}$ & -- & -- & $0.37 \pm 0.03$ \\
\hline $\mathrm{CS} / \mathrm{cm}-\mathrm{CNC}^{28}$ & -- & -- & $0.5 \pm 0.03$ \\
\hline Calcium alginate ${ }^{29}$ & -- & -- & $189.6 \pm 2.4$ \\
\hline $\mathrm{CG} / \mathrm{CNC}^{7}$ & $(2.61 \pm 0.08) \times 10^{-10}$ & $(2.57 \pm 1.02) \times 10^{-12}$ & $0.07-0.55$ \\
\hline $\mathrm{CCi}_{0.6}$ & $(1.33 \pm 0.11) \times 10^{-11}$ & $(8.48 \pm 2.39) \times 10^{-13}$ & $0.36 \pm 0.03$ \\
\hline $\mathrm{CCi}_{1.0}$ & $(1.35 \pm 0.12) \times 10^{-11}$ & $5.11 \times 10^{-11}$ & $0.81 \pm 0.02$ \\
\hline
\end{tabular}


MC: methyl cellulose, rGO: reduced graphene oxide, CRC: cross-linked regenerated cellulose, GO: graphene oxide, CMC: carboxymethyl cellulose, ST: starch, CNC: cellulose nanocrystals, SPI: soy protein isolate, PVA: poly(vinyl alcohol), PLLA: Poly(L-lactide), PDLA: Poly(D-lactide), RC: regenerated cellulose, HNBR: hydrogenated nitrile rubber, EVA: ethylenevinyl acetate copolymer, EC: ethyl cellulose, ESO: epoxidized soybean oil, CA: cellulose acetate, LDH: Layered double hydroxide, PS: polystyrene, LDPE: low density polyethylene, OC: organoclay, PU: polyurethane, PVAc: polyvinyl acetate, BPSH: biphenol-based sulfonated poly(arylene ether sulfone), SRC: semi-refined kappa-carrageenan, CS: cassava starch, cm-CNC: carboxymethyl cellulose nanocrystals, CG: cassia-gum.

\section{REFERENCES}

(1) Samaranayake, G.; Glasser, W. G. Cellulose Derivatives with Low DS. I. A Novel Acylation System. Carbohydr. Polym. 1993, 22, 1-7.

(2)Wang, Y.; Heinze, T.; Zhang, K. Stimuli-Responsive Nanoparticles from Ionic Cellulose Derivatives. Nanoscale 2016, 8, 648-657.

(3) Vaca-Garcia, C.; Borredon, M.-E.; Gaseta, A. Determination of the Degree of Substitution (DS) of Mixed Cellulose Esters by Elemental Analysis. Cellulose 2001, 8, 225-231.

(4)Westlund, H. B.; Meyer, G. W. Applying Appearance Standards to Light Reflection Models. In Proceedings of the 28th annual conference on Computer graphics and interactive techniques; August, 2001; pp 501-510.

(5) ASTM Standard D882-02, Standard Test Method for Tensile Properties of Thin Plastic Sheeting. ASTM International, West Conshohocken, PA, USA, 2002.

(6) ASTM Standard E96-00, Standard Test Methods for Water Vapour Transmission of Materials. Annual book of American Society for Testing Materials (ASTM) standards, 2000. 
(7)Cao, L.; Ge, T.; Meng, F.; Xu, S.; Li, J.; Wang, L. An Edible Oil Packaging Film with Improved Barrier Properties and Heat Sealability from Cassia Gum Incorporating Carboxylated Cellulose Nano Crystal Whisker. Food Hydrocoll. 2020, 98, 105251.

(8)Wang, W.; Liang, T.; Bai, H.; Dong, W.; Liu, X. All Cellulose Composites Based on Cellulose Diacetate and Nanofibrillated Cellulose Prepared by Alkali Treatment. Carbohydr. Polym. 2018, 179, 297-304.

(9) Meng, X.; Matson, J. B.; Edgar, K. J. Olefin Cross-Metathesis as a Source of Polysaccharide Derivatives: Cellulose Omega-Carboxyalkanoates. Biomacromolecules 2014, $15,177-187$

(10) Dai, J.; Kim, J.-C. Photo and Thermal Properties of Cinnamoyl Pluronic F-127. Polym. Int. 2014, 63, 501-506.

(11) Liu, H.; Liu, C.; Peng, S.; Pan, B.; Lu, C. Effect of Polyethyleneimine Modified Graphene on the Mechanical and Water Vapor Barrier Properties of Methyl Cellulose Composite Films. Carbohydr. Polym. 2018, 182, 52-60.

(12) Li, L.; Zhou, Z. H.; Yang, B.; Ji, X.; Huang, H. D.; Zhong, G. J.; Xu, L.; Li, Z. M. Robust Cellulose Nanocomposite Films Based on Covalently Cross-Linked Network with Effective Resistance to Water Permeability. Carbohydr. Polym. 2019, 211, 237-248.

(13) El Miri, N.; Abdelouahdi, K.; Barakat, A.; Zahouily, M.; Fihri, A.; Solhy, A.; El Achaby, M. Bio-Nanocomposite Films Reinforced with Cellulose Nanocrystals: Rheology of Film-Forming Solutions, Transparency, Water Vapor Barrier and Tensile Properties of Films. Carbohydr. Polym. 2015, 129, 156-167.

(14) Al-Hassan, A. A.; Norziah, M. H. Starch-Gelatin Edible Films: Water Vapor Permeability and Mechanical Properties as Affected by Plasticizers. Food Hydrocoll. 2012, 26, $108-117$.

(15) Su, J.-F.; Huang, Z.; Zhao, Y.-H.; Yuan, X.-Y.; Wang, X.-Y.; Li, M. Moisture Sorption and Water Vapor Permeability of Soy Protein Isolate/Poly(vinyl alcohol)/Glycerol Blend Films. Ind. Crops Prod. 2010, 31, 266-276.

(16) Tsuji, H.; Tsuruno, T. Water Vapor Permeability of Poly(L-lactide)/Poly(D-lactide) Stereocomplexes. Macromol. Mater. Eng. 2010, 295, 709-715. 
(17) Bedane, A. H.; Eić, M.; Farmahini-Farahani, M.; Xiao, H. Water Vapor Transport Properties of Regenerated Cellulose and Nanofibrillated Cellulose Films. J. Membr. Sci. 2015, $493,46-57$.

(18) Wolińska-Grabczyk, A.; Kubica, P.; Jankowski, A.; Wójtowicz, M.; Kansy, J.; Wojtyniak, M. Gas and Water Vapor Transport Properties of Mixed Matrix Membranes Containing 13x Zeolite. J. Membr. Sci. 2017, 526, 334-347.

(19) Colussi, R.; Pinto, V. Z.; El Halal, S. L. M.; Biduski, B.; Prietto, L.; Castilhos, D. D.; da Rosa Zavareze, E.; Dias, A. R. G. Acetylated Rice Starches Films with Different Levels of Amylose: Mechanical, Water Vapor Barrier, Thermal, and Biodegradability Properties. Food Chem. 2017, 221, 1614-1620.

(20) Yang, D.; Peng, X.; Zhong, L.; Cao, X.; Chen, W.; Zhang, X.; Liu, S.; Sun, R. "Green" Films from Renewable Resources: Properties of Epoxidized Soybean Oil Plasticized Ethyl Cellulose Films. Carbohydr. Polym. 2014, 103, 198-206.

(21) Dou, Y.; Xu, S.; Liu, X.; Han, J.; Yan, H.; Wei, M.; Evans, D. G.; Duan, X. Transparent, Flexible Films Based on Layered Double Hydroxide/Cellulose Acetate with Excellent Oxygen Barrier Property. Adv. Funct. Mater. 2014, 24, 514-521.

(22) Compton, O. C.; Kim, S.; Pierre, C.; Torkelson, J. M.; Nguyen, S. T. Crumpled Graphene Nanosheets as Highly Effective Barrier Property Enhancers. Adv. Mater. 2010, 22, $4759-4763$.

(23) Russo, G. M.; Simon, G. P.; Incarnato, L. Correlation between Rheological, Mechanical, and Barrier Properties in New Copolyamide-Based Nanocomposite Films. Macromolecules 2006, 39, 3855-3864.

(24) Ali Dadfar, S. M.; Alemzadeh, I.; Reza Dadfar, S. M.; Vosoughi, M. Studies on the Oxygen Barrier and Mechanical Properties of Low Density Polyethylene/Organoclay Nanocomposite Films in the Presence of Ethylene Vinyl Acetate Copolymer as a New Type of Compatibilizer. Mater. Des. 2011, 32, 1806-1813.

(25) Semsarzadeh, M. A.; Ghalei, B. Characterization and Gas Permeability of Polyurethane and Polyvinyl Acetate Blend Membranes with Polyethylene OxidePolypropylene Oxide Block Copolymer. J. Membr. Sci. 2012, 401, 97-108. 
(26) Mohamed, H. F. M.; Kobayashi, Y.; Kuroda, C. S.; Takimoto, N.; Ohira, A. Free Volume, Oxygen Permeability, and Uniaxial Compression Storage Modulus of Hydrated Biphenol-Based Sulfonated Poly(arylene ether sulfone). J. Membr. Sci. 2010, 360, 84-89.

(27) Farhan, A.; Hani, N. M. Characterization of Edible Packaging Films Based on SemiRefined Kappa-Carrageenan Plasticized with Glycerol and Sorbitol. Food Hydrocoll. 2017, 64, $48-58$.

(28) Ma, X.; Cheng, Y.; Qin, X.; Guo, T.; Deng, J.; Liu, X. Hydrophilic Modification of Cellulose Nanocrystals Improves the Physicochemical Properties of Cassava Starch-Based Nanocomposite Films. LWT 2017, 86, 318-326.

(29) Biao, Y.; Yuxuan, C.; Qi, T.; Ziqi, Y.; Yourong, Z.; McClements, D. J.; Chongjiang, C. Enhanced Performance and Functionality of Active Edible Films by Incorporating Tea Polyphenols into Thin Calcium Alginate Hydrogels. Food Hydrocoll. 2019, 97, 105197. 


\section{Publication 3}

\section{Hydroplastic polymer as eco-friendly hydrosetting plastics}

Jiaxiu Wang ${ }^{1}$, Lukas Emmerich ${ }^{2}$, Jianfeng Wu ${ }^{3}$, Philipp Vana ${ }^{4}$, Kai Zhang ${ }^{1 *}$

1 Wood Technology and Wood Chemistry, Department of Wood Technology and Woodbased Composites, Georg-August-University of Göttingen, Büsgenweg 4, D-37077, Göttingen, Germany.

2 Wood Biology and Wood Products, Georg-August-University of Göttingen, Büsgenweg 4, D-37077, Göttingen, Germany.

3 Sino-German Joint Research Lab for Space Biomaterials and Translational Technology, School of Life Sciences, Northwestern Polytechnical University, Xi'an, 710072, P. R. China.

4 Institute of Physical Chemistry, Georg-August-University of Göttingen, Tammannstraße 6, D-37077, Göttingen, Germany.

${ }^{\star}$ Corresponding author: kai.zhang@uni-goettingen.de 


\section{Abstract}

Plastics are everywhere in modern life. To address environmental issues caused by plastics, eco-friendly processing of plastics and their lifetime extension are highly desired but still extremely challenging. Hydroplastic polymers, with water massively affecting their properties, are scarcely studied. Herein, we reported a novel, eco-friendly and sustainable hydrosetting method for processing plastics based on a hydroplastic polymer - cellulose cinnamate (CCi). Transparent plastic membranes, obtained via facile solvent casting method, were mechanically robust with a tensile strength of 92.4 $\mathrm{MPa}$ and Young's modulus of $2.6 \mathrm{GPa}$, which were superior than most common plastics. These bio-based planar plastic membranes can be transformed into versatile twodimensional (2D) and three-dimensional (3D) shapes by utilizing their hydroplastic properties, i.e., using water to manipulate the plasticity for shaping. The plasticity of CCi membranes was only prominently enhanced for shape-programming at relative humidity (RH) of $>78 \%$ and total water sorption amount of $>13.2 \mathrm{wt} \%$ allowing the multilayer water sorption. In particular, these programmed shapes maintained for more than 6 months and can be repeatedly reprogrammed into other 2D/3D shapes by the facile hydrosetting method, greatly extending their lifetime for real applications. The shape stability depends mainly on the stability of $\mathrm{RH}$, which is closely related to the mechano-sorptive creep behavior of CCi membranes.

Keywords: plastics, polymer processing, hydroplastic polymer, hydrosetting, cellulose, cinnamate 
Plastics have become increasingly indispensable in modern life since 1950s with their incredibly desirable characteristics, such as light weight, low cost and adaptable shapes. ${ }^{1}$ Around 359 million tons of plastics were estimated to be produced in 2019 worldwide, ${ }^{2}$ and around $79 \%$ of them were accumulated in landfills or the natural environment, ${ }^{1}$ which caused severe impacts on all forms of life on earth. Academic research has been conducted to eliminate these negative influences, for instance very recently by using depolymerase to break down poly (ethylene terephthalate) (PET) for recycling plastic bottles. ${ }^{3}$ Plastics are typically polymers and can be produced from various raw materials. One major type of plastics is of fossil origin with petrochemicals, such as crude oil and gas, as raw materials for the monomers. ${ }^{4}$ Another category of plastics originates from renewable sources, which is also referred to as bio-based plastics. Feedstocks utilizing renewable sources, such as carbon dioxide, terpenes, vegetable oils and carbohydrates, were reported for the production of sustainable plastics to prevent resource depletion and eliminate greenhouse gas emission. ${ }^{4}$ Cellulose, with an annual production of around 75 billion tons globally, is the most abundant natural polymer on earth, constituting virtually an inexhaustible source of raw material for plastics manufacture. ${ }^{5}$ Utilizing cellulose as a raw material to produce cellulose nitrate as plastics with camphor as the plasticizer can be dated back to $\sim 1870$ s. ${ }^{6}$ Later on, cellulose derivatives including cellulose acetates and cellulose butyrate were produced as plastic products. ${ }^{6}$

Currently widely used plastics can be mainly classified into two categories according to their thermal properties: thermoplastics and thermosets, while elastomers are 
comparatively still much less. ${ }^{7-8}$ Thermoplastics generally comprise single chains of polymers, which remarkably change their states at their transition temperatures. Thermosets are composed of polymer networks, which cannot return to a moldable state once the network formed. Thus, thermoplastics are re-moldable and recyclable via temperature control while the recycling of thermosets is usually highly challenging. ${ }^{7-8}$ Based on the properties of plastics mentioned above, plastics were processed via a variety of methods ranging from extrusion, injection molding and thermoforming, through calendaring to rotational molding, compression molding, transfer molding, additive manufacturing, etc. ${ }^{8-9}$ The above-mentioned methods usually involve expensive and complex machines; harsh conditions, such as high temperature, curing processes, and with water or oxygen exclusion. ${ }^{10-12}$ Thus, the manufacture of plastics by using these methods suffers from diverse problems, for instance being uneconomic, requiring large energy input, and the difficulty of integrating other functional components that cannot stand harsh conditions.

For the sustainable development of the society, new eco-friendly methods for plastic engineering and processing are strongly desired, which virtually demands corresponding novel properties of plastics. It should be addressed that above-mentioned shape-engineering methods of plastics are often based on the conventional characters of polymers, such as thermoplastic and thermosetting. To establish eco-friendly methods for plastic engineering, we focused on hydroplastic polymers, a category of polymers that have long been neglected and hardly studied yet. Similar to thermoplastic polymers that remarkably change the states at their transition temperatures, the states 
of hydroplastic polymers can be massively influenced by water. Until today, specific hydroplastic polymers used for plastic engineering have not been realized and systematically studied. We envisage that hydroplastic polymers should have the great potential to be a new type of environmental-friendly plastics, which possibly can be molded by using a highly environmental-friendly method with the aid of water. Thus, taking aforementioned aspects into account, we attempted to include the following points in our study: (1) using sustainable materials as raw materials for the production of plastics, e.g. cellulose, (2) a corresponding facile and green engineering method for processing obtained plastics, and (3) the obtained plastics being reusable, recyclable with highly extended life-cycles.

Herein, we reported for the first time a hydroplastic polymer CCi derived from cellulose and showed the facile shape-changing/-fixing with a hydrosetting method. Plastic strips made of CCi polymers via facile solvent casting method were readily transformed and repeatedly reprogrammed into versatile $2 \mathrm{D}$ and $3 \mathrm{D}$ shapes via hydrosetting and their shapes maintained long-term stable. Their mechanical properties were systematically analyzed using dynamic mechanical thermal analysis (DMTA) under controlled temperature and RH. These mechanical tests under precisely controlled conditions together with other analyses, such as dynamic vapor sorption (DVS), provided further evidence about the effect of water molecules on hydroplastic properties.

\section{Preparation and characterization of $\mathrm{CCi}$ membranes}

$\mathrm{CCi}$ was synthesized after the esterification of microcrystalline cellulose with 
cinnamoyl chloride in dimethylacetamide (DMAc)/lithium chloride ( $\mathrm{LiCl}$ ) under homogeneous conditions (Fig. 1a). ${ }^{13-14}$ Its chemical structure was confirmed using ${ }^{13} \mathrm{C}$ and ${ }^{1} \mathrm{H}$ NMR spectra according to characteristic signals derived from carbons and hydrogens from both cellulose backbone and cinnamoyl groups (Supplementary Fig. 1). In particular, the cinnamoyl moieties were only introduced into the C6 position of anhydroglucose units of cellulose chains. The degree of substitution of obtained CCi was calculated to be 0.27 based on the results of elemental analysis (Supplementary Information). $\mathrm{CCi}$ is only well soluble in dimethyl sulfoxide (DMSO), but not in any other common solvent.

(a)

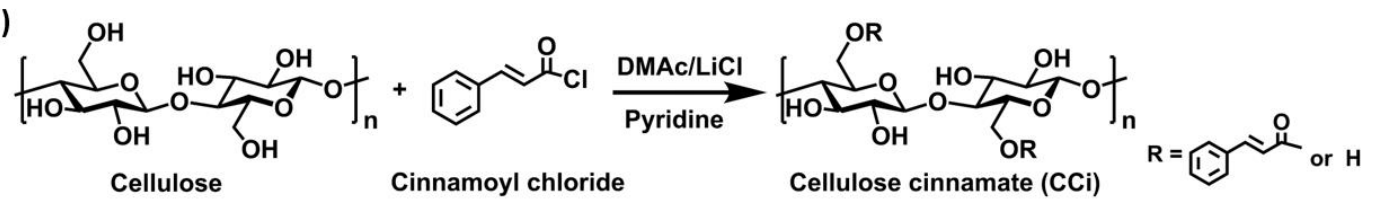

(b)

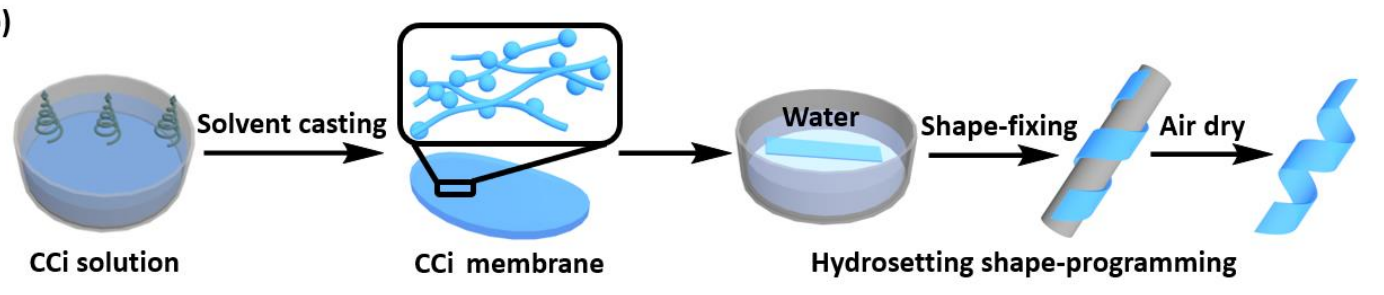

(c)

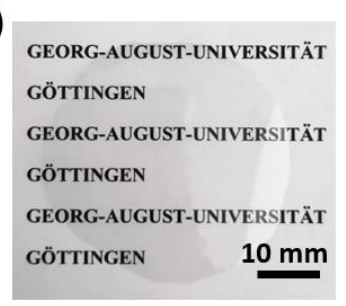

(d)
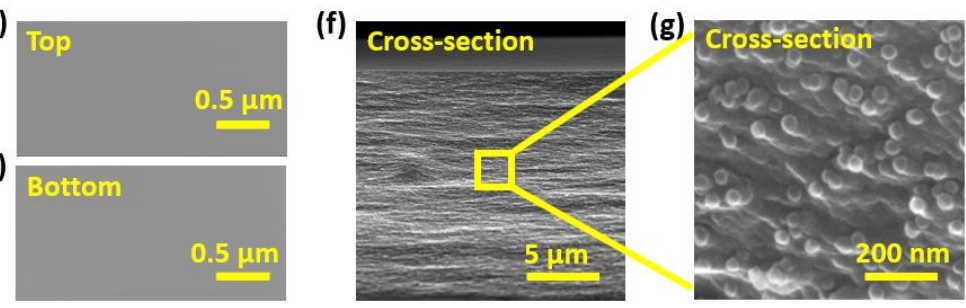

Fig. 1 Preparation of hydroplastic CCi membranes. (a) Synthesis of CCi under homogeneous conditions. (b) Schematic illustration for the fabrication of CCi membranes via solvent-casting method as well as the conceptual illustration for the hydrosetting shape-engineering of CCi membranes. (c) A representative photo image 
of a transparent CCi membrane over the printed name of Georg-August-University of Göttingen. (d-g) SEM images showing the (d) top surface, (e) bottom surface, (f) crosssection and (g) enlarged cross-section of CCi membranes.

By casting $10 \mathrm{mg} / \mathrm{ml} \mathrm{CCi} \mathrm{solution} \mathrm{in} \mathrm{DMSO} \mathrm{and} \mathrm{subsequent} \mathrm{drying} \mathrm{in} \mathrm{a} \mathrm{vacuum} \mathrm{oven}$ at $80{ }^{\circ} \mathrm{C}$ overnight, $\mathrm{CCi}$ membranes with thicknesses of $10-20 \mu \mathrm{m}$ were fabricated. Obtained CCi membranes were generally flat and could be transformed into other shapes, such as a helix shape via a facile hydrosetting method by immersing in water and air-drying (Fig. 1b). Obtained CCi membranes were highly transparent (Fig. 1c). Both the top and bottom surfaces of CCi membranes were highly smooth according to their SEM images (Fig. 1d and 1e). In comparison, the interior of the CCi membrane consisted of a nanocomposite structure with NPs evenly dispersing in a continuous matrix (Fig. 1f, $1 \mathrm{~g}$ and Supplementary Fig. 2a). The NPs had diameters in the range of 35-50 nm (Supplementary Fig. 2b) with an average diameter of $42.0 \pm 3.2 \mathrm{~nm}$. The presence of two distinct topographies as NPs and continuous matrix within the same membrane should be due to the phase separation during the drying process. Moreover, no significant cleavage between the two morphologies was observed, and the formation of such nanocomposite structure by the same $\mathrm{CCi}$ polymer should ensure their mechanical strength due to numerous entanglements of polymer chains.

\section{Sustainable and highly facile hydrosetting method}

CCi membranes could be easily transformed into various 2D/3D shapes via the facile 
and sustainable hydrosetting method (Fig. 1b and 2a). The hydrosetting process comprised of (1) the immersion of CCi membrane strips in water for 5 min that allowed the programming into desired shapes in wet state, and (2) following air-drying in the ambient environment (room temperature and RH between 30-40 \%) for 10-30 min until constant weights. To fix the shapes, assistant molds were used only as templates, such as a cylinder or a cube. After drying, self-standing membranes were fixed in distinct shapes, for instance helix, ring, holder and block (Fig. 2a), which were exactly the desired shapes as programmed in the wet state. These fixed shapes were stable and maintained for a long term of more than 6 months.

Moreover, the shapes of CCi membranes could be sequentially programmed and fixed into versatile 2D/3D shapes in diverse sequences by using hydrosetting method (Fig. 2b-2d, Supplementary Fig. 3). For example, they were programmed in four exemplarily demonstrated shapes as helix, ring, holder and block with distinct sequences and diverse orders. As well, these shapes could be transformed into each other reversibly and arbitrarily (Fig. 2e). Furthermore, one single CCi membrane strip could be continuously reprogrammed and fixed in distinct 2D/3D shapes for at least 15 cycles without fatigue via the facile hydrosetting process, which demonstrated the sustainable reusability of these nanocomposite CCi membranes with extended life-cycles. 
(a)

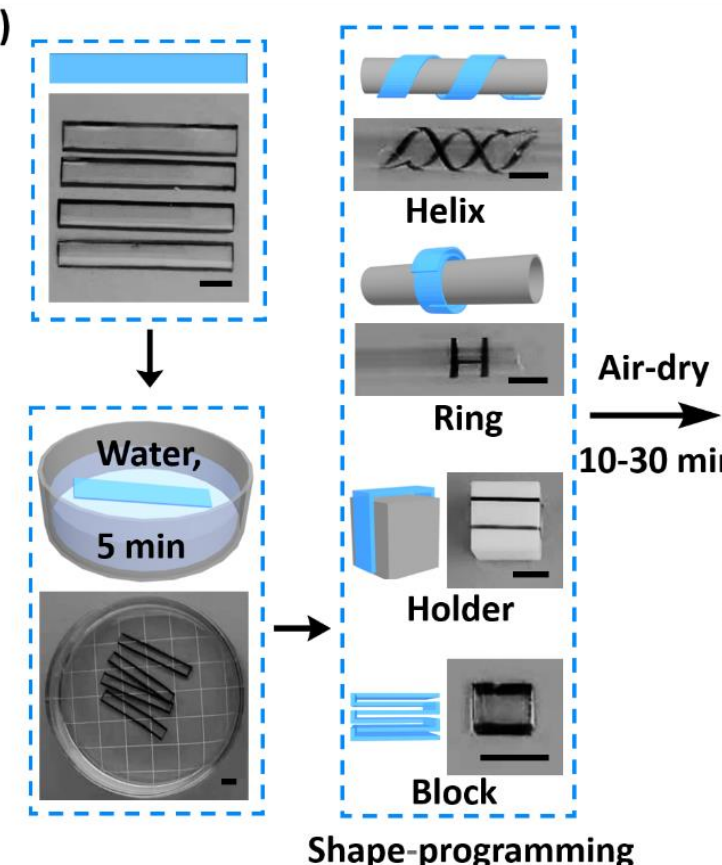

(b)

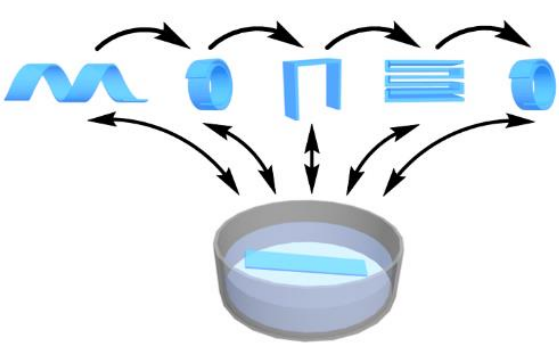

(d)

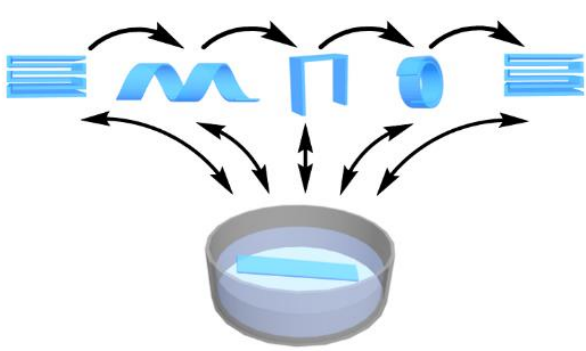

(c)

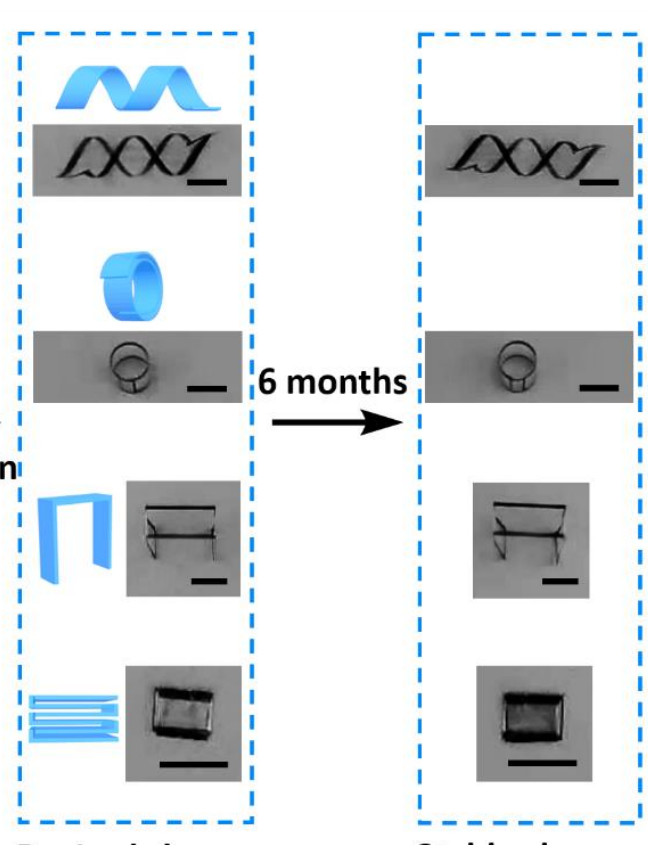

Desired shapes

Stable shapes

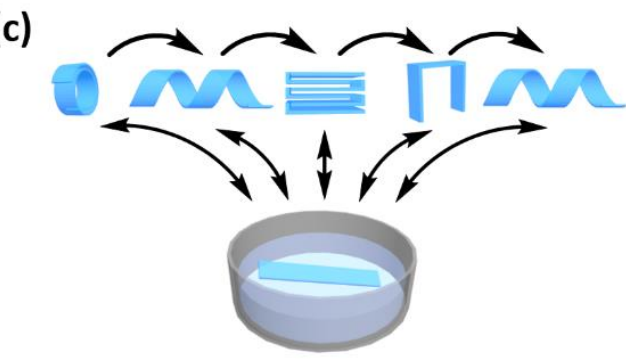

(e)

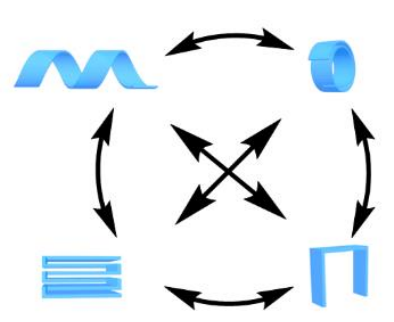

Fig. 2 Sustainable and highly facile hydrosetting shape-programming of CCi

membranes. (a) Schematic diagram and experimental demonstration for programming $\mathrm{CCi}$ strips into diverse 2D/3D shapes via the hydrosetting method and their shape stability under constant RH (see also Supplementary Fig. 4c), scale bars: 5 mm. CCi membrane strips with a dimension of $30 \mathrm{~mm} \times 5 \mathrm{~mm}$ were stroked by mark pens on the edges for clarity. (b-d) Schematic flow charts showing the continuous programming of the same CCi membrane strip into versatile shapes in diverse sequences via the 
hydrosetting process. See also Supplementary Fig. 3 for experimental demonstrations. (e) A summary chart exemplifying the reversible and random transformation of $\mathrm{CCi}$ membrane from one $2 \mathrm{D} / 3 \mathrm{D}$ shape to other diverse $2 \mathrm{D} / 3 \mathrm{D}$ shapes via the facile hydrosetting shape-programming.

Furthermore, these $\mathrm{CCi}$ membranes with distinct shapes were highly stable and maintained their shapes at constant surroundings, i.e. constant temperature and $\mathrm{RH}$, for more than 6 months without significant deformation of their shapes (Fig. 2a, Supplementary Fig. 4c). In comparison, only the RH variation in the environment led to slight or severe deformations of the programmed shapes of $\mathrm{CCi}$ membranes (Supplementary Fig. 4a, 4b and 4d). This shape instability under varying RH could be related to mechano-sorptive creep of CCi membranes (Fig. 4c, Supplementary Fig. 5). In spite of the influence by the fluctuating $\mathrm{RH}$ in the surroundings, the shape of programmed $\mathrm{CCi}$ membranes maintained stable at a constant $\mathrm{RH}$, and even at a high $\mathrm{RH}$ of $80 \%$ at room temperature. 
(a)

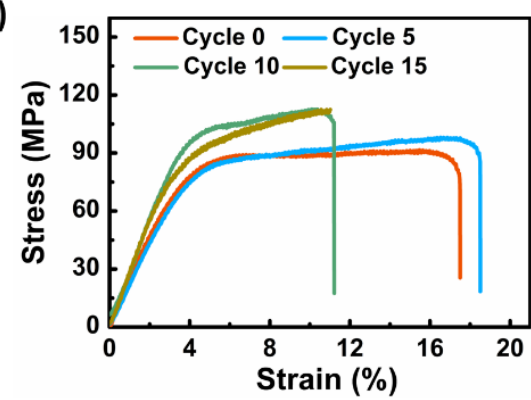

(c)

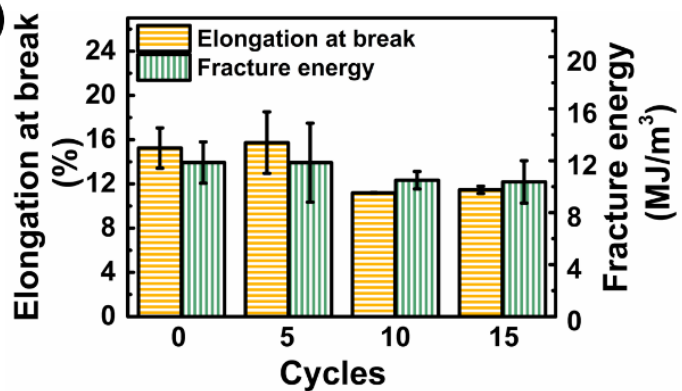

(b)

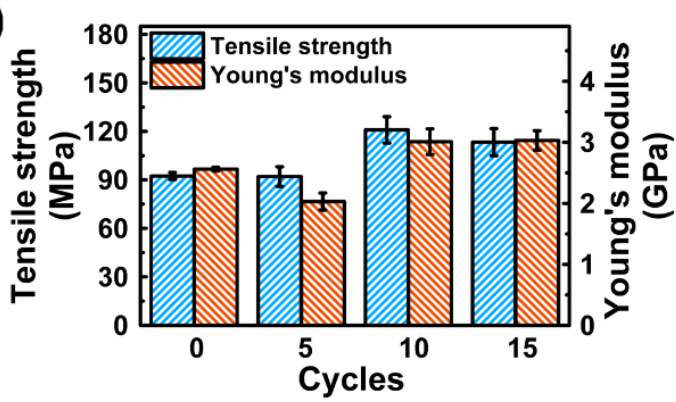

(d)

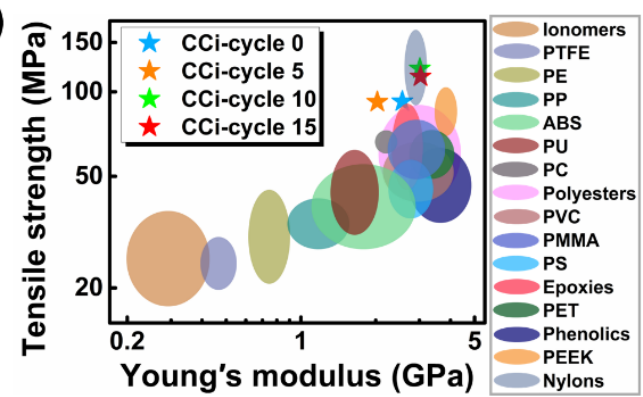

Fig. 3 Static mechanical properties of hydroplastic CCi membranes. (a) stressstrain curves, (b) tensile strength and Young's modulus, (c) elongation at break and fracture energy of as-prepared $\mathrm{CCi}$ membranes (Cycle 0) as well as those after 5, 10 and 15 times of shape-programming (Cycle 5, 10 and 15) via hydrosetting. (d) tensile strengths and Young's moduli of CCi hydroplastics membranes compared with currently widely-used thermoplastic and thermosetting plastics. ${ }^{18}$

\section{Static mechanical properties}

Static mechanical properties of dried as-prepared CCi membranes (Cycle 0) as well as those after 5, 10 and 15 times of shape-programming (Cycle 5, 10 and 15) via hydrosetting method were further analyzed (Fig. 3). The as-prepared membranes were stiff, strong and tough with a tensile strength of $92.4 \pm 2.2 \mathrm{MPa}$, Young's modulus of $2.6 \pm 0.1 \mathrm{GPa}$, elongation at break of $(15.2 \pm 1.8) \%$ and fracture energy of $11.9 \pm 1.6$ $\mathrm{MJ} / \mathrm{m}^{3}$. After 5 hydrosetting shape changes (Cycle 5), the tensile strength, Young's 
modulus, elongation at break and fracture energy of CCi membrane strips maintained at $92.0 \pm 6.1 \mathrm{MPa}, 2.0 \pm 0.1 \mathrm{GPa},(15.7 \pm 2.8) \%$ and $11.9 \pm 3.0 \mathrm{MJ} / \mathrm{m}^{3}$, respectively. In the as-prepared membranes (Cycle 0), the presence of aggregated NPs dispersed in the polymer matrix should have dissipated much energy when loaded with external forces, e.g., stretching, due to the presence of coiled and entangling polymer chains within NPs and matrix as well as between them. This allowed the membranes to be sufficiently tough and this toughness remained after 5 hydrosetting shape changes (Cycle 5). Moreover, the presence of numerous entanglements between polymer chains as well as other interactions, including hydrogen bonds between remaining hydroxyl groups and probably to a much smaller extent the $\pi-\pi$ stacking between the cinnamoyl moieties, should contribute to the high stiffness and strength of as-prepared CCi membranes and those after 5 shape changes.

After 10 hydrosetting shape changes (Cycle 10), the CCi membranes became slightly stiffer and stronger with trivial sacrifice of ductility and toughness. The tensile strength and Young's modulus slightly increased to $120.9 \pm 8.2 \mathrm{MPa}$ and $3.0 \pm 0.2 \mathrm{GPa}$, while the elongation at break and fracture energy deceased to $(11.2 \pm 0.1) \%$ and $10.5 \pm 0.7$ $\mathrm{MJ} / \mathrm{m}^{3}$, respectively. These mechanical properties did not show substantial change with the shape-programming increased to 15 cycles. The CCi membranes (Cycle 15) showed similar tensile strength and Young's modulus of 113.4 $\pm 8.4 \mathrm{MPa}$ and $3.0 \pm 0.2 \mathrm{GPa}$, and the elongation at break and fracture energy also remained around $11.5 \pm 0.3 \%$ and $10.4 \pm 1.6 \mathrm{MJ} / \mathrm{m}^{3}$ compared to those after 10 cycles. Thus, dried CCi membranes maintained their mechanical properties after 10 hydrosetting processes, although varied 
from the initial state. Compared with currently widely-used thermoplastic materials, such as PE, PP, PET, PVC and thermosetting plastic materials including epoxies and phenolics, as-prepared CCi membranes as well as those after 5, 10, and 15 cycles of hydrosetting shape-programming showed comparable or superior tensile strengths and Young's moduli (Fig. 3d). ${ }^{15}$

\section{The importance of water during dynamic hydrosetting process}

On the one hand, the increase of the tensile strength and the Young's modulus of $\mathrm{CCi}$ membranes after 10 shape changes should be primarily due to the partially stretched and stressed polymer chains during the deformation processes, which however caused at the same time a reduced elongation. On the other hand, the interaction between $\mathrm{CCi}$ membranes with water accompanying the hydrosetting process should also have strongly affected the mechanical properties of CCi membranes. In general, the rupture and rebuilding of hydrogen bond networks can modify the toughness and ductility of materials. ${ }^{16}$ In particular, the above-mentioned results showed that the fluctuating RH in the surroundings strongly decreased the shape stability of CCi membranes. To further reveal the hydroplastic properties of $\mathrm{CCi}$ membranes, their water vapor sorption behavior was analyzed with DVS (Fig. 4a). 
(a)

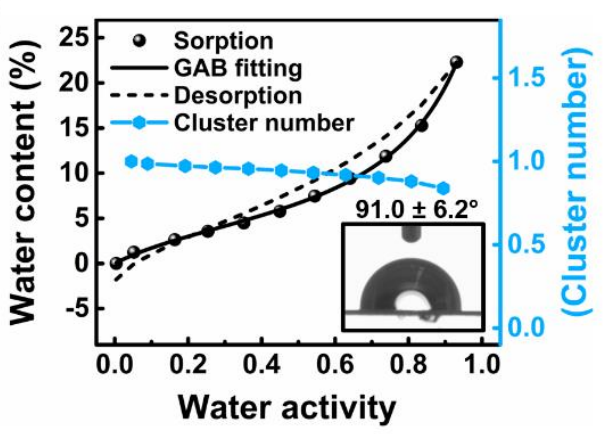

(c)

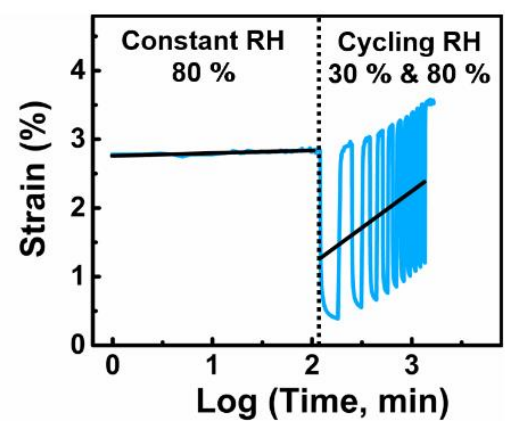

(b)

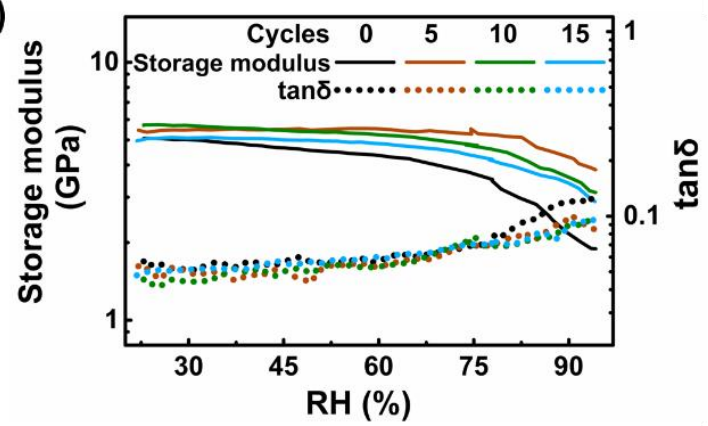

(d)

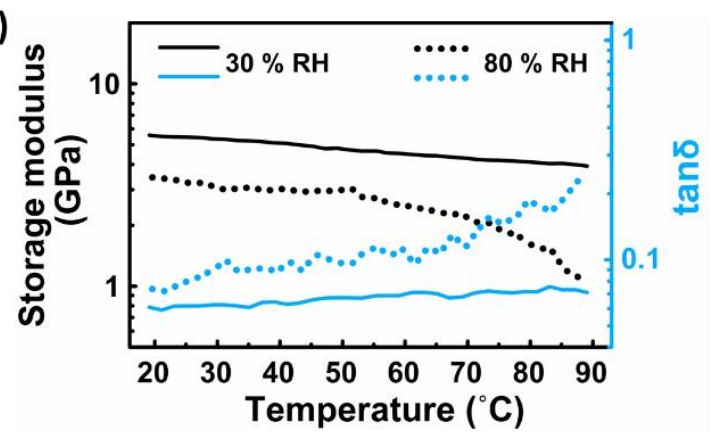

Fig. 4 Significant effect of water on the properties of hydroplastic CCi membranes.

(a) Dynamic water vapor sorption isotherm of as-prepared CCi membranes, fitting of sorption curve according to GAB model and calculated cluster number of water in dependence of water activity. Inset shows the static water contact angle on a $\mathrm{CCi}$ membrane. (b) Humidity sweep with RH increasing rate of $2 \% / \mathrm{min}$ at $25{ }^{\circ} \mathrm{C}$ and frequency of $10 \mathrm{~Hz}$ for as-prepared CCi membranes (Cycle 0) as well as those after 5, 10 and 15 times of shape-programming (Cycle 5, 10 and 15) via hydrosetting processes. (c) Mechano-sorptive creep behaviors of as-prepared CCi membranes at $25{ }^{\circ} \mathrm{C}$ with a constant stress of $1.5 \mathrm{MPa}$ measured under constant $\mathrm{RH}$ of $80 \%$ and subsequently under cycling RH with repeating change of RH between $30 \%$ and $80 \%$ with cycling time of $2 \mathrm{~h}$. The samples were preconditioned for $30 \mathrm{~min}$ at $25^{\circ} \mathrm{C}$ and $80 \% \mathrm{RH}$ before loading. See Supplementary Fig. 5 for experimental scheme. (d) Temperature sweep with temperature increasing rate of $0.5^{\circ} \mathrm{C} / \mathrm{min}$ and frequency of $10 \mathrm{~Hz}$ of as-prepared $\mathrm{CCi}$ membranes at $\mathrm{RH}$ of $30 \%$ and $80 \%$. Dynamic mechanical thermal analysis was 
implemented within linear viscoelastic region of CCi membranes (Supplementary Fig. $6)$.

The sorption isotherms of CCi membranes were characterized by a low moisture uptake at low RH and a steep increase in moisture content at elevated $\mathrm{RH}$ with hysteresis. This feature resembled a sorption isotherm of type IV according to IUPAC classifications. ${ }^{17}$ At constant temperature $\left(20^{\circ} \mathrm{C}\right)$, the water vapor sorption at low $\mathrm{RH}$ ranges rose only very slowly, which was explained by the hydrophobic character of the CCi membranes with a static water contact angle of $91.0 \pm 6.2^{\circ}$ on surface (inset in Fig. $4 \mathrm{a}$ ). At RH of $>$ $60 \%$, the water sorption increased faster and the equilibrated water content reached 22 wt $\%$ at $93 \% \mathrm{RH}$. The desorption curve finally ended up in the negative range at $0 \%$ $\mathrm{RH}$, which should be due to the water sorption within CCi membranes during storage in ambient environment. The sorption curve was fitted to the Guggenheim-Andersonde Boer (GAB) model, ${ }^{18}$ which is usually mathematically expressed as equation (1):

$$
M=\frac{C K M_{0} a_{w}}{\left(1-K a_{w}\right)\left(1-K a_{w}+C K a_{w}\right)}
$$

where $M$ is the equilibrated water content (g/100 g solid), $a_{w}$ is water activity (RH), $M_{0}$ is the water content in (the first) monolayer ( $\mathrm{g} / 100 \mathrm{~g}$ solid), $C$ is the Guggenheim constant that is related to the different enthalpy of monolayer and multilayer sorption, and $K$ is a constant related to the different sorption heat of multilayers water and bulk liquid water.

As shown in Fig. 4a, the sorption curve was well fitted to GAB model with $\mathrm{R}^{2}$ of 0.999 and $M_{0}, C, K$ of $4.84,5.15$ and 0.85 , respectively. According to the fitting results, the 
sorption increased at the beginning of the sorption with low RH, mainly due to the quick occupation of the primary sorption sites. Then, it rose gradually without a distinctive "knee" point, which means a significant overlap of the total coverage of the monolayer and the beginning of the multilayer sorption. ${ }^{17}$ The steep sorption increase in the high $\mathrm{RH}$ range was generally due to the multilayer sorption. Based on GAB fitting, the cluster number of water in dependence of diverse water activity were estimated according to the following equation: ${ }^{19}$

$$
N_{C}=-\left(1-\varphi_{1}\right) \times\left(\frac{\varphi_{1}}{M_{0} C}\left(-2 C K a_{w}+2 K a_{w}+C-2\right)-1\right)
$$

where $N_{C}$ is the cluster number of water, $\varphi_{1}$ is the volume fraction of water, $M_{0}, C$, and $K$ are parameters from GAB model, and $a_{w}$ is water activity. Surprisingly, the cluster number for $\mathrm{CCi}$ membranes decreases from 1 to 0.84 when water activity increases from 0.004 to 0.93 , which indicates no water clustering even at high RH region (Fig. 4a). Several reasons could account for no water clustering for $\mathrm{CCi}$ membranes. On one hand, $M_{0}$ value from GAB fitting is relatively large, which implies large amount of primary sorption sites for monolayer water sorption. On the other hand, the significant overlap of the monolayer coverage and the beginning of multilayer sorption as indicated from the absent "knee" point should also impede the formation of water clusters. In fact, no water clustering is advantageous for hydroplastic properties as big water clusters hinder water transport within CCi membranes. Fast water molecule transmission in $\mathrm{CCi}$ membranes facilitates quick plasticity change in sorption/desorption processes for precise shape-programming and rapid shape-fixing. Particularly, fast water transport within $\mathrm{CCi}$ membranes leads to rapid and thorough remove of water in drying processes, which benefits the shape stability of programmed shapes.

In addition to the aforementioned GAB model fitting, DMTA at diverse RH provided further information about the hydroplastic properties of CCi membranes in dependence 
on water. As shown in Fig. 4b, the storage moduli of as-prepared CCi membranes decreased gradually from $4.94 \pm 0.12 \mathrm{GPa}$ to $3.54 \pm 0.02 \mathrm{GPa}$ with increasing $\mathrm{RH}$ from $23 \%$ to $78 \%$. Then, it dropped drastically to $1.92 \pm 0.03 \mathrm{GPa}$, when the $\mathrm{RH}$ further rose from $78 \%$ to $93 \%$. Correspondingly, the damping factors of as-prepared $\mathrm{CCi}$ membranes increased gently from $0.056 \pm 0.001$ to $0.073 \pm 0.002$ in the $\mathrm{RH}$ range of $23 \%-78 \%$ and intensely to $0.121 \pm 0.005$, when RH further increased to $93 \%$ (Fig. $4 b)$. No substantial change of loss moduli with the variation of $\mathrm{RH}$ was observed for as-prepared CCi membranes (Supplementary Fig. 7c). According to the DVS data and the fitting values based on the GAB model, the water content of CCi membranes was $13.2 \mathrm{wt} \%$ at $78 \% \mathrm{RH}$ with multilayer water. Thus, the mobility of CCi polymer chains should have gradually increased with the monolayer water sorption at low RH range. The chain mobility increased drastically, only when the total amount of water sorption was larger than $13.2 \mathrm{wt} \%$ with multilayer water sorption. In other words, CCi chain mobility increased drastically only with the presence of multilayer water.

Moreover, the storage and loss moduli of CCi membranes became higher after 5 cycles of hydrosetting shape changes and afterwards decreased to a constant level after 10 cycles over the whole range of RH, which showed similar evolution of the mechanical properties as measured with static tensile tests (Fig. 4b and Supplementary Fig. 7c). The RH-dependent development of the storage and loss moduli of CCi membranes after multiple shape-programming steps was similar to those of as-prepared ones, but their storage moduli became generally higher and reached $5.21 \pm 0.16 \mathrm{GPa}, 5.12 \pm 0.57 \mathrm{GPa}$ and $4.69 \pm 0.38 \mathrm{GPa}$ at $23 \% \mathrm{RH}$ for samples after 5, 10 and 15 cycles, respectively 
(Fig. 4b). Therefore, the effect of water molecules within dried CCi membranes after diverse shape changes should be similar and the multiple shape-programming do not significantly affect the mechanical properties of CCi membranes.

RH-dependent hydroplasticity of CCi membranes led to higher storage and loss moduli at lower RH, e.g., as-prepared CCi membranes showed higher storage and loss moduli of $5.85 \pm 0.58 \mathrm{GPa}$ and $0.30 \pm 0.05 \mathrm{GPa}$ at $30 \% \mathrm{RH}$ than $3.79 \pm 0.36 \mathrm{GPa}$ and $0.26 \pm$ $0.07 \mathrm{GPa}$ at $80 \% \mathrm{RH}$, respectively (Supplementary Fig. 7a, 7b, 7e and 7f). In comparison, their storage and loss moduli as well as damping factors generally maintained at a constant RH. For instance, the storage moduli and damping factors of as-prepared CCi membranes remained stable after $4 \mathrm{hr}$ at $10 \mathrm{~Hz}$ (Supplementary Fig. 7a) or between 0.1 and $100 \mathrm{~Hz}$ (Supplementary Fig. 7b), when the RH was fixed at $30 \%$ or $80 \%$. In particular, the constant moduli and damping factors within the frequency sweep tests further verified the strong interaction between $\mathrm{CCi}$ chains in dried $\mathrm{CCi}$ membranes. These results further explained the prominent long-term shape stability of CCi membranes under a constant condition (Supplementary Fig. 4c).

In comparison, $\mathrm{CCi}$ membranes gradually changed their shapes under surroundings with varying RH (Supplementary Fig. 4a, 4b and 4d). The shape instability with varying RH should be related to the mechano-sorptive creep of CCi membranes (Fig. 4c). The creep of as-prepared $\mathrm{CCi}$ membrane under constant $\mathrm{RH}$ of as high as $80 \%$ was very small with the strain increased very slightly from $2.78 \%$ to $2.84 \%$ under constant load of 1.5 MPa. In contrast, the strain increased in a relatively higher rate under cycling RH that alternatively changed between $30 \%$ and $80 \%$, which implies the mechano-sorptive 
creep character of CCi membranes. The very small strain change under constant RH coincides with the shape stability of programmed CCi membranes under constant RH while the relatively larger creep under cyclic RH is in accordance with the shape instability of programmed CCi membranes with varying RH. Such mechano-sorptive creep and shape changes with varying $\mathrm{RH}$ are generally attributed to the sorptioninduced gradient stress changes within the materials. ${ }^{20-21}$ In a similar manner, water sorption with cycling $\mathrm{RH}$ could induce stress gradient within $\mathrm{CCi}$ membranes, which leads to accelerated creep and thus instability of programmed shapes. In particular, the obvious disparity of stain between $80 \% \mathrm{RH}$ and $30 \% \mathrm{RH}$ also indicates higher plasticity of CCi membranes at $80 \% \mathrm{RH}$ compared with that at $30 \% \mathrm{RH}$.

As well, the hydroplastic $\mathrm{CCi}$ membranes at a fixed $\mathrm{RH}$ also showed temperaturedependent thermoplastic properties, while the performance highly depended on the RH (Fig. 4d). At $30 \%$ RH, the storage moduli decreased steadily (around $24 \%$ ) from 5.70 $\pm 0.19 \mathrm{GPa}$ to $4.32 \pm 0.31 \mathrm{GPa}$ with increasing temperature from $20^{\circ} \mathrm{C}$ to $88^{\circ} \mathrm{C}$, which was accompanied by a slight increase of damping factor $(25 \%)$ from $0.056 \pm 0.005$ to $0.070 \pm 0.001$. This indicates the higher mobility of CCi polymer chains in membranes at higher temperature. This trend is greatly enhanced at $80 \% \mathrm{RH}$ with drastic decrease of storage moduli (around $69 \%$ ) from $4.05 \pm 0.43 \mathrm{GPa}$ to $1.26 \pm 0.17 \mathrm{GPa}$ and prominent increase of damping factor $(96 \%$ ) from $0.068 \pm 0.005$ to $0.23 \pm 0.04$. Moreover, this greatly enhanced thermo-dependent reduction of the storage moduli at $80 \% \mathrm{RH}$ further approved the significant impact of high $\mathrm{RH}$ on the mechanical properties and thus the hydroplastic character of $\mathrm{CCi}$ membranes. Therefore, $\mathrm{CCi}$ 
membranes in fact showed hydroplastic and RH-dependent thermoplastic properties. Both $\mathrm{RH}$ and temperature can be used as triggers to regulate the mechanical properties and shapes of CCi membranes, but RH played the predominant role on the mechanical properties of hydroplastic $\mathrm{CCi}$ in the hydrosetting process.

Based on the results shown above, the interaction between water molecules and $\mathrm{CCi}$ polymer chains strongly affected the mechanical properties of hydroplastic CCi (Fig. 4). $\mathrm{CCi}$ membranes adsorbed water molecules first as monolayer then as multilayers with the saturation of sorption sites, when immersed in water. When the water content exceeds $13.2 \mathrm{wt} \%$ with multilayer water sorption, the mobility of CCi chains increases prominently and allows simple shape-changes. Subsequent drying leads to water desorption and the formation of new programmed shapes with gradually lower mobility of the CCi polymer chains. This hydrosetting shape-programming process is reversible and sustainable thanks to the readily increase and decrease of plasticity of CCi polymer chains with water sorption and desorption. The reversible and highly facile hydrosetting process on hydroplastics provided an eco-friendly, sustainable method for processing and engineering plastics as well as extending their lifetimes.

\section{Conclusion}

In conclusion, we revealed a hydroplastic polymer $\mathrm{CCi}$ as one scarcely investigated group of polymers and utilized it for the formation of a new type of plastics hydroplastics. CCi membranes were fabricated via facile solvent-casting of $\mathrm{CCi}$ solution and exhibited a nanocomposite structure with aggregated CCi NPs dispersing 
in the continuous CCi matrix. The hydroplastic features of CCi allowed the highly facile and sustainable hydrosetting shape-programming of these hydroplastic membranes. $\mathrm{CCi}$ membranes were programmed in wet state and fixed in various 2D/3D shapes after air-drying. The shape-programmed CCi membranes could be further reprogrammed and fixed in other arbitrary 2D/3D shapes with different sequences for multiple times via facile hydrosetting. The plasticity of $\mathrm{CCi}$ membranes was only prominently enhanced at high RH ( > $78 \%$ ) with multilayer water sorption. These programmed shapes maintained long-term stable in environments with designated temperature and $\mathrm{RH}$, which should be closely related to the mechano-sorptive creep behaviors of $\mathrm{CCi}$ membranes. The findings in this study provide more insights into hydroplastic polymers, which opens a new window for novel, eco-friendly, and sustainable processing as well as reusing of plastics.

\section{Methods}

Materials. Commercial microcrystalline cellulose with a particle size of $50 \mu \mathrm{m}$ and degree of polymerization of $~ 270$ was purchased from Sigma-Aldrich Chemie GmbH (Steinheim, Germany). N, N-Dimethylacetamide (DMAc, 99.5\%) and cinnamoyl chloride (98\%) were purchased from J \& K Scientific GmbH. Lithium chloride ( $\mathrm{LiCl}$ ) was purchased from MP Biomedicals, LLC. Pyridine (99 \%) was purchased from abcr GmbH. Dimethyl sulfoxide (DMSO, $99.5 \%$ ) was purchased from Carl Roth GmbH \& Co. KG. Methanol (99.8 \%) was purchased from TH. Geyer GmbH \& Co. KG. Dummy CZ-Si wafer (called wafer briefly) with diameter of 8 inch and thickness of $700 \pm 25$ 
$\mu \mathrm{m}$ was purchased from MicroChemicals $\mathrm{GmbH}$.

Synthesis of $\mathbf{C C i}$. CCi was synthesized by the acylation of cellulose under homogeneous condition according to previously reported method with modifications. ${ }^{13-}$

${ }^{14}$ Briefly, microcrystalline cellulose was firstly dried in a vacuum oven at $103{ }^{\circ} \mathrm{C}$ overnight. $1 \mathrm{~g}$ dried microcrystalline cellulose and $40 \mathrm{ml}$ DMAc were then fed into a $100 \mathrm{ml}$ three-necked flask, which was equipped with a magnetic stir bar and connected to a condenser. The mixture was stirred at $130{ }^{\circ} \mathrm{C}$ for $30 \mathrm{~min}$, followed by adding $3 \mathrm{~g}$ $\mathrm{LiCl}$ to the system under stirring. After cooling down to room temperature, a clear cellulose solution was obtained. The solution was then heated to $60{ }^{\circ} \mathrm{C}$ before $2.00 \mathrm{ml}$ cinnamoyl chloride and $2.24 \mathrm{ml}$ pyridine were dropped into the solution under stirring. The reaction was carried out by maintaining the temperature at $60{ }^{\circ} \mathrm{C}$ with stirring for $3 \mathrm{hr}$. The mixture was subsequently precipitated in $200 \mathrm{ml}$ methanol. The product was collected by centrifugation and purified by repeated dissolution in DMSO and precipitation in methanol. The pure product was dried in vacuum before dissolved in DMSO for storage.

Nuclear magnetic resonance (NMR) spectroscopy. CCi were dissolved in deuterated DMSO for liquid-state ${ }^{1} \mathrm{H}$ and ${ }^{13} \mathrm{C}$ NMR measurement on a Bruker DRX 500 spectrometer (Bruker, BioSpin GmbH; Ettlingen, Germany) with a frequency of 500 $\mathrm{MHz}$ for ${ }^{1} \mathrm{H}$ NMR and $125 \mathrm{MHz}$ for ${ }^{13} \mathrm{C}$ NMR. 65 scans were collected for ${ }^{1} \mathrm{H}$ NMR 
spectroscopy, whereas 16000 scans were accumulated for ${ }^{13} \mathrm{C}$ NMR spectroscopy. The repetition delay was $5 \mathrm{~s}$ for ${ }^{1} \mathrm{H}$ NMR and $1 \mathrm{~s}$ for ${ }^{13} \mathrm{C}$ NMR spectra.

Elemental analysis. Elemental analysis was performed on an elemental analyzer Vario EL III CHN instrument from Elementar (Hanau, Germany).

Preparation of CCi membranes. CCi membranes were prepared via facile solventcasting. Firstly, a mold was assembled by sandwiching a wafer substrate between two blocks of Teflon. The wafer substrate $(60 \mathrm{~mm} \times 60 \mathrm{~mm} \times 0.7 \mathrm{~mm})$ was sonicated twice at $37 \mathrm{~Hz}, 60{ }^{\circ} \mathrm{C}$ in DMSO and deionized water respectively, each time for $3 \mathrm{~min}$, followed by blow-drying with nitrogen before use. The Teflon blocks were $90 \mathrm{~mm} \times$ $90 \mathrm{~mm} \times 15 \mathrm{~mm}$ in size with a hollow cylindrical shape $(\varnothing=50 \mathrm{~mm}, \mathrm{~h}=15 \mathrm{~mm})$ in the center and thread in the surrounding margin for assembly fixation and level adjustment. Thereafter, the assembled mold was placed in a vacuum oven. Then, $5 \mathrm{ml}$ of CCi solutions with a concentration of $10 \mathrm{mg} / \mathrm{ml}$ was transferred into the molds. CCi membranes were obtained after drying at $80{ }^{\circ} \mathrm{C}$ and 15 mbar in a vacuum oven for overnight. CCi membranes were peeled off from wafer after disassembly of the Teflon molds.

Scanning electron microscopy (SEM). The images of cross-section and surfaces of CCi membranes were measured using a SEM Leo SUPRA 35 instrument (Carl Zeiss SMT GmbH, Oberkochen, Germany). A layer of carbon (with a thickness of $\sim 10 \mathrm{~nm}$ ) 
was vacuum-coated on the samples before the observation. The sizes of NPs were measured by using the program Nano Measure, and 40 NPs were measured to calculate the average diameter and standard deviation.

Static mechanical test. Tensile tests were performed on a Z3 microtensile test machine with a $50 \mathrm{~N}$ load cell (Grip-Engineering Thümler GmbH). Samples were prepared with a dimension of $30 \mathrm{~mm} \times 5 \mathrm{~mm}$. The samples were loaded into the test machine with a clamp distance of $8.0 \mathrm{~mm}$ and subjected to uniaxial extension with a constant rate of 2 $\mathrm{mm} / \mathrm{min}$. The samples were stretched until rupture. In each case, at least 6 equal samples were measured to ensure accuracy of the results. The stress of membranes was calculated by dividing force by cross-section area, while the strain (\%) of membranes was defined as $\left(\mathrm{L}^{-} \mathrm{L}_{0}\right) / \mathrm{L}_{0} \times 100 \%$, where $\mathrm{L}$ is the instantaneous length and $\mathrm{L}_{0}$ is the initial length of the sample. It should be noted that toe compensation was performed before any calculation to obtain correct values by using stress-strain curves. The calculation of tensile strength, Young's modulus, elongation at break and fracture energy, as well as the toe compensation were performed according to ASTM D88202.22

Dynamic vapor sorption (DVS). A DVS apparatus (DVS Advantage, Surface measurement systems, London, UK) was used to assess the dynamic water vapor sorption behavior of CCi membranes. CCi membranes, with a dimension of $10 \mathrm{~mm} \times$ $10 \mathrm{~mm}$ and a mass of approx. 11.5-11.8 $\mathrm{mg}$, were used for the measurements. The 
measurement was executed at $20{ }^{\circ} \mathrm{C}$ with $\mathrm{RH}$ first reduced to $0 \%$, until the mass change of the films per minute $(\mathrm{dm} / \mathrm{dt})$ was $<0.002 \% \mathrm{~min}^{-1}$ over a period of $10 \mathrm{~min}$, and the initial dry mass was recorded. Subsequently, the RH was increased from $5 \%$ to $95 \%$ in $10 \%$ step (sorption) followed by a decrease to $0 \%$ in reverse order (desorption). During each measurement, the RH was maintained constant, until the mass change of the CCi membranes was $<0.002 \% \mathrm{~min}^{-1}$ over a period of $10 \mathrm{~min}$, and the equilibrated mass was detected. The moisture content at each $\mathrm{RH}$ was calculated based on the mass of the films in equilibrium.

Static water contact angle. The wetting properties of $\mathrm{CCi}$ membranes were assessed on a Contact Angle System OCA 15EC (dataphysics, Filderstadt, Germany). Static water contact angles were measured by using the sessile droplet method with a dosing volume of $2.0 \mu \mathrm{L}$ and dosing rate $1.0 \mu \mathrm{L} / \mathrm{s}$. The result was acquired by taking the average value from more than 10 measurements.

Dynamic mechanical thermal analysis (DMTA). DMTA measurements were carried out by using a NETZSCH GABO EPLEXOR system (NETZSCH GABO Instruments GmbH, Ahlden, Germany) with a force sensor of 150 N. Samples were prepared with a dimension of $30 \mathrm{~mm} \times 5 \mathrm{~mm}$. The samples were loaded into the test machine with a clamp distance of $8.0 \mathrm{~mm}$ and the measurements were conducted with a contact force of $0.5 \mathrm{~N}$, a static strain of $0.5 \%$ (control range $\pm 0.2 \%$ ) and a dynamic strain of $0.1 \%$ (control range $\pm 0.05 \%$ ). With this setting, all measurements were carried out within 
the linear viscoelastic region of the samples. For each case, at least 3 5 measurements were implemented to ensure that the collected data are reliable.

Mechano-sorptive creep. $\mathrm{CCi}$ membranes with a dimension of $30 \mathrm{~mm} \times 5 \mathrm{~mm}$ were loaded into a NETZSCH GABO EPLEXOR system with a clamp distance of $8.0 \mathrm{~mm}$. Samples were preconditioned in $25^{\circ} \mathrm{C}, 80 \% \mathrm{RH}$ for $30 \mathrm{~min}$. Then, constant load of 1.5 $\mathrm{MPa}$ (control range $\pm 0.5 \mathrm{MPa}$ ) was applied on the samples for measurement under constant RH of $80 \%$ as well as cycling RH between $30 \%$ and $80 \%$.

\section{Supplementary Information}

Supplementary information can be found online.

\section{Acknowledgements}

K.Z. thanks the German Research Foundation (DFG) and Lower Saxony Ministry of Science and Culture for the project INST186/1281-1/FUGG. J.X.W. thanks the Chinese Scholarship Council (CSC) for the financial support of her PhD study. We thank Dr. Tao Chen from Institute of Physics-Biophysics, Georg-August-University of Göttingen, for the support of SEM images. We thank Dr. Qiyun Tang from Institute for Theoretical Physics, Georg-August-University of Göttingen, for the helpful suggestions on the calculations. We thank Dr. Yang Yang, Dr. Peiwen Liu and Dan Xu from Department of Wood Technology and Wood-based Composites, Georg-August-University of Göttingen, for the valuable suggestions on the Figures. 


\section{Author contributions}

K.Z. and J.X.W. conceived the idea and designed the experiments. K.Z. supervised the project. J.X.W. conducted the experiments with the assistance of L.E. and P.V. The data were analyzed and processed by J.X.W., J.F.W and K.Z. J.X.W. and K.Z. prepared the manuscript and all authors contributed to the revision.

\section{Competing interests}

The authors declare no competing interests

\section{Data availability}

The data supporting the findings are provided within this article, its Supplementary Information file and are available from the corresponding author upon reasonable request.

\section{References}

1. Geyer, R., Jambeck, J. R. \& Law, K. L. Production, use, and fate of all plastics ever made. Sci. Adv. 3, e1700782 (2017).

2. Plastics-the Facts 2019. An analysis of European plastics production, demand and waste data. PlasticsEurope, https://www.plasticseurope.org/application/.

3. Tournier, V. et al. An engineered PET depolymerase to break down and recycle plastic bottles. Nature 580, 216-219 (2020).

4. Zhu, Y., Romain, C. \& Williams, C. K. Sustainable polymers from renewable resources. Nature 540, 354-362 (2016).

5. Khalil, H. A. et al. Production and modification of nanofibrillated cellulose using various 
mechanical processes: a review. Carbohydr. Polym. 99, 649-65 (2014).

6. Kabasci, S. Bio-based Plastics: Materials and Applications Ch. 1 (JohnWiley \& Sons, Ltd, 2014).

7. Ghosh, S. K., Pal, S. \& Ray, S. Study of microbes having potentiality for biodegradation of plastics. Environ. Sci. Pollut. Res. 20, 4339-55 (2013).

8. Crawford, R. J. Plastics Engineering Ch. 4 (Butterworth-Heinemann, 1998).

9. Truby, R. L. \& Lewis, J. A. Printing soft matter in three dimensions. Nature 540, 371-378 (2016).

10. Kumar, B. B. et al. Processing of cenosphere/HDPE syntactic foams using an industrial scale polymer injection molding machine. Mater. Des. 92, 414-423 (2016).

11. Chowdhury, M. R., Steffes, J., Huey, B. D. \& McCutcheon, J. R. 3D printed polyamide membranes for desalination. Science 361, 682-686 (2018).

12. Deng, S., Wu, J., Dickey, M. D., Zhao, Q. \& Xie, T. Rapid open-air digital light 3D printing of thermoplastic polymer. Adv. Mater. 31, 1903970 (2019).

13. Samaranayake, G. \& Glasser, W. G. Cellulose derivatives with low DS. I. A novel acylation system. Carbohydr. Polym. 22, 1-7 (1993).

14. Zhang, K. et al. Moisture-responsive films of cellulose stearoyl esters showing reversible shape transitions. Sci. Rep. 5, 11011 (2015).

15. Ashby, M. F. Materials Selection in Mechanical Design (Elsevier Ltd, 2011).

16. Chen, Z. \& Lu, H. Constructing sacrificial bonds and hidden lengths for ductile graphene/polyurethane elastomers with improved strength and toughness. J. Mater. Chem. 22, 12479 (2012).

17. Thommes, M. et al. Physisorption of gases, with special reference to the evaluation of surface area and pore size distribution (IUPAC Technical Report). Pure Appl. Chem. 87, 1051-1069 (2015).

18. Rao, M. A., Rizvi, S. S. H., Dotta, A. K. \& Ahmed, J. Engineering Properties of Foods Ch. 11 (CRC Press, 2014).

19. Zhang, Z., Britt, I. J. \& Tung, M. A. Water absorption in EVOH films and its influence on glass transition temperature. J. Polym. Sci., Part B: Polym. Phys. 37, 691-699 (1999). 
20. Habeger, C. C. \& Coffin, D. W. The role of stress concentrations in accelerated creep and sorption-induced physical aging. J. Pulp Pap. Sci. 26, 145-157 (2000).

21. Habeger, C. C., Coffin, D. W. \& Hojjatie, B. Influence of humidity cycling parameters on the moisture-accelerated creep of polymeric fibers. J. Polym. Sci., Part B. Polym. Phys. 39, 2048-2062 (2001).

22. ASTM D882-02, Standard test method for tensile properties of thin plastic sheeting. (ASTM International, 2002) DOI: 10.1520/D0882-02, www.astm.org. 


\section{Supplementary Information}

\section{Hydroplastic polymer as eco-friendly hydrosetting plastics}

Jiaxiu Wang ${ }^{1}$, Lukas Emmerich ${ }^{2}$, Jianfeng Wu³ , Philipp Vana ${ }^{4}$, Kai Zhang ${ }^{1 \star}$

1 Wood Technology and Wood Chemistry, Department of Wood Technology and Woodbased Composites, Georg-August-University of Göttingen, Büsgenweg 4, D-37077, Göttingen, Germany.

2 Wood Biology and Wood Products, Georg-August-University of Göttingen, Büsgenweg 4, D-37077, Göttingen, Germany.

3 Sino-German Joint Research Lab for Space Biomaterials and Translational Technology, School of Life Sciences, Northwestern Polytechnical University, Xi'an, 710072, P. R. China.

4 Institute of Physical Chemistry, Georg-August-University of Göttingen, Tammannstraße 6, D-37077, Göttingen, Germany.

${ }^{*}$ Corresponding author: kai.zhang@uni-goettingen.de 
(a)

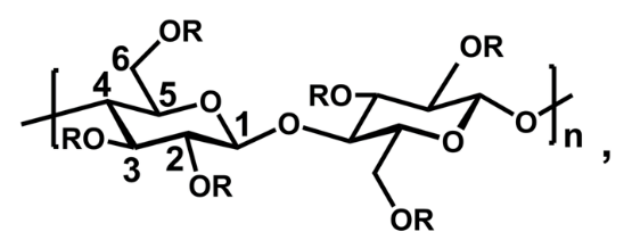

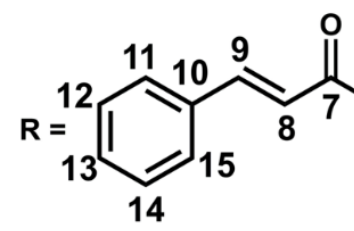
or $\mathbf{H}$

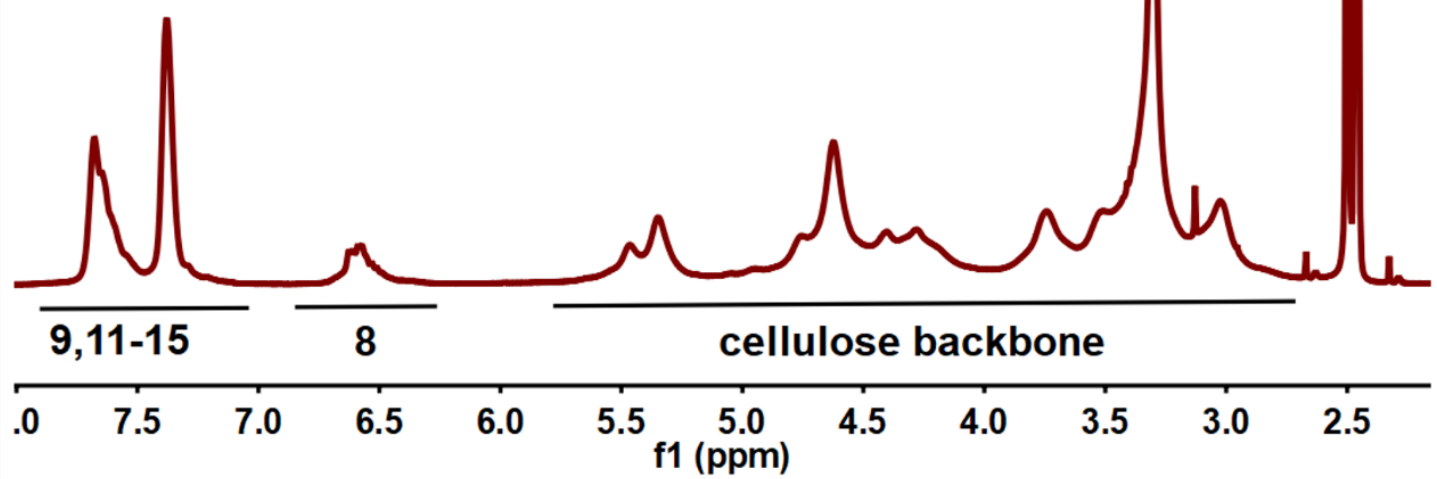

(b)

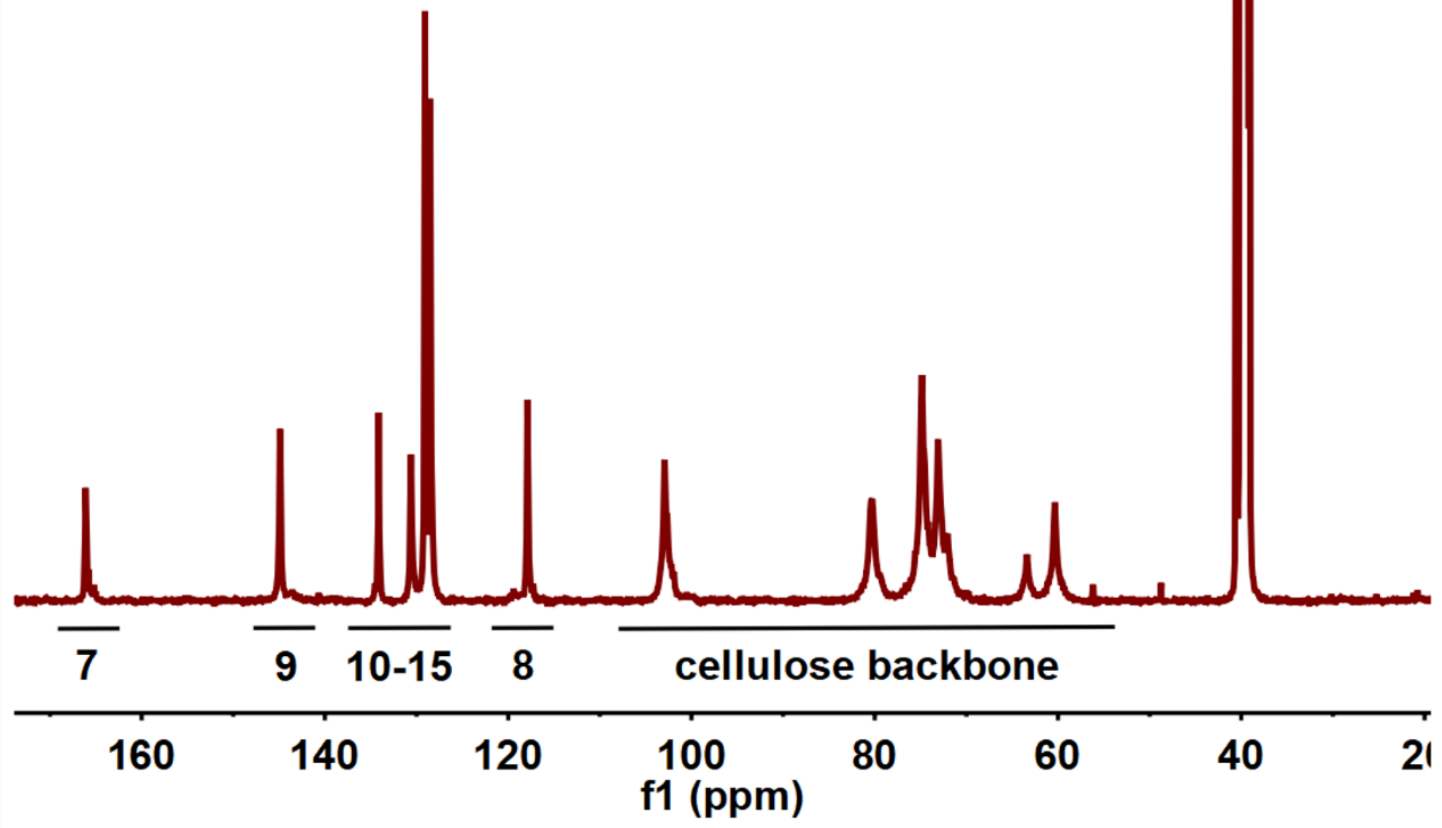

Supplementary Fig. 1 (a) ${ }^{1} \mathrm{H}$ and (b) ${ }^{13} \mathrm{C}$ NMR spectra of cellulose cinnamate (CCi) in DMSO-d6. 


\section{Nuclear magnetic resonance (NMR) analysis}

Within the ${ }^{1} \mathrm{H}$ NMR spectrum (Supplementary Fig. 1a), the signals from 6 to $6.8 \mathrm{ppm}$ denote the hydrogen at $\alpha$ position of carboxyl groups. The peaks from 7 to $7.8 \mathrm{ppm}$ represent the hydrogen at $\beta$ position of carboxyl groups and the hydrogen from the benzene ring. ${ }^{1}$ The peaks between 3.0 to 5.8 ppm originate from cellulose backbone. ${ }^{2}$

Within the ${ }^{13} \mathrm{C}$ NMR spectrum (Supplementary Fig. 1b), the peak at 166 ppm denotes the carboxyl groups, while the signal at around $145 \mathrm{ppm}$ represents the carbon at $\beta$ position and the peak at around $117 \mathrm{ppm}$ originates from the carbon at $\alpha$ position. ${ }^{3}$ The signals from 126 to $135 \mathrm{ppm}$ correspond to the carbon from benzene ring, while the signals from 60 to $105 \mathrm{ppm}$ are derived from cellulose backbone. ${ }^{2}$ Moreover, C6 of the anhydroglucose units of cellulose has a new signal at $\sim 63 \mathrm{ppm}$ in addition to the signal at $\sim 60 \mathrm{ppm}$, showing the esterification at $\mathrm{C} 6$ position. In comparison, the signal attributed to $\mathrm{C} 1$ at $~ 102 \mathrm{ppm}$ is not split, indicating no modification of $\mathrm{C} 2$ position.

\section{Elemental analysis}

The carbon and hydrogen content of the $\mathrm{CCi}$ was measured using elemental analysis to be averagely $51.3 \%$ and $5.67 \%$, respectively. The degree of substitution (DS) of CCi was calculated according to previously published method based on the content of carbon with modification: ${ }^{4}$

$$
D S=\frac{162.141 \times c-72.066}{108.099-130.146 \times c}
$$


where $c$ is the carbon content measured by elemental analysis.

\section{Characterization of the structure of hydroplastic CCi membranes}
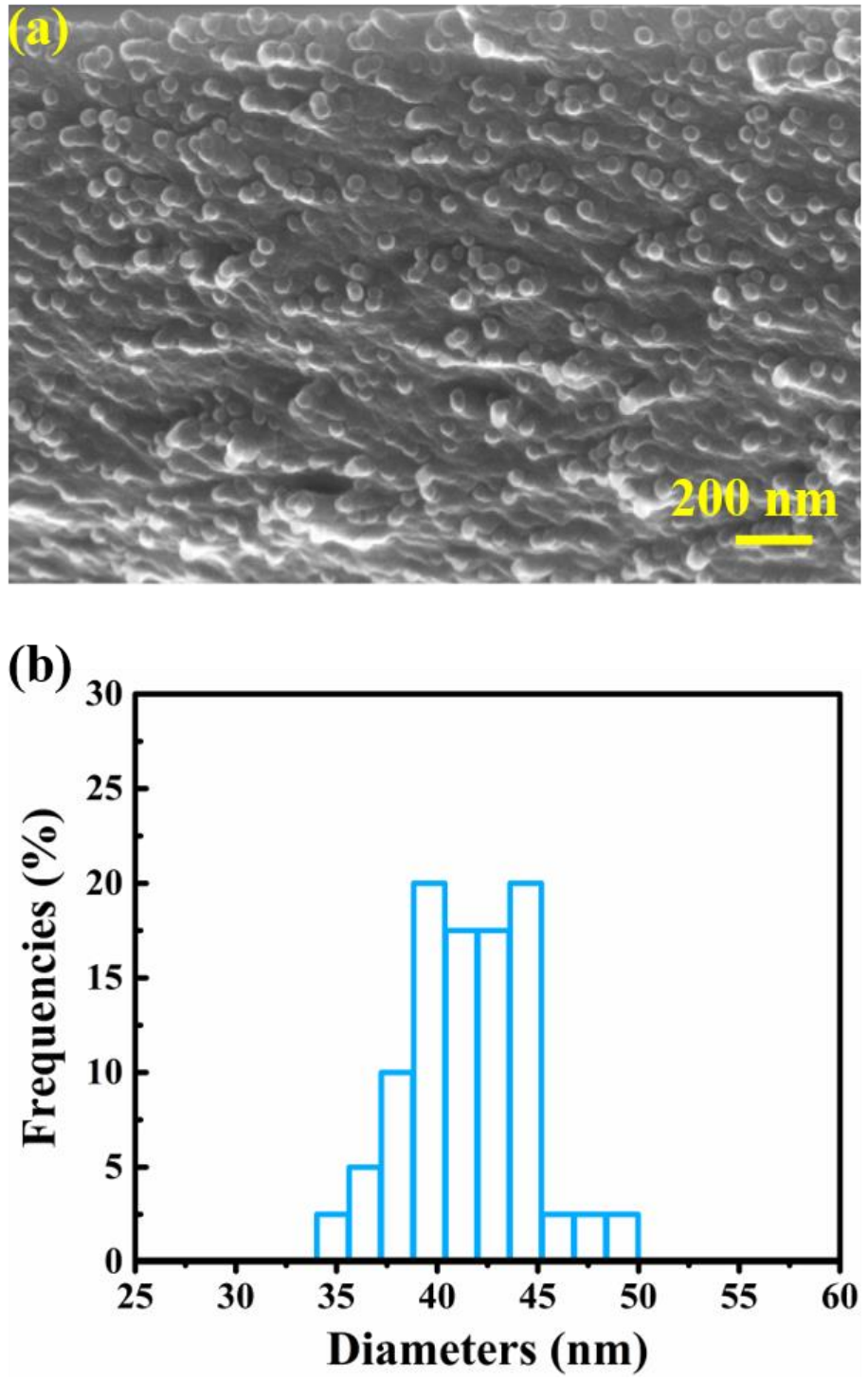

Supplementary Fig. 2 (a) The cross-section SEM image of a representative hydroplastic CCi membrane, (b) the size distribution of NPs calculated from (a) via Nano Measure. 
(a)

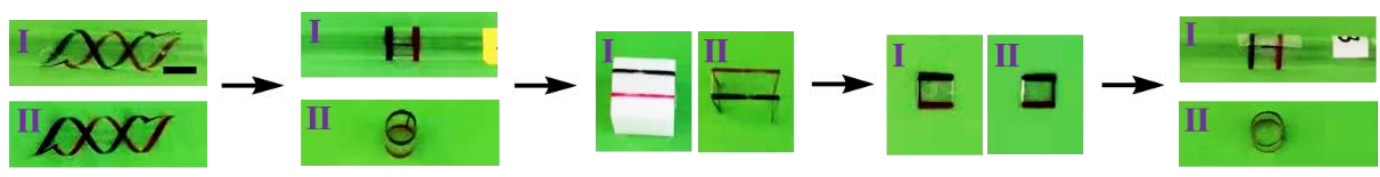

(b)

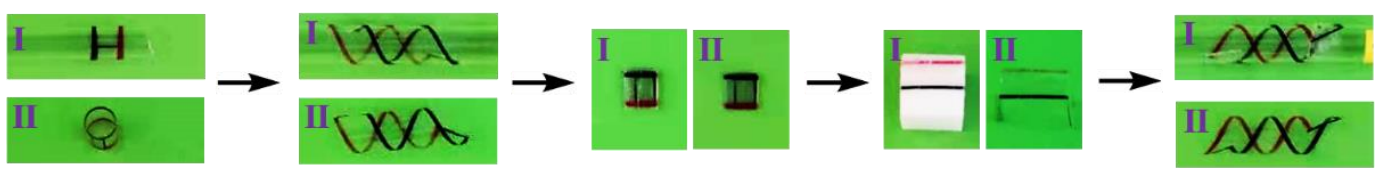

(c)

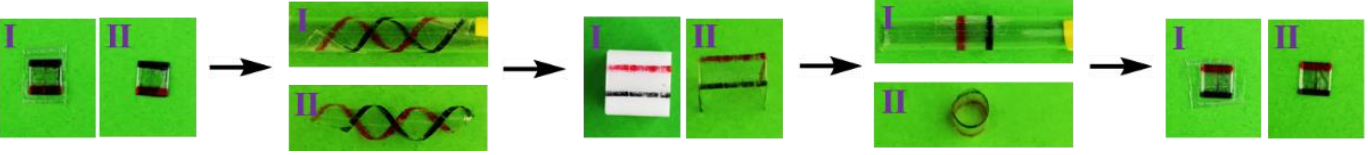

Supplementary Fig. 3 (a-c) Experimental demonstration of $\mathrm{CCi}$ membranes transformed to diverse shapes in three distinct sequences via hydrosetting. Photos marked with I are the to be programmed shapes with the assistance of molds, while photos marked with II are the programmed shapes after separation from these molds. Scale bar: $5 \mathrm{~mm}$.

\section{Shape stability of CCi membranes after hydrosetting shape-programming}

$\mathrm{CCi}$ membranes were immersed in water for 5 mins and then programmed into shapes, such as helix shape (Supplementary Fig. 4a and 4c) or the shape of a holder (Supplementary Fig. 4b and 4d) with the assistance of a cylinder or a cube, respectively. After drying in ambient environment with room temperature (RT) and fluctuating relative humidity $(\mathrm{RH})$ of $30-40 \%$ for $30 \mathrm{~min}$, the programmed CCi membranes were removed from the cylinders/cubes and stored in ( $a$ and b) ambient environment with slight fluctuation of RH, (c) a designated environment (RT, constant $80 \% \mathrm{RH}$ ) or (d) an environment with alternate RH of $25 \%$ and $75 \%$.

As shown in Supplementary Fig. 4a, the shapes can keep around 2 weeks in ambient 
environment with fluctuating RH between 30-40\%. After 2 weeks, the helix shape began to deform gradually. This deformation proceeds in a very slow way and the CCi membrane strips is still in helix shape even after 13 weeks though with some deformation.

The shapes maintain perfectly for a much longer time in an environment with a steady RH. For instance, CCi membranes maintain the perfect helix shape for more than 6 months at RT under constant $80 \%$ RH (Supplementary Fig. 4c). In comparison, the frequent change of $\mathrm{RH}$ with a big difference, e.g. between $25 \%$ and $75 \%$, resulted in the severe shape deformation of programmed CCi membranes (Supplementary Fig. 4d). Therefore, programmed $\mathrm{CCi}$ membranes maintain relatively stable shapes in environments with slight RH variation (Supplementary Fig. 4a and 4b) and are totally stable in environments with constant RH (Supplementary Fig. 4c). 
(a)
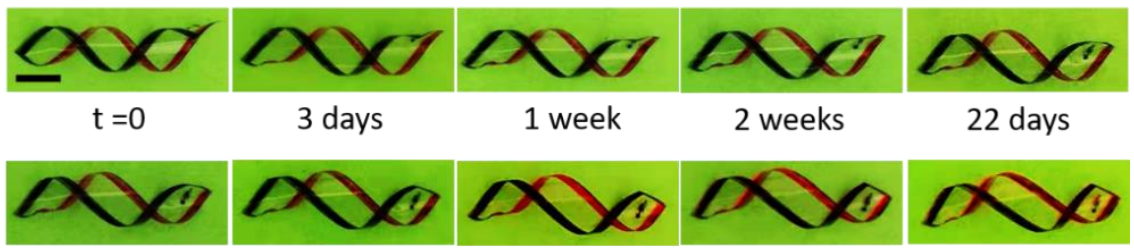

4 weeks $\quad 5$ weeks $\quad 40$ days 7 weeks 8 weeks

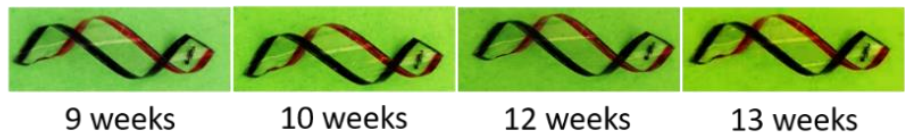

(b)

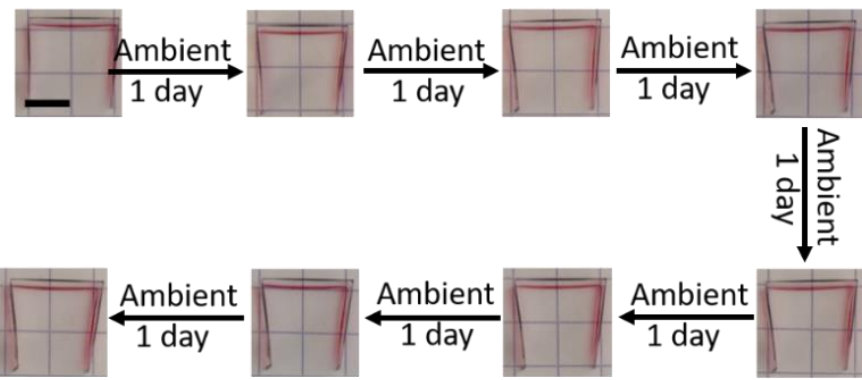

(c)

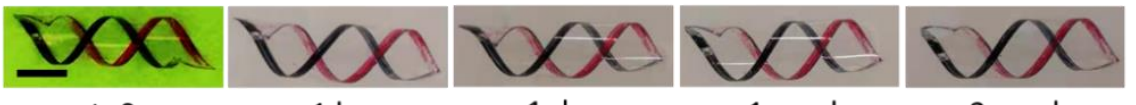

$\mathrm{t}=0$

1 day

1 week

2 weeks

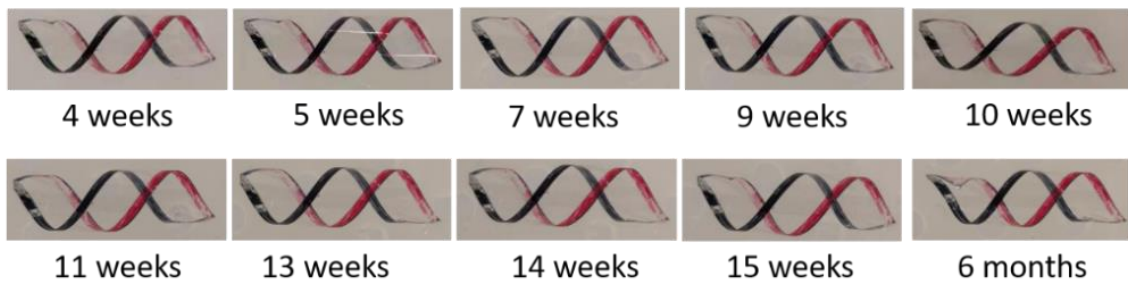

(d)

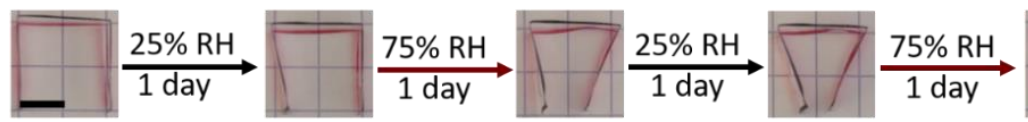

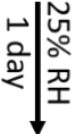
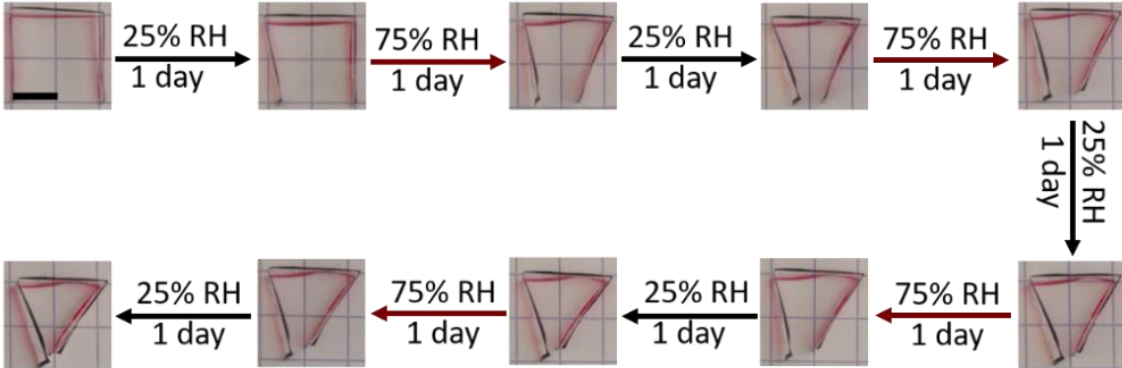

Supplementary Fig. 4 Shape stability of programmed CCi membranes stored at (a, b) ambient environment (RT, fluctuating RH between 30-40 \%), (c) designated environment (RT, constant $80 \% \mathrm{RH}$ ) (d) environment with alternative RH of $25 \%$ and $75 \%$ after hydrosetting processes. Scale bars: $5 \mathrm{~mm}$. 


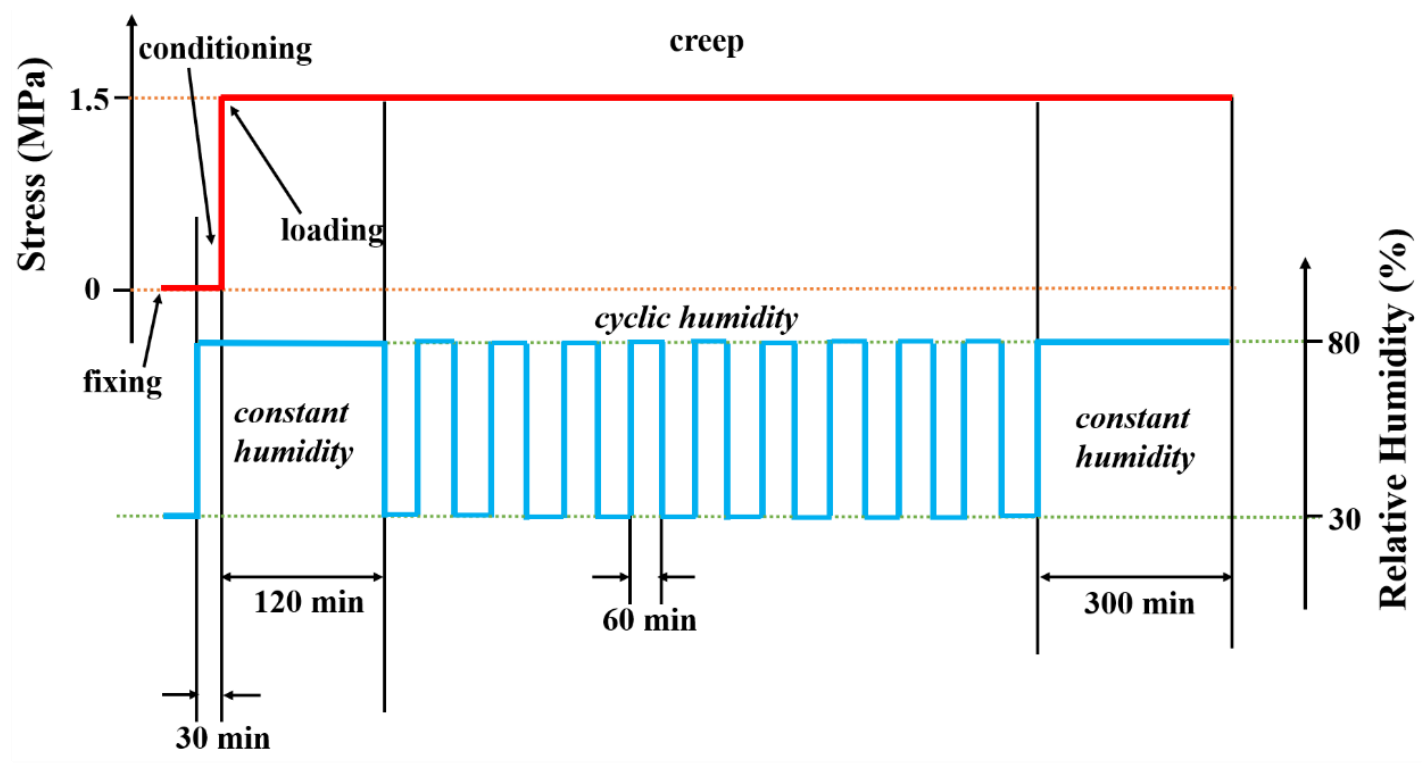

Supplementary Fig. 5 Schematic representation of the mechano-sorptive creep

experiments on $\mathrm{CCi}$ membranes at $25^{\circ} \mathrm{C}$ loaded with constant load of $1.5 \mathrm{MPa}$.
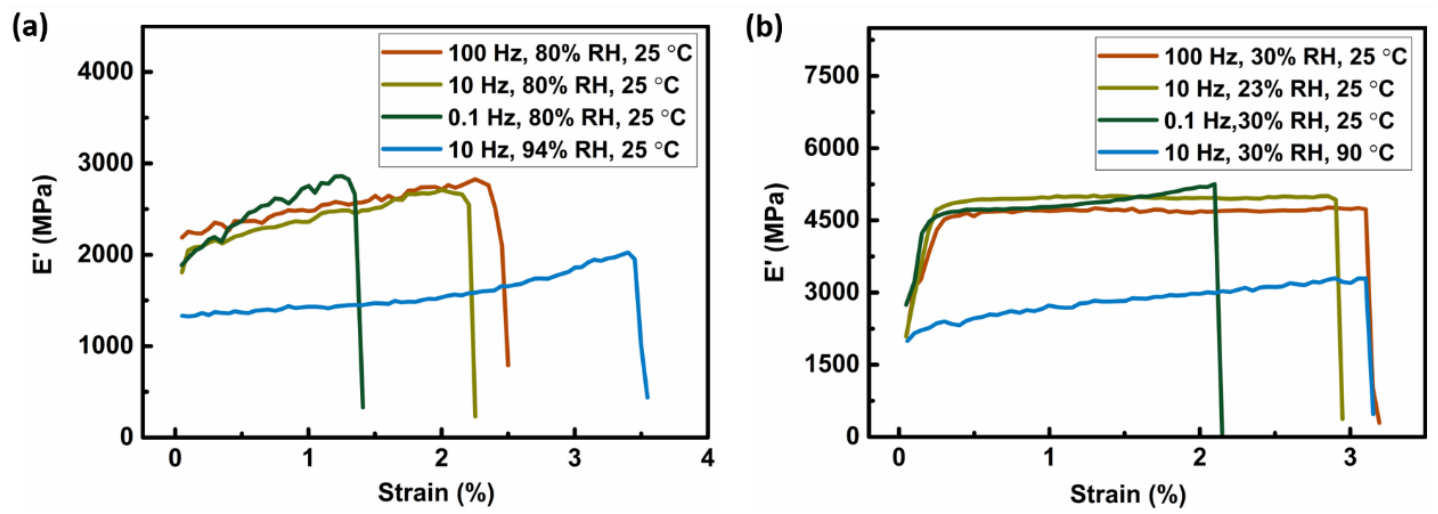

Supplementary Fig. 6 Strain sweep of as-prepared CCi membranes under diverse conditions including (a) high RH conditions of $80 \%$ and $94 \%$ and (b) low RH conditions of $23 \%$ and $30 \%$ representing the conditions used for DMTA measurements. 
(a)

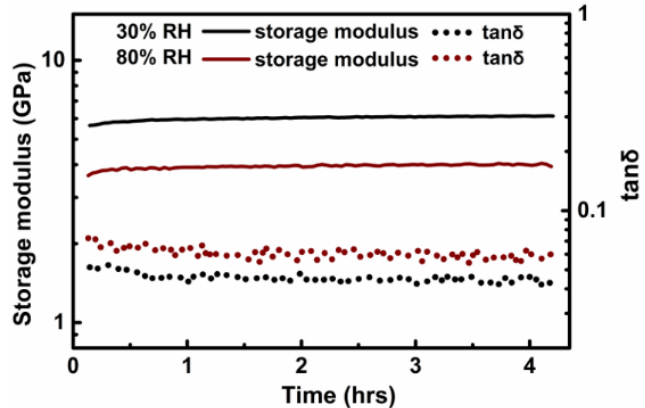

(c)

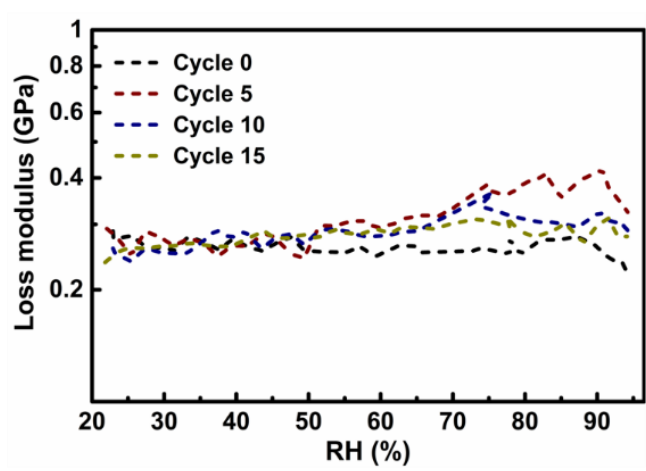

(e)

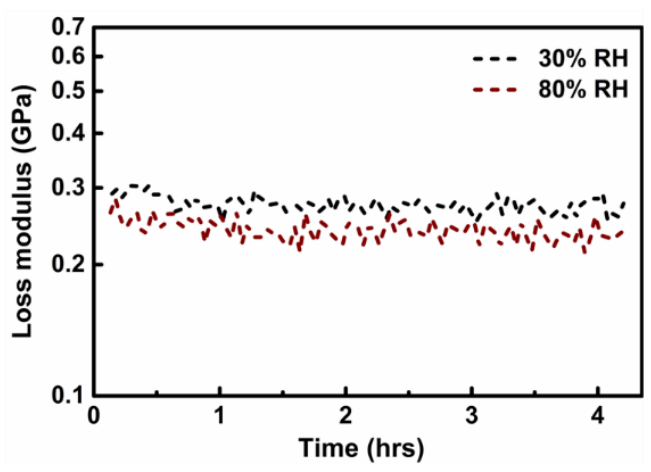

(b)

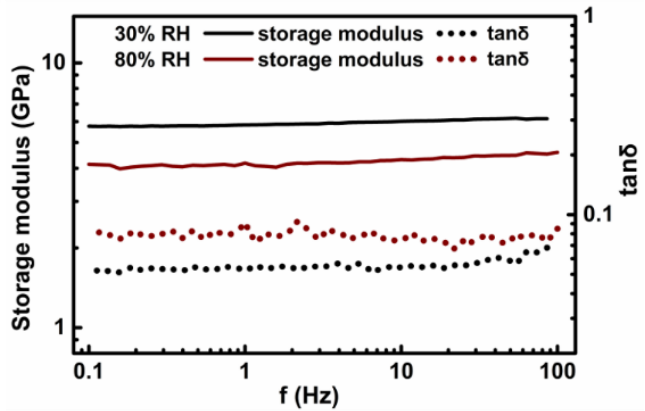

(d)

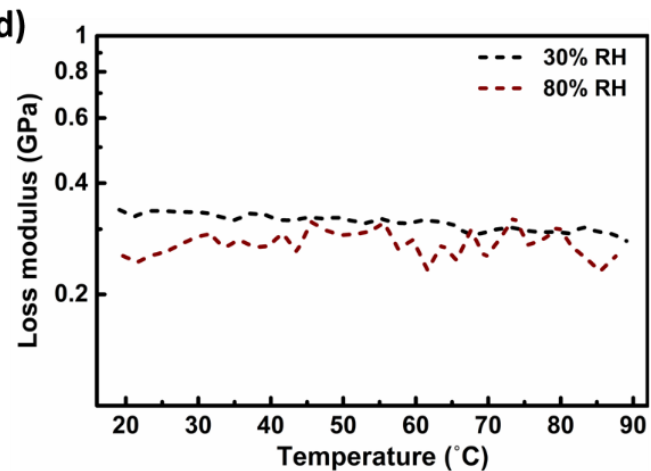

(f)

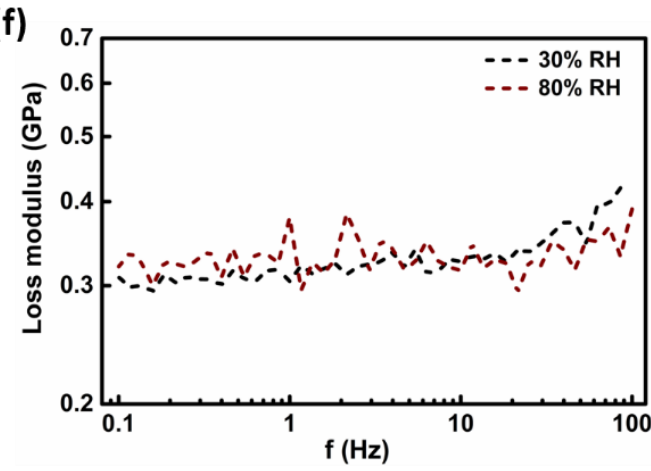

Supplementary Fig. 7 Dynamic mechanical thermal analysis of CCi membranes. (a,

b) storage moduli and damping factors of (a) time sweep with a frequency of $10 \mathrm{~Hz}$ at $25{ }^{\circ} \mathrm{C}$ and (b) frequency sweep at $25{ }^{\circ} \mathrm{C}$ of as-prepared $\mathrm{CCi}$ membranes at $30 \% \mathrm{RH}$ and $80 \%$ RH. (c-f) Loss moduli of (c) humidity sweep with RH increasing rate of $2 \% / \mathrm{min}$ at $25^{\circ} \mathrm{C}$, with a frequency of $10 \mathrm{~Hz}$ for as-prepared membranes (Cycle 0 ) as well as those after 5, 10 and 15 times of hydrosetting processing (cycle 5, 10 and 15). (d) temperature sweep with temperature increasing rate of $0.5^{\circ} \mathrm{C} / \mathrm{min}$ and a frequency of $10 \mathrm{~Hz}$, (e) time sweep with a frequency of $10 \mathrm{~Hz}$ at $25^{\circ} \mathrm{C}$ and (f) frequency sweep at $25{ }^{\circ} \mathrm{C}$ of as-prepared CCi membranes at $30 \% \mathrm{RH}$ and $80 \% \mathrm{RH}$. 


\section{References}

1. Dai, J. \& Kim, J.-C. Photo and thermal properties of cinnamoyl Pluronic F-127. Polym. Int. 63, 501-506 (2014).

2. Meng, X., Matson, J. B. \& Edgar, K. J. Olefin cross-metathesis as a source of polysaccharide derivatives: cellulose omega-carboxyalkanoates. Biomacromolecules 15, 177-187 (2014).

3. Edgar, K. J., Heinze, T. \& Buchanan, C. M. Polysaccharide Materials: Performance by Design Ch. 13 (American Chemical Society, 2009).

4. Vaca-Garcia, C., Borredon, M. E. \& Gaseta, A. Determination of the degree of substitution (DS) of mixed cellulose esters by elemental analysis. Cellulose 8, 225-231 (2001). 